
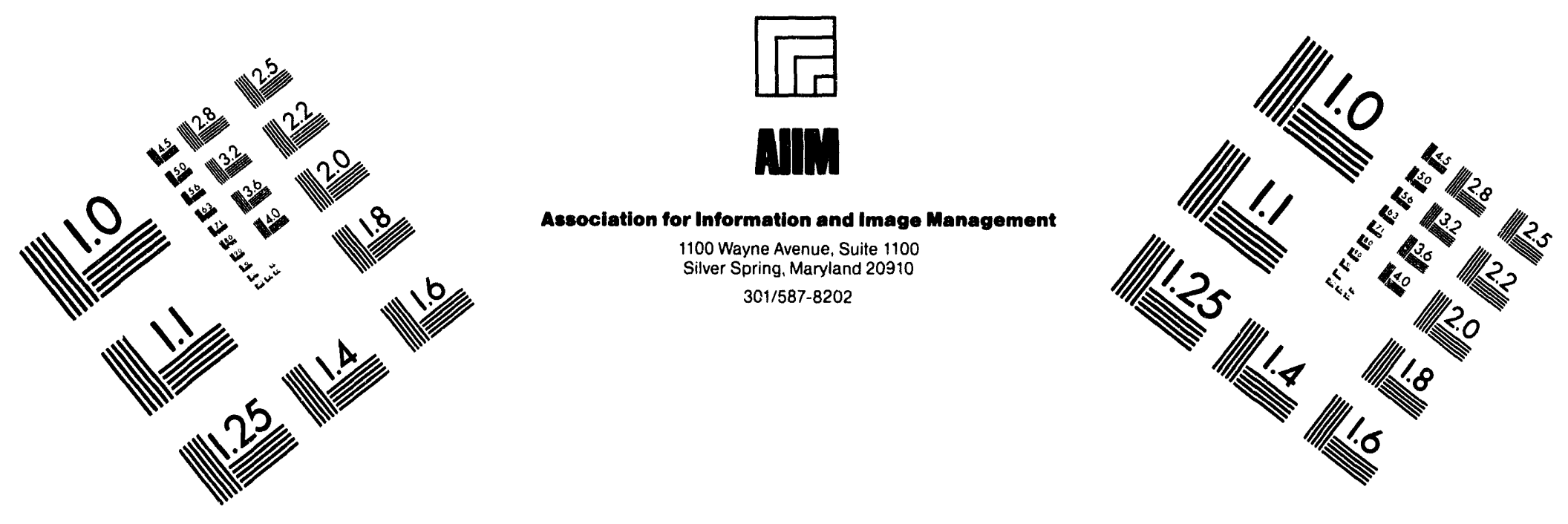

\title{
Centimeter
}

$\begin{array}{llllllllllllllll}1 & 2 & 3 & 4 & 5 & 6 & 7 & 8 & 9 & 10 & 11 & 12 & 13 & 14 & 15 & \mathrm{~mm}\end{array}$

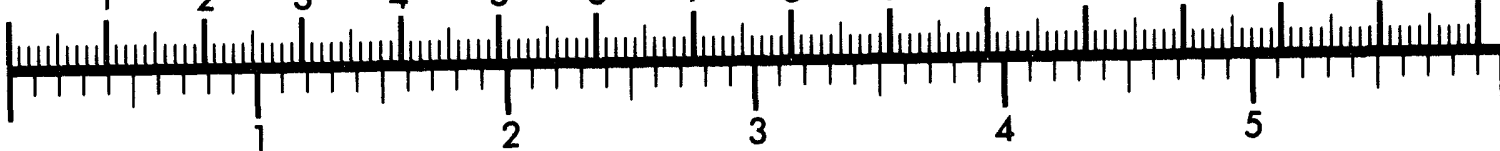
Inches
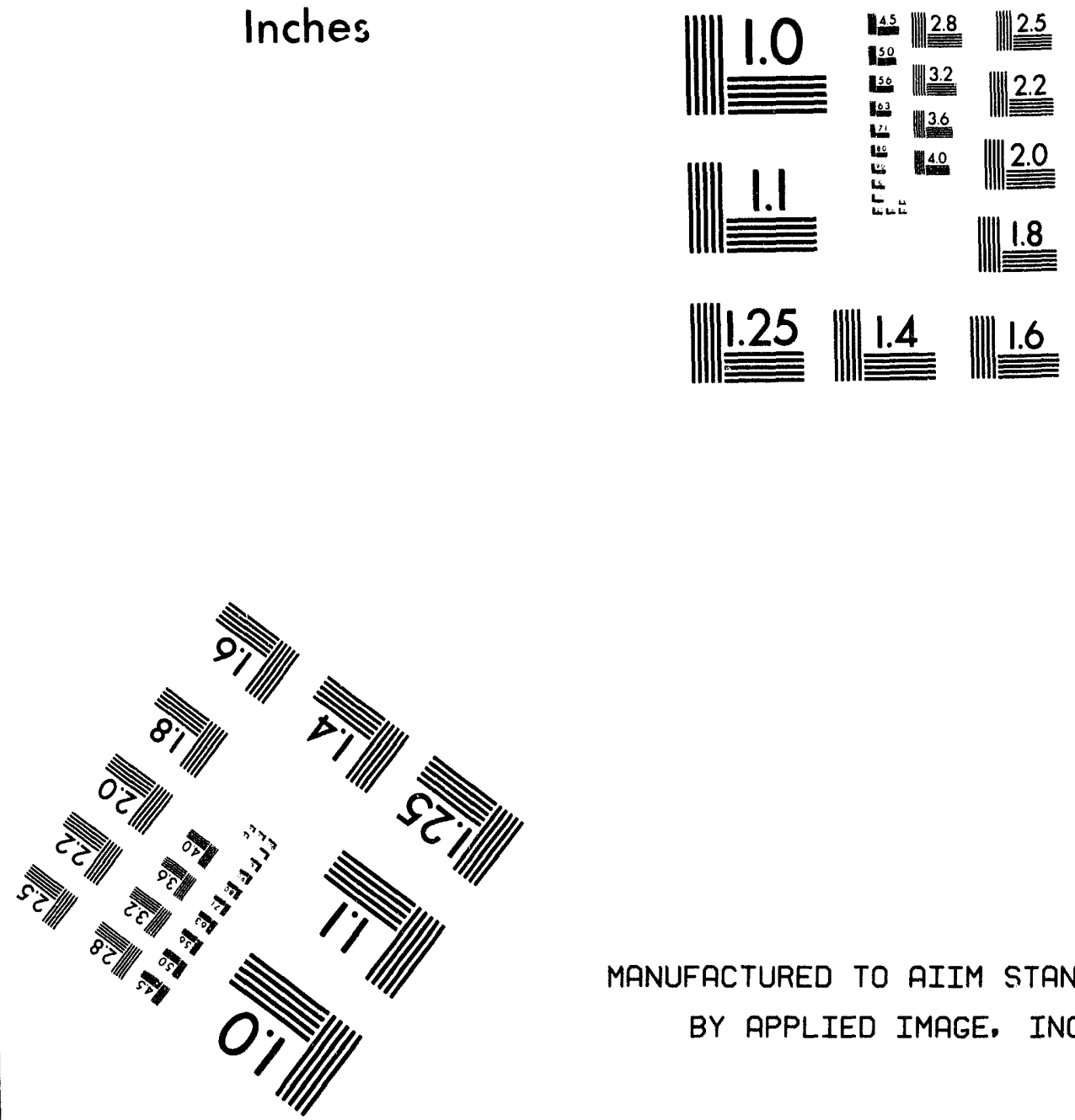

MANUFACTURED TO AIIM STANDARDS

BY APPLIED IMAGE, INC.

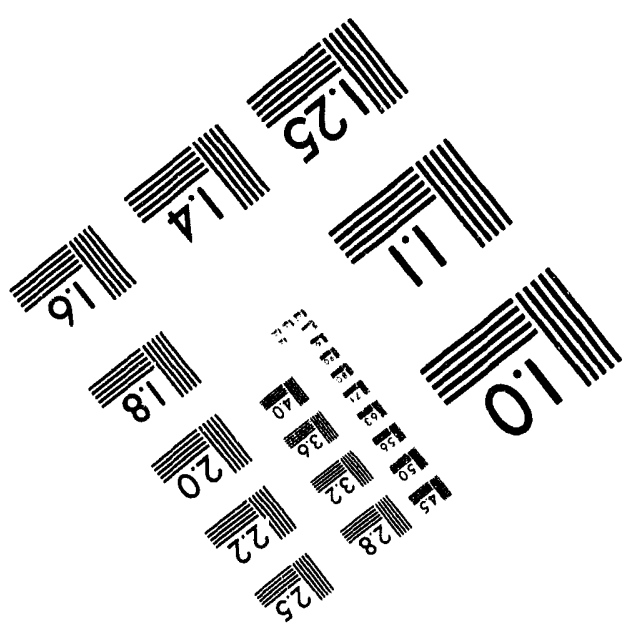



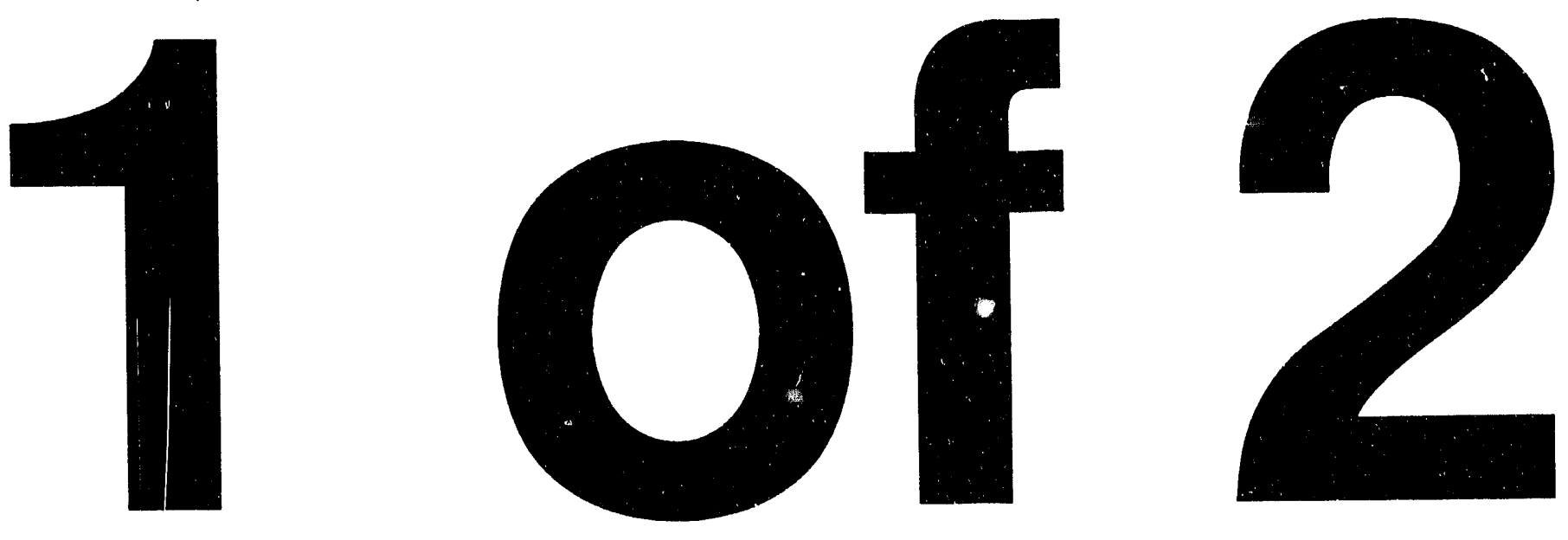


\section{Testing of Organic Waste Surrogate Materials in Support of the Hanford Organic Tank Program - Final Report}

D. A. Turner

Westinghouse Hanford Company

Yael Miron

Bureau of Mines

Date Published

January 1994

Prepared for the U.S. Department of Energy Office of Environmental Restoration and Waste Management

\footnotetext{
(2) Westinghouse P.O. Box 1970

Hanford Company Richland, Washington 99352

Hanford Operations and Engineering Contractor for the

U.S. Department of Energy under Contract DE-AC06-87RL10930
} 


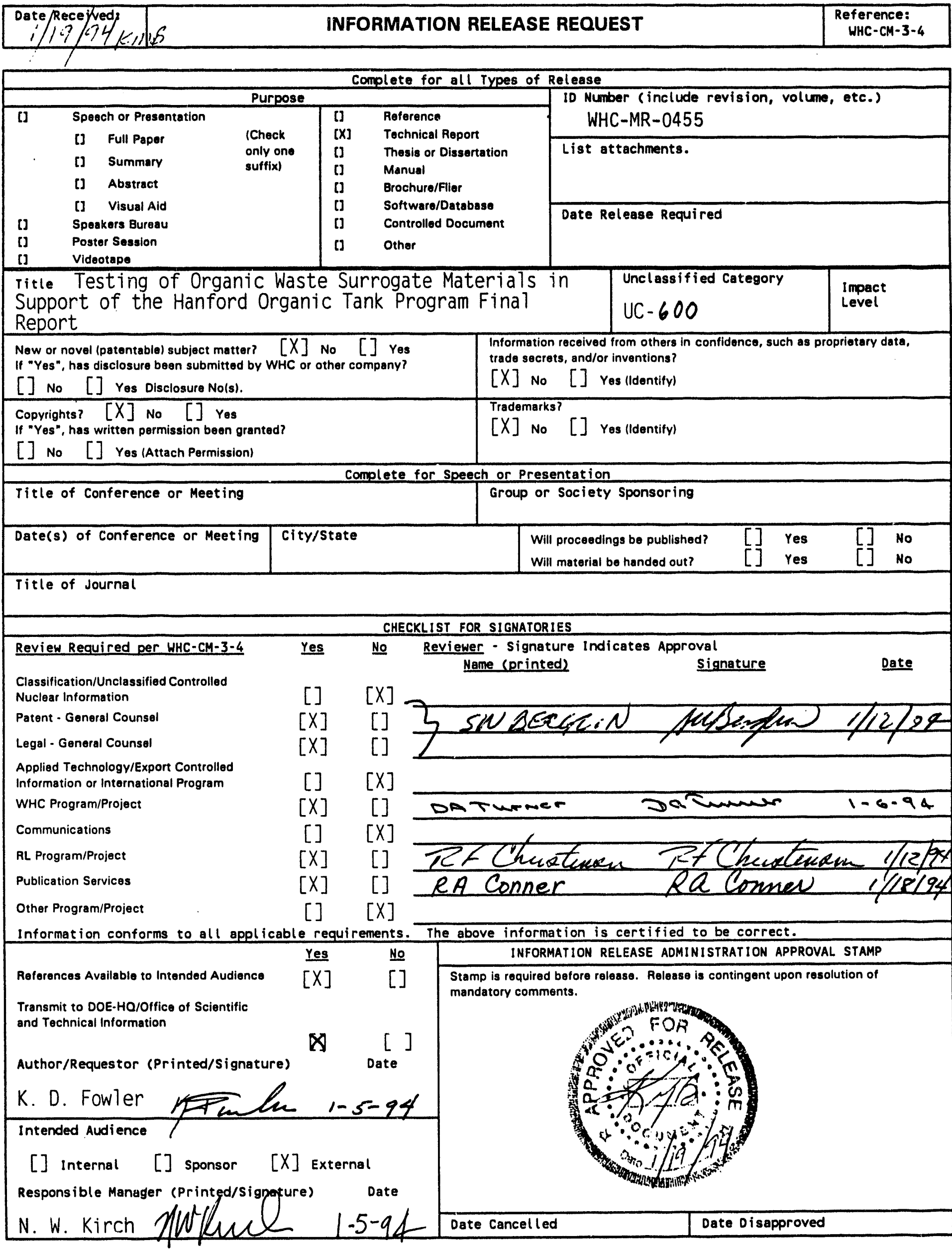


Summary . ........... 1

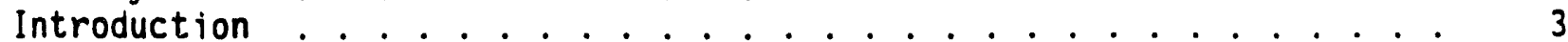

Background ........................ 3

objectives . . . . . . . . . . . . . . . . 4

Test Details . . . . . . . . . . . . . . . . . . . 5

Materials . . . . . . . . . . . . . . . 5

Tests . . . . . . . . . . . . . . . 5

Test Equipment and Procedures................. . . . 7

Test Matrix . . . . . . . . . . . . . . . . . . . . . . . 11

Sample Preparation . . . . . . . . . . . . . . . . . . 14

Experimental Results and Discussion................. 15

Explosive Tests .................. . . . 15

Impact and Friction Tests.................. 15

Internal Ignition Tests . . . . . . . . . . . . . . . 17

Modified Trauzle Test . . . . . . . . . . . . . . . . . . . . . . . 17

Flammability Tests . . . . . . . . . . . . . . . . . . . . . . . . 21

Flame Spread Rate Tests . . . . . . . . . . . . . . 21

Explosive and $\mathrm{Flammability} \mathrm{Tests} \mathrm{...} \mathrm{.} \mathrm{.} \mathrm{.} \mathrm{.} \mathrm{.} \mathrm{.} \mathrm{.} \mathrm{.} \mathrm{.} \mathrm{.} \mathrm{.} 23$

Summary . . . . . . . . . . . . . . . 23

Thermal Analysis Tests . . . . . . . . . . . . . . . . . 23

Calibration of the DSC . . . . . . . . . . . . . 23

Calibration of the TGA .................. 23

DSC and TGA Tests of Sodium Nitrate, Sodium Nitrite and

Sodium Nitrate-Sodium Nitrite Mixtures . . . . . . . . . . . . . . 24

Sodium Oxalate and Oxalate Mixtures . . . . . . . . . . . . . 25

EDTA and EDTA Mixture . . . . . . . . . . . . . . . . . . . 34

Sodium Citrate and Citrate Mixtures . . . . . . . . . . . . . . 43

Polyethylene and Polyethylene Mixtures ............. 51

FeCN Sample..................... . . . 57

Bomb Calorimeter Tests . . . . . . . . . . . . . . . 62

Conclusions . . . . . . . . . . . . . . . . . . . 63

References . . . . . . . . . . . . . . 65

Appendix ......................... 169

TABLES

A. Summary of thermal test results . . . . . . . . . . . 2

1. Composition matrix for DSC/TGA tests ............. 11

2. Composition matrix for friction and impact tests......... 13

3. Composition matrix for internal ignition tests.......... 13

4. Composition matrix for flame spread rate tests........... 14

5. Composition for Modified Trauzle test . . . . . . . . . . . . . . 14

6. Impact and friction test results for standards, oxidants, sodium oxalate and oxalate mixtures .......... 15

7. Impact and friction test results for standards, for sodium EDTA and EDTA mixtures, and for sodium citrate and citrate mixtures

8. Impact and friction test results for standards, for polyethylene and polyethylene mixtures, and for FeCN ............ 16

9. Modified Trauzle Lead Block test results ............... 21

10. DSC thermal analysis results for the oxalate-nitrate mixtures . . 27 
TABLES - - Cont'd

Page

11. DSC thermal analysis results for the oxalate-nitrate-nitrite mixtures ................... 29

12. TGA thermal anaiysis resuits for the oxalate-nitrate mixtures . 30

13. TGA thermal analysis results for the oxalate-nitrate-nitrite mixtures

14. DSC thermal anaiysis results for the EDTA and EDTA-nitrate mixtures . . . . . . . . . . . 37

15. OSC thermal analysis resuits for the EDTA-nitrate-nitrite mixtures . . . . . . . . . . . . . . 39

16. TGA thermal analysis results for the EDTA and EDTA-nitrate mixtures .............. . . . 41

17. TGA thermal analysis results for the EDTA-nitrate-nitrite mixtures . . . . . . . . . . . . . . . 42

18. DSC thermal analysis results for the citrate and citrate-nitrate mixtures . . . . . . . . . . . . . . . . 46

19. DSC thermal analysis results for the citrate-nitrate-nitrite mixtures .................. 47

20. TGA thermal analysis results for the citrate and citrate-nitrate mixtures ................... 49

21. TGA thermal analysis results for the citrate-nitrate-nitrite mixtures . . . . . . . . . . . . . . . 50

22. DSC thermal anaiysis resuits for the polyethylene and polyethylene-nitrate mixtures . . . . . . . . . . . 53

23. DSC thermal analysis results for the polyethylene-nitratenitrite mixtures .......... 54

24. TGA thermal analysis resuits for the polyethylene and the polyethylene-nitrate mixtures . . . . . . . . . . 55

25. TGA thermal analysis results for the polyethylene-nitrate-nitrite mixtures ................... 56

26. DSC thermal analysis results for the FeCN sample......... 58

27. TGA thermal analysis results for the FeCN sample......... 61

\section{PHOTOGRAPHS}

1. Pipe for internal ignition test, filled with a mixture of EDTA-nitrate $(9 A) \ldots . . . . . .18$

2. Pipe capped and ready for the test . . . . . . . . . . . . . 18

3. Pipe with blown, misshapen cap, after the test . . . . . . . 19

4. Pipe is empty; mixture consumed or vaporized during the test . . 19

5. Empty pipe and misshapen cap after internal ignition test with a mixture of citrate-nitrate (11A) . . . . . . . . . . 20 


\section{ILLUSTRATIONS -- (following page 67)}

1. DSC thermogram for indium

2. DSC thermogram for zinc

3. TGA calibration thermogram for nickel-perkalloy

4. OSC thermogram for sodium nitrate

5. DSC thermogram for sodium nitrite

6. DSC thermogram for sodium nitrate-sodium nitrite mixture

7. TGA thermogram for sodium nitrate

8. TGA thermogram for sodium nitrite

9. TGA thermogram for sodium nitrate-sodium nitrite mixture

10. DSC thermogram for sodium oxalate

11. DSC thermogram for oxalate-nitrate mixture $13 \mathrm{~A}(1: 1)$

12. Optimized and scaled DSC thermogram of the exotherm in figure 11 , for oxalate-nitrate mixture $13 A$

13. DSC thermogram for oxalate-nitrate mixture 13A (1:1)

14. DSC thermogram for oxalate-nitrate mixture 13B $(1: 3)$

15. DSC thermogram for oxalate-nitrate mixture $13 C(1: 3$; dil)

16. DSC thermogram for oxalate-nitrate mixture $130(1: 10)$

17. DSC thermogram for oxalate-nitrate-nitrite mixture 14A (1:1)

18. DSC thermogram for oxalate-nitrate-nitrite mixture $14 \mathrm{~A}(1: 1)$

19. DSC thermogram for oxalate-nitrate-nitrite mixture 14A (1:1)

20. DSC thermogram for oxalate-nitrate-nitrite mixture 14B (1:3)

21. Optimized and scaled DSC thermogram for endotherms in oxalate-nitrate-/nitrite mixture $14 C(1: 3 ;$ dil). Complete thermogram in figure 21A

21A. DSC thermogram for oxalate-nitrate-nitrite mixture $14 C$ $(1: 3 ;$ dil)

22. DSC thermogram for oxalate-nitrate-nitrite mixture $140(1: 10)$

23. DSC thermogram for oxalate-nitrate-nitrite mixture $140(1: 10)$

24. DSC thermogram for oxalate-nitrate-nitrite mixture $140(1: 10)$

25. DSC thermogram for oxalate-nitrite mixture

26. TGA thermogram for sodium oxalate

27. TGA thermogram for oxalate-nitrate mixture $13 \mathrm{~A}(1: 1)$

28. TGA thermogram for oxalate-nitrate mixture $13 C(1: 3$; di1)

29. TGA thermogram for oxalate-nitrate mixture $130 \quad(1: 10)$

30. DSC thermogram for residue from DSC test with oxalate-nitrate mixture 13A $(1: 1)$

31. DSC thermogram for residue from DSC test with oxalate-nitrate mixture $13 A(1: 1)$

32. DSC thermogram for sodium EDTA

33. DSC thermogram for sodium EDTA

34. DSC thermogram for EDTA-nitrate mixture $9 A(1: 1)$

35. DSC thermogram for EDTA-nitrate mixture $9 B(1: 3)$

36. DSC thermogram for EDTA-nitrate-nitrite mixture $10 \mathrm{~A}(1: 1)$

37. DSC thermogram for EDTA-nitrate-nitrite mixture 1OA $(1: 1)$

38. TGA thermogram for sodium EDTA

39. TGA thermogram for EDTA-nitrate mixture $9 A(1: 1)$

40. TGA thermogram for EDTA-nitrate mixture $9 B(1: 3)$

41. TGA thermogram for EDTA-nitrate mixture $9 C(1: 3 ;$ di1)

42. TGA thermogram for EDTA-nitrate mixture $9 D(1: 10)$

43. TGA thermogram for EDTA-nitrate-nitrite mixture 1OA (1:1)

44. TGA thermogram for EDTA-nitrate-nitrite mixture $1 O B(1: 3)$

45. TGA thermogram for EDTA-nitrate-nitrite mixture $1 O C(1: 3 ;$ dil) 


\section{ILLUSTRATIONS -- Continued}

46. TGA thermogram for EDTA-nitrate-nitrite mixture $100(1: 10)$

47. DSC thermogram for sodium citrate

48. DSC thermogram for citrate-nitrate mixture $11 \mathrm{~A}(1: 1)$

49. DSC thermogram for citrate-nitrate mixture $11 \mathrm{~A}(1: 1)$

50. DSC thermogram for citrate-nitrate mixture 11B $(1: 3)$

51. DSC thermogram for citrate-nitrate mixture $11 \mathrm{C}(1: 3 ;$ di1)

52. DSC thermogram for citrate-nitrate mixture $110(1: 10)$

53. DSC thermogram for citrate-nitrate mixture $110(1: 10)$

54. DSC thermogram for citrate-nitrate-nitrite mixture $12 \mathrm{~A}(1: 1)$

55. DSC thermogram for citrate-nitrate-nitrite mixture $12 B(1: 3)$

56. DSC thermogram for citrate-nitrate-nitrite mixture $12 \mathrm{C}(1: 3 ; \mathrm{di})$

57. DSC thermogram for citrate-nitrate-nitrite mixture $120(1: 10)$

58. TGA thermogram for sodium citrate

59. TGA thermogram for citrate-nitrate mixture $11 \mathrm{~A}(1: 1)$

60. TGA thermogram for citrate-nitrate mixture $11 B(1: 3)$

61. TGA thermogram for citrate-nitrate mixture $11 \mathrm{C}(1: 3 ;$ dil)

62. TGA thermogram for citrate-nitrate mixture $110(1: 10)$

63. TGA thermogram for citrate-nitrate mixture $11 \mathrm{~A}(1: 1)$

64. TGA thermogram for citrate-nitrate mixture $110(1: 10)$

65. TGA thermogram for citrate-nitrate-nitrite mixture $12 \mathrm{~A}(1: 1)$

66. TGA thermogram for citrate-nitrate-nitrite mixture $12 B(1: 3)$

67. TGA thermogram for citrate-nitrate-nitrite mixture $12 \mathrm{C}(1: 3 ;$ di1)

68. TGA thermogram for citrate-nitrate-nitrite mixture $120(1: 10)$

69. DSC thermogram for polyethylene

70. DSC thermogram for polyethylene

71. DSC thermogram for polyethylene

72. DSC thermogram for polyethylene-nitrate mixture $15 \mathrm{~A}(1: 1)$

72A. Optimized and scaled DSC thermogram of figure 72 , for polyethylene-nitrate mixture 15A $(1: 1)$

73. DSC thermogram for polyethylene-nitrate mixture $15 B(1: 3)$

74. DSC thermogram for polyethylene-nitrate mixture $15 \mathrm{C}(1: 3 ;$ dil)

75. DSC thermogram for polyethylene-nitrate mixture $150(1: 10)$

76. DSC thermogram for polyethylene-nitrate-nitrite mixture $16 \mathrm{~A}(1: 1)$

77. DSC thermogram for polyethylene-nitrate-nitrite mixture 16B $(1: 3)$

78. DSC thermogram for polyethylene-nitrate-nitrite mixture $16 C$

( $1: 3 ; \mathrm{dil})$

79. DSC thermogram for polyethylene-nitrate-nitrite mixture $160(1: 10)$

80. TGA thermogram for polyethylene

81. TGA thermogram for polyethylene

82. TGA thermogram for polyethylene-nitrate mixture $15 A(1: 1)$

83. TGA thermogram for polyethylene-nitrate mixture $15 B(1: 3)$

84. TGA thermogram for polyethylene-nitrate mixture $15 \mathrm{C}(1: 3 ;$ dil)

85. TGA thermogram for polyethylene-nitrate mixture $150(1: 10)$

86. TGA thermogram for polyethylene-nitrate-nitrite mixture $16 \mathrm{~A}(1: 1)$

87. TGA thermogram for polyethylene-nitrate-nitrite mixture $16 B(1: 3)$

88. TGA thermogram for polyethylene-nitrate-nitrite mixture $16 C$ ( $1: 3 ;$ dil)

89. TGA thermogram for polyethylene-nitrate-nitrite mixture $160(1: 10)$

90. DSC thermogram for predried FeCN sample 17A

91. DSC thermogram for predried FeCN sample 17A

92. DSC thermogram for predried FeCN sample 17A 


\section{ILLUSTRATIONS -- Continued}

93. DSC thermogram for paste FeCN sample 17A

94. DSC thermogram for white crystals, formed on surface of FeCN sample during drying

95. Optimized and scaled DSC thermogram of figure 94, for white crystals formed on the surface of FeCN sample during drying

96. TGA thermogram for predried FeCN sample 17A

97. TGA thermogram for predried FeCN sample 17A

98. TGA thermogram for predried FeCN sample 17A

99. Optimized and scaled DSC thermogram of figure 97 , for predried $\mathrm{FeCN}$ sample 17A 
WHC-MR-0455

vii 


\section{SUMMARY}

To address safety issues regarding effective waste management efforts of underground organic waste storage tanks at the Hanford Site, the Bureau of Mines conducted a series of tests, at the request of the Westinghouse Hanford company. In this battery of tests, the thermal and explosive characteristics of surrogate materials, chosen by Hanford, were determined. The surrogate materials were mixtures of inorganic and organic sodium salts, representing fuels and oxidants. The oxidants were sodium nitrate and sodium nitrite. The fuels were sodium salts of oxalate, citrate and ethylenediamine tetraacetic acid (EDTA). Polyethylene powder was also used as a fuel with the oxidant(s). Sodium aluminate was used as a diluent. In addition, a sample of FeCN, supplied by Hanford was also investigated.

Three standard explosive tests, friction, impact and internal ignition tests, and one flammability test, the flame spread rate test, were used to characterize the explosive nature of the test mixtures. Negative results were obtained in the explosive tests with the four mixtures designated as "A" in the various test matrices. These were the 1:1 mixtures of fuel with one oxidant (sodium nitrate) or the 1:1 mixtures of fuel with the equimolar combination of the two oxidants (sodium nitrate and sodium nitrite). The FeCN sample was evaluated in the modified Trauzle lead block test, which measures the explosive power of a substance, and the result was negative.

In the flammability test, three 1:1 mixtures, those of sodium citrate, sodium EDTA, and polyethylene with sodium nitrate were tested. Of these three mixtures, only the sodium citrate mixture behaved as a flammable solid. Flame spread rates for this latter sample were $1.7,2.5$, and $3.1 \mathrm{~mm} / \mathrm{s}$, and a $\mathrm{fl}$ ame spread rate of more than $2.2 \mathrm{~mm} / \mathrm{s}$ is considered a positive result.

All the mixtures shown in table 1 of this report were tested by differential scanning calorimetry and by thermogravimetry. All the mixtures displayed exothermic behavior. In general, onset of exothermic behavior was not strongly dependent on heating rate, mixture ratio, size of sample or atmosphere (other than for the mixtures with polyethylene). Based on these observations it was deemed proper to average the values for onsets of exothermic behavior for the various fuel mixtures at the different ratios. Onset of exothermic behavior in most of the mixtures was delayed, to a smaller or larger extent, by the presence of the diluent. Thus, average values were calculated separately for mixtures with diluent and without diluent, for the two thermal analyzers, and are shown in the table A. Additionally, when both sodium nitrate and sodium nitrite were used, the onset temperatures were somewhat lower in many of the cases, than when sodium nitrate alone was used as oxidant.

In summary, the lowest onset temperatures for exothermic behavior were found for the citrate and polyethylene mixtures, at about $200^{\circ} \mathrm{C}$. For the EDTA mixtures the corresponding temperatures were between $240^{\circ}$ and $300^{\circ} \mathrm{C}$. For the oxalate mixtures onset temperatures were more varied and ranged on the average between $310^{\circ}$ and $420^{\circ} \mathrm{C}$, but a temperature as low as $275^{\circ} \mathrm{C}$ was al so observed. Finally, onset temperatures for the $\mathrm{FeCN}$ sample ranged from $330^{\circ}$ to $360^{\circ} \mathrm{C}$, in the TGA tests, and from $350^{\circ}$ to $370^{\circ} \mathrm{C}$ in the DSC tests. 
Table A. - Summary of thermal test results

\begin{tabular}{|c|c|c|c|c|c|c|c|c|c|c|c|c|c|c|c|c|}
\hline \multirow[b]{4}{*}{ Oxidizer } & \multicolumn{16}{|c|}{ Unset Tomperatures for Exothermlc Bohavior'. 'C } \\
\hline & \multicolumn{4}{|c|}{ CITPATE } & \multicolumn{4}{|c|}{ POLYETHYLENE ${ }^{2}$} & \multicolumn{4}{|c|}{ EDTA } & \multicolumn{4}{|c|}{ OXALATE } \\
\hline & \multicolumn{2}{|c|}{ DSC } & \multicolumn{2}{|c|}{ TGA } & \multicolumn{2}{|c|}{ DSC } & \multicolumn{2}{|c|}{ TGA } & \multicolumn{2}{|c|}{ DSC } & \multicolumn{2}{|c|}{ TGA } & \multicolumn{2}{|c|}{ DSC } & \multicolumn{2}{|c|}{ TGA } \\
\hline & $\mathrm{NaNO}_{3}$ & $\begin{array}{l}\mathrm{NaNO}_{3} \\
\text { and } \\
\mathrm{NaNO}_{2}\end{array}$ & $\mathrm{NaNO}_{3}$ & $\begin{array}{l}\mathrm{NaNO}_{3} \\
\text { and } \\
\mathrm{NaNO}_{2}\end{array}$ & $\mathrm{NaNO}_{3}$ & $\begin{array}{l}\mathrm{NaNO}^{3} \\
\text { and } \\
\mathrm{NaNO}_{2}\end{array}$ & NanO, & $\begin{array}{l}\mathrm{NaNO}_{3} \\
\text { and } \\
\mathrm{NaNO}_{2}\end{array}$ & $\mathrm{NaNO}_{3}$ & $\begin{array}{l}\mathrm{NaNO}_{3} \\
\text { and } \\
\text { NaNO } \\
\end{array}$ & $\mathrm{NaNO}_{3}$ & $\begin{array}{l}\mathrm{NaNO}_{3} \\
\text { and } \\
\mathrm{NaNO}_{2}\end{array}$ & $\mathrm{NaNO}_{3}$ & $\begin{array}{l}\mathrm{NaNO}_{3} \\
\text { and } \\
\mathrm{NaNO}_{2}\end{array}$ & $\mathrm{NaNO}_{3}$ & $\begin{array}{l}\text { NanO, } \\
\text { and } \\
\mathrm{NaNO}_{2}\end{array}$ \\
\hline $\begin{array}{l}\text { Mixtures } \\
\text { without diluont }\end{array}$ & 195 & 220 & 253 & 229 & 208 & 193 & 216 & 220 & 300 & 290 & 296 & 242 & $\begin{array}{l}390 \text { to } \\
420\end{array}$ & $\begin{array}{l}355 \text { to } \\
385\end{array}$ & $\begin{array}{l}310 \text { to } \\
420\end{array}$ & $\begin{array}{l}275 \text { to } \\
345\end{array}$ \\
\hline $\begin{array}{l}\text { Mixtures with } \\
\text { dilluent }\end{array}$ & 201 & 240 & 267 & 228 & 272 & 204 & $\begin{array}{l}235 \text { to } \\
270^{3}\end{array}$ & 275 & 306 & 295 & 304 & 300 & 440 & 400 & 370 & 385 \\
\hline
\end{tabular}

Based on Initial Deviation of the decomposition step from baseline.

For tests in air atmosphere only.

Difficult to dotormino. 
WHC-MR-0455

\section{INTRODUCTION}

\section{BACKGROUND}

Radioactive waste from defense operations has been accumulating in underground waste tanks at the Hanford Site since the early 1940's. There are 177 waste tanks: 149 singie-shell tanks and 28 double-shell tanks. Over the years, waste has been systematically disposed of among the various tanks. In this process, the two primary objectives were to segregate different types of waste and to reduce the need for additional tanks by concentrating the waste. The major constituents of the waste are sodium nitrate, sodium nitrite, metal silicates, aluminates, hydroxides, phosphates, sulfates, carbonates of iron, calcium and other metals, a variety of organic materials, ferrocyanide and uranium salts, in addition to the fission products.

The presence of organic chemicals in the Hanford Site waste tanks became an issue needing reevaluation when information became available on the deflagration of a waste tank in Kyshtym, U.S.S.R., which occurred September 29, 1957. The Soviet tank event occurred because cooling was disrupted; the aqueous salts evaporated to dryness, and the mixture of oxidizing salts and organic chemical waste self-heated to deflagrationinitiating temperatures. The constituents in the tank that caused this incident were sodium nitrate and sodium nitrite mixed with sodium acetate. The chemical safety issue associated with the Hanford Site organic-containingtanks is the possibility of exothermic reactions occurring due to the presence of heated organic waste components mixed with oxidizing salts (e.g., sodium nitrite and sodium nitrate) under conditions of low moisture.

The potential for reactions of nitrate with organic constituents stored in the Hanford Site waste tanks has been studied. For example, a paper published in April 1976 described some combustion screening studies with sodium nitrate (Beite1, 1976), (1)'. However, in keeping with the concerns at that time, this work was directed toward the oxidative power of sodium nitrate rather than the reactivity of specific organic tank waste chemicals.

A screening study was conducted at the Hanford Site in 1989 (Fisher, WHC, 1990), (2). Twenty six tests were performed to study the reactivity of mixtures containing various proportions of sodium acetate, sodium nitrate/sodium nitrite, and diluents. The results were used to define an upper limit for organic carbon constituents in the waste. The limit was defined as 10 percent organic equivalent weight to sodium acetate, which corresponds to $3 \%$ total organic carbon. The latter is the present organic tank watch list criteria. The results of this study, along with process engineering knowledge, form the basis for placing waste tanks on the Organic Tanks Watch List. Three percent total organic carbon (dry weight basis) was formally established as the safety specification for single-shell tanks containing organic materials. Process engineering knowledge involves

\footnotetext{
The numbers in parentheses refer to items in the list of references at the end of the report.
} 
evaluating process flow sheets, the waste inventory database, and other plant records. Eight single-shell tanks were identified as possibly having an organic content in excess of the $3 \%$ total organic carbon threshold concentration, and were placed on the list.

Process engineering knowledge of waste composition, rather than actual assay results, is required because of 1 imitations in the historical records. The most accurate records generally were maintained for the radioactive constituents. In the past, the need for detailed chemical constituent information was not anticipated. Thus it is not precisely known what chemicals actually went into the tanks, what chemicals remain in the tanks, and what chemicals have been formed from reactions between stored waste components. Without this information, process knowledge had to be used to obtain a conservative listing for the Organic Tanks Watch List. Double-shell tanks which contain mostly aqueous waste, were not included since they present no credible organic deflagration related safety concern.

Public Law 101-510, Section 3137, "Safety Measures for Waste Tanks at Hanford Nuclear Reservation," (3), requires that Westinghouse Hanford Company (WHC) develop plans to resolve issues for tanks that could lead to excessive temperature changes or pressure increases or a release of material from any high-activity waste single-shell tank (SST) or double-shell tank (DST) on the watch list at the Hanford Site. Fifty-three tanks have been identified and categorized by tanks contents. Categories include those tanks that (a) contain ferrocyanide compounds, (b) have the potential for flammable gas generation, (c) contain organics, or (d) have high heat loads. These form four distinct, but related, programs. Logic for the resolution of these safety issues, as well as candidate technologies for resolution or mitigation of the safety issues, show a large degree of commonality among the programs (Babad, Fulton, DeFigh-Price, 1993), (4). Discussions of the flammable gas and ferrocyanide programs had been reported at Waste Management ' 92 and ' 93 [Johnson, 1992, (5); Cash, 1992, (6); and Simpson, 1993, (7)]. In addition, three of the organic tanks also are included in the flammable gas or

ferrocyanide tanks program.

\section{OBJECTIVES}

The objectives of this study were to: (a) evaluate the thermal characteristics of the solid organic waste surrogate materials, and (b) determine the explosive nature of these materials. To accomplish these objectives, a series of tests was conducted on a full range of material compositions, which were selected to represent the surrogates for possible various constituents and compositions in the storage tanks. 


\title{
TEST DETAILS
}

\begin{abstract}
MATERIALS
Mixtures of organic and inorganic sodium compounds were chosen to represent the contents of the tanks. The test samples were composed of two (fuel and oxidant) or three (fuel, oxidant, and diluent) components at specified ratios. The organic salts, representing fuels, included sodium oxalate $\left(\mathrm{Na}_{2} \mathrm{C}_{2} \mathrm{O}_{4}\right)$, sodium citrate $\left(\mathrm{Na}_{3} \mathrm{C}_{8} \mathrm{H}_{5} \mathrm{O}_{7}\right)$, and sodium ethylenediamine tetraacetic acid (EDTA; $\left.\mathrm{Na}_{4} \mathrm{C}_{10} \mathrm{H}_{12} \mathrm{O}_{8} \mathrm{~N}_{2}\right)$. In addition, polyothylene powder, $\left(\mathrm{C}_{2} \mathrm{H}_{4}\right)_{n}$, was used to simulate the hydrocarbon species present in some tanks. The inorganic salts, sodium nitrate, $\left(\mathrm{NaNO}_{3}\right)$, and sodium nitrite, $\left(\mathrm{NaNO}_{2}\right)$, were the oxidants, and sodium aluminate, $\left(\mathrm{NaAlO}_{2}\right)$, was the diluent. The mixtures were prepared with both the nitrate and nitrate/nitrite salts at specified stoichiometric and fuellean concentrations (equivalence ratios of $1,1 / 3$, and $1 / 10$ ). In addition to the above fuel/oxidant mixtures, mixtures containing an equal weight of sodium aluminate as a diluent were prepared with the $1 / 3$ equivalence ratio mixtures.

In addition to the above mixtures, a sample of FeCN was provided by Hanford. This sample contained the following sodium salts: nitrate, nitrite, sulfate, phosphate and nickel ferrocyanide. Both the original paste and a dried sample were tested.
\end{abstract}

\section{TESTS}

The following tests were chosen to characterize the behavior of the mixtures of the organic and inorganic materials:

Differential Scanning Calorimetry (DSC)/Thermogravimetric Analysis (TGA) ASTM E 537 and E 1131

These tests determine the minimum temperature at which a sample of material starts to react. In the DSC test, a test sample and an inert reference are heated at a constant rate and the energy flow to or from the sample is measured. The onset of the first exotherm is recorded. Other exotherms and endotherms may be of interest but the onset of the initial reaction is generally the parameter of interest for safety analysis and operational safety. In the TGA test, a sample is heated at a constant rate and changes in the weight of the sample are recorded. The TGA test complements the DSC test, and the combined results identify the various thermal events more clearly. Most tests in the DSC and TGA were performed in an atmosphere of gently flowing air, while some selective tests were performed in an atmosphere of flowing nitrogen. 


\section{WHC-MR-0455}

Bomb Calorimetry Test - ISO 1928-1976 (E)

This test determines the reaction energy and products of reaction of a sample undergoing combustion, via calorimetry (Parr bomb calorimeter or equivalent). A test sample is ignited in a small container and the heat evolved and final pressure measured. The reaction gases are then vented through a device to measure molecular composition; the solid residues may also be analyzed. Benzoic acid is used as a calibration standard.

In the standard procedure oxygen is used to fill the bomb to a pressure of $30 \mathrm{~atm}$. In this test series the bomb was filled to $1 \mathrm{~atm}$ with nitrogen. A few tests were conducted in air or oxygen. Provisions were made for analysis of the gaseous products as well as of the residues.

Friction Test - United Nations Test 3B (I), Section 25.

This test determines the maximum frictional energy which will not ignite a sample of test material. A test sample is exposed to the friction generated between a ceramic peg and an anvil surface. Reaction is detected via flash, odor, or noise. The loads are varied until a positive reaction is detected or the equipment limits are reached.

Impact Test - United Nations Test 3A (I), Section 20.

This test determines the maximum impact energy which will not ignite a sample of material. A steel hammer is dropped against a steel anvil which contains the test sample. Reaction is detected via flash, odor, or noise. The height of the hammer is increased until a positive reaction is detected or the equipment limits are reached.

Internal Ignition Test - United Nations Test 1B (II), Section 8.

This test estimates the detonability of a sample contained in a $45.7 \mathrm{~cm}$ length of 3 -in schedule 80 steel pipe by initiating the sample with $20 \mathrm{~g}$ of black powder. The results are considered positive only if the pipe fragments. Lesser damage to the pipe is considered a negative result. This test is applicable to compounds or mixtures that are specifically designed as explosives or pyrotechnics. It is an estimate of the shock sensitivity of the test material.

Flame Spread Rate Test - United Nations Test for Flammable Solids 14.5.2.

This test estimates flame velocity for a particular configuration. It uses a standard $250-\mathrm{mm}-1$ ong pile which is ignited at one end and the flame speed is noted in the middle of the pile. The other end of the pile is usually wetted and the ability of the wetted portion to quench the flame propagation is also noted. A burning rate of more than $2.2 \mathrm{~mm} / \mathrm{s}$ is considered a positive test. Since the surface area of the pile is large relative to the cross section of the material to react, the results may be very different for different configurations. 


\section{WHC-MR-0455}

Modified Trauzle Test - United Nations Test F.4, Section 7.5 (lead block assembly $V$, for solids).

This test measures the explosive power of a substance by the expansion of a cavity carefully machined in a pure lead block, when the sample contained in a vial, and placed in the block, is initiated by a detonator. The criterion for a negative result is an average block expansion equal to or less than $12 \mathrm{~cm}^{3}$.

\section{TEST EQUIPMENT AND PROCEDURES}

Standard test procedures, as prescribed for each test, were followed. Test sample duplicates were included, unless otherwise noted, for verification of test results.

DSC/TGA Tests

Perkin Elmer DSC 7 and TGA 7 modules were used in all the thermal analysis tests. The two instruments are computer-controlled. Other components of the system include a TAC 7/DX thermal analysis instrument controller, a graphic plotter, and a 7 series/UNIX software.

The operation of the DSC 7 is based on a power compensated "null-balance" principle. Energy absorbed or evolved by the sample is compensated by adding or subtracting an equivalent amount of electrical energy to a heater located in the sample holder. The continuous and automatic adjustment of heater power needed to keep the sample holder temperature identical to the temperature of the reference holder provides a varying electrical signal equivalent to the varying thermal behavior of the sample.

In the DSC tests, small, milligram-size samples are heated at a constant rate and endothermic and exothermic processes undergone by the samples are recorded as a function of temperature. The temperatures of onset of exothermic behavior are obtained from the thermograms. Additional important information includes the temperatures of exothermic peak or peaks and the energies released and absorbed in the various thermal processes. The DSC was calibrated with standard compounds, such as indium metal and zinc metal. In preliminary tests, the effects of static and dynamic atmospheres on the calibrations and the test results were evaluated. The effect of heating rate on the onset temperatures of some of the mixtures was also evaluated, and optimum test conditions for the samples were chosen. In general, equal weight samples, when heated at the same heating rate and in the same atmosphere will yield essentially identical thermograms. Onset temperatures of the first exotherms can be reproduced to within $10^{\circ} \mathrm{C}$.

The TGA 7 measures the weight changes resulting from a variety of events undergone by a sample, such as decomposition, vaporization and oxidation. The TGA 7 is made up of two major components: a sensitive ultra microbalance and a furnace. The microbalance can detect weight changes as small as $1 \mu \mathrm{g}$. A null balance design uses a servo-controlled torque motor to automatically compensate for weight changes in the sample. The amount of current needed to 
maintain the "null" state is directly proportional to the weight change in the sample. The standard furnace is a small, platinum-wound microfurnace, and a chromel-alumel thermocouple which passes through the base of the furnace, and is in close proximity to the sample, provides sample temperat .'e during a test.

In the TGA tests, small, milligram-size samples are heated at a constant rate and weight losses or gains undergone by a sample due to processes such as decomposition, oxidation, or vaporization are measured as a function of temperature. TGA test conditions, in general, duplicated conditions in the DSC tests.

Bomb Calorimeter Test

A Parr bomb calorimeter with a fuse wire ignitor was used to ignite and burn $1 \mathrm{~g}$ samples. The heat released by the reaction is obtained and the final gas pressure and temperature are measured. The product gases are then collected in a sampling tube or cylinder and analyzed by gas chromatography and if necessary, by infrared or mass spectroscopy. In standard tests, oxygen at $30 \mathrm{~atm}$ fill s the bomb. A few of the listed mixtures were tested under $1 \mathrm{~atm}$ of nitrogen, as well as in air and in oxygen.

Friction Test

A BAM frictional ignition test apparatus was used in the tests. This test determines the sensitivity of solid substances to ignition by friction and yields quantitative results in the form of limiting loads. The friction apparatus consists of a cast steel base on which is mounted the friction device proper. This comprises a fixed porcelain peg and a moving porcelain plate, on which the sample is placed. A loading arm fitted with six notches is provided for attachment of a weight. Weights of different masses are used. The use of the different weights in the different notches results in a series of loads including $5,10,20,40,60,80,120,160,240$, and $360 \mathrm{~N}$ (newtons). In the interpretation of the results, a distinction is made between "no reaction," "decomposition" (change of color, odor) and "explosion" (report, crackling, sparking or inflammation).

The series of trials is started with a single trial at the highest load. If at this trial the result "explosion" is observed, the series is continued with trials at stepwise lower loads until the result "decomposition" or "no reaction" is observed. At this load level the trial is repeated up to the total number of six if no "explosion" occurs; otherwise the friction load is reduced in steps until the limiting load is determined. If at the first single trial at $360 \mathrm{~N}$ the result "decomposition" or "no reaction" occurs, this trial is repeated also up to the total number of six. If at these repeating trials the result "decomposition" or "no reaction" occurs, the substance is deemed to be insensitive to friction. If at these repeating trials a result "explosion" is obtained, the limiting load is determined by lowering the load as described above. The limiting load, characterizing the friction sensitiveness of a substance, is defined as the lowest load at which the result "explosion" is obtained from at least one out of at least six trials. 
The next lower load level is then the maximum tested load at which no "explosion" is observed in six trials.

Standard materials which are generally used to verify the test procedures included the sensitive, nitrated explosive pentaerythritol tetranitrate (PETN) and black powder. Black powder consists of an intimate mixture of potassium nitrate $\left(\mathrm{KNO}_{3}\right)$, charcoal and sulfur. Due to the procedures of the test, duplicate tests were not necessary.

Impact Test

A Bureau of Explosives' Impact machine was used for the impact tests. This test measures the sensitivity of a substance to mechanical stimuli involving normal impact. In the apparatus, a weight of $81 \mathrm{bs}(3.63 \mathrm{~kg})$ is free to fall between two parallel cylindrical guide rods, from heights of up to 15 in $(38.1 \mathrm{~cm})$ onto a plunger-and-plug assembly. The plunger-and-plug assembly is in contact with the sample which is placed on a die-and-anvil assembly and confined in a cylindrical casing. The inside diameter of the casing is just sufficient to permit free movement of the plunger and plug.

In a test, $10 \mathrm{mg}$ of sample is loaded onto the die. The anvil and die are placed in the sample housing and the casing is screwed down over them. The plug and plunger are then inserted on top of the sample. The drop weight is raised to the desired height and released. A measurement is considered positive if either an audible report or flame is observed. A sample is considered impact sensitive at a specified drop height if a flame or report is observed in at least 50 pct of the test trials. This value of $\mathrm{H}_{50}$ is determined by the Bruceton up-and-down method (8).

Standard materials generally used to calibrate the friction test apparatus are cyclotrimethylene trinitramine (RDX) and cyclotetramethylene tetranitramine (HMX); PETN is also used. Additionally, black powder was tested. Due to the procedures of the test, duplicate tests are not necessary.

\section{Internal Ignition Test}

This test is designed to determine the response of the test sample to rapidly rising temperature and pressure. The test sample is contained in a $45.7 \mathrm{~cm}$ length of 3 -in schedule 80 carbon steel pipe with i.d. of $7.37 \mathrm{~cm}$, and wall thickness of $0.76 \mathrm{~cm}$. Both ends are capped with "3,000 pound" forged steel pipe caps. An ignitor consisting of black powder (100 pct passed through a No. 20 sieve, $0.84 \mathrm{~mm}$, and 100 pct retained by a No. 50 sieve, $0.297 \mathrm{~mm}$ ) is located at the center of the sample vessel. The ignitor assembly consists of a cylindrical container $2.06 \mathrm{~cm}$ in diameter and $6.4 \mathrm{~cm}$ long, which is made from $0.054-\mathrm{cm}$ thick cellulose acetate held together by two layers of nylonfilament-reinforced cellulose acetate tape. The ignitor capsule contains a small loop formed from a $2.54-\mathrm{cm}$ length of nickel-chromium alloy resistance wire, $0.030 \mathrm{~cm}$ in diameter having a resistance of $0.35 \mathrm{ohms}$. This 10op is attached to two insulated tinned copper lead wires. In a Bureau adaptation, the placement of the ignitor wires has been changed from the walls of the pipe to the center of the lower cap, for easier assembly. Results are not affected 
by this modification. A $20-\mathrm{g}$ ignitor is positioned in the center of the pipe as the lower cap is screwed on. The sample is then loaded, and the top cap screwed on. The test sample is generally loaded to the density obtained by repeated tapping of the pipe against a hard surface. The ignitor is fired by a current of 15 amperes obtained from a 20-volt transformer.

The criterion used for a positive result is that either the pipe or at least one of the end caps be fragmented into at least two distinct pieces, i.e., results in which the pipe is merely split or laid open or in which the pipe or caps are distorted to the point at which caps are blown off are considered to be negative results.

\section{Flame Spread Rate Test}

This test estimates flame velocity for a particular configuration. It uses a 250-mm-long mold with a triangular cross-section of inner height $10 \mathrm{~mm}$ and width $20 \mathrm{~mm}$. On both sides of the mold, in the longitudinal direction, two metal sheets are mounted, to confine the powdered substance which is loosely filled into the mold. The mold is dropped three times from a height of $20 \mathrm{~mm}$ onto a solid surface. An impervious, non-combustible, iow heat-condscting plate is placed on top of the mold, the apparatus is inverted and the mold is then removed. The powder train is ignited at one end by a small flame or a hot wire of minimum temperature of $1,000^{\circ} \mathrm{C}$. When the pile has burned a distance of $80 \mathrm{~mm}$, the flame speed is measured over the next $100 \mathrm{~mm}$. The other end of the pile is usually wetted and the ability of the wetted portion to quench the flame propagation is also noted.

If the substance does not ignite and propagate combustion either by burning with flame or smoldering along the $250 \mathrm{~mm}$ of powder train within 2 minutes, then the substance is not classified as a flammable solid. A burning rate of more than $2.2 \mathrm{~mm} / \mathrm{s}$ is considered a positive result.

Modified Trauzle Test

A machined, chemically pure extruded lead rod, $5.08 \mathrm{~cm}$ in diameter by $7.00 \mathrm{~cm}$ long is cut by a standard drill to contain a $2.54 \mathrm{~cm}$ diameter by $5.71 \mathrm{~cm}$ long cayity. A flat area at the bottom of the cavity is produced by the chisel point of a standard drill. A $6-\mathrm{g}$ sample is placed in a commercial, $16 \mathrm{ml}$, $24.9 \mathrm{~mm} 0 . \mathrm{d}$. vial which is provided with a standard polyethylene stopper. A $10 \mathrm{~mm}$ diameter hole drilled in the center of the stopper is used to hold securely in place a pyrex culture tube of $10 \mathrm{~mm} 0 . d$. by $75 \mathrm{~mm}$ long, into which a standard No. 8 (USA) detonator is inserted. The assembled vial is placed in the lead block, and the block is placed on a solid surface. The detonator is then fully inserted, and fired. The volume of the cavity in the lead block is measured accurately with water to the nearest $0.1 \mathrm{ml}$ before and after the test. Three tests are conducted for each substance. The explosive power of the test sample is expressed in terms of the average increase of the cavity in the lead block as follows:

"Not Low" - Average block expansion is equal to or greater than $22 \mathrm{~cm}^{3}$. "Low" - Average block expansion is less than $22 \mathrm{~cm}^{3}$ but greater than $12 \mathrm{~cm}^{3}$. "No" - Average block expansion is $12 \mathrm{~cm}^{3}$ or less. 
TEST MATRIX

The following tables list the chemical compositions of the mixtures subjected to the various tests.

Table 1. - Composition matrix for DSC/TGA tests

\begin{tabular}{|c|c|c|c|c|c|}
\hline No. & Fuel/wt frac & Oxid/wt frac & $\begin{array}{l}\text { Molar } \\
\text { ratio }\end{array}$ & $\begin{array}{c}\text { Dilu/ } \\
\text { wt frac }\end{array}$ & Remarks \\
\hline $2 A$ & EDTA/1 & -10 & - & 0 & Calibration \\
\hline $3 A$ & Citr/1 & -10 & - & 0 & Calibration \\
\hline $4 A$ & $0 \times a 1 / 1$ & -10 & - & 0 & Calibration \\
\hline $5 A$ & $\mathrm{PE} / \mathrm{I}$ & -10 & - & 0 & Calibration \\
\hline $6 A$ & - & Pure/1 & - & 0 & Calibration \\
\hline $7 \mathrm{~A}$ & - & $\operatorname{Mix} / 1$ & - & 0 & Calibration \\
\hline $9 A$ & EDTA/0.3586 & Pure/0.6414 & $1: 1$ & 0 & \\
\hline 98 & EDTA/0.1571 & Pure/0.8429 & $1: 3$ & 0 & \\
\hline $9 \mathrm{C}$ & EDTA/0.0786 & Pure $/ 0.4214$ & $1: 3$ & 0.5 & \\
\hline 90 & EDTA/0.0530 & Pure $/ 0.9470$ & $1: 10$ & 0 & \\
\hline $10 A$ & EDTA/0.3304 & Mix/0.6696 & $1: 1$ & 0 & \\
\hline $10 B$ & EDTA/0.1412 & Mix/0.8588 & $1: 3$ & 0 & \\
\hline $10 \mathrm{C}$ & EDTA/0.0706 & Mix/0.4294 & $1: 3$ & 0.5 & \\
\hline 100 & EDTA/0.0470 & Mix/0.9530 & $1: 10$ & 0 & \\
\hline $11 \mathrm{~A}$ & Citr/0.4574 & Pure/0.5426 & $1: 1$ & 0 & \\
\hline 118 & Citr/0.2194 & Pure/0.7806 & $1: 3$ & 0 & \\
\hline $11 C$ & Citr/0.1097 & Pure/0.3903 & $1: 3$ & 0.5 & \\
\hline 110 & Citr/0.0777 & Pure/0.9223 & $1: 10$ & 0 & \\
\hline $12 \mathrm{~A}$ & $\mathrm{Citr} / 0.4268$ & Mix/0.5732 & $1: 1$ & 0 & \\
\hline $12 B$ & Citr/0.1988 & $M+x / 0.8012$ & $1: 3$ & 0 & \\
\hline $12 \mathrm{C}$ & Citr/0.0994 & Mix/0.4006 & $1: 3$ & 0.5 & \\
\hline 120 & $\mathrm{Citr} / 0.0693$ & Mix/0.9307 & $1: 10$ & 0 & \\
\hline $13 A$ & $0 \times a 1 / 0.7976$ & Pure/0.2024 & $1: 1$ & 0 & \\
\hline $13 B$ & $0 \times a 1 / 0.5678$ & Pure/0.4322 & $1: 3$ & 0 & \\
\hline
\end{tabular}




\section{WHC-MR-0455}

Table 1. - Composition matrix for DSC/TGA tests (cont'd)

\begin{tabular}{|c|c|c|c|c|c||}
\hline No. & Fuel/wt frac & Oxid/wt frac & $\begin{array}{c}\text { Molar } \\
\text { ratio }\end{array}$ & $\begin{array}{c}\text { Dilu/ } \\
\text { wt frac }\end{array}$ & Remarks \\
\hline $13 C$ & $0 \times a 1 / 0.2839$ & Pure/0.2161 & $1: 3$ & 0.5 & \\
\hline 130 & $0 \times a 1 / 0.2827$ & Pure/0.7173 & $1: 10$ & 0 & \\
\hline $14 \mathrm{~A}$ & $0 \times a 1 / 0.7768$ & Mix/0.2232 & $1: 1$ & 0 & \\
\hline $14 B$ & $0 \times a 1 / 0.5371$ & Mix/0.4629 & $1: 3$ & 0 & \\
\hline $14 C$ & $0 \times a 1 / 0.2685$ & Mix/0.2315 & $1: 3$ & 0.5 & \\
\hline 140 & $0 \times a 1 / 0.2582$ & Mix/0.7418 & $1: 10$ & 0 & \\
\hline $15 \mathrm{~A}$ & PE/0.1207 & Pure/0.8793 & $1: 1$ & 0 & \\
\hline $15 B$ & $P E / 0.0438$ & Pure/0.9562 & $1: 3$ & 0 & \\
\hline $15 C$ & $P E / 0.0219$ & Pure/0.4781 & $1: 3$ & 0.5 & \\
\hline 150 & $P E / 0.0135$ & Pure/0.9865 & $1: 10$ & 0 & \\
\hline $16 \mathrm{~A}$ & $P E / 0.1081$ & Mix/0.8919 & $1: 1$ & 0 & \\
\hline $16 B$ & $P E / 0.0388$ & Mix/0.9612 & $1: 3$ & 0 & \\
\hline $16 C$ & $P E / 0.0194$ & Mix/0.4806 & $1: 3$ & 0.5 & \\
\hline 160 & $P E / 0.0120$ & Mix/0.9880 & $1: 10$ & 0 & \\
\hline $17 \mathrm{~A}$ & FeCN & As supplied material (mixture of five salts) \\
\hline
\end{tabular}

Note: wt frac $=$ weight fraction

Oxid = Oxidant

Dilu $=$ Diluent

Pure = Sodium nitrate

Mix = equimolar mixture of sodium nitrate and sodium nitrite; (wt ratio $=85.01 / 69.01$ ) 
Table 2. - Composition matrix for friction and impact tests

\begin{tabular}{|c|c|c|c|c|}
\hline No. & $\begin{array}{c}\text { Fuel/ } \\
\text { wt frac }\end{array}$ & $\begin{array}{l}\text { oxid/ } \\
\text { wt frac }\end{array}$ & $\begin{array}{l}\text { Molar } \\
\text { ratio }\end{array}$ & Remarks \\
\hline $1 \mathrm{~A}$ & \multicolumn{2}{|c|}{ PETN \& Gun Powder } & - & Standards \\
\hline $2 A$ & EDTA/1 & -10 & - & Calibration \\
\hline $3 A$ & $\mathrm{Citr} / \mathrm{I}$ & -10 & - & Calibration \\
\hline $4 A$ & $0 \times a 1 / 1$ & -10 & - & Calibration \\
\hline $5 A$ & $P E / 1$ & -10 & - & Calibration \\
\hline $6 A$ & -10 & Pure/1 & - & Calibration \\
\hline $7 A$ & -10 & $M i x / 1$ & - & Calibration \\
\hline $9 A$ & EDTA/0.3586 & Pure/0.6414 & $1: 1$ & \\
\hline $10 A$ & EDTA $/ 0.3304$ & Mix/0.6696 & $1: 1$ & \\
\hline $11 A$ & Citr/0.4574 & Pure/0.5426 & $1: 1$ & \\
\hline $12 A$ & Citr/0.4268 & Mix/0.5732 & $1: 1$ & \\
\hline $13 A$ & $0 \times a 1 / 0.7976$ & Pure/0.2024 & $1: 1$ & \\
\hline $14 A$ & $0 \times a l / 0.7768$ & $M i x / 0.2232$ & $1: 1$ & \\
\hline $15 A$ & $\mathrm{PE} / 0.1207$ & Pure/0.8793 & $1: 1$ & \\
\hline $16 \mathrm{~A}$ & $\mathrm{PE} / 0.1081$ & Mix/0.8919 & $1: 1$ & \\
\hline $17 A$ & $\mathrm{FeCN}$ & -10 & - & \\
\hline
\end{tabular}

Table 3. - Composition matrix for internal ignition tests

\begin{tabular}{|c|c|c|c||}
\hline No. & Fuel/wt frac & Oxid/wt frac & $\begin{array}{c}\text { Molar } \\
\text { ratio }\end{array}$ \\
\hline $9 A$ & EDTA $/ 0.3586$ & Pure/0.6414 & $1: 1$ \\
\hline $11 A$ & Citr/0.4574 & Pure/0.5426 & $1: 1$ \\
\hline $2 A$ & EDTA $/ 1$ & $-/ 0$ & - \\
\hline $6 A$ & -10 & Pure/1 & - \\
\hline
\end{tabular}


Table 4. - Composition matrix for flame spread rate tests

\begin{tabular}{|c|c|c|c||}
\hline No. & Fuel/wt frac & Oxid/wt frac & $\begin{array}{c}\text { Molar } \\
\text { ratio }\end{array}$ \\
\hline $9 A$ & EDTA/0.3586 & Pure/0.6414 & $1: 1$ \\
\hline $11 A$ & Citr/0.4574 & Pure/0.5426 & $1: 1$ \\
\hline $15 A$ & $P E / 0.1207$ & Pure/0.8793 & $1: 1$ \\
\hline
\end{tabular}

Table 5. - Composition for Modified Trauzle test

\begin{tabular}{||c|c|c|}
\hline No. & \multicolumn{2}{|c|}{ Sample } \\
\hline 17A & FeCN & As supplied material (mixture of five salts) \\
\hline
\end{tabular}

\section{SAMPLE PREPARATION}

All the materials were of certified reagent grade quality, and all, other than the polyethylene, were ground and sieved to provide size fractions smaller and greater than 100 mesh $(0.15 \mathrm{~mm})$. The polyethylene powder was not ground; it was sieved to provide the same two size fractions. The FeCN sample was supplied in paste form. The paste was dried in an oven at $65^{\circ} \mathrm{C}$, to constant weight, and the dried material was ground, sieved through a 100 mesh sieve and then mixed well.

The quantity of the sample used in the DSC, TGA, friction and impact tests is very small, of the order of $10 \mathrm{mg}$ or less. In preliminary tests in the DSC it was observed that some of the mixtures leaked out of the sample pans during the tests, due to frothing, foaming or effervescent behavior. In order to minimize leakage and loss of sample, some of the samples were 2 to $3 \mathrm{mg}$ in size. To assure representative samples, as well i good contact between the various ingredients, only the -100 mesh $(<0.15 \mathrm{~mm})$ size fractions of the individual compounds were used in the preparation of the mixtures. Additionally, extensive mixing and tumbling were conducted. Furthermore, at least a few mixtures from each fuel set were analyzed by ion chromatography for the nitrate, nitrite, and the respective fuel anion (e.g. oxalate, citrate, etc.) before the mixtures were used in the various tests. In most cases the results of the analyses agreed with the actual amounts, within experimental error. If agreement was not satisfactory, all the mixtures from that fuel set underwent additional mixing and tumbling and then some of the mixtures were analyzed a second time. In most cases, this second procedure was not required. Two of the fuels, the sodium oxalate and the polyethylene were anhydrous. Anhydrous salts of the tetrasodium EDTA and of the sodium 
citrate were not commercially available. Instead, tetrasodium EDTA dihydrate and sodium citrate dihydrate were used in the tests. The weights of the fuels in the mixtures of the hydrous salts were modified to allow for the presence of the water of hydration. In each of the mixtures containing these fuels the water of hydration was released at a lower temperature than the temperature at which decomposition began in the DSC tests.

\section{EXPERIMENTAL RESULTS AND DISCUSSION}

\section{EXPLOSIVE TESTS}

Impact and Friction Tests

Gun powder and PETN were used as standards each time a fuel set or two fuel sets were tested. Sodium nitrate and the sodium nitrate-sodium nitrite combination were tested once, as were the individual fuels. Tests with the mixtures were started with the "A" designated mixtures. All the " $A$ " samples were tested, and negative results were obtained at maximum parameters for all the samples. Thus, samples designated "B", "C" and "D", as seen in table 1 for the DSC and TGA tests, and originally also considered for the explosive tests, were not tested. Results are summarized in tables 6 to 8 for the various test materials. The results for the standards are within the experimental variation expected for explosives. The sample numbers used in all the tables of experimental results refer to numbers used in table 1, to identify mixtures. Sample numbers are also used throughout the report.

Table 6. - Impact and friction test results for standards, oxidants, sodium oxalate and oxalate mixtures

\begin{tabular}{|c|c|c|c|c|}
\hline \multicolumn{3}{|c|}{ Samples } & \multicolumn{2}{|c|}{ Results } \\
\hline No. & Fuel/wt frac & oxid/wt frac & Impact, $\mathrm{H}_{50}$ & Friction \\
\hline $1 A$ & \multicolumn{2}{|c|}{ Gun Powder } & $17.3 \mathrm{~cm}(6.8 \mathrm{in})$ & 360 Newtons, six no \\
\hline $1 A$ & \multicolumn{2}{|c|}{ PETN } & $4.1 \mathrm{~cm}(1.6 \mathrm{in})$ & $\begin{array}{l}120 \text { Newtons, one yes } \\
80 \text { Newtoris, six no }\end{array}$ \\
\hline $6 A$ & - & Pure/1 & $\begin{array}{c}38.1 \mathrm{~cm}(15.0 \mathrm{in}), \\
\text { ten no }\end{array}$ & 360 Newtons, six no \\
\hline $7 A$ & - & $\operatorname{Mix} / 1$ & $"$ & $"$ \\
\hline $4 A$ & $0 \times a 1 / 1$ & -10 & $"$ & $"$ \\
\hline $13 A$ & $0 \times a 1 / 0.7976$ & Pure $/ 0.2024$ & $"$ & $"$ \\
\hline $14 A$ & $0 \times a 1 / 0.7768$ & $\operatorname{Mix} / 0.2232$ & $"$ & $"$ \\
\hline
\end{tabular}


Table 7. - Impact and friction test results for standards, for sodium EDTA and EDTA mixtures, and for sodium citrate and citrate mixtures

\begin{tabular}{|c|c|c|c|c|}
\hline \multicolumn{3}{|c|}{ Samples } & \multicolumn{2}{|c|}{ Results } \\
\hline No. & Fuel/wt frac & Oxid/wt frac & Impact, $H_{50}$ & Friction \\
\hline $1 A$ & \multicolumn{2}{|c|}{ Gun Powder } & $20.8 \mathrm{~cm}(8.2 \mathrm{in})$ & 360 Newtons, six no \\
\hline $1 A$ & \multicolumn{2}{|c|}{ PETN } & $4.1 \mathrm{~cm}(1.6 \mathrm{in})$ & $\begin{array}{c}80 \text { Newtons, one yes } \\
60 \text { Newtons, six no }\end{array}$ \\
\hline $2 A$ & EDTA/1 & -10 & $\begin{array}{c}38.1 \mathrm{~cm}(15.0 \mathrm{in}), \\
\text { ten no }\end{array}$ & 360 Newtons, six no \\
\hline $9 A$ & EDTA/0.3586 & Pure/0.6414 & $"$ & $"$ \\
\hline $10 \mathrm{~A}$ & EDTA $/ 0.3304$ & Mix/0.6696 & $"$ & $"$ \\
\hline $3 A$ & Citr $/ 1$ & -10 & $"$ & $"$ \\
\hline $11 \mathrm{~A}$ & Citr $/ 0.4574$ & Pure/0.5426 & $"$ & $"$ \\
\hline $12 A$ & Citr/0.4268 & $M i x / 0.5732$ & $"$ & $"$ \\
\hline
\end{tabular}

Table 8. - Impact and friction test results for standards, for polyethylene and polyethylene mixtures, and for $\mathrm{FeCN}$

\begin{tabular}{|c|c|c|c|c|}
\hline \multicolumn{3}{|c|}{ Samples } & \multicolumn{2}{|c|}{ Results } \\
\hline No. & Fuel/wt frac & Oxid/wt frac & Impact, $\mathrm{H}_{50}$ & Friction \\
\hline $1 A$ & \multicolumn{2}{|c|}{ Gun Powder } & $23.9 \mathrm{~cm}(9.4 \mathrm{in})$ & 360 Newtons, six no \\
\hline $1 A$ & \multicolumn{2}{|c|}{ PETN } & $4.1 \mathrm{~cm}(1.6 \mathrm{in})$ & $\begin{array}{l}60 \text { Newtons, one yes } \\
40 \text { Newtons, six no } \\
\end{array}$ \\
\hline $5 A$ & $P E / 1$ & -10 & $\begin{array}{c}38.1 \mathrm{~cm}(15 \mathrm{in}), \\
\text { ten no } \\
\end{array}$ & 360 Newtons, six no \\
\hline $15 A$ & PE/0.1207 & Pure/0.8793 & $"$ & $"$ \\
\hline $16 A$ & $\mathrm{PE} / 0.1081$ & $M i x / 0.8919$ & $"$ & $"$ \\
\hline $17 \mathrm{~A}$ & $\mathrm{FeCN}$ & -10 & $"$ & $"$ \\
\hline
\end{tabular}


Internal Ignition Tests

Two mixtures were tested in the internal ignition test, EDTA with nitrate, 9A, and citrate with nitrate, $11 \mathrm{~A}$, and each mixture was tested twice. The commercially-bought EDTA and citrate salts were used as-received, without grinding. The sodium nitrate was ground but not sieved, however, the grinding plates in the grinder were set to give a fine powder of about 100 mesh. The mixtures were tumbled and rolled in a ball mill roller for a few hours, to obtain homogeneous mixtures. In the tests with the EDTA-nitrate mixture, the samples weighed 2186 and $1918 \mathrm{~g}$, respectively. A smaller amount was used in the second test, to prevent entrainment of the crystals in the threads of the pipe and the top cap. In both trials the top cap was blown off, and a small amount of solidified molten white residue remained in the bottom cap. In the tests with the citrate-nitrate mixture, the samples weighed 2412 and $2376 \mathrm{~g}$, respectively, In the first test the top cap blew off after a slight delay of 1 to $2 \mathrm{~s}$, following the firing of the ignitor. A small amount of solidified molten white residue remained in the bottom cap. In the second test both caps were blown off. When only the cap, or caps, are blown off the pipe, the results are considered negative. The tests are conducted in a bomb-proof facility, which is exhausted by a fan after each test. The vapors, gases, and any entrained solid residue are thereby removed from the room before the next test is conducted. Vapors and smoke (solid residue) were seen in the exhaust after each test. Photographs showing some details of two of the tests, one with the EDTA mixture, and one with the citrate mixture are shown in photographs 1 to 5 .

An additional test was conducted with EDTA, $2 \mathrm{~A}$, by itself. The sample weighed $1154 \mathrm{~g}$. In this test neither cap was blown off and most of the powder was recovered. A small amount of the powder near the ignitor fused. A final test was conducted with sodium nitrate by itself. The sample weighed $2390 \mathrm{~g}$. Likewise, in this test neither cap was blown off. The powder near the igniter was compressed, and probably fused. Thus, the results indicate that the mixture of EDTA with the sodium nitrate interacts to release a larger amount of gases, thereby increasing the pressure, as well as the temperature, with these two effects combining to blow the cap off.

Modified Trauzle Test

This test was not originally scheduled. However, it was desired to assess the explosive properties of the $\mathrm{FeCN}, 17 \mathrm{~A}$, sample. Since the available quantity was not sufficient for conducting the internal ignition test or the flame spread rate test, this test, which requires relatively small quantities, was conducted.

The modified Trauzle test is used to measure the explosive power of a substance by the expansion of a cavity carefully machined in a pure lead block. Table salt and PETN are used as standards, and results of tests with these standards and with the $\mathrm{FeCN}$ sample are given in table 9 . As is seen in the table, the $\mathrm{FeCN}$ is only slightly more reactive than the table salt. If the average expansion is $12 \mathrm{~cm}^{3}$ or less, the test criterion is "NO". 


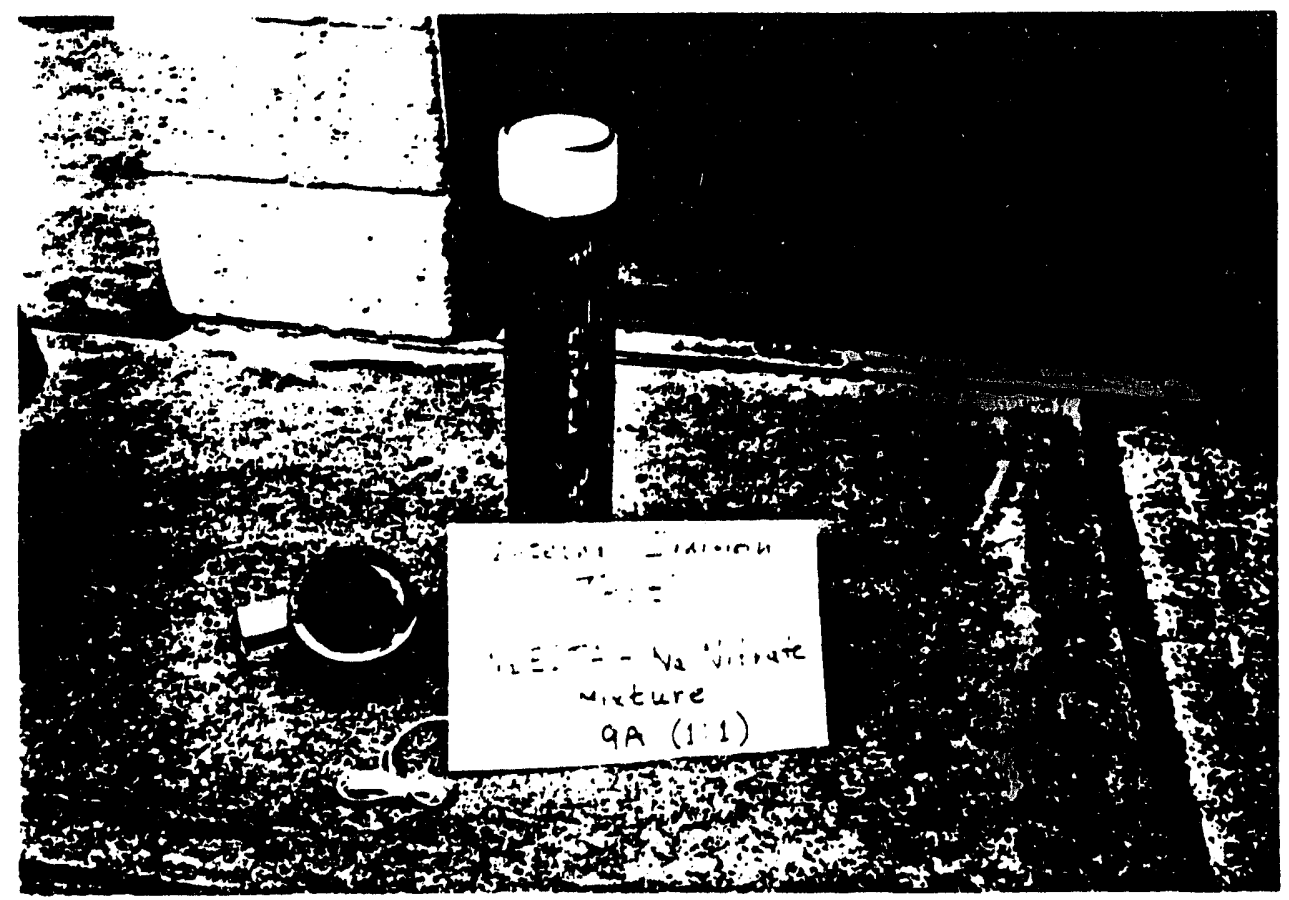

$$
\begin{gathered}
\text { Photograph 1. - Pipe for internal ignition test, } \\
\text { filled with a mixture of } \\
\text { EDTA-nitrate (9A) }
\end{gathered}
$$

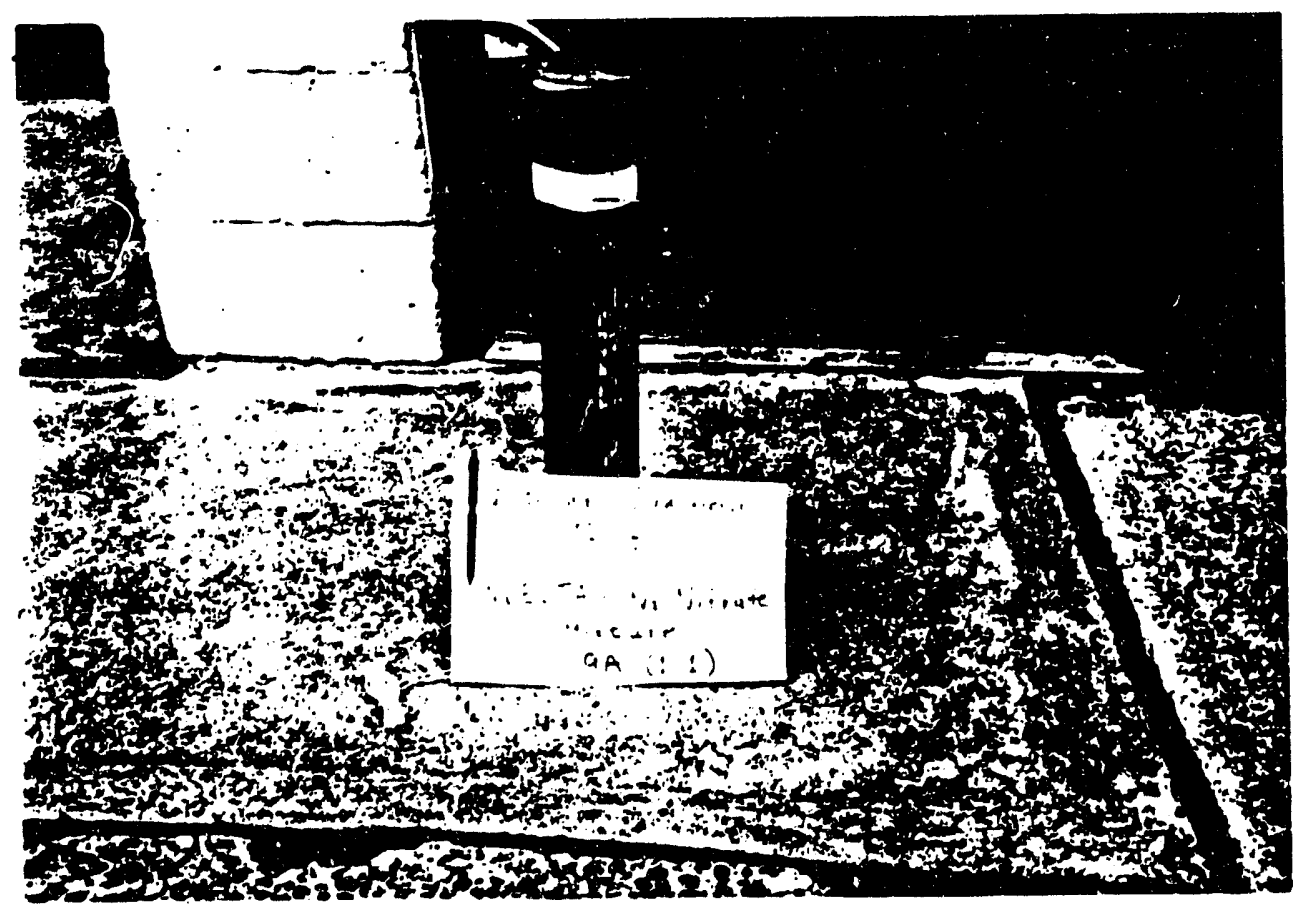

Photograph 2. - Pipe capped and ready for the test 


\section{WHC-MR-0455}

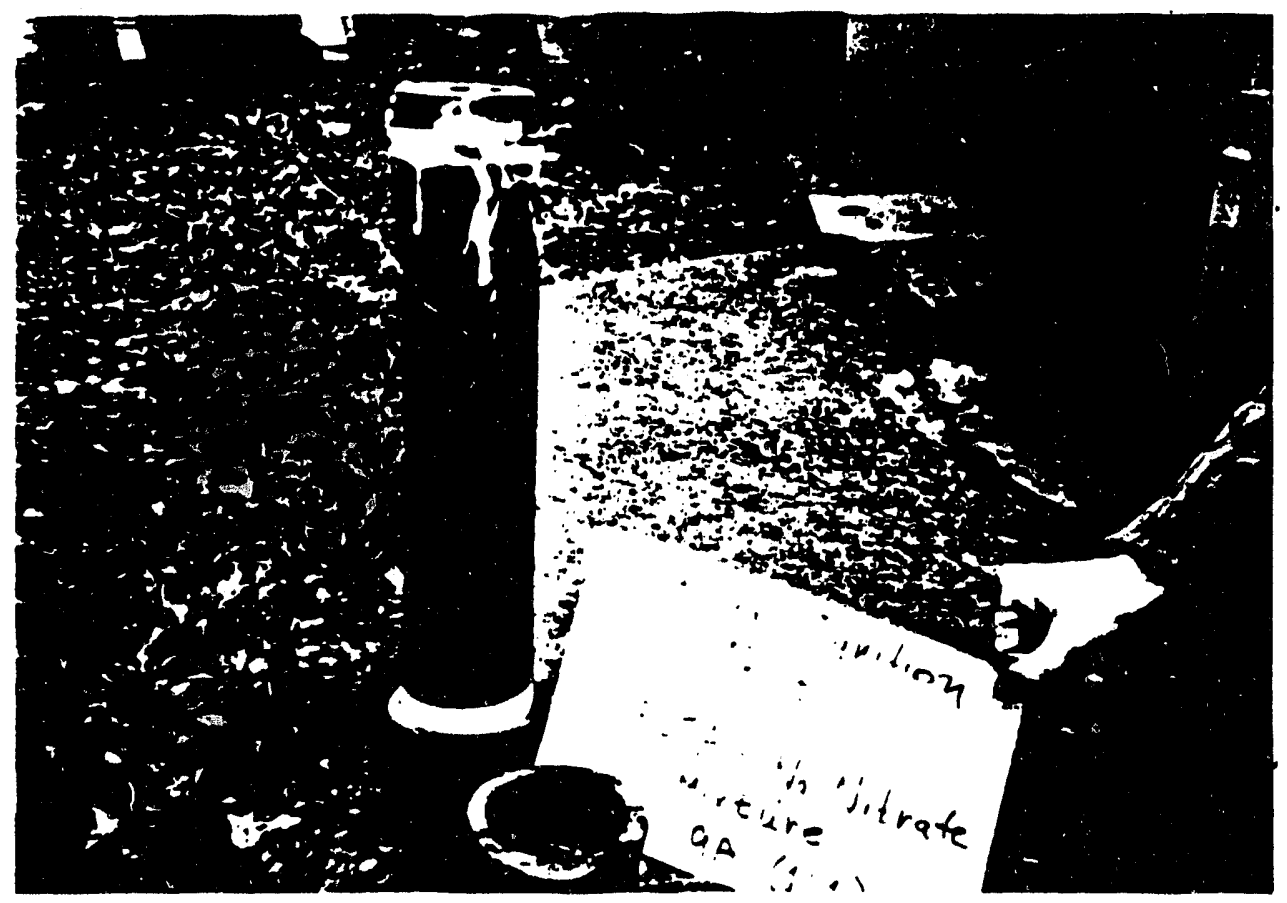

Photograph 3. - Pipe with blown, misshapen cap, after the test

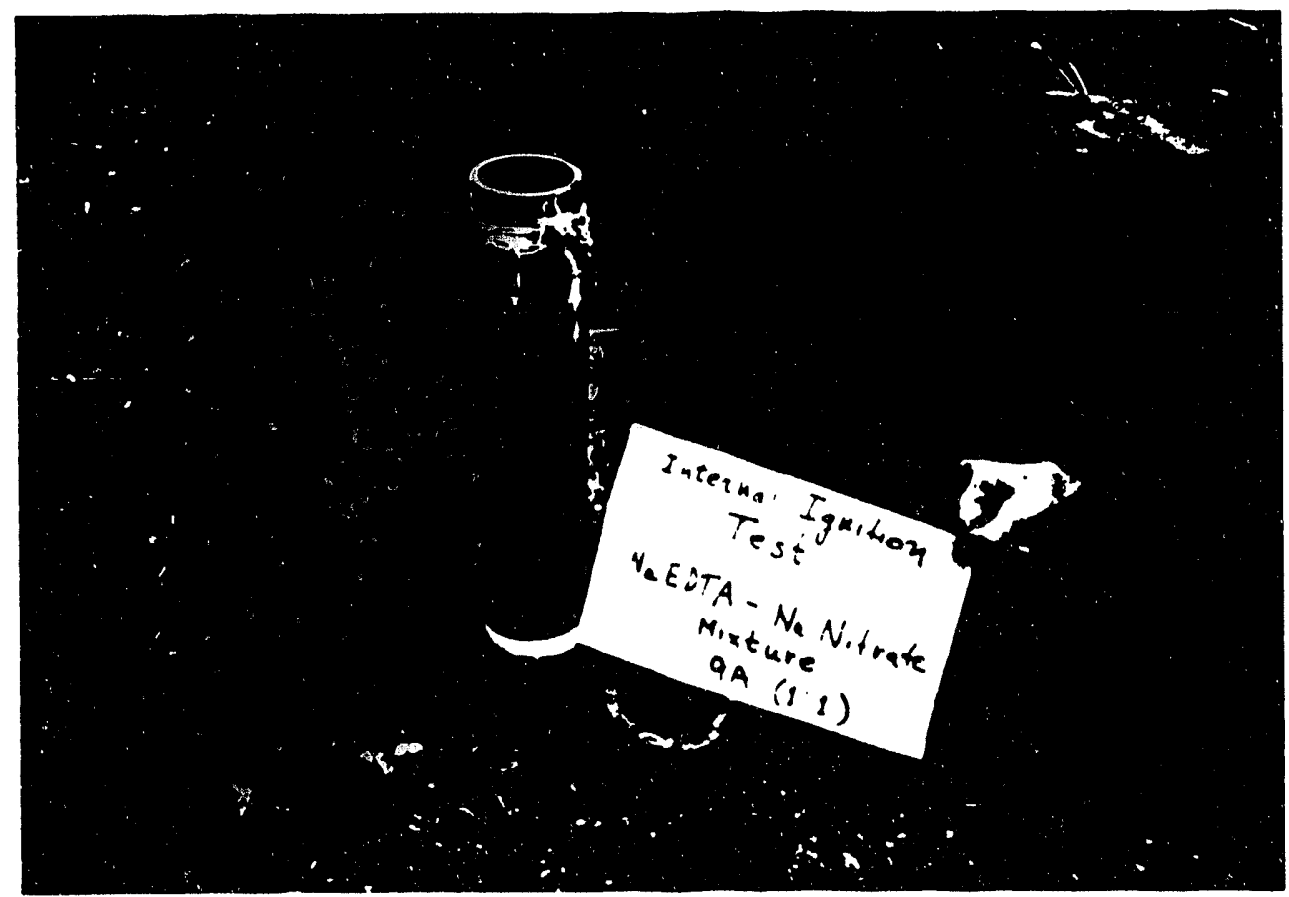

Photograph 4. - Pipe is empty; mixture consumed or vaporized during the test 
WHC-MR-0455

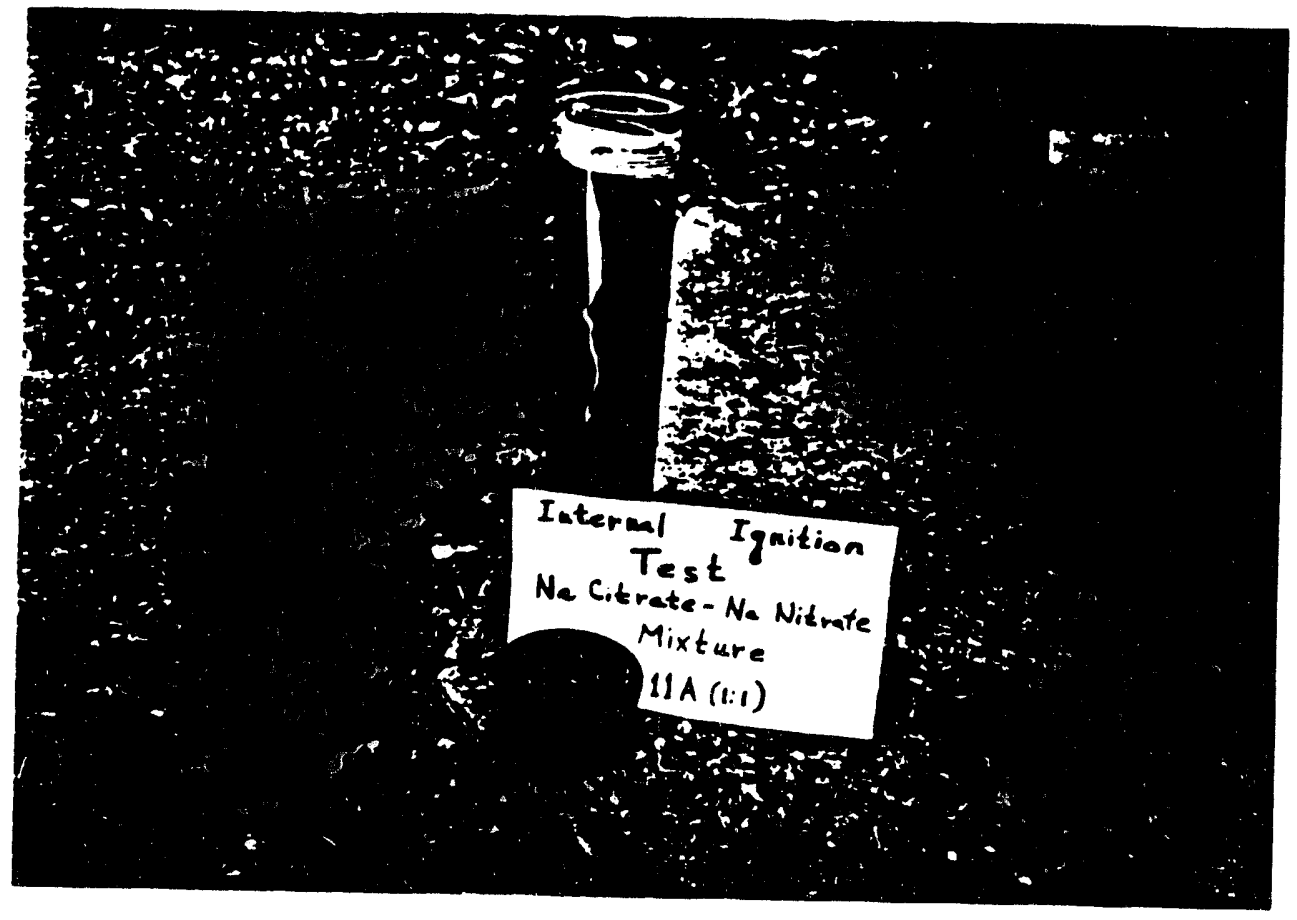

Photograph 5. - Empty pipe and misshapen cap after internal ignition test with a mixture of citrate-nitrate (11A) 


\section{WHC-MR-0455}

Table 9. - Modified Trauzle Lead Block test results

\begin{tabular}{|c|c|c|}
\hline Sample & $\begin{array}{c}\text { Weight, } \\
g\end{array}$ & $\begin{array}{c}\text { Expansion of cavity from } \\
\text { detonator and sample, } \\
\mathrm{cm}^{3}\end{array}$ \\
\hline $\mathrm{FeCN}, 17 \mathrm{~A}^{1}$ & 6 & 6.9 \\
\hline$"$ & 6 & 7.9 \\
\hline table salt ${ }^{2}$ & 6 & 5.5 \\
\hline 1 & 6 & 5.6 \\
\hline$"$ & 6 & 5.9 \\
\hline PETN ${ }^{2}$ & 1 & 37.4 \\
\hline 1 & 1 & 43.5 \\
\hline$"$ & 1 & 41.7 \\
\hline$"$ & 3 & 3 \\
\hline
\end{tabular}

'Particle size was -100 mesh.

${ }^{2}$ Standard.

${ }^{3}$ Lead block split into 8 pieces.

\section{FLAMMABILITY TESTS}

Flame Spread Rate Tests

Flame spread rate (or burning rate) tests were conducted with three mixtures, EDTA-nitrate, 9A, citrate-nitrate, 11A, and polyethylene-nitrate, 15A. These mixtures were all-100 mesh in size. The results for the first set of tests were as follows:

1. The polyethylene-nitrate mixture, 15A, did not ignite after several attempts.

2. The EDTA-nitrate mixture, $9 A$, burned a length of $10 \mathrm{~mm}$ and stopped. Burn time was $38 \mathrm{~s}$.

3. The citrate-nitrate mixture, 11A, was tested twice. In the first test sparks caused the ignition front to move ahead, and the test was considered invalid. In the second trial, a burn time of $110 \mathrm{~s}$ was recorded for the $100 \mathrm{~mm}$ section. Resultant burn rate was $0.91 \mathrm{~mm} / \mathrm{s}$.

According to test specifications, the pile is to burn $80 \mathrm{~mm}$, and $\mathrm{fl}$ ame speed is measured over the next $100 \mathrm{~mm}$. If the substance does not propagate combustion either by burning with flame or smoldering along the powder train 
within two minutes, then the substance is not classified a flammable solid. A burning rate of more than $2.2 \mathrm{~mm} / \mathrm{s}$ is considered a positive result. Based on these criteria, all three mixtures gave negative results. The tests were videotaped.

Two other samples, one of EDTA-Nitrate, 9A, and one of citrate-nitrate, 11A, were tested. Each of the individual salts used in preparing the mixtures was lightly ground and used without sieving. The mixtures were tumbled in a ball mill roller. These mixtures did not ignite after several attempts. Particle size distributions of these two mixtures were the following:

EDTA-nitrate, 9A, Citrate-nitrate, 11A,

\begin{tabular}{l} 
Mesh size \\
\hline$+30 ;(>0.6 \mathrm{~mm})$ \\
$+50 ;(>0.3 \mathrm{~mm})$ \\
$+100 ;(>0.15 \mathrm{~mm})$ \\
$+200 ;(>0.075 \mathrm{~mm})$ \\
$-200 ;(<0.075 \mathrm{~mm})$
\end{tabular}

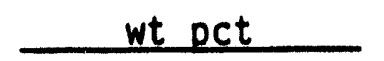

2.6

27.3

36.5

19.8

13.8 wt pct

35.9

35.4

13.1

8.8

6.8

The unused portions of the latter two mixtures were reground, retumbled and tested. The following results were found:

1. Three samples of the EDTA-nitrate mixture, 9A, were ignited. Burn times in two of these tests for the $100 \mathrm{~mm}$ sections were 177 and $150 \mathrm{~s}$, and the respective burn rates were 0.56 and $0.67 \mathrm{~mm} / \mathrm{sec}$. In the third test the sample burned a length of $80 \mathrm{~mm}$ and then stopped. Burn time was $100 \mathrm{~s}$.

2. Three samples of the citrate-nitrate mixture, $11 \mathrm{~A}$, were ignited, and all the samples burned through. Burn times for the $100 \mathrm{~mm}$ sections were 60 , 40 , and $32 \mathrm{~s}$ and burn rates were $1.66,2.50$ and $3.12 \mathrm{~mm} / \mathrm{s}$.

In this set of tests the EDTA-nitrate mixture gave negative results and is not classified as a flammable solid. The citrate-nitrate mixture had two burn rates higher than $2.2 \mathrm{~mm} / \mathrm{s}$, and is therefore classified as a flammable solid. The particle size distribution for these two mixtures was the following:

$$
\text { EDTA-nitrate, 9A, Citrate-nitrate, 11A, }
$$

$$
\begin{gathered}
\frac{\text { Mesh size }}{+50 \quad(>0.3 \mathrm{~mm})} \\
+100 \quad(>0.15 \mathrm{~mm}) \\
+200 \quad(>0.075 \mathrm{~mm}) \\
-200 \quad(<0.0 .75 \mathrm{~mm})
\end{gathered}
$$

wt pct

6.1

27.9

28.0

38.0 wt pct

\section{7}

16.8

26.0

52.5 
As can be seen from all the above results, the relatively coarse mixtures are not easily ignited. On the other hand, the mixtures do not have to be extremely fine in order to burn. A certain optimum size, which al so can contain air between the particles may be best for burning. These tests were also videotaped.

\section{EXPLOSIVE AND FLAMMABILITY TESTS}

Summary

The stoichiometric mixtures of all four fuel sets, designated " $A$ ", underwent impact and friction tests. Results were negative in these tests for all these mixtures. Two of the mixtures, those of EDTA and citrate with sodium nitrate, designated " $A$ " were tested in the internal ignition test, and results were negative for these tests.

In the flame spread rate test three "A" mixtures were tested, those of EDTA, citrate and polyethylene with sodium nitrate. Results were negative for the EDTA and polyethylene mixtures, whereas, the mixture with citrate, of a specific particle size distribution, burned twice at a rate higher than $2.2 \mathrm{~mm} / \mathrm{s}$, and was classified as a flammable solid. Finally, the FeCN sample was evaluated in the modified Trauzle lead block test, and the result was negative.

\section{THERMAL ANALYSIS TESTS}

Calibration of the DSC

Pure indium and zin: metal standards, provided by Perkin Elmer, were used to calibrate the DSC for temperature and enthalpy. Once calibration is performed, the analyzer usually remains calibrated, unless major condition changes are made. The calibration of the DSC was checked prior to the testing of each fuel set, and if found necessary, was recalibrated. It was also calibrated following each adjustment of balance and slope controls. Balance control is used to minimize baseline curvature, while slope control is used to adjust the slope of the baseline. Figure 1 shows a calibration test with indium while figure 2 is for a calibration test with zinc, both in flowing air. The onset temperature shown in figure 1, for the melting point of indium, $156.66^{\circ} \mathrm{C}$, agrees with its melting temperature of $156.6^{\circ} \mathrm{C}$, and the heat of melting, $28.6 \mathrm{j} / \mathrm{g}$, compares well with the established value of $28.45 \mathrm{j} / \mathrm{g}$. Indium is the preferred material for the calibration of enthalpy. As can be seen in both figures, endotherms in the Perkin Elmer DSC rise above the baseline; exotherms, on the other hand, extend downward, below the baseline.

\section{Calibration of the TGA}

Three calibrations are required for the TGA, weight calibration, temperature calibration and furnace calibration. When all calibrations are performed, periodic checks of the calibration are all that are usually necessary to verify calibration. Weight calibration is performed with a $100-\mathrm{mg}$ calibration weight. Temperature calibration is done with one or two magnetic standards, 
in the temperature range of interest. Nickel and Perkalloy, supplied by Perkin Elmer, and with magnetic transition temperatures of $354^{\circ}$ and $596^{\circ} \mathrm{C}$, respectively, were used for this study. Fresh metal samples were used for each calibration. Figure 3 shows a calibration check with both magnetic standards. Calculated results, seen on the figure, indicated that calibration was needed, and calibration was then done. The furnace calibration performs a nine-point callbration between operator-selected lower and upper temperature limits. When calibration is complete, the thermocouple temperature is matched to the programmed furnace temperature. This furnace temperature calibration is performed after each temperature calibration.

DSC and TGA Tests of Sodium Nitrate, Sodium Nitrite and Sodium Nitrate-Sodium Nitrite Mixtures.

The thermal behavior of the individual oxidants and of the mixture of both oxidants was studies in the DSC. Both nitrate and nitrite salts undergo a solid phase transition, and then melt. Figures 4 to 6 show thermograms for the sodium nitrate, the sodium nitrite and the mixture of the two salts, respectivaly. The thermograms were obtained at a heating rate of $10^{\circ} \mathrm{C} / \mathrm{min}$; the thermogram in figure 4 was obtained in air, while the thermograms in figures 5 and 6 were done in an atmosphere of flowing nitrogen, and they are essentially identical to the respective thermograms, obtained at the same heating rate, in flowing air.

The same three materials were tested in the TGA, at the same heating rate, in flowing air, and the resultant TGA thermograms are presented in figures 7 to 9. In the DSC thermograms, only solid phase changes and transitions from the solid to the liquid phase are seen. No evidence is seen for decomposition, and essentially no weight loss is observed in the TGA thermograms. The weight loss in figure 7 is 1.2 pct, whereas in figure 9 it is 0.3 pct, in both cases, undoubtedly due to loss of moisture. In figure 8 there was a weight gain of $0.8 \mathrm{pct}$, due to formation of sodium nitrate.

It is known that sodium nitrate and sodium nitrite decompose at higher temperatures and evolve various gases. Since compounds such as sodium nitrate are used in explosives and pyrotechnic mixtures, and ince sodium nitrite is a decomposition product of the nitrate, the decomposition modes of both salts have been studied in detail under various conditions. Freeman (9) reported that sodium nitrate started to decompose slowly at $600^{\circ} \mathrm{C}$. Bond and Jacobs (10) reported that decomposition of sodium nitrate, at the temperature range of $570^{\circ}$ to $760^{\circ} \mathrm{C}$, occurred in two stages. The first stage is the reversible decomposition of the nitrate to the nitrite:

$$
2 \mathrm{NO}_{3}^{\circ} \stackrel{600^{\circ} \mathrm{C}}{=} 2 \mathrm{NO}_{2}^{\circ}+\mathrm{O}_{2} \text {. }
$$

The second, and slower, stage is the decomposition of the nitrite to the oxide:

$$
\text { and } \quad \begin{aligned}
& 2 \mathrm{NO}_{2} \rightarrow 0^{2}+2 \mathrm{NO}+1 / 2 \mathrm{O}_{2}, \\
& 2 \mathrm{NO}_{2} \cdot \rightarrow 0^{2 \cdot}+\mathrm{N}_{2}+3 / 2 \mathrm{O}_{2},
\end{aligned}
$$


with the latter being the major route, and the oxide, $\mathrm{Na}_{2} \mathrm{O}$, being the residue. Many other publications present similar data, and some suggest that the sodium nitrate melt decomposes at much lower temperatures, but the extent of decomposition at equilibrium is minimal.

Other schemes for the decomposition of sodium nitrite have been suggested. $0 z a$ and Walawalkar (11) review some of these schemes, and offer some of their own:

$$
\begin{aligned}
& 4 \mathrm{MNO}_{2} \rightleftharpoons 2 \mathrm{M}_{2} \mathrm{O}+2 \mathrm{NO}+2 \mathrm{NO}_{2}, \\
& \mathrm{M} 2 \mathrm{O}+2 \mathrm{NO}_{2} \rightarrow \mathrm{MNO}_{2}+\mathrm{MNO}_{3}, \\
& \mathrm{MNO}_{2}+\mathrm{NO}_{2} \rightarrow \mathrm{MNO}_{3}+\mathrm{NO}, \\
& 2 \mathrm{MNO}_{2}+2 \mathrm{NO} \rightarrow 2 \mathrm{MNO}_{3}+\mathrm{N}_{2},
\end{aligned}
$$

with $M$ being either sodium or potassium. Their experiments were conducted at lower temperatures than the temperatures used in the experiments by Freeman (9) and by Bond (10), in the range of $330^{\circ}$ to $380^{\circ} \mathrm{C}$. The oxide, $\mathrm{Na}_{2} \mathrm{O}$, and the nitrate, $\mathrm{NaNO}_{3}$, products of the reactions, coated the nitrite and slowed down, or halted, the decomposition of the sodium nitrite. They may have had impurities in their test mixtures, which acted as catalysts, and contributed to decomposition at a lower temperature. When other compounds are present in the melt, additional reactions take place, as well. It is important to point out that the nitrates and nitrites can evolve oxidizing gases, including oxygen, nitric oxide and nitrogen dioxide inside the melt, and that reactions between such gases and other compounds, especially organic materials, can take place in the melt, or in the gas-melt interface, in addition to reactions between these materials and the melt itself. It is as important to know that sodium oxide is insoluble in sodium nitrite and can coat the nitrite and nitrate and slow down reactions.

Nitrate melts and mixed nitrate melts have also been studied extensively because of their use as heat transfer media and their potential use as reaction media, and solvents. They are excellent solvents for various ionic salts, gases and metals. They have low vapor pressure and low viscosity, as well as good electrical conductivity and high thermal stability, the latter characteristic being very important for such uses. The nitrate salts are used for digestion and analysis of organic samples (12), and at times these reactions can be highly exothermic and even violent.

Sodium Oxalate and Oxalate Mixtures

Sodium oxalate, when heated in air or in nitrogen to $550^{\circ} \mathrm{C}$ in the DSC, did not undergo any visible changes such as melting or decomposition. A thermogram shown in figure 10, which was obtained in an atmosphere of nitrogen at a heating rate of $10^{\circ} \mathrm{C} / \mathrm{min}$, does not display any endotherms or exotherms. A similar thermogram, without any endotherms or exotherms was found in air. Salts of carboxylic acids are crystalline non-volatile solids, and the strong electrostatic forces holding the ions in the crystal lattice 
can be overcome only by heating to a high temperature or by a very polar solvent (13). Sodium oxalate is the sait of a dicarboxylic acid, and in general, dicarboxylic acids show the same behavior as the monocarboxylic acids. The thermal decomposition of sodium oxalate at higher temperatures was evaluated by Patnaik and Maharana (14). They used $100 \mathrm{mg}$ samples in their tests, and noted initiation of decomposition at about $500^{\circ} \mathrm{C}$.

The mixtures of sodium oxalate with sodium nitrate, tested in the OSC in the same temperature range, do contain in their thermograms, in addition to the endotherms due to the two phase changes of sodium nitrate, a sharp exothermic phase change. Figure 11 contains a thermogram for sample $13 \mathrm{~A}(1: 1)$, heated in air, at $10^{\circ} \mathrm{C} / \mathrm{min}$, while figure 12 shows an optimized and scaled version of the exotherm in figure 11. The calculations for the exotherm, including peak temperature and the enthalpy of the exotherm, $\Delta H$, are shown in the figures. The thermogram in figure 13 is for sample 13A, heated in nitrogen, at $10^{\circ} \mathrm{C} / \mathrm{min}$. Whereas in figure 12 , following the melting of sodium nitrate, the thermogran inclines downward, in figure 13 the slope points upward. This same behavior was seen at times for other mixtures; it depends, to an extent, on the differing heat capacities of the flowing gases and the continuousiychanging thermal properties of the samples. Figures 14 to 16 present thermograms for samples 13B (1:3), 13C (1:3; with diluent), and $130(1: 10)$, respectively. The exotherms in figures 14 and 15 are sharp, and very similar to the exotherm in figure 11. However, the exotherm in figure 16 is proportionally smaller, and not as sharp, due to the small amount of sodium oxalate in the mixture. Sample 13C contained the diluent, sodium aluminate, which was also used as a diluent in all the other test mixtures. Sodium aluminate itself was tested in the DSC, and its resultant thermograms contained various shallow endotherms and/or exotherms (it was difficult to differentiate them). In each mixture from the complete DSC test matrix that contained the diluent, some of the same endotherms were seen in its thermograms. They are visible in figure 15 , at about $80^{\circ} \mathrm{C}$, and specifically at $200^{\circ} \mathrm{C}$. Finaliy, the residues from the $13 \mathrm{~A}$ mixtures were grey while those from the other mixtures, 138 to 130, with higher amounts of nitrate, were white. The grey color was due to the presence of char in the residue, from the decomposition of the oxalate. The onset temperatures of the exotherms for representative samples of the mixtures of sodium oxalate with sodium nitrate were determined by the method described in ASTM E 537-86 ("Standard Test Method for Assessing the Thermal Stability of Chemicals by Methods of Differential Thermal Analysis", ASTM vol. 14.02, Pp. 399-402). Thus an onset temperature is found by extrapolating the baseline (prior to the peak), and the leading side of the peak to their intersection. Due to the shape of some of the exotherms obtained for the test samples with oxalate, whereby the onset of the peak is quite sharp, these onset temperatures are acceptable. When the exotherms are not sharp, and exothermic behavior commences somewhat more slowly, or in a jagged and unsmooth manner, as in figure 16, the onset of exothermic behavior is the temperature where deviation from the baseline is first noted. Both sets of onset temperatures are shown in table 10 . In general, for these oxalate-nitrate mixtures, the onset temperatures for exothermic behavior decreased with increasing sodium nitrate content, as seen in table 10. The presence of the diluent, on the other hand, delayed the reaction either by absorbing the initial heat released by the reaction, and/or by decreasing the concentration of both reactants in the mixture, thereby 
increasing the onset temperature. These onset temperatures range from $390^{\circ}$ to $420^{\circ} \mathrm{C}$, for the samples without diluent. For the sample with the diluent, onset temperature was $439^{\circ} \mathrm{C}$.

Table 10. - OSC thermal analysis results for the oxalate-nitrate mixtures

\begin{tabular}{|c|c|c|c|c|c|c|}
\hline Sample & $\begin{array}{c}\text { Mixture } \\
\text { ratio }\end{array}$ & $\begin{array}{l}\text { Heating } \\
\text { rate, } \\
{ }^{\circ} \mathrm{C} / \mathrm{min} \\
\end{array}$ & $\begin{array}{c}\text { Atmosphere, } \\
\text { dynamic }\end{array}$ & $\begin{array}{c}\text { Extrapolated } \\
\text { onset } \\
\text { temperature, } \\
\text { C }\end{array}$ & $\begin{array}{c}\text { Onset } \\
\text { temperature, }{ }^{\prime} \\
{ }^{C} \mathrm{C}\end{array}$ & $\begin{array}{c}\text { Exothermic } \\
\text { peak } \\
\text { temperature, } \\
\text { - } \mathrm{C}\end{array}$ \\
\hline \multirow[t]{2}{*}{$13 A$} & \multirow[t]{2}{*}{$1: 1$} & 10 & atr & 422 & 413 & 437 \\
\hline & & 10 & $N_{2}$ & 422 & 420 & 435 \\
\hline \multirow[t]{4}{*}{$13 B$} & \multirow[t]{4}{*}{$1: 3$} & 10 & air & 410 & 406 & 429 \\
\hline & & 5 & $"$ & 404 & 395 & 416 \\
\hline & & 2 & $n$ & 401 & 388 & 403 \\
\hline & & 10 & $N_{2}$ & 419 & 410 & 430 \\
\hline $13 C$ & $\begin{array}{l}1: 3 \\
(d i 1)\end{array}$ & 10 & air & 445 & 439 & 455 \\
\hline 130 & $1: 10$ & 10 & $"$ & 405 & 398 & 412 \\
\hline
\end{tabular}

'Based on initial deviation of the decomposition step from baseline.

The results of the tests in the OSC for the mixtures of sodium oxalate with the sodium nitrate-sodium nitrite combination were various. Figure 17 shows the resultant thermogram for a test in flowing air, at $10^{\circ} \mathrm{C} / \mathrm{min}$, while figure 18 is for a test in static air, at the same heating rate, both for samples of mixture $14 A(1: 1)$. Both thermograms have the same features; the four endothermic peaks, below $300^{\circ} \mathrm{C}$ indicate that the sodium nitrate and sodium nitrite did not melt smoothly together, as a eutectic, and the reason for that is not known. Incomplete mixing, and a nonrepresentative sample can be one cause. It could also be that the presence of the oxalate interferes with the formation of the eutectic. In the 14A mixture, oxalate constitutes 78 pct by weight of the mixture. Following these endotherms, another, wide endotherm is observed, and it is overtaken by the exotherm. It is difficult to discern where the endotherm ends and the exotherm begins, and therefore, it is just as questionable how to measure the enthalpy. As both oxidants change solid phases and then melt, the heat capacity of the mixture changes. As a result the baseline of the thermogram changes. The same happens due to the exothermic reaction and formation of final products. This variable baseline hinders the measurement of the enthalpy, as well. [The sharp endothermic peaks at about $450^{\circ}$ and $500^{\circ} \mathrm{C}$ in figure 18 are due to an accidental manipulation of the valve for the airflow, and not due to reactions in the 
sample]. In some other tests with samples from the same mixture (14A), the resultant thermograms were altogether different in their exothermic shape, as for example in figure 19. The four endotherms below $300^{\circ} \mathrm{C}$ are again present, and they indicate continuous melting of portions of the nitrate and nitrite, and the exotherm is quite shallow and indicative of a slow reaction.

Thermograms for the $148(1: 3)$ mixture are similar to those for the oxalatenitrate mixtures. Figure 20 contains only two endotherms, one for a solid phase transition of the nitrite, and the other for the combined melting of the nitrate and nitrite. A well define exotherm is also present, with a peak at $400^{\circ} \mathrm{C}$. In this mixture, the oxalate concentration is smaller than it is in $14 \mathrm{~A}$, and the nitrate-nitrite combination is $46 \mathrm{pct}$ by weight; formation of the eutectic is thus easier. The changes in the slope of the baseline are due to the different, and varying, heat capacities and thermal conductivities of the three starting ingredients and of the additional reaction products toward the latter portion of the thermogram. A thermogram for the mixture with diluent, 14C (1:3; diluent), shows clearly, in figure 21 , a scaled version of the many endotherms due to the presence of sodium aluminate, mentioned earlier. A complete thermogram, including the exotherm is seen in figure 21A. Finally, three thermograms for the mixture with the least amount of fuel, $140(1: 10)$, two obtained in flowing air, and one in a flow of nitrogen, are shown in figures 22 to 24, respectively. These three tests were conducted at a heating rate of $10^{\circ} \mathrm{C} / \mathrm{min}$. Figures 22 and 23 are presented in order to show the degree of reproducibility of the results, for different size samples. The exotherms in these latter three thermograms are smaller, as is expected for the mixtures with the least amount of fuel. All three figures show evidence of gaseous evolution, and/or agitation in the reaction mixture, starting at about $300^{\circ} \mathrm{C}$. The same behavior was noted in figure 16 , starting at about $350^{\circ} \mathrm{C}$. A similar trend is noted for the oxalate-nitrate-nitrite mixtures as was found for the oxalate-nitrate mixtures, whereby the lowest onset temperatures are in general seen for the mixtures with highest oxidant content, as presented in table 11. Again, the highest onset temperatures are noted for the mixtures with diluent. These onset temperatures range from $355^{\circ}$ to $385^{\circ} \mathrm{C}$, for the mixtures without diluent. The onset temperature is somewhat higher for the mixtures with diluent. These temperatures are lower by about $40^{\circ} \mathrm{C}$ than the onset temperatures obtained for the oxalate-nitrate mixtures. The melting point of the eutectic nitrate-nitrite pair is at about $228^{\circ}$ to $230^{\circ} \mathrm{C}$. This melting point is lower than the melting point of either the nitrate $\left(306.8^{\circ} \mathrm{C}\right)$ or the nitrite $\left(271^{\circ} \mathrm{C}\right)$. Thus, more time is allowed for the oxalate to disperse in the melt and come in better contact with it, before reacting. It may also be that this combination is more reactive than the sodium nitrate is by itself, or perhaps the nitrite is more reactive. The role of the nitrite vs. the nitrate in inducing the exothermic reaction at a lower temperature is not known. 
Table 11. - DSC thermal analysis results for the oxalate-nitrate-nitrite mixtures

\begin{tabular}{|c|c|c|c|c|c|c|}
\hline Sample & $\begin{array}{c}\text { Mixture } \\
\text { ratio } \\
\end{array}$ & $\begin{array}{l}\text { Heating } \\
\text { rate, } \\
-\quad C / m i n \\
\end{array}$ & $\begin{array}{c}\text { Atmosphare, } \\
\text { dynamic }\end{array}$ & $\begin{array}{c}\text { Extrapolated } \\
\text { onset } \\
\text { temperature, } \\
{ }^{C} \mathrm{C} \\
\end{array}$ & $\begin{array}{c}\text { Onset } \\
\text { temperature, } \\
{ }^{\circ} \mathrm{C} \\
\end{array}$ & $\begin{array}{c}\text { Exothermic } \\
\text { peak } \\
\text { temperature, } \\
{ }^{C} \mathrm{C} \\
\end{array}$ \\
\hline \multirow[t]{3}{*}{$14 A$} & \multirow[t]{3}{*}{$1: 1$} & 10 & air & 369 & 370 & 408 \\
\hline & & 5 & $"$ & 385 & 385 & 408 \\
\hline & & 10 & Static air & 388 & 377 & 420 \\
\hline \multirow[t]{2}{*}{$14 B$} & \multirow[t]{2}{*}{$1: 3$} & 10 & air & 368 & 359 & 404 \\
\hline & & 10 & Static air & 374 & 356 & 403 \\
\hline \multirow[t]{2}{*}{$14 C$} & \multirow{2}{*}{$\begin{array}{l}1: 3 \\
(d i 1)\end{array}$} & 10 & air & 411 & 406 & 425 \\
\hline & & 5 & $"$ & 401 & 400 & 413 \\
\hline \multirow[t]{2}{*}{140} & \multirow[t]{2}{*}{$1: 10$} & 10 & $n$ & 362 & 360 & 384 \\
\hline & & 10 & $N_{2}$ & 366 & 355 & 375 \\
\hline
\end{tabular}

'Based on initial deviation of the decomposition step from baseline.

A mixture of sodium oxalate and sodium nitrite, prepared with ingredients which were not weighed, but were of about equal volumes, was lightly ground and a sample was heated in the DSC at $10^{\circ} \mathrm{C} / \mathrm{min}$. The onset temperature of the exotherm was at about $350^{\circ} \mathrm{C}$, as seen in figure 25 , suggesting that the lower onset temperatures in the mixtures with the nitrate-nitrite combination are promoted by the presence of the sodium nitrite in the melt. This thermogram also indicates that the oxalate reacts with the nitrite as it does with the nitrate. The small endothermic peaks, preceding the exotherm and seen also in previous figures for the oxalate-nitrate-nitrite combination, may be due to mixing of the two salts or due to partial melting.

Representative experimental results for the tests in the TGA with the sodium oxalate and with mixtures of the sodium oxalate with the sodium nitrate are shown in figure 26 for the pure oxalate salt and in figures 27 to 29 for mixtures $13 A(1: 1), 13 C(1: 3$; diluent $)$, and $130(1: 10)$. In addition to the main weight loss curves, derivative curves (DTGA) are also depicted. In figure 27 , no evidence of any reactivity associated with a weight loss is noted until the single-step weight loss which starts at $420^{\circ} \mathrm{C}$. In figure 28 , for the mixture with diluent, 13C, a weight loss of about 1 pct of the total weight occurs at the start of the run, and it is followed by a small weight loss at $-198^{\circ} \mathrm{C}$. These losses are due to the effects of the diluent, and the presence of moisture. A small, and continuous sloping of the thermogram is present until the beginning of the main weight loss step. This is probably also due to changes in the aluminate, and its reactivity with the nitrate 
and/or the oxalate, via acid/base reactions. The peak temperatures for these derivative curves usually represent the temperatures at which reaction rate is at a maximum. Extrapolated onset temperatures were found by the same method used for obtaining the respective temperatures in the DSC thermograms, and are shown in table 12. However, it is usually accepted that the temperature at which deviation from the baseline is first noted is a more realistic onset temperature. This latter temperature is usually lower than the extrapolated onset temperature, and therefore gives an additional degree of safety when assessing thermal stabilities of materials. Thus, because of the shapes of the curves, and the slow and continuous rates of weight losses, onset temperatures were also determined from the initial deviation from the baseline. These values, which are substantially lower than the extrapolated values, as well as being quite lower in some cases than the respective DSC values, are believed to be the more meaningful values. They are also shown in table 12. The oven and the sample pan in the TGA are both open to the atmosphere of the flowing air. Evolution of possible decomposition gases ( such as $\mathrm{CO}, \mathrm{CO}_{2}, \mathrm{O}_{2}$, and/or $\mathrm{NO}_{2}$ ) is facilitated by this geometry. The samples in the DSC pans are covered by loose $1 \mathrm{ids}$, and were contained inside sample holders which are also covered with lids. Such geometry hinders gas evolution somewhat, and slows the reaction. Weight losses, determined in the TGA tests, are also reported in the table.

Table 12. - TGA thermal analysis results for the oxalate-nitrate mixtures

\begin{tabular}{|c|c|c|c|c|c|}
\hline Sample & $\begin{array}{c}\text { Mixture } \\
\text { ratio }\end{array}$ & $\begin{array}{l}\text { Heating } \\
\text { rate, } \\
\text { C/ min }\end{array}$ & $\begin{array}{c}\text { Extrapolated } \\
\text { onset } \\
\text { temperature, } \\
C\end{array}$ & $\begin{array}{c}\text { Onset } \\
\text { temperature, } \\
\cdot \mathrm{C} \\
\end{array}$ & $\begin{array}{l}\text { Weight } \\
\text { loss, } \\
\text { pct }\end{array}$ \\
\hline $13 A$ & $1: 1$ & 10 & 440 & 420 & 19.5 \\
\hline \multirow[t]{2}{*}{$13 B$} & \multirow[t]{2}{*}{$1: 3$} & 10 & 425 & 390 & 19.8 \\
\hline & & 5 & 412 & 385 & 19.6 \\
\hline \multirow[t]{2}{*}{$13 C$} & \multirow[t]{2}{*}{$1: 3(d i l)$} & 10 & 467 & 370 & 12.0 \\
\hline & & 5 & 460 & 382 & 11.8 \\
\hline \multirow[t]{2}{*}{130} & \multirow[t]{2}{*}{$1: 10$} & 10 & 404 & 315 & 9.8 \\
\hline & & 5 & 398 & 310 & 9.8 \\
\hline
\end{tabular}

'Based on initial deviation of the decomposition step from baseline.

Similar results were found for the oxalate-nitrate-nitrite mixtures, and they are all presented in table 13. They include both the extrapolated onset temperatures, and onset temperatures based on deviation from base line. 
Table 13. - TGA thermal analysis results for the oxalate-nitrate-nitrite mixtures

\begin{tabular}{|c|c|c|c|c|c|}
\hline Sample & $\begin{array}{c}\text { Mixture } \\
\text { ratio }\end{array}$ & $\begin{array}{l}\text { Heating } \\
\text { rate, } \\
\text { C/ min } \\
\end{array}$ & $\begin{array}{c}\text { Extrapolated } \\
\text { onset } \\
\text { temperature, } \\
C\end{array}$ & $\begin{array}{c}\text { Onset } \\
\text { temperature, } \\
\cdot \mathrm{C} \\
\end{array}$ & $\begin{array}{c}\text { Weight } \\
\text { loss, } \\
\text { pct }\end{array}$ \\
\hline \multirow[t]{2}{*}{$14 \mathrm{~A}$} & \multirow[t]{2}{*}{$1: 1$} & 10 & 411 & 314 & 17.8 \\
\hline & & 5 & 401 & 314 & 18.8 \\
\hline \multirow[t]{2}{*}{$14 B$} & \multirow[t]{2}{*}{$1: 3$} & 10 & 386 & 300 & 19.2 \\
\hline & & 5 & 382 & 345 & 19.0 \\
\hline \multirow[t]{2}{*}{$14 C$} & \multirow[t]{2}{*}{$1: 3(d i l)$} & 10 & 454 & 400 & 11.8 \\
\hline & & 5 & 427 & 386 & 12.4 \\
\hline 140 & $1: 10$ & 10 & 364 & 276 & 10.0 \\
\hline
\end{tabular}

'Based on initial deviation of the decomposition step from baseline.

of all the fuel-oxidant mixtures tested, the oxalate-containing mixtures were the simplest and easiest for the calculations of enthalpy changes. The sodium oxalate did not decompose by itself, whereas, the various mixtures did undergo one distinct exothermic reaction. The other fuels underwent decomposition by themselves as well as in the presence of the oxidant(s), and a variety of exotherms was registered. For these latter fuel combinations, calculation of the total enthalpy exchanged was not as simple. In addition to the exotherms, all the thermograms for the oxalate mixtures contained endotherms resulting from the melting of nitrate or nitrate-nitrite. The areas under all these peaks were measured, and the energies were calculated. The results for some of the oxalate-nitrate mixtures were as follows: 


\begin{tabular}{|c|c|c|c|c|}
\hline Sample & $\begin{array}{c}\text { Sample } \\
\text { weight, } \\
\text { mg }\end{array}$ & $\begin{array}{l}\text { Heating } \\
\text { rate, } \\
{ }^{\circ} \mathrm{C} / \min \end{array}$ & $\begin{array}{c}\text { Nitrate } \\
\text { melting peak, } \\
\mathrm{J} / \mathrm{g} \text { of } \mathrm{Na} \text { Nitrate } \\
\end{array}$ & $\begin{array}{l}\text { Exothermic peak } \\
\mathrm{J} / \mathrm{q} \text { of } \mathrm{Na} \text { Oxalate }\end{array}$ \\
\hline $13 A-2$ & 4.0 & 10 & 220 & Not Measured \\
\hline $13 A-3$ & 8.0 & 10 & 221 & Not Measured \\
\hline $13 A-4$ & 5.97 & 10 & 183 & 460 \\
\hline $13 A-5$ & 5.74 & 10 & 183 & 283 (nitrogen) \\
\hline $13 B-1$ & 5.5 & 10 & 178 & 629 \\
\hline $13 B-2$ & 4.0 & 10 & 160 & 429 \\
\hline $13 B-3$ & 8.5 & 5 & 178 & 816 \\
\hline $13 B-4$ & 4.0 & 10 & 191 & 358 (nitrogen) \\
\hline $13 C-1$ & 4.0 & 10 & 186 & 567 \\
\hline $13 C-2$ & 7.5 & 10 & 175 & 586 \\
\hline $130-1$ & 4.0 & 10 & 198 & 479 \\
\hline $130-2$ & 8.0 & 10 & $\underline{199}$ & $\underline{637}$ \\
\hline & & \multicolumn{2}{|c|}{ Average $=189$} & $\begin{array}{l}563 \text { (for the } 13 B \text {, } \\
130 \text { samples) }\end{array}$ \\
\hline
\end{tabular}

The melting of sodium nitrate can serve as an internal standard. Literature value for the heat of melting of sodium nitrate is $189.58 \mathrm{~J} / \mathrm{g}$. Thus, DSC results for the sodium nitrate are quite good. The energy release values for the reaction are more or less reproducible for the 13B, 13C and 13D mixtures. The average value for all the $13 B$ to 130 samples tested in air is $575 \mathrm{~J} / \mathrm{g}$ of oxalate.

For the theoretical reaction:

$\mathrm{Na}_{2} \mathrm{C}_{2} \mathrm{O}_{2}(\mathrm{~s})+0.4 \mathrm{NaNO}_{3}(\mathrm{~s}) \rightarrow 1.2 \mathrm{Na}_{2} \mathrm{CO}_{3}(\mathrm{~s})+0.8 \mathrm{CO}_{2}(\mathrm{~g})+0.2 \mathrm{~N}_{2}(\mathrm{~g})$,

and with the following values for heats of formation used in the calculation,

$$
\begin{aligned}
& \Delta \mathrm{H}_{12} \mathrm{Kcal} / \mathrm{mole} \quad \Delta \mathrm{H}_{12} \mathrm{Kcal} / \mathrm{mole} \\
& \mathrm{Na}_{2} \mathrm{C}_{2} \mathrm{O}_{4}(\mathrm{~s}) \quad-315.0 \quad \mathrm{Na}_{2} \mathrm{CO}_{3}(\mathrm{~s}) \quad-270.26 \\
& \mathrm{NaNO}_{3}(\mathrm{~s}) \quad-111.82 \quad \mathrm{CO}_{2}(\mathrm{~g}) \quad-94.05 \\
& \Delta H_{A}=-39.827 \mathrm{kcal} / \mathrm{mole} \text { of oxalate, } \\
& =-1,243.57 \mathrm{~J} / \mathrm{g} \text { of oxalate, } \\
& \text { and weight loss } \approx 24.3 \% \text {. }
\end{aligned}
$$


For the reaction:

$$
\begin{aligned}
\mathrm{Na}_{2} \mathrm{C}_{2} \mathrm{O}_{4}(\mathrm{~s}) & \rightarrow \mathrm{Na}_{2} \mathrm{CO}_{3}(\mathrm{~s})+\mathrm{CO}(\mathrm{g}), \\
\Delta \mathrm{H}_{\mathrm{R}}= & -577 \mathrm{~J} / \mathrm{g} \text { of oxalate, } \\
& \text { and weight loss } \approx 21.4 \% .
\end{aligned}
$$

Both the heat of reaction and weight loss for the second reaction agree with the experimental results, but the agreement in these energy values is believed to be coincidental. Rather, a reaction did take place between the oxalate and the nitrate, but the proportions were different than the ones depicted in Equation 4.

The reaction of oxalate in nitrate melts was evaluated by varic - researchers who used electrochemical instrumentation in their studies. Mccormick and Swofford (15) used a melt of potassium nitrate-sodium nitrate eutectic and potassium oxalate, and reported that at $250^{\circ} \mathrm{C}$ the oxalate did not decompose, but that it did decompose when the temperature was raised to near $300^{\circ} \mathrm{C}$. They reported the following reaction:

$$
\mathrm{C}_{2} \mathrm{O}_{4}{ }^{2 \cdot}=\mathrm{CO}_{2}+\mathrm{CO}+\mathrm{O}^{2 \cdot} \text {. }
$$

They did not suggest a reaction between the oxalate and the nitrate. ET Hosary and Shams El Din (16), who used the same eutectic melt, and potassium oxalate, reported a reaction between the oxalate and the nitrate melt, as follows:

$$
(\mathrm{COO})_{2}^{2 \cdot}+\mathrm{NO}_{3}^{-}=\mathrm{CO}_{3}{ }^{2-}+\mathrm{NO}_{2}^{-}+\mathrm{CO}_{2} \text {. }
$$

Their reaction shows formation of nitrite, carbonate, and the evolution of carbon dioxide. Although the reaction is not strictly balanced with respect to oxygen, the heat of this reaction is equal to $-724.7 \mathrm{~J} / \mathrm{g}$ of sodium oxalate. These proportions of oxalate to nitrate, rather than the ones in equation 4, give energy release values which are closer to the experimental results than values calculated for equation 4. They are probably more realistic. The same reaction was proposed by Keenan and Fernandez [17] for the reaction of potassium oxalate in a potassium nitrate melt, with the condensed products being the carbonate and the nitrite.

In order to understand the experimental results more accurately, a few of the residues from the tests in the DSC of the mixtures of the oxalate with the nitrate, (13A), were tested in the DSC a second time, in the same sample pans. The resultant thermograms, presented in figures 30 and 31 , do not show any thermal activity such as endothermic peaks for the melting of unreacted sodium nitrate or of its decomposition product sodium nitrite nor exothermic peaks. The melting temperature of sodium carbonate is much higher than the temperature range used in the DSC, and its presence would not be detected by these means. If unreacted sodium oxalate is present in the residue, its presence would also not be observed in the thermogram. These results indicate that all the nitrate was used up, as was its decomposition product sodium nitrite. Keenan and Fernandez [17] found the same stoichiometry in the melt (as given in equation 7) when the melt was held at $350^{\circ} \mathrm{C}$ for a period of up 


\section{WHC-MR-0455}

to 12 hours. If this is the case, then the reaction in their test was very slow. And since sodium nitrite reacts with the oxalate in the same manner that sodium nitrate does, then the final reaction product should be the sodium oxide, $\mathrm{Na}_{2} \mathrm{O}$, rather than the nitrite. Sodium nitrite might also react with the released $\mathrm{CO}_{2}$ (from either proposed reaction) to form sodium carbonate, instead of decomposing to sodium oxide, as follows:

$$
2 \mathrm{NaNO}_{2}+\mathrm{CO}_{2} \rightarrow \mathrm{Na}_{2} \mathrm{CO}_{3}+\mathrm{N}_{2} \mathrm{O}_{3} \text {. }
$$

Such a reaction will depend on the solubility of $\mathrm{CO}_{2}$ in the melt. Thus, continuous analysis of gas evolution, in addition to residue analys is at intermediate steps, is required for a complete understanding of the actual reaction, which might be a combination of the various proposed reactions. Schlegel and Pitak (18) studied the reaction of sodium oxalate in a eutectic melt of sodium and potassium nitrates, by measuring the pressure of evolved $\mathrm{CO}_{2}$, as a function of time. They reported the same reaction scheme as given in equation 7 . They detected carbonate in the products only if the temperature of the reaction mixture was equal to or higher than approximately $350^{\circ} \mathrm{C}$. These results, and the results of Keenan and Fernazdez (17) explain partly the results of McCormick and Swofford (15) who did not detect a reaction in their tests; the temperatures used by McCormick and Swofford, $250^{\circ}$ and $300^{\circ} \mathrm{C}$, were not sufficiently high for an extensive, measurable reaction to occur.

In summary, there is evidence for an exothermic reaction between the sodium oxalate and the sodium nitrate, and between the oxalate and the mixture of the two oxidants. For the mixtures without diluent, onset temperatures for exothermic behavior, determined in the DSC tests, varied from about $395^{\circ}$ to $420^{\circ} \mathrm{C}$, and from $355^{\circ}$ to $385^{\circ} \mathrm{C}$ for the single oxidant and double oxidant mixtures, respectively. These results indicate that the double oxidant mixture is more reactive toward the oxalate. Also, for these fuel mixtures onset temperatures in general decreased with increasing amounts of oxidant(s). Similar trends were also found in the TGA tests, whereby onset temperatures for exothermic behavior decreased with increasing oxidant(s) concentration. Likewise, lower onset temperatures were observed for the mixtures with the two oxidants. These onset temperatures for the mixtures with sodium nitrate were between $310^{\circ}$ and $420^{\circ} \mathrm{C}$, and for the mixtures with the nitrate-nitrite combination they were between $275^{\circ}$ and $345^{\circ} \mathrm{C}$. The reason for this large range in temperatures in the TGA tests is unknown. Some of the reasons for the lower onset temperatures in the TGA tests were given earlier in the report. One other reason can be that sweeping out the gaseous decomposition products influences the reaction process. The carbon dioxide may be required for the formation of the carbonate. Finally, for the mixtures with diluent, onset temperatures for exothermic behavior were higher in almost all the cases.

EDTA and EDTA Mixtures

The pure EDTA and all the mixtures with nitrate and with the nitrate-nitrite combination they were tested in the DSC, at a heating rate of $10^{\circ} \mathrm{C} / \mathrm{min}$ in flowing air. Some tests were also conducted at a heating rate of $5^{\circ} \mathrm{C} / \mathrm{min}$, in 
air, while a few of the samples were heated in nitrogen. Calibrations with indium and zinc were done prior to the tests with the mixtures.

The OSC thermograms obtained for EDTA [ethylenediamine tetraacetic acid, tetrasodium dihydrate, $\left.\left(\mathrm{NaO}_{2} \mathrm{CCH}_{2}\right)_{2} \mathrm{NCH}_{2} \mathrm{CH}_{2} \mathrm{~N}\left(\mathrm{CH}_{2} \mathrm{CO}_{2} \mathrm{Na}\right)_{2} \cdot 2 \mathrm{H}_{2} \mathrm{O}\right]$, in air, show a variety of endotherms and one main exotherm, as shown in figure 32 . The loss of water of hydration is responsible for at least two of these endotherms. During dehydration, the amount of water split off in each step varies. Escrivá, Fuertes et al, (19) describe the existence of structurally distinct water molecules in EDTA complexes, depending on their bonding in the molecule. Coordination water molecules are bonded to the inorganic ions as well as to the carboxylate oxygens. Lattice water is bonded to an oxygen from a carboxylate unit and also to one of the coordination water molecules. The presence of the differing bonds explains the loss of the water molecules at different temperatures. Water combined with the organic portion is released at lower temperatures than water connected to the inorganic elements (20). Loss of adsorbed gases can also appear as an endotherm. EDTA decomposes and releases $\mathrm{CO}_{2}$ and/or $\mathrm{CO}$ from the four acetic acid groups. The ethylenediamine portion $\left(-\mathrm{NCH}_{2} \mathrm{CH}_{2} \mathrm{~N}-\right)$ is more stable, but if heated further, EDTA decomposes and forms a carbonate. Conversion to carbonate is complete at about $750^{\circ} \mathrm{C}$. The released $\mathrm{CO}$ and the decomposition product oxidize in the flowing air and give rise to the large exotherm. The total amount of energy released during the exothermic process in three separate tests, all at a heating rate of $10^{\circ} \mathrm{C} / \mathrm{min}$, was approximately $7,700,8,000$ and $7,900 \mathrm{~J} / \mathrm{g}$ of EDTA. Tests in a nitrogen flow resulted in thermograms with the same endotherms at the lower temperature range of about $70^{\circ}$ to $170^{\circ} \mathrm{C}$. These were followed by a broad exotherm which extends from roughly $185^{\circ}$ to $405^{\circ} \mathrm{C}$, as seen in figure 33 . It should be noted that the heat flow and temperature scales in the figures vary from figure to figure, as a result of "optimization" of the curves for ease of calculation of various values of interest. The energy release for the main exotherm, found in two tests in nitrogen, was 490 and $600 \mathrm{~J} / \mathrm{g}$, respectively. The residues from the tests in nitrogen were black, due to pyrolys is without oxidation, whereas the residues from the tests in air varied in color.

The EDTA-nitrate mixtures were tested in a similar manner, with most tests done at $10^{\circ} \mathrm{C} / \mathrm{min}$, in flowing air. Preliminary tests indicated that the mixtures leaked out of the sample pans if samples were larger than $-4 \mathrm{mg}$. Samples of the order of 2 to $3 \mathrm{mg}$ were then used in the tests, while somewhat larger samples were utilized with mixtures $9 C$ and 90 which contained much less EDTA. Thermograms obtained in tests with these mixtures show similar features, as seen in figures 34 and 35 , for samples from the $9 A(1: 1)$ and $98(1: 3)$ mixtures. The low temperature endotherms present in the pure EDTA thermograms are also found in the thermograms for the mixtures. They are followed by the endotherm due to the melting of sodium nitrate. Both the onset and peak temperatures for these melting endotherms of the sodium nitrate are lower than the same values for the pure sodium nitrate which are $306.5^{\circ}$ and $308^{\circ} \mathrm{C}$, respectively, (average value from three tests. The onset temperature of $306.5^{\circ} \mathrm{C}$ agrees quite well with the published value of $306.8^{\circ} \mathrm{C}$, for the melting temperature). These endotherms are followed immediately by exotherms. The exotherm in figure 34 extends from $300^{\circ}$ to $400^{\circ} \mathrm{C}$, while the exotherm in figure 35 is smaller in both size and 
temperature range $\left(300^{\circ}\right.$ to $\left.340^{\circ} \mathrm{C}\right)$. The size of the exotherm decreased with the decreasing amount of EDTA in the mixture, from 9A to 9D. This exotherm can be a result of (a) a reaction between the nitrate and EDTA;

(b) decomposition of the EDTA by itself; or (c) a combination of (a) and (b). The amount of energy released in three separate tests with $9 A$ samples was the following:

\begin{tabular}{|c|c|c|c|}
\hline Sample & $\begin{array}{l}\text { Heating rate, } \\
\cdot \mathrm{C} / \mathrm{min} \\
\end{array}$ & Atmosphere & $\begin{array}{c}\text { Energy released, } \\
\mathrm{J} / \mathrm{g} \text { EDTA }\end{array}$ \\
\hline $9 A-1$ & 10 & air & 5,200 \\
\hline $9 A-2$ & 10 & nitrogen & 1,500 \\
\hline $9 A-3$ & 5 & air & 3,650 \\
\hline
\end{tabular}

These values, and especially the values for the two tests in air, when compared with the average value found for the exothermic decomposition of EDTA by itself $(7,870 \mathrm{~J} / \mathrm{g})$, suggest, that even in the mixtures, EDTA decomposes by itself, and that the nitrate melt, rather than react with the EDTA, actually slows down the oxidation/decomposition reaction by blocking contact of EDTA with air. On the other hand, it could be that a partial reaction between these two compounds does take place, but that it is slowed down by intermediates of the reaction, and by the evolved gases.

Another feature of interest in figure 34 is the presence of many tooth-like small peaks, superimposed on the main exotherm. These are believed to be a result of the frothing behavior of EDTA, which caused the leakage mentioned above, when larger samples were used. The exotherm in the thermogram depicted in figure 35, for a $9 B(1: 3)$ sample, also shows evidence of some frothing, and/or evolution of gases through a viscous melt. Similar thermograms were obtained for samples from mixtures $9 C$ and $9 D$, but the exotherms were much smaller, or even nonexistent in a few of the thermograms.

The main interest in this test series is the determination of the onset temperatures for exothermic behavior by these mixtures. Onset temperatures for EDTA, and the EDTA-nitrate mixtures, determined by the first deviation of the exotherm from the baseline, are presented in table 14 . These onset temperatures are about $300^{\circ} \pm 10^{\circ} \mathrm{C}$ for all the mixtures and for EDTA. Extrapolated onset temperatures, determined by the method prescribed in ASTM E 537-86 were $30^{\circ}$ to $40^{\circ} \mathrm{C}$ higher.

Similar tests were conducted with the mixtures of EDTA with the sodium nitrate-sodium nitrite combination ( $10 A$ to 10D). Thermograms for two of the tests with samples from the 10A (1:1) mixture are shown in figures 36 and 37 . The test depicted in figure 36 was conducted in flowing air, while the test shown in figure 37 was done in flowing nitrogen. The sharp endotherm due to the melting of the eutectic mixture of sodium nitrate and sodium nitrite is clearly evident and onset and peak temperatures for this endotherm are at $226^{\circ}$ and $228^{\circ} \mathrm{C}$. As is common for eutectic mixtures, their melting temperatures are lower than the respective melting temperatures of the individual 
Table 14. - DSC thermal analysis results for the EDTA and EDTA-nitrate mixtures

\begin{tabular}{|c|c|c|c|c|c|}
\hline \multirow[b]{2}{*}{ Sample } & \multirow[b]{2}{*}{$\begin{array}{l}\text { Mixture } \\
\text { ratio }\end{array}$} & \multirow[b]{2}{*}{$\begin{array}{c}\text { Heating } \\
\text { rate, } \\
\text { - C/min } \\
\end{array}$} & \multirow[b]{2}{*}{$\begin{array}{c}\text { Atmosphere, } \\
\text { dynamic }\end{array}$} & \multicolumn{2}{|c|}{ First exotherm } \\
\hline & & & & $\begin{array}{c}\text { Onset } \\
\text { temperature' } \\
{ }^{\circ} \mathrm{C}\end{array}$ & $\begin{array}{c}\text { Peak } \\
\text { temperature, } \\
{ }^{C} \mathrm{C}\end{array}$ \\
\hline \multirow[t]{2}{*}{$2 A$} & & 10 & air & $290-300$ & $400-410$ \\
\hline & & 10 & $\mathrm{~N}_{2}$ & 2 & 370 \\
\hline \multirow[t]{3}{*}{$9 A$} & \multirow[t]{3}{*}{$1: 1$} & 10 & air & 299 & 351 \\
\hline & & 10 & $\mathrm{~N}_{2}$ & 310 & 319 \\
\hline & & 5 & air & 292 & 330 \\
\hline \multirow[t]{2}{*}{$9 B$} & \multirow[t]{2}{*}{$1: 3$} & 10 & $"$ & 305 & 315 \\
\hline & & 5 & $"$ & 296 & 307 \\
\hline \multirow[t]{2}{*}{$9 C$} & \multirow{2}{*}{$\begin{array}{r}1: 3 \\
\text { (di1) } \\
\end{array}$} & 10 & $"$ & 306 & 315 \\
\hline & & 5 & $"$ & 306 & 309 \\
\hline \multirow[t]{3}{*}{90} & \multirow[t]{3}{*}{$1: 10$} & 10 & $"$ & 3 & $307-319$ \\
\hline & & 10 & $\mathrm{~N}_{2}$ & 3 & 3 \\
\hline & & 5 & air & 3 & 3 \\
\hline
\end{tabular}

'Based on initial deviation of the decomposition step from baseline. ${ }^{2}$ Difficult to determine.

${ }^{3}$ Difficult to determine, or exotherm nonexistent. 


\section{WHC-MR-0455}

compounds. However, it is reported in the literature that the decomposition temperatures of the nitrate and nitrite do not change, even in the presence of a eutectic melt. Thus, exothermic behavior for the EDTA-nitrate-nitrite mixtures was not initiated immediately after the melting of the nitratenitrite combination. Instead, onset temperatures of exothermic behavior are only about $10^{\circ} \mathrm{C}$ lower than the respective temperatures for the nitrate mixtures. These onset temperatures and onset temperatures for all the $10 \mathrm{~A}$ to 100 mixtures are shown in table 15. Exothermic energy release values for the samples in figures 36 and 37 are 4,430 and $1,860 \mathrm{~J} / \mathrm{g}$ of EDTA for the air and nitrogen atmospheres. These results are of the same order of magnitude as the results found for the EDTA-nitrate mixtures. These results lead to the same question asked before, namely, is this energy due to decomposition of the EDTA by itself, due to a reaction between EDTA and the nitrate-nitrite mixture or due to a combination of both. It is difficult to say, but it is probable that some reaction does take place between the fuel and oxidants. However, this reaction is slow, and may be impeded by the melt, and by the intermediate products of reaction, both fluid and gaseous, as suggested for the EDTAnitrate mixtures. In the EDTA mixtures, the proportion of the fuel by weight is smaller than it is for the oxalate and citrate mixtures. Thus, the viscosity of the melt may be higher. In the tests with samples $10 \mathrm{C}$ and 100 , as was the case in tests with samples $9 C$ and 9D, the exotherms were quite small, and at times essentially nonexistent.

The pure EDTA and its mixtures with nitrate and with the nitrate-nitrite combination were tested in the TGA, at heating rates of $10^{\circ}$ and $5^{\circ} \mathrm{C} / \mathrm{min}$, in flowing air. Calibration of the instrument was conducted with a $100 \mathrm{mg}$ weight and with a nickel curie point prior to the tests.

The TGA thermogram for EDTA, presented in figure 38 , for a test at $10^{\circ} \mathrm{C} / \mathrm{min}$, shows five small steps of weight loss, all at temperatures lower than $180^{\circ} \mathrm{C}$. These steps are more easily discerned in the derivative curve as peaks, with the peak temperatures indicative of the temperatures at which weight loss rates are at a maximum. Total weight loss in the five steps is about 12 pct, whereas, weight loss in the first three steps, which are completed at $120^{\circ} \mathrm{C}$, is 8.6 pct. The theoretical weight loss due to water of hydration is 8.65 pct. Thus, the first three steps account for loss of water of hydration, and the other two steps may be due to loss of additional water (such as adsorbed moisture), and perhaps of adsorbed gas. The main decomposition of EDTA, with the major amount of weight loss, occurs at higher temperatures. Onset temperature for this decomposition is at $322^{\circ} \mathrm{C}$, and the derivative peak temperatures is $390^{\circ} \mathrm{C}$. When total weight loss of the sample is $40 \mathrm{pct}$, and temperature is almost $400^{\circ} \mathrm{C}$, an abrupt change occurs; the rate of weight loss slows down significantly. Final weight loss, at $540^{\circ} \mathrm{C}$, is $50 \mathrm{pct}$. Conversion of the dihydrate sample of tetrasodium EDTA to sodium carbonate would result in a weight loss of 51 pct. The temperature at which conversion to carbonate is complete depends on the type and number of metal atoms combined with the EDTA. At even higher temperatures, the carbonate can decompose to the oxide and/or the metal. The final product of decomposition of an EDTA salt is a function of the type and number of metal atoms, the number of water of hydration molecules, and the atmosphere in which decomposition takes place. During the decarboxylation phase of decomposition 
Table 15. - OSC thermal analysis results for the EDTA-nitrate-nitrite mixtures

\begin{tabular}{|c|c|c|c|c|c|}
\hline \multirow[b]{2}{*}{ Sample } & \multirow[b]{2}{*}{$\begin{array}{c}\text { Mixture } \\
\text { ratio } \\
\end{array}$} & \multirow[b]{2}{*}{$\begin{array}{l}\text { Heating } \\
\text { rate } \\
\text { c C/min } \\
\end{array}$} & \multirow[b]{2}{*}{$\begin{array}{c}\text { Atmosphere, } \\
\text { dynamic }\end{array}$} & \multicolumn{2}{|c|}{ First exotherm } \\
\hline & & & & $\begin{array}{c}\text { Onset } \\
\text { temperature' } \\
{ }^{\circ} \mathrm{C}\end{array}$ & $\begin{array}{c}\text { Peak } \\
\text { temperature, } \\
{ }^{C} \mathrm{C}\end{array}$ \\
\hline \multirow[t]{4}{*}{$10 A$} & \multirow[t]{4}{*}{$1: 1$} & 10 & air & 291 & 335 \\
\hline & & 10 & $"$ & 291 & 327 \\
\hline & & 5 & $"$ & 278 & 325 \\
\hline & & 10 & $N_{2}$ & 293 & 333 \\
\hline \multirow[t]{3}{*}{$10 B$} & \multirow[t]{3}{*}{$1: 3$} & 10 & air & 312 & 320 \\
\hline & & 10 & $"$ & 269 & 302 \\
\hline & & 5 & $"$ & 295 & 297 \\
\hline \multirow[t]{3}{*}{$10 C$} & \multirow{3}{*}{$\begin{array}{c}1: 3 \\
(\mathrm{di} i)\end{array}$} & 10 & $"$ & 304 & 320 \\
\hline & & 10 & $"$ & 290 & 314 \\
\hline & & 5 & $"$ & 291 & 309 \\
\hline \multirow[t]{3}{*}{100} & \multirow[t]{3}{*}{$1: 10$} & 10 & $"$ & 2 & 2 \\
\hline & & 10 & $"$ & 2 & 2 \\
\hline & & 5 & $"$ & 2 & 2 \\
\hline
\end{tabular}

'Based on initial deviation of the decomposition step from baseline. ${ }^{2}$ Difficult to determine, or exotherm nonexistent.

(loss of $\mathrm{CO}_{2}$ and/or $\mathrm{CO}$ ) char can form as an intermediate product, and usually does. With these considerations, the final product can not be determined from the weight loss information itself. The residues found in both the DSC and TGA tests with the EDTA mixtures were either black, brown or a mixture of black and white, depending on the final temperature, indicating that carbon, or char, was indeed a product in addition to carbonate. Finally, the derivative curve of the thermogram in figure 38 , from $400^{\circ} \mathrm{C}$ on, contains two minor peaks, the second one barely discernible, and each a result of a change in the decomposition mode. Aqueous solutions of EDTA are used in many analytical quantitative titrations, and EDTA is commonly used as a chelating and complexing agent for a large variety of metals. Studies of the thermal decompositions of some of these metal complexes are available in print, including one for the disodium dihydrate salt (21), but none was found for the tetrasodium dihydrate EDTA. 
The EDTA-nitrate mixtures were tested in the TGA in a similar manner.

Thermograms obtained in the tests with these mixtures show similar overall features but vary in detalls, as seen in figures 39 to 42 , for samples $9 A$ (1:1) to $90(1: 10)$. Figure 39 , for sample $9 A$ contains the five peaks in the derivative curve, identical to the peaks found for the pure EDTA. The major weight loss step starts at $298^{\circ} \mathrm{C}$, which is a somewhat lower temperature than the one at which EDTA decomposes by itself. At $350^{\circ} \mathrm{C}$ there is a pronounced change in the slope of the weight loss curve, and between $350^{\circ} \mathrm{C}$ and $450^{\circ} \mathrm{C}$ the slope changes direction again, as indicated by the two peaks in the derivative curve. This complex decomposition process shows the changes in the mechanisms and kinetics of decomposition as the various bonds in the EDTA molecule break apart. Total weight loss for this test was 34.4 pct. Assuming complete reaction of the EDTA with the sodium nitrate, as follows:

$$
\mathrm{Na}_{4} \mathrm{C}_{10} \mathrm{H}_{12} \mathrm{O}_{8} \mathrm{~N}_{2}(s)+8 \mathrm{NaNO}_{3}(\mathrm{~s}) \rightarrow 6 \mathrm{Na}_{2} \mathrm{CO}_{3}(\mathrm{~s})+6 \mathrm{H}_{2} \mathrm{O}(\mathrm{g})+4 \mathrm{CO}_{2}(\mathrm{~g})+5 \mathrm{~N}_{2}(\mathrm{~g}) \text {, }
$$

weight loss would be 40 pct, and for the dihydrate sample of EDTA, which was used in preparing the mixtures, weight loss would be 42 pct. If, on the other hand, the reaction was the following,

$$
\begin{array}{r}
\mathrm{Na}_{4} \mathrm{C}_{10} \mathrm{H}_{12} \mathrm{O}_{8} \mathrm{~N}_{2} \cdot 2 \mathrm{H}_{2} \mathrm{O}(\mathrm{s})+8 \mathrm{Na}_{2} \mathrm{NO}_{3}(\mathrm{~s}) \rightarrow 2 \mathrm{Na}_{2} \mathrm{CO}_{3}(\mathrm{~s})+8 \mathrm{NaNO}_{2}(\mathrm{~s})+8 \mathrm{H}_{2} \mathrm{O}(\mathrm{g}) \\
+8 \mathrm{CO}_{2}(\mathrm{~g})+5 \mathrm{~N}_{2}(\mathrm{~g})+4 \mathrm{O}_{2}(\mathrm{~g}),
\end{array}
$$

weight loss would be 31 pct. The experimental results are between these two values and are closer to the weight loss found for equation 10 . Analyses of the residue and the evolved gases are required before the actual reaction can be determined accurately.

Figure 40 shows the thermogram for sample $9 B(1: 3)$ which was heated at $5^{\circ} \mathrm{C} / \mathrm{min}$. Essentially the same features are seen as were seen in figure 39 , although not all the peaks are of the same relative size in the derivative curve, and temperatures at which changes occur are shifted slightly. Onset of the main decomposition is at $293^{\circ} \mathrm{C}$ and total weight loss is about 15 pct. Doing the same calculations for the $1: 3$ mixture,

$\mathrm{Na}_{4} \mathrm{C}_{10} \mathrm{H}_{12} \mathrm{O}_{8} \mathrm{~N}_{2} \cdot 2 \mathrm{H}_{2} \mathrm{O}(\mathrm{s})+24 \mathrm{NaNO}_{3}(\mathrm{~s}) \rightarrow 6 \mathrm{Na}_{2} \mathrm{CO}_{3}(\mathrm{~s})+16 \mathrm{NaNO}_{3}(\mathrm{~s})+$ gases,

weight loss would be 18.7 pct, while for

$$
\begin{array}{rl}
\mathrm{Na}_{4} \mathrm{C}_{10} \mathrm{H}_{12} \mathrm{O}_{8} \mathrm{~N}_{2} \cdot 2 \mathrm{H}_{2} \mathrm{O}(\mathrm{s})+24 \mathrm{NaNO}_{3}(\mathrm{~s}) \rightarrow 2 & 2 \mathrm{Na}_{2} \mathrm{CO}_{3}(\mathrm{~s})+8 \mathrm{NaNO}_{2}(\mathrm{~s})+ \\
+ & 16 \mathrm{NaNO}_{3}(\mathrm{~s}) \\
+ \text { gases, }
\end{array}
$$

weight loss would be 14.5 pct.

The thermogram in figure 41 depicts weight losses undergone by the $9 \mathrm{C}$ sample $\left(1: 3\right.$; diluent), at a heating rate of $5^{\circ} \mathrm{C} / \mathrm{min}$. Similar features are seen in this figure as were seen in figures 39 and 40 . The only additional feature is another small weight loss step which encis at $200^{\circ} \mathrm{C}$, and likewise, in the derivative curve a few additional peaks are noted. These peaks are due to the presence of the diluent, sodium aluminate, and its interaction with the other compounds and/or due to its own dissociation. Onset of the major 
decomposition step is at $303^{\circ} \mathrm{C}$. The last mixture tested, at $10^{\circ} \mathrm{C} / \mathrm{min}$, was the $90(1: 10)$ sample. Its thermogram is shown in figure 42 . Main decomposition onset is at $297^{\circ} \mathrm{C}$; it is followed by various weight loss steps, as seen in the three main peaks clustered between $370^{\circ} \mathrm{C}$ and $425^{\circ} \mathrm{C}$, in the derivative curve. Overall weight loss is 5.9 pct. When a similar sample was heated at $5^{\circ} \mathrm{c} / \mathrm{min}$, the onset of main decomposition was at $294^{\circ} \mathrm{C}$. Similar weight loss calculations, as above, show a weight loss of 6.3 pct, if both the sodium nitrate and tetrasodium EDTA convert to sodium carbonate, whereas if only the EDTA forms carbonate, while the corresponding amount of nitrate decomposes to nitrite then weight loss is 4.4 pct. Minor variations in the amount of EDTA in the 90 sample, which contains a small amount of EDTA, due to sampling, will influence the weight loss. All the results are summarized in table 16 .

The mixtures of EDTA with the sodium nitrate-sodium nitrite combination were tested at $5^{\circ}$ and $10^{\circ} \mathrm{C} / \mathrm{min}$. The thermograms for samples $10 \mathrm{~A}(1: 1)$ to 100 $(1: 10)$ are presented in figures 43 to 46 . Thermograms in figures 43 to 45 show features similar to those found for the mixtures of EDTA with pure sodium nitrate and will not be elaborated upon. In general, onset temperatures for the main decomposition reaction are much lower for all these samples (other than for the 1OC samples), whereas weight losses are about the same, when compared to the respective onset temperatures and weight losses found for the mixtures with sndium nitrate.

Table 16. - TLA !!ermal analysis results for the EDTA and EDTA-nitrate mixtures

\begin{tabular}{||c|c|c|c|c|l||}
\hline Sample & $\begin{array}{c}\text { Mixture } \\
\text { ratio }\end{array}$ & $\begin{array}{c}\text { Heating } \\
\text { rate, } \\
\text { 'C/min }\end{array}$ & $\begin{array}{c}\text { Onset } \\
\text { temperature, } \\
\text { C }\end{array}$ & $\begin{array}{c}\text { Weight } \\
\text { loss, } \\
\text { pct }\end{array}$ & \multicolumn{1}{|c||}{$\begin{array}{c}\text { Residue } \\
\text { appearance }\end{array}$} \\
\hline $2 A$ & - & 10 & 322 & 50.0 & Black \& White \\
\hline $9 A$ & $1: 1$ & 10 & 298 & 34.4 & Gray \\
\cline { 3 - 7 } & & 5 & 297 & 34.0 & Light Gray \\
\hline $9 B$ & $1: 3$ & 10 & 296 & 14.9 & Gray \\
\cline { 3 - 7 } & & 5 & 293 & 15.2 & Light Gray \\
\hline $9 D$ & $1: 3$ & 10 & 303 & 10.2 & White \\
\cline { 3 - 7 } & 1 (dil) & 5 & 304 & 9.4 & White \\
\hline 90 & $1: 10$ & 10 & 297 & 5.9 & Gray \\
\cline { 3 - 7 } & & 5 & 294 & 5.4 & White \\
\hline
\end{tabular}

'Based on the initial deviation of the main decomposition step from baseline. 
It is of interest to see in figures 44 to 46 that at the completion of the decomposition phase, there is a small weight gain for the residue. This could be in part due to partial oxidation of the charred residue formed in the decomposition of EDTA and/or due to oxidation of sodium nitrite to the nitrate, mentioned previously. The residues left at the end of the tests with samples 9A, 98, 90,10A, 10B and 100 were all gray, suggesting that char was a product in all these cases. Char is mentioned as a decomposition product of various compounds of EDTA. For instance, when lanthanide and yttrium chelates of EDTA decompose thermally, 5 to 7 pct by weight of the residues consist of char (22). If char is a notable constituent, then the calculations of weight losses, which do not consider char, may not be as accurate, and in themselves cannot be used to indicate the detailed types of reactions that take place. This can be done when reactions are simple and straight forward. Otherwise, analyses of intermediates, of the final residue, and of all the gases evolved during the decomposition are required. The only white residues were found for samples $9 C$ and $10 C$ which contained sodium aluminate. The results of the tests with the nitrate-nitrite mixtures are summarized in table 17.

Table 17. - TGA thermal analysis results for the EDTA-nitrate-nitrite mixtures

\begin{tabular}{|c|c|c|c|c|c|}
\hline Sample & $\begin{array}{c}\text { Mixture } \\
\text { ratio }\end{array}$ & $\begin{array}{l}\text { Heating } \\
\text { rate, } \\
\text { c/min }\end{array}$ & $\begin{array}{c}\text { Onset }{ }^{1} \\
\text { temperature, } \\
{ }^{\circ} \mathrm{C}\end{array}$ & $\begin{array}{c}\text { Weight } \\
\text { loss, } \\
\text { pct }\end{array}$ & $\begin{array}{l}\text { Residue } \\
\text { appearance }\end{array}$ \\
\hline \multirow[t]{2}{*}{$10 A$} & \multirow[t]{2}{*}{$1: 1$} & 10 & 254 & 35.4 & Dark Gray \\
\hline & & 5 & 252 & 33.3 & Dark/Light Gray \\
\hline \multirow[t]{2}{*}{$10 B$} & \multirow[t]{2}{*}{$1: 3$} & 10 & 239 & 13.4 & Gray \\
\hline & & 5 & 238 & 14.3 & Gray \\
\hline \multirow[t]{2}{*}{$10 C$} & \multirow{2}{*}{$\begin{array}{r}1: 3 \\
(d i 1) \\
\end{array}$} & 10 & 306 & 9.3 & Light Gray \& White \\
\hline & & 5 & 293 & 9.0 & White \\
\hline \multirow[t]{2}{*}{100} & \multirow[t]{2}{*}{$1: 10$} & 10 & 236 & 4.7 & Light Gray \\
\hline & & 5 & 235 & 5.1 & Light Gray \\
\hline
\end{tabular}

'Based on initial deviation of the main decomposition step from baseline.

Results from the DSC tests with the same mixtures, suggested that the interaction between EDTA and the nitrate or the nitrate-nitrite combination was not extensive, energy-wise, especially for the " $B$ ", "C", and "D" mixtures. This conclusion was based on the calculations of the areas of the first exothermic peak only. Other exothermic peaks were also present in the thermograms, following the main peak. These peaks should al so be integrated, and the energies added up, to obtain a correct value for the complete release of energy in each case. However, it should be noted that these peaks were 
small in comparison to the main peak and their contribution will be small. It is also possible that the formation of char during the decomposition in the nitrate and/or reaction with the melt is not as highly an exothermic process. The main differences between the DSC and TGA are also responsible, in part, for the different results. Larger samples, in the open sample pan of the TGA, afford the release of gases at a lower temperature. The flow of air inside the glass tube housing the TGA furnace and sample helps sweep away the decomposition gases. In the DSC, smaller samples were used, to prevent leakage due to frothing, and a lid was used in each sample pan. Such a setup will slow down the escape of the gases, and the reactions.

In summary, onset temperatures for exothermic behavior for EDTA with nitrate were at about $300^{\circ}$ to $305^{\circ} \mathrm{C}$, as measured in the DSC, and at about $295^{\circ} \mathrm{C}$, or slightly higher, when measured in the TGA. The respective onset temperatures for the mixtures with the nitrate-nitrite combination, in the DSC tests were also clustered near $290^{\circ} \mathrm{C}$, although a value as low as $269^{\circ} \mathrm{C}$ was also observed. The lowest onset temperatures were seen in the TGA thermograms for the mixtures with the nitrate-nitrite combination. Temperatures as low as $235^{\circ}$ were seen, and they ranged from $235^{\circ}$ to $254^{\circ} \mathrm{C}$, for the "A", "B" and "D" mixtures. Thus, it is seen that the presence of nitrite lowers the onset temperature, as was also seen for the oxalate mixtures. The onset temperature for exothermic decomposition of the EDTA sample was not different from the onset temperatures of the various mixtures, in the DSC tests, whereas, in the TGA it was higher by about $20^{\circ} \mathrm{C}$, than the respective temperatures found for the mixtures with sodium nitrate.

Sodium Citrate and Citrate Mixtures

The pure sodium citrate dihydrate $\left(\mathrm{Na}_{3} \mathrm{C}_{6} \mathrm{H}_{5} \mathrm{O}_{7} \cdot 2 \mathrm{H}_{2} \mathrm{O}\right)$ and all the mixtures with sodium nitrate (11A to $11 D$ ) and with the sodium nitrate-sodium nitrite combination (12A to 12D) were tested in the DSC, in flowing air, at a heating rate of $10^{\circ} \mathrm{C} / \mathrm{min}$. Some tests were also conducted at a heating rate of $5^{\circ} \mathrm{C} / \mathrm{min}$ in air, and a few samples were tested in a nitrogen flow. The sodium citrate and the citrate mixtures leaked out from the sample pans when samples weighed more than 4 or $5 \mathrm{mg}$. They even leaked at times when smaller samples were used. Calibrations with indium and zinc preceded this series of tests.

The DSC thermogram for the sodium citrate sample, in figure 47 , contains one major endotherm followed by four exotherms of small and medium sizes, and the beginning of a fifth exotherm at $500^{\circ} \mathrm{C}$. The endotherm, with onset at $160^{\circ} \mathrm{C}$ and a peak at $169^{\circ} \mathrm{C}$, indicates the loss of the water of hydration. The four exotherms signify various steps in the decomposition process of sodium

citrate. The first exotherm, a relatively small one, peaks at about $229^{\circ} \mathrm{C}$. Onset temperatures for this first exotherm were about $200^{\circ}$ to $220^{\circ} \mathrm{C}$. Energy release values for this first exotherm, obtained from thermograms of three tests in air at $10^{\circ} \mathrm{C} / \mathrm{min}$, and of one test in nitrogen at $5^{\circ} \mathrm{C} / \mathrm{min}$ were 108.6, $100.5,115.6$ and $109.8 \mathrm{~J} / \mathrm{g}$ of citrate, respectively. The average value is $107 \pm 6 \mathrm{~J} / \mathrm{g}$ of citrate. The second exotherm, with onset temperature of $299^{\circ} \mathrm{C}$ and peak temperature of $310^{\circ} \mathrm{C}$, evolved less energy than was released in the first exotherm. This exotherm is in the temperature range where sodium nitrate melts. The third exotherm, larger in size than the first two, shows 
evidence of an active reaction, probably due to rapid decomposition and evolution of gases, such as $\mathrm{CO}_{2}$, from the citrate. Leakage from the sample pan often resulted from such a reaction.

When the sodium citrate sample was observed after being heated to $310^{\circ} \mathrm{C}$, a gray residue was present, whereas, when the samples were heated to $390^{\circ} \mathrm{C}$ or to $550^{\circ} \mathrm{C}$, a black residue was found in the sample pan. Although theoretically the three carboxylate groups of the citrate can split off as $\mathrm{CO}_{2}$, a significant quantity of carbon is known to remain after decomposition of citrates in air. The sample heated in nitrogen to $500^{\circ} \mathrm{C}$ also left a black residue in the sample pan. On heating, anhydrous citric acid loses water to form aconitic acid which in turn loses carbon dioxide and water to form itaconic acid or itaconic anhydride, as follows:

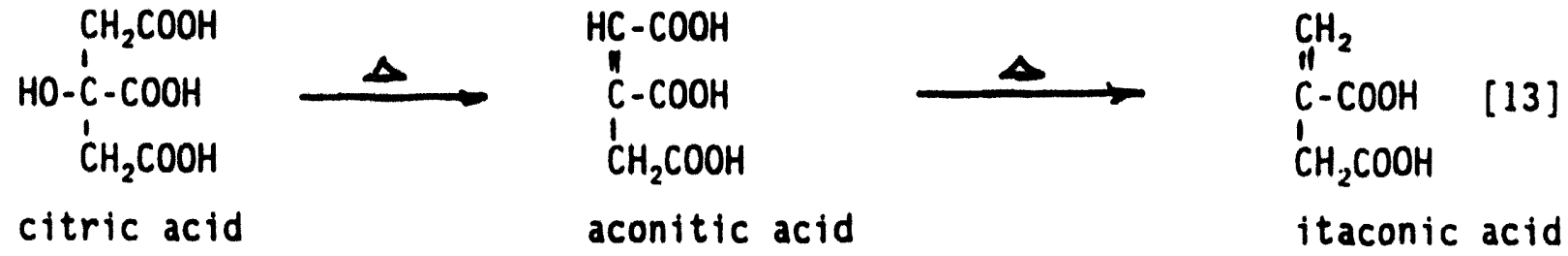

Calcium and barium citrates, likewise form the respective salts of these two acids, during thermal decomposition (23). Sodium citrate probably decomposes in similar fashion. On further decomposition the carbonates form. Carbon formation accompanies the decomposition steps, as is evident in the residues.

A thermogram from a test with a sample of the citrate with sodium nitrate, $11 \mathrm{~A}(1: 1)$, obtained in air at a heating rate of $10^{\circ} \mathrm{C} / \mathrm{min}$, is presented in figure 48. Another thermogram for a sample heated at $5^{\circ} \mathrm{C} / \mathrm{min}$, is shown in figure 49; the thermograms are similar in their features. Of interest is the endotherm at about $260^{\circ}$ to $270^{\circ} \mathrm{C}$. In four separate tests with this mixture, the following onset temperatures were seen for this endotherm: $257^{\circ}, 268^{\circ}$, $277^{\circ}$, and $262^{\circ} \mathrm{C}$. These temperatures are lower than the melting temperature of pure sodium nitrate by as much as $50^{\circ} \mathrm{C}$. This endotherm can be due to the melting of the sodium nitrate, whose melting temperature has been lowered by the presence of the citrate. On the other hand, this endotherm can be due to a reaction between the nitrate and the citrate such as mixing or dissolution. In the four tests cited above, with samples weighing between 3.9 to $4.1 \mathrm{mg}$, a fast reaction was evident, by a sharp excursion, starting as an exotherm just after the endothermic phase was complete, at about $270^{\circ} \mathrm{C}$, but instantly reverting to an endotherm as a result of leakage or expulsion of material from the sample pan. Such behavior is commonly seen in DSC tests when leakage or fast expulsion occurs. These four tests were concluded at about $350^{\circ} \mathrm{C}$ or at $500^{\circ} \mathrm{C}$, and in all cases the residues were black.

Samples from the 11B mixture (1:3) produced thermograms that were both similar to, and different from, those for the $11 \mathrm{~A}$ samples. Figure 50 shows one example. The endotherm due to water loss from the citrate, followed by the first exotherm of citrate decomposition are easily recognizable. These two are followed by the endotherm at $260^{\circ} \mathrm{C}$ which is almost $50^{\circ} \mathrm{C}$ lower than the temperature of melting of pure sodium nitrate. Before completion, this 
endotherm is overtaken by an extensive exotherm which stretches from $263^{\circ}$ to $470^{\circ} \mathrm{C}$. This exotherm is initially overlapped by various small peaks, and starting at about $370^{\circ} \mathrm{C}$, shows an array of many sharp peaks. Other samples behaved in a similar manner. The energy released during this exothermic phase was about $6,070 \mathrm{~J} / \mathrm{g}$ of citrate; the energy for the same exotherm, from another test with an $118 \mathrm{~B}$ sample, was $7,310 \mathrm{~J} / \mathrm{g}$ of citrate. It should be noted that energy values calculated from areas in a thermogram depend, among other things, on the two points chosen to bracket the area. Repeated calculations of an area vary somewhat, unless a peak is sharp. Other variations in calculated areas under peaks are due to inhomogeneity of the sample, its size distribution and packing in the sample pan, as well as the influence of variable instrumental parameters. With this in mind, the difference in the above two energy values may be acceptable. The residues from the tests with samples from the 11B mixtures were all white, regardless of the atmosphere (air or nitrogen). The array of sharp peaks suggests the behavior of an effervescent mixture. The samples from the $11 \mathrm{C}$ mixtures $(1: 3$; diluent) produced their own unique thermograms which contain signatures of the sodium aluminate, such as the second endotherm in figure 51. The first two endotherms are followed by two other endotherms. The first of these latter two may be due to the reaction between citrate and some of the nitrate, proposed previously, whereas the second endotherm can be due to the more typical melting of the remainder of the sodium nitrate. This latter endotherm is then superseded by an extended, somewhat shallow exotherm.

Finally, thermograms for samples from the 110 mixtures $(1: 10)$ are shown in figures 52 and 53. A very shallow first exotherm is present in the temperature range of $200^{\circ}$ to $240^{\circ} \mathrm{C}$, while a second exothermic area is seen between $260^{\circ}$ and $290^{\circ} \mathrm{C}$. A smaller number of the many sharp peaks seen in figure 50 is seen in figures 52 and 53 . These peaks were not present in figure 51, representing the results for the samples of the $11 \mathrm{C}$ mixture. The diluent, sodium aluminate, may be responsible for damping this behavior. Onset of exothermic behavior for all the mixtures of sodium citrate with sodium nitrate was at $200^{\circ} \pm 10^{\circ} \mathrm{C}$, and was due to the initiation of citrate decomposition. The results for these tests are given in table 18.

Figures 54 to 57 display thermograms for tests with samples from the mixtures of sodium citrate with the nitrate-nitrite combination, 12A, 12B, 12C, and 120 , respectively. The thermograms all contain two endotherms followed by exotherms. When the diluent is present, an additional small endotherm is found between the two endotherms. The size and number of exothermic peaks diminishes with decreasing amount of citrate. A small degree of effervescent behavior was noted only in a few of the tests, all of which resulted in white residues. The second endotherm, presumably either the nitrate-nitrite melting peak, or a peak representing a reaction between the nitrate-nitrite and the citrate, appears at a low temperature. In figures 54 and 55 , for the $12 \mathrm{~A}$ and $12 B$ samples, the onset and peak temperatures for this specific endotherm are at $190^{\circ}$ to $195^{\circ} \mathrm{C}$ and $204^{\circ}$ to $210^{\circ} \mathrm{C}$, respectively. Higher temperatures were registered for this peak in the tests with the 120 mixtures, and the temperatures were highest for the $12 \mathrm{C}$ mixtures, with onset and peak temperatures being $221^{\circ}$ and $239^{\circ} C$ respectively. The sodium citrate sample itself shows initiation of exothermic behavior at $200^{\circ} \mathrm{C}$. Thus, these exothermic and endothermic events overlap partly. Exothermic behavior by all 
the mixtures of sodium citrate with the nitrate-nitrite combination is seen starting soon after completion of the endotherm at $210^{\circ} \pm 10^{\circ} \mathrm{C}$. A more energetic exothermic stage starts at $250^{\circ} \mathrm{C}$ for most mixtures. Results are summarized in table 19.

Table 18. - DSC thermal analysis results for the citrate and citrate-nitrate mixtures

\begin{tabular}{|c|c|c|c|c|}
\hline Sample & $\begin{array}{c}\text { Mixture } \\
\text { ratio }\end{array}$ & $\begin{array}{c}\text { Heating } \\
\text { rate, } \\
{ }^{\circ} \mathrm{C} / \min \\
\end{array}$ & $\begin{array}{c}\text { Atmosphere, } \\
\text { dynamic }\end{array}$ & $\begin{array}{c}\text { Exotherm } \\
\text { onset } \\
\text { temperature, } \\
\text { 'C } \\
\end{array}$ \\
\hline $3 A-1$ & \multirow{4}{*}{ - } & 10 & air & 205 \\
\hline $3 A-2$ & & 10 & $"$ & 205 \\
\hline $3 A-3$ & & 5 & $\mathrm{~N}_{2}$ & 206 \\
\hline $3 A-4$ & & 10 & air & 205 \\
\hline $11 A-1$ & \multirow{4}{*}{$1: 1$} & 10 & $"$ & 196 \\
\hline $11 A-2$ & & 5 & $"$ & 195 \\
\hline $11 A-3$ & & 10 & $"$ & 195 \\
\hline $11 A-4$ & & 10 & $"$ & 195 \\
\hline $11 \mathrm{~B}-1$ & \multirow{5}{*}{$1: 3$} & 10 & $"$ & 192 \\
\hline $11 B-2$ & & 10 & $"$ & 190 \\
\hline $11 B-3$ & & 5 & $"$ & 195 \\
\hline $11 B-4$ & & 10 & $\mathrm{~N}_{2}$ & 194 \\
\hline $11 B-5$ & & 5 & $"$ & 194 \\
\hline $11 C-1$ & \multirow{3}{*}{$\begin{array}{c}1: 3 \\
(d i 1)\end{array}$} & 10 & air & 203 \\
\hline $11 C-2$ & & 5 & $"$ & 195 \\
\hline $11 C-3$ & & 10 & $"$ & 205 \\
\hline $110-1$ & \multirow{3}{*}{$1: 10$} & 10 & $"$ & $200^{2} ; 265$ \\
\hline $110-2$ & & 5 & $"$ & 200 \\
\hline $110-3$ & & 10 & $"$ & 263 \\
\hline
\end{tabular}

'Based on initial deviation of the main decomposition step from the baseline.

${ }^{2} A$ very minimal exotherm. 
Table 19. - DSC thermal analysis results for the citratenitrate-nitrite mixtures

\begin{tabular}{|c|c|c|c|c|}
\hline Sample & $\begin{array}{c}\text { Mixture } \\
\text { ratio } \\
\end{array}$ & $\begin{array}{c}\text { Heating } \\
\text { rate, } \\
{ }^{\circ} \mathrm{C} / \mathrm{min} \\
\end{array}$ & $\begin{array}{c}\text { Atmosphere, } \\
\text { dynamic }\end{array}$ & $\begin{array}{c}\text { Exotherm } \\
\text { onset } \\
\text { temperature, } \\
\text { 'C } \\
\end{array}$ \\
\hline $12 A-1$ & \multirow{3}{*}{ - } & 10 & air & 217 \\
\hline $12 A-2$ & & 5 & $"$ & 212 \\
\hline $12 A-3$ & & 10 & $\mathrm{~N}_{2}$ & 217 \\
\hline $12 B-1$ & \multirow{3}{*}{$1: 3$} & 10 & air & 218 \\
\hline $12 B-2$ & & 5 & $"$ & 215 \\
\hline $12 B-3$ & & 10 & $"$ & 219 \\
\hline $12 C-1$ & \multirow{3}{*}{$\begin{array}{c}1: 3 \\
(\mathrm{dii})\end{array}$} & 10 & $"$ & 230 \\
\hline $12 C-2$ & & 5 & $"$ & 242 \\
\hline $12 C-3$ & & 10 & $"$ & 247 \\
\hline $12 D-1$ & \multirow{3}{*}{$1: 10$} & 10 & $"$ & 229 \\
\hline $120-2$ & & 5 & $"$ & 225 \\
\hline $12 D-3$ & & 10 & $"$ & 228 \\
\hline
\end{tabular}

'Based on initial deviation of the main decomposition step from the baseline.

${ }^{2} A$ very minor exothermic activity, with onset temperature at $175^{\circ} \mathrm{C}$, was observed in all the tests.

The pure trisodium citrate dihydrate and the mixtures with nitrate and with the nitrate-nitrite combination were tested in the TGA, at heating rates of $10^{\circ}$ and $5^{\circ} \mathrm{C} / \mathrm{min}$, in flowing air. Calibration of the instrument was conducted with a $100 \mathrm{mg}$ weight, and with a nickel curie point prior to the tests with each mixture.

The TGA thermogram for the sodium citrate, presented in figure 58, for a test at $10^{\circ} \mathrm{C} / \mathrm{min}$, shows seven steps of weight loss, two of them minor. The accompanying derivative curve, with its peaks, helps to visualize the various steps. The first small loss is due to the loss of some moisture. It is followed by a main loss of weight, with onset at about $150^{\circ} \mathrm{C}$, due to loss of the water of hydration, equal to approximately 13 pct of the original weight. From there a gently descending curve, with a small step initiated at about $220^{\circ} \mathrm{C}$, indicates the beginning of decomposition of the citrate though weight 
WHC-MR-0455

loss is small. The next loss of weight, with onset at about $300^{\circ} \mathrm{C}$, is due to the major decomposition phase of the citrate and the loss of the $\mathrm{CO}_{2}$ and/or the $\mathrm{OH}$ groups. The loss of one $\mathrm{CO}_{2}$ molecule will increase the weight loss to 27.2 pct. This value agrees with the remaining weight of 73 pct at the end of the step. The next two stages of weight loss are depicted by the two small peaks in the derivative curve, and increase the total weight loss to near 30 pct, while the last step of weight loss increases the weight loss to a total of 38 pct. A complete conversion to sodium carbonate would require a total weight loss of 46 pct. The residue was black, indicating that char was formed. Thus, higher temperatures are needed to oxidize the char left in the residue.

The thermograms for the mixtures of citrate with sodium nitrate were obtained in the same manner. The thermograms in figures 59 to 62 are for samples $11 \mathrm{~A}$ to $110(1: 1$ to $1: 10)$, at heating rates of $10^{\circ} \mathrm{C} / \mathrm{min}$, while figures 63 and 64 are for samples $11 \mathrm{~A}(1: 1)$ and $110(1: 10)$, heated at $5^{\circ} \mathrm{C} / \mathrm{min}$. In general, all the thermograms have similar features, with three or four stages of weight loss, some of them overlapping, as different reactions occur. As usual, the mixture with the diluent, sample 11C (1:3; diluent) shows additional variations, as was found to be the case for the other fuel mixtures. The effect due to change in heating rate is small. Weight loss for most of the important stages starts and ends at a slightly lower temperature when the heating rate is lower. In figure 59 we see the identical loss of water of hydration that we observe for the pure citrate, including the two minor losses before and after the primary water loss stage. The next weight loss process starts at $260^{\circ} \mathrm{C}$ and continues to the point where 15 pct of total weight has been lost. The weight loss continues, from that point, in phases of varying rates until, at $540^{\circ} \mathrm{C}$, total weight loss is 38 pct. If we assume that the following reaction occurs,

$\mathrm{Na}_{3} \mathrm{C}_{6} \mathrm{H}_{5} \mathrm{O} \cdot 2 \mathrm{H}_{2} \mathrm{O}(\mathrm{s})+3.6 \mathrm{NaNO}_{3}(\mathrm{~s}) \rightarrow 3.3 \mathrm{Na}_{2} \mathrm{CO}_{3}(\mathrm{~s})+4.5 \mathrm{H}_{2} \mathrm{O}(\mathrm{g})$

$$
+2.7 \mathrm{CO}_{2}(\mathrm{~g})+1.8 \mathrm{~N}_{2}(\mathrm{~g}) \text {, }
$$

then the total weight loss should be 41.7 pct. Since the residue was gray, char formation was prevalent in the presence of the nitrate, as well. This means that the reaction depicted in equation 14 is not the only reaction taking place.

Onset of the main decomposition event is at an even lower temperature, of $250^{\circ} \mathrm{C}$ or less, for mixtures $11 \mathrm{~B}, 11 \mathrm{C}$, and 110 , as shown in figures 60 to 62 . Total weight losses shown in the thermograms of these figures agree, within experimental error, with the values calculated from reaction 14, taking into account the proper amount of excess sodium nitrate in each case and assuming that this excess nitrate remains unchanged throughout. It should be remembered, though, that agreement between theoretical calculations and experimental weight loss values does not prove that reaction 14 is the one taking place. As evidence we see the presence of char in the residue, but not in the theoretical reaction products. For comparison with tests conducted at a heating rate of $10^{\circ} \mathrm{C} / \mathrm{min}$, figures 63 and 64 are for samples $11 \mathrm{~A}$ and 110 
which were heated at $5^{\circ} \mathrm{C} /$ min during these tests. Results for the tests with the nitrate mixtures are found in table 20.

Table 20. - TGA thermal analysis results for the citrate and citrate-nitrate mixtures

\begin{tabular}{|c|c|c|c|c|c|}
\hline Sample & $\begin{array}{c}\text { Mixture } \\
\text { ratio }\end{array}$ & $\begin{array}{l}\text { Heating } \\
\text { rate, } \\
{ }^{\circ} \mathrm{C} / \mathrm{min} \\
\end{array}$ & $\begin{array}{c}\text { Onset } \\
\text { temperature, } \\
\text { 'C }\end{array}$ & $\begin{array}{l}\text { Weight } \\
\text { loss, } \\
\text { pct }\end{array}$ & $\begin{array}{c}\text { Residue } \\
\text { appearance }\end{array}$ \\
\hline $3 A$ & - & 10 & 220 & 38 & Black \\
\hline \multirow[t]{2}{*}{$11 \mathrm{~A}$} & \multirow[t]{2}{*}{$1: 1$} & 10 & 263 & 38 & Grey \\
\hline & & 5 & 256 & 38 & Grey \\
\hline \multirow[t]{2}{*}{$11 B$} & $1: 3$ & 10 & 257 & 20 & Grey \\
\hline & & 5 & 256 & 19 & Grey \\
\hline \multirow[t]{2}{*}{$11 C$} & \multirow{2}{*}{$\begin{array}{r}1: 3 \\
(d i 1) \\
\end{array}$} & 10 & 263 & 11 & White \\
\hline & & 5 & 270 & 11 & White \\
\hline \multirow[t]{2}{*}{110} & \multirow[t]{2}{*}{$1: 10$} & 10 & 249 & 7 & White \\
\hline & & 5 & 234 & 7 & off-White \\
\hline
\end{tabular}

'Based on initial deviation of the main decomposition step from the baseline.

The onset temperatures for initiation of reaction, or decomposition, in all these TGA thermograms are well below the melting temperature of the pure sodium nitrate. These results agree with the DSC results for the same mixtures, although the onset temperatures of exothermic behavior in the DSC tests are lower than the onset temperatures for major weight loss in the TGA tests. The reverse results were found for the oxalate and EDTA mixtures, when comparing DSC and TGA results; lower onset temperatures were obtained in the TGA tests for weight loss, than exothermic onset temperatures found in the DSC tests, for the oxalate and EDTA mixtures. Since the citrate itself undergoes initially structural changes with only a minimal weight loss of water at these lower temperatures, the results are understandable.

When the mixtures of sodium citrate with the nitrate-nitrite combination were evaluated in likewise manner, the resultant thermograms were quite similar to the respective thermograms for the mixtures with sodium nitrate. These thermograms are shown in figures 65 to 68 , for mixtures $12 \mathrm{~A}$ to 120 $(1: 1$ to $1: 10)$. Onset temperatures for decomposition are even lower than they were for the nitrate mixtures. The effervescent behavior of the citrate mixtures, noted previously, is evident in the "noisy" derivative curves. Results for the citrate-nitrate-nitrite mixtures are summarized in table 21. 
Table 21. - TGA thermal analysis results for the citrate-nitrate-nitrite mixtures

\begin{tabular}{|c|c|c|c|c|c|}
\hline Sample & $\begin{array}{c}\text { Mixture } \\
\text { ratio }\end{array}$ & $\begin{array}{c}\text { Heating } \\
\text { rate, } \\
\text {-C/min } \\
\end{array}$ & $\begin{array}{c}\text { Onset } \\
\text { temperature, }{ }^{1} \\
{ }^{\circ} \mathrm{C} \\
\end{array}$ & $\begin{array}{l}\text { Weight } \\
\text { loss, } \\
\text { pct }\end{array}$ & $\begin{array}{c}\text { Residue } \\
\text { appearance }\end{array}$ \\
\hline \multirow[t]{2}{*}{$12 A$} & \multirow[t]{2}{*}{$1: 1$} & 10 & 235 & 33.5 & Dark Grey \\
\hline & & 5 & 235 & 32.8 & Dark Grey \\
\hline \multirow[t]{2}{*}{$12 B$} & \multirow[t]{2}{*}{$1: 3$} & 10 & 220 & 17.4 & Black \\
\hline & & 5 & 223 & 16.1 & Dark Grey \\
\hline \multirow[t]{2}{*}{$12 C$} & \multirow{2}{*}{$\begin{array}{l}1: 3 \\
\text { (di1) } \\
\end{array}$} & 10 & 236 & 10.7 & White \\
\hline & & 5 & 220 & 8.8 & White \\
\hline \multirow[t]{2}{*}{$12 D$} & \multirow[t]{2}{*}{$1: 10$} & 10 & 226 & 6.9 & White \\
\hline & & 5 & 235 & 4.2 & White \\
\hline
\end{tabular}

'Based on initial deviation of the main decomposition step from the baseline.

Citrates are used in the preparation of precursors of various metal and metal oxide catalysts. Both citrate and nitrate ions are present in the initial mixtures of such preparations, which are then heated, and calcined. Carbonates are formed as intermediates, and oxides as the final products, in the calcination. There have been reports of exothermic reactions between the citrate and nitrate ions during the heating phase (24), with concurrent release of $\mathrm{CO}_{2}, \mathrm{H}_{2} \mathrm{O}$ and $\mathrm{NO}$. Courty, Ajot and Marcilly (25), proposed that the same type of reaction occurred in precursors that they prepared in a similar fashion. Shannon (26), who adopted the same preparation procedure used by Courty et al (25), reported that explosions occurred in the evaporation flasks during the drying phase. The metal oxide product formed in his preparation, which was not identified, was known to be an oxidation catalyst, according to Shannon. Lastly, an explosion occurred when a sample of sodium citrate, which was treated with nitric acid and/or a nitrate salt, was being ashed in a furnace (27). These references indicate that not only do citrate with nitrate react exothermally, but that they can undergo explosive reactions. The presence of metals that can act as catalysts may promote the exothermic reaction; the ratio of citrate to nitrate may also be an important parameter.

The results from the tests in the DSC indicate that initial exothermic reaction is due to the decomposition of the sodium citrate, at $190^{\circ}$ to $205^{\circ} \mathrm{C}$, when nitrate is the oxidant. With the nitrate-nitrite mixture, onset temperatures for exothermic behavior are somewhat higher and range from $212^{\circ}$ to $230^{\circ} \mathrm{C}$, for the mixtures without diluent. Once the sodium citrate has gone through this first decomposition step, its decomposition product either dissolves in, or mixes with, the nitrate endothermally, and then reacts 
exothermally, at a fast rate. This is evident in the fast excursions in the thermograms, as for example at $270^{\circ} \mathrm{C}$ in figure 48 , for sample $11 \mathrm{~A}$, and in the concurrent expulsion of sample matter from the sample pan. The relative amounts of citrate and nitrate are probably important with respect to the extent of the exothermic reaction, and its fast onset. This behavior in the small samples, used in the DSC tests, may be indicative of more aggressive behavior in larger scale samples.

Onset temperatures for initiation of weight loss in the TGA tests are at $220^{\circ}$ to $235^{\circ} \mathrm{C}$ for the mixtures with the two oxidants. For the mixtures with the nitrate only, the onset temperatures are higher, and vary from $235^{\circ}$ to $263^{\circ} \mathrm{C}$ for the mixtures without diluent.

\section{Polyethylene and Polyethylene Mixtures}

The polyethylene powder and the mixtures of polyethylene with sodium nitrate and with the nitrate-nitrite combination were tested in the DSC at a heating rate of $10^{\circ} \mathrm{C} / \mathrm{min}$ in flowing air. Some tests were also conducted at $5^{\circ} \mathrm{C} / \mathrm{min}$ in air, while a few of the samples were heated in nitrogen. Calibrations with indium and zinc were done prior to the tests.

DSC thermograms obtained for polyethylene in flowing air are shown in figures 69 and 70 for heating rates of $5^{\circ}$ and $10^{\circ} \mathrm{C} / \mathrm{min}$, while a thermogram obtained in flowing nitrogen at $10^{\circ} \mathrm{C} / \mathrm{min}$ is presented in figure 71 . All three thermograms show an extended melting endotherm which ranges from approximately $55^{\circ}$ to $115^{\circ} \mathrm{C}$ in figure 69 , and from about $70^{\circ}$ to $115^{\circ} \mathrm{C}$ in figure 71 . Polyolefines are partially crystalline polymers containing crystallites surrounded by amorphous regions. This endotherm indicates the amount of energy needed to transform the sample to a completely amorphous state, which will depend on the type of polyethylene and its mode of preparation. This transformation is often referred to as fusion. The polyethylene then undergoes an exothermic decomposition in air, beginning near $200^{\circ} \mathrm{C}$, and depending on the heating rate and on sample size, an ignition-type behavior is seen at $400 \pm 10^{\circ} \mathrm{C}$. An ignition temperature for polyethylene, measured in a specially designed laboratory furnace, is given as $430^{\circ} \mathrm{C}(28)$, although lower ignition temperatures, of about $400^{\circ} \mathrm{C}$, have al so been cited (29). Ignition temperature, just like the fusion temperature and fusion energy. is a function of the type of polyethylene. All the sample was consumed in these tests. In nitrogen, the polyethylene undergoes endothermic pyrolysis which is observed at a much higher temperature than for the onset of oxidative decomposition.

The polyethylene-sodium nitrate mixture, 15A, (1:1) was heated in flowing air at $10^{\circ} \mathrm{C} / \mathrm{min}$. The resulting thermogram is seen in figure 72 ; it contains two endotherms, for the fusion of polyethylene and the nitrate, respectively, as well as three exotherms, and the beginning of a fourth one at $480^{\circ} \mathrm{C}$. A scaled version of figure 72 is given in figure $72 A$. The thermograms for the other three mixtures, 15B (1:3), 15C (1:3; diluent) and 15D (1:10) are shown in figures 73 to 75 . They are similar in their features to those in figure 72. The amount of polyethylene used to prepare its mixtures is proportionally the smallest of the four fuels tested. In mixture 150, polyethylene constitutes 1.4 pct by weight, and yet its decomposition process is quite visible in figure 75 . The presence of the sodium nitrate in the four 
WHC-MR-0455

mixtures, and the energy required for its two endothermic phase changes, amidst the exothermic decomposition of the polyethylene, result in competing processes. It is seen in the thermograms where the two endotherms are superimposed on the middle exotherm, and, in all probability, are responsible for the disruption of the first exotherm seen in figure 70 (due to the decomposition of polyethylene) into the two exotherms seen in figure 72 . For a better comparison, figure $72 \mathrm{~A}$ is an optimized version of figure 72 , scaled down to the same scale as figure 70 . Polyethylene constitutes only 12 pct by weight of the mixture; thus, the relatively small size of the exotherms in the thermograms for the mixtures is not surprising. The onset temperatures for exothermic behavior for the four mixtures are all well below the melting temperature of the nitrate, so that, in general, the presence of the solid sodium nitrate does not interfere with the initiation of polyethylene degradation. It is possible that once the nitrate melts, some reaction does take place between it and the polyethylene, but owing to the shape of the thermogram such a reaction can not be easily identified. Results are presented in table 22, and the range for onset temperatures for the mixtures without the diluent is between $200^{\circ}$ and $211^{\circ} \mathrm{C}$; it is somewhat higher for the pure polyethylene, but it is much higher for the mixtures containing the diluent, although indications for possible onsets were noted at lower temperatures (between $235^{\circ}$ and $250^{\circ} \mathrm{C}$ ), for the $15 \mathrm{C}$ mixtures. Only one test was conducted in nitrogen, because of the endothermic nature of polyethylene pyrolysis. In the presence of sodium nitrate, a very shallow and wide exotherm was noted, starting at $392^{\circ} \mathrm{C}$, as delineated in table 22 , for sample 15B-3.

The mixtures of polyethylene with the nitrate-nitrite combination were also tested in the DSC. In these mixtures, the endotherm for the eutectic melt occurs, as always, at a lower temperature than the fusion temperature of sodium nitrate. The thermogram for mixture $16 \mathrm{~A}(1: 1)$, in figure 76 , has a small exotherm, starting at $199^{\circ} \mathrm{C}$. It is followed by the eutectic endotherm, which in turn is followed by a gently downward sloping baseline $\left(230^{\circ}\right.$ to $-350^{\circ} \mathrm{C}$ ), and by a more pronounced exotherm that extends from $350^{\circ}$ to $480^{\circ} \mathrm{C}$. A similar thermogram, in figure 77 , is for mixture $16 \mathrm{~B}(1: 3)$. It contains the initial exotherm, with onset at $192^{\circ} \mathrm{C}$, between the solid phase change of sodium nitrite and the fusion endotherm for the eutectic, with the latter being followed directly by the larger exotherm, starting at $240^{\circ} \mathrm{C}$. This exotherm and the respective one in figure 76 , contain a multiplicity of small peaks, superimposed on the main curve. The thermogram for the mixture with the diluent, 16C $(1: 3$; dil), in figure 78 , contains additional events, which at times confuse the issue. Onset of exothermic behavior is at $205^{\circ} \mathrm{C}$. The endothermic fusion is taking place at a higher temperature in this mixture, containing the nitrate, nitrite and aluminate. The final DSC thermogram for this fuel set, for the mixture $160(1: 10)$, shown in figure 79 , shows two calculations, one for onset temperature and one for peak temperature. The calculated, extrapolated onset temperature for the first exotherm is $199^{\circ} \mathrm{C}$, whereas the onset temperature, as determined by first deviation from the baseline, is at $171^{\circ} \mathrm{C}$, coinciding with the value of $x_{1}$, seen in the calculation. Similarly, the onset temperature of the second exotherm is at $241^{\circ} \mathrm{C}$, as shown again by the $X_{1}$ value. The results for the mixtures $16 A$ to 160 are detailed in table 23. Onset temperatures for these mixtures cluster at about 
WHC-MR-0455

$200^{\circ} \mathrm{C}$, and are lower by about $10^{\circ} \mathrm{C}$ from the onset temperatures for the mixtures with the sodium nitrate. All the mixtures start to decompose exothermally in air well before the melting of the nitrate or of the nitratenitrite eutectic takes place.

Table 22. - DSC thermal analysis results for the polyethylene and polyethylene-nitrate mixtures

\begin{tabular}{|c|c|c|c|c|}
\hline Sample & $\begin{array}{c}\text { Mixture } \\
\text { ratio }\end{array}$ & $\begin{array}{c}\text { Heating } \\
\text { rate, } \\
\text { 'c/min }\end{array}$ & $\begin{array}{c}\text { Atmosphere, } \\
\text { dynamic }\end{array}$ & $\begin{array}{c}\text { Exotherm } \\
\text { onset } \\
\text { temperature, } \\
\text { 'C }\end{array}$ \\
\hline $5 A-1$ & \multirow{3}{*}{ - } & 10 & air & 215 \\
\hline $5 A-2$ & & 5 & $"$ & 230 \\
\hline $5 A-3$ & & 10 & $\mathrm{~N}_{2}$ & 393 \\
\hline $15 A-1$ & \multirow{2}{*}{$1: 1$} & 10 & air & 203 \\
\hline $15 A-2$ & & 10 & $"$ & 202 \\
\hline $15 B-1$ & \multirow{3}{*}{$1: 3$} & 10 & $"$ & 209 \\
\hline $15 B-2$ & & 10 & $"$ & 209 \\
\hline $15 B-3$ & & 10 & $\mathrm{~N}_{2}$ & 392 \\
\hline $15 C-1$ & \multirow{2}{*}{$\begin{array}{l}1: 3 \\
(\mathrm{di} i)\end{array}$} & 10 & air & 272 \\
\hline $15 C-2$ & & 10 & $"$ & 272 \\
\hline $15 D-1$ & \multirow[t]{2}{*}{$1: 10$} & 10 & $"$ & 211 \\
\hline $150-2$ & & 10 & $"$ & 211 \\
\hline
\end{tabular}

'Based on initial deviation of the main decomposition step from the baseline. 
Table 23. - DSC thermal analysis results for the polyethylenenitrate-nitrite mixtures ${ }^{1}$

\begin{tabular}{|c|c|c|}
\hline Sample & $\begin{array}{c}\text { Mixture } \\
\text { ratio }\end{array}$ & $\begin{array}{c}\text { Exotherm } \\
\text { onset } \\
\text { temperature, } \\
\text { 'C } \\
\end{array}$ \\
\hline $16 A-1$ & \multirow[t]{3}{*}{$1: 1$} & 199 \\
\hline $16 A-2$ & & 196 \\
\hline $16 \mathrm{~A}-3$ & & 198 \\
\hline $168-1$ & \multirow[t]{2}{*}{$1: 3$} & 192 \\
\hline $16 \mathrm{~B}-2$ & & 199 \\
\hline $16 C-1$ & \multirow{2}{*}{$\begin{array}{l}1: 3 \\
(d i i)\end{array}$} & 205 \\
\hline $16 C-2$ & & 202 \\
\hline $160-1$ & \multirow[t]{2}{*}{$1: 10$} & 171 \\
\hline $160-2$ & & 197 \\
\hline
\end{tabular}

'All the tests were conducted at a heating rate of $10^{\circ} \mathrm{C} / \mathrm{min}$, in a flow of air.

${ }^{2}$ Based on initial deviation of the main decomposition step from the baseline.

Polyethylene and its mixtures were tested in the TGA, all in a flowing air atmosphere. Results for tests with polyethylene, at heating rates of $5^{\circ}$ and $10^{\circ} \mathrm{C} / \mathrm{min}$ are shown in figures 80 and 81 , together with the derivative curves. Interestingly, in both figures a small weight gain is seen in the thermograms just prior to decomposition. It is more clearly evident in the derivative curves, at about $215^{\circ}$ and $225^{\circ} \mathrm{C}$. Following this, decomposition begins and continues in various phases. A sharp change takes place at $400^{\circ} \mathrm{C}$, in agreement with the results from the DSC tests. Both samples were completely consumed, also in agreement with results from the DSC tests. Thermograms for the mixtures $15 \mathrm{~A}(1: 1)$ to $150(1: 10)$ appear in figures 82 to 85 . Figures 82 , 83 , and 85 show the same weight gain seen for the polyethylene by itself, at the vicinity of $200^{\circ} \mathrm{C}$, or at somewhat higher temperatures. It may be due to adsorption of oxygen. Immediately following the small amount of weight gain, decomposition begins. Onset temperatures for initiation of decomposition for these three mixtures range between $215^{\circ}$ and $220^{\circ} \mathrm{C}$. A different behavior was noted for the mixture with diluent, 15C, which began iosing weight from the start of the test. Upon reaching $200^{\circ} \mathrm{C}$, the mixture remained at a plateau, without loss of weight, until it attained the temperature of $260^{\circ} \mathrm{C}$, when 
weight loss resumed. The TGA thermograms for the $16 \mathrm{C}$ mixtures show that the sodium aluminate influences the decomposition process in a variety of ways, as a difluent as well as a reactant.

The sharp change seen at $400^{\circ} \mathrm{C}$ in the thermograms for the pure polyethylene is not prominent, or present, in the thermograms for the mixtures. Results for polyethylene and the mixtures are given in table 24. They include weight loss values which are quite reproducible for the individual mixtures.

Table 24. - TGA thermal analysis results for the polyethylene and polyethylene-nitrate mixtures'

\begin{tabular}{|c|c|c|c|c|}
\hline Sample & $\begin{array}{c}\text { Mixture } \\
\text { ratio } \\
\end{array}$ & $\begin{array}{l}\text { Heating } \\
\text { rate, } \\
{ }^{\circ} \mathrm{C} / \mathrm{min} \\
\end{array}$ & $\begin{array}{c}\text { Exothermic } \\
\text { onset } \\
\text { temperature, } \\
\text { 'C } \\
\end{array}$ & $\begin{array}{c}\text { Weight } \\
\text { loss, } \\
\text { pct }\end{array}$ \\
\hline $5 A-1$ & \multirow{3}{*}{ - } & 10 & 191 & 100 \\
\hline $5 A-2$ & & 10 & 225 & 100 \\
\hline $5 A-3$ & & 5 & 215 & 97.0 \\
\hline $15 A-1$ & \multirow[t]{2}{*}{$1: 1$} & 10 & 220 & 23.9 \\
\hline $15 A-2$ & & 10 & 215 & 24.7 \\
\hline $15 B-1$ & \multirow[t]{2}{*}{$1: 3$} & 10 & 221 & 8.5 \\
\hline $15 B-2$ & & 5 & 213 & 8.4 \\
\hline $15 C-1$ & \multirow{2}{*}{$\begin{array}{c}1: 3 \\
\text { (dil) }\end{array}$} & 10 & $235-270^{3}$ & 7.6 \\
\hline $15 C-2$ & & 5 & $230-250^{3}$ & 7.4 \\
\hline $150-1$ & \multirow[t]{2}{*}{$1: 10$} & 10 & 221 & 2.8 \\
\hline $150-2$ & & 5 & 208 & 3.0 \\
\hline
\end{tabular}

'All the tests were conducted in a flow of air.

${ }^{2}$ Based on initial deviation of the main decomposition step from the baseline.

${ }^{3}$ Difficult to determine accurately because of the presence of the aluminate. 
The weight pct of polyethylene in the mixtures and the average weight loss values observed were:

\begin{tabular}{|c|c|c|}
\hline Mixture & $\begin{array}{l}\text { Weight } \\
\text { pet }\end{array}$ & $\begin{array}{c}\text { Average weight } \\
\text { - loss_ oct }\end{array}$ \\
\hline $15 A$ & 12.07 & 24.7 \\
\hline $15 B$ & 4.38 & 8.5 \\
\hline $15 C$ & 2.19 & 7.5 \\
\hline 150 & 1.35 & 2.9 \\
\hline
\end{tabular}

Weight losses from the mixtures are double the amount of polyethylene in the mixtures, and therefore, must result as least in part, from changes in the nitrate. Increased weight loss is seen in the presence of aluminate.

Results from TGA tests with the polyethylene mixtures containing the nitratenitrite combination are presented in figures 86 to 89 for mixtures $16 \mathrm{~A}(1: 1)$ to 16D $(1: 10)$. Decomposition is undergone in two main steps. The slight weight gain just prior to onset of decomposition is visible in figures 86 and 87. Results are summarized in table 25.

Table 25. - TGA thermal analysis results for the polyethylene-nitrate-nitrite mixtures

\begin{tabular}{|c|c|c|c|c|}
\hline Sample & $\begin{array}{c}\text { Mixture } \\
\text { ratio } \\
\end{array}$ & $\begin{array}{c}\text { Heating } \\
\text { rate, } \\
\cdot \mathrm{C} / \mathrm{min} \\
\end{array}$ & $\begin{array}{c}\text { Exothermic } \\
\text { onset } \\
\text { temperature, } \\
\text { 'C } \\
\end{array}$ & $\begin{array}{c}\text { Weight } \\
\text { loss, } \\
\text { pet }\end{array}$ \\
\hline $16 A-1$ & \multirow{2}{*}{$1: 1$} & 10 & 217 & 24.1 \\
\hline $16 A-2$ & & 20 & 228 & 23.2 \\
\hline $16 \mathrm{~B}-1$ & \multirow{2}{*}{$1: 3$} & 10 & 220 & 10.5 \\
\hline $16 \mathrm{~B}-2$ & & 10 & 217 & 9.3 \\
\hline $16 C-1$ & \multirow{3}{*}{$\begin{array}{l}1: 3 \\
(d i 1)\end{array}$} & 10 & 246 & 6.7 \\
\hline $16 C-2$ & & 10 & 267 & 8.3 \\
\hline $16 C-3$ & & 5 & 284 & 9.1 \\
\hline $160-1$ & \multirow[t]{2}{*}{$1: 10$} & 10 & 214 & 9.1 \\
\hline $160-2$ & & 20 & 224 & 4.5 \\
\hline
\end{tabular}

'All the tests were conducted in a flow of air.

${ }^{2}$ Based on initial deviation of the main decomposition step from the baseline. 
Reproducibllity of results is adequate for these three- and four-compound mixtures with the amount of polyethylene being even smaller than for the mixtures with nitrate. Weight pet of polyethylene in the mixtures with the combination of oxidants and the average weight loss were:

\begin{tabular}{|c|c|c|}
\hline Mixture & $\begin{array}{l}\text { Weight, } \\
\text { Det }\end{array}$ & $\begin{array}{c}\text { Average weight } \\
\text { loss, oct }\end{array}$ \\
\hline $16 \mathrm{~A}$ & 10.81 & 23.6 \\
\hline $16 \mathrm{~B}$ & 3.88 & 9.8 \\
\hline $16 C$ & 1.94 & 8.0 \\
\hline 160 & 1.20 & 6.7 \\
\hline
\end{tabular}

Weight loss for these mixtures is more than double the amount of polyethylene in the mixtures, once again indicating that the nitrate-nitrite mixture is more reactive than the nitrate alone. Likewise, the results show that losses in weight must result in part, from changes in the oxidants.

Polyethylene decomposes mostly by a random-chain scission type mechanism involving free-radical reactions. Under thermooxidative conditions, oxygenated free radicals take part in the reactions. Carbon monoxide and carbon dioxide are the main decomposition products, but included in the products are various hydrocarbons and oxygenated organic compounds (29).

\section{FeCN Sample (a mixture of five salts)}

Samples of the dried powder were tested in the DSC, at various heating rates, in flowing air. A test in a flow of nitrogen was also done. Thermograms of tests at heating rates of $10^{\circ}$ and $30^{\circ} \mathrm{C} / \mathrm{min}$, in flowing air, are shown in figures 90 and 91 . In figure 90 we see two small endotherms followed by two exotherms. In figure 91, there is a small amount of moisture loss at about $120^{\circ} \mathrm{C}$. Two endotherms and two exotherms are al so seen, as in figure 90; however, both exotherms are split and each contains two peaks. A thermogram for a test in nitrogen, at $20^{\circ} \mathrm{C} / \mathrm{min}$, is presented in figure 92 ; it is very similar to figure 91 , including the split exotherms. A sample of the original paste was also tested in flowing air, at $10^{\circ} \mathrm{C} / \mathrm{min}$, and the resultant thermogram is shown in figure 93 . Aside from the loss of moisture, this thermogram contains the same features as observed in figure 90 , and the exotherms are single-peaked. Finally, a very small sample of the white crystals, which initially appeared on the paste as it was being dried, was collected and tested in air at $10^{\circ} \mathrm{C} / \mathrm{min}$. The resultant thermogram is shown in figure 94, and an optimized and scaled view of the two endotherms is presented in figure 95. The results for the tests are summarized in table 26. White crystals formed on the surface of the paste soon after it was placed in the oven to dry. After the paste was dried, it was finely ground and well mixed to homogenize it. Yet, the endothermic peaks seen in figures 94 and 95 , are also observed in all the other thermograms, including the thermogram in figure 93, for the paste sample, indicating preferential crystallization. 
Table 26. - DSC thermal analysis results for the FeCN sample

\begin{tabular}{|c|c|c|c|c|c|c|c|c|c|c|c|c|}
\hline \multirow[b]{4}{*}{ Sample } & \multirow{4}{*}{$\begin{array}{c}\text { Sample } \\
\text { weight. } \\
\text { mg } \\
\end{array}$} & \multirow[b]{4}{*}{$\begin{array}{c}\text { Almosphero. } \\
\text { dynamic }\end{array}$} & \multirow{4}{*}{$\begin{array}{l}\text { Hoating } \\
\text { rate. } \\
{ }^{\circ} \mathrm{C} / \mathrm{min} \\
\end{array}$} & \multicolumn{2}{|c|}{ Endothorms } & \multicolumn{7}{|c|}{ Exotherms } \\
\hline & & & & \multirow{3}{*}{$\begin{array}{c}\text { Peak of } \\
\text { first } \\
\text { endotherm. } \\
{ }^{\circ} \mathrm{C} \\
\end{array}$} & \multirow{3}{*}{$\begin{array}{l}\text { Peak of } \\
\text { socond } \\
\text { ondotherm. } \\
{ }^{\circ} \mathrm{C}\end{array}$} & & & & & & & \\
\hline & & & & & & \multicolumn{3}{|c|}{ First exotherm } & \multicolumn{3}{|c|}{ Second exotherm } & \multirow{2}{*}{$\begin{array}{c}\text { Combined } \\
\text { energy. } \\
\mathrm{J} / \mathrm{g}\end{array}$} \\
\hline & & & & & & $\begin{array}{c}\text { onset.' } \\
\circ \mathrm{C} \\
\end{array}$ & $\begin{array}{l}\text { peak. } \\
{ }^{\circ} \mathrm{C} \\
\end{array}$ & $\begin{array}{c}\text { onergy. } \\
\mathrm{J} / \mathrm{g} \\
\end{array}$ & $\begin{array}{c}\text { onset,' } \\
\circ \mathrm{C} \\
\end{array}$ & $\begin{array}{c}\text { paak. } \\
\cdot \mathrm{C} \\
\end{array}$ & $\begin{array}{c}\text { energy. } \\
\mathrm{J} / \mathrm{g}\end{array}$ & \\
\hline $\begin{array}{l}\text { 17A-1. } \\
\text { pasto }\end{array}$ & 11.87 & Air & 10 & 226 & 275 & 353 & 370 & -418 & 397 & 430 & 306 & $\begin{array}{c}-724 \text { (moist) } \\
-1,321 \text { (d)y } \\
\text { besis) }\end{array}$ \\
\hline $\begin{array}{r}17 \mathrm{~A}-2 . \\
\text { dried } \\
\end{array}$ & 4.04 & Air & 10 & 222 & 276 & 351 & 373 & -648 & 397 & 426 & -416 & $-1,064$ \\
\hline $\begin{array}{l}17 A-4 . \\
\text { dried }\end{array}$ & 3.96 & Air & 10 & 222 & 275 & 354 & 372 & -679 & 398 & 432 & -300 & $-1,058$ \\
\hline $\begin{array}{l}17 \mathrm{~A} \cdot 3 \\
\text { dried }\end{array}$ & 690 & Air & 30 & 225 & 278 & 370 & 393 & -446 & 420 & 461 & -618 & $-1,063$ \\
\hline $\begin{array}{l}17 \mathrm{~A}-5 \\
\text { dried }\end{array}$ & 9.77 & $\mathbf{N}_{2}$ & 20 & 223 & 278 & 362 & 384 & -432 & 410 & 457 & -482 & -914 \\
\hline $\begin{array}{l}\text { 17A-6. } \\
\text { while } \\
\text { crystals }\end{array}$ & 5.06 & Air & 10 & 223 & 286 & - & - & - & - & - & - & - \\
\hline
\end{tabular}

'Based on initial deviation of the decomposition step from baseline. 


\section{WHC-MR-0455}

These two endotherms are either due to the melting of the sodium nitratesodium nitrite eutectic followed by the melting of remaining sodium nitrite or to the loss of water of hydration by one or two of the other salts, such as the sodium sulfate and sodium phosphate. The presence of the various salts in the FeCN sample will influence the melting temperature, and usually lowers it. Also, in such a case, the endotherm is not a sharp peak, as it is when a pure material melts. The possibility also exists for melting of other combinations of the various salts, or even for their endothermic interaction. To clearly identify the source of these endotherms, various binary, ternary and quaternary mixtures of all the individual ingredients, and the individual ingredients themselves have to be evaluated in the DSC. However, since the main concern in this program is with the exothermic behavior, the endothermic processes are of less interest. The temperatures of the peaks of the two endotherms are very reproducible for all the sampl $=3$ tested. Good agreement is also found for the onset and peak temperatures of the two exotherms, especially for the tests conducted at the heating rate of $10^{\circ} \mathrm{C} / \mathrm{min}$. When the heating rate is increased, onset and peak temperatures for exotherms are usually shifted to somewhat higher temperatures, due to the response time of the instrument. For the tests at $10^{\circ} \mathrm{C} / \mathrm{min}$, onset temperature for exothermic behavior is at $350^{\circ} \mathrm{C}$; and it is at $360^{\circ}$ and $370^{\circ} \mathrm{C}$ for the higher heating rates of $20^{\circ}$ and $30^{\circ} \mathrm{C} / \mathrm{min}$, respectively.

The amount of energy released in the overall exothermic process undergone by the sample, which includes both exotherms, is of concer Excellent agreement was found for the $\Delta H$ values for the three tests in air, with the average energy release being $1,065 \mathrm{~J} / \mathrm{g}$ or $1 \mathrm{MJ} / \mathrm{kg}$. For the test in nitrogen the amount of energy released was slightly smaller. For the paste, the amount of energy released, when calculated on a dry basis (weight loss during drying in the oven was $45.14 \mathrm{pct}$ ), was higher than $1,065 \mathrm{~J} / \mathrm{g}$. Drying of the paste is a very slow process. A crust forms on the surface and considerably slows down the evaporation of the water. It is highly probable that the sample was not completely dry when decomposition began in the DSC test. Hence, the real amount of energy released (for the paste) is between the values of 724 and $1,323 \mathrm{~J} / \mathrm{g}$, given in table 26 .

The value of $1 \mathrm{MJ} / \mathrm{kg}$ is lower than the value of $4 \mathrm{MJ} / \mathrm{kg}$ reported by Fauske and Associates, Inc. But we believe (based on a phone conversation with $\mathrm{Mr}$. H. Fauske) that their reported value was obtained for the ferrocyanide compound itself, which comprises 24.9 pct by weight of the FeCN sample.

The FeCN sample was tested in the TGA, in flowing air, at heating rates of $5^{\circ}$, $10^{\circ}$, and $20^{\circ} \mathrm{C} / \mathrm{min}$, with respective thermograms shown in figures 96 to 98 . The three thermograms have similar features, which include a downward sloping first portion followed by two main steps of weight loss, with the second step itself being a combination of two or more modes of dissociation, as seen in figures 97 and 98 . As with the DSC results, here too, the onset temperature of the second step of weight loss, which represents the exothermic phase, is shifted to higher temperatures with increased heating rate. The main points of the thermograms are summarized in table 27, with onset temperatures for exothermic decomposition ranging between $330^{\circ}$ and $360^{\circ} \mathrm{C}$. The weight loss, of the order of 4.0 to $4.6 \mathrm{pct}$, in the down-sloping portion indicates the loss of remaining moisture not completely removed in the drying process. The first 
step of weight loss, of the order of 4.3 to 4.7 pct, following the sloping portion, could be due to the loss of water of hydration, mentioned earlier. Sodium sulfate can contain either seven or ten molecules of water of hydration $\left(\mathrm{Na}_{2} \mathrm{SO}_{4} \cdot 7 \mathrm{H}_{2} \mathrm{O}\right.$ or $\mathrm{Na}_{2} \mathrm{SO}_{4} \cdot 1 \mathrm{H}_{2} \mathrm{O}$; the decahydrate sodium sulfate loses its water at around $100^{\circ} \mathrm{C}$ ). Various sodium phosphates are known which contain large amounts of water of hydration. A few of them, which either lose the water or decompose (d.) at the same temperature range coinciding with the weight loss temperature range are the following (30):

$$
\begin{array}{ll}
\text { sodium phosphate monobasic, } \mathrm{NaH}_{2} \mathrm{PO}_{4} \cdot \mathrm{H}_{2} \mathrm{O}, & \text { d. } 200^{\circ} \mathrm{C} \\
\text { sodium phosphate dibasic, } \mathrm{Na}_{2} \mathrm{HPO}_{4} \cdot 12 \mathrm{H}_{2} \mathrm{O}, & -12 \mathrm{H}_{2} \mathrm{O}, 180^{\circ} \mathrm{C} \\
\text { sodium phosphate (pyrosodium), } \mathrm{Na}_{2} \mathrm{H}_{2} \mathrm{P}_{2} \mathrm{O}_{7}, & \text { d. } 220^{\circ} \mathrm{C}
\end{array}
$$

Other phosphates, for which a specific temperature is not cited in the handbook, are:

sodium phosphate dibasic, $\mathrm{Na}_{2} \mathrm{HPO}_{4} \cdot 7 \mathrm{H}_{2} \mathrm{O}$, which decomposes, and

sodium pyrophosphate, $\mathrm{Na}_{4} \mathrm{P}_{2} \mathrm{O}_{7} \cdot 1 \mathrm{OH}_{2} \mathrm{O}$.

The ferrocyanide compound also contains water of hydration. The temperature at which this water is lost is not known.

Onset of this step of weight loss in the three thermograms is at a lower temperature than the onset temperature for the first endotherm in the DSC thermograms. This is partly due to the differences between the two thermal analyzers, described previously. Onset temperatures for the second step of weight loss, due to the exothermic reactions, for the tests at $10^{\circ}$ and $20^{\circ} \mathrm{C} / \mathrm{min}$, are in close agreement with the temperatures found in the DSC tests at the same heating rates. Total weight loss may not exactly agree with the sum of the various weight losses, due to rounding up. It seems to be somewhat dependent on sample size and heating rate, but can also be due to experimental variations. Another feature of interest is the behavior observed during the second step of weight loss, close to its termination. A magnified, thermogram in figure 99 (correlating with figure 96), shows unusual behavior, with

falling temperatures rather than rising temperatures, just at the end of the weight loss period. This behavior was seen for the three samples but was most notable with the sample of greatest weight. The highly exothermic behavior increased the sample temperature at a rate greater than the programmed temperature rise, and the furnace shifted to a cooling mode for a short period.

The residues left in the sample pans at the end of the tests in the DSC were all brown. The residues left in the open platinum pan at the end of the TGA tests were all hard and shiny black in appearance. If any carbonate formed, it could not be detected visually. The ferrocyanide contains both iron and nickel. Iron oxide $\left(\mathrm{Fe}_{3} \mathrm{O}_{4}\right)$ is black; nickel oxide $\left(\mathrm{Ni}_{2} \mathrm{O}_{3}\right)$ is gray-black.

These two compounds may have formed during the decomposition. Phosphate glass formation will impart a shiny appearance to the residues. The total weight loss was 28 to 31 pct. 
Table 27. - TGA thermal analysis results for the FeCN sample

\begin{tabular}{|c|c|c|c|c|c|c|c|c|c|}
\hline \multirow[b]{2}{*}{ jample } & \multirow[b]{2}{*}{$\begin{array}{c}\text { Sample } \\
\text { we ight, } \\
\mathrm{mg} \\
\end{array}$} & \multirow[b]{2}{*}{$\begin{array}{l}\text { Heating } \\
\text { rate, } \\
\cdot \mathrm{C} / \mathrm{min} \\
\end{array}$} & \multirow{2}{*}{$\begin{array}{l}\text { Weight loss } \\
\text { in down- } \\
\text { sloping } \\
\text { portion, } \\
\text { pct } \\
\end{array}$} & \multicolumn{2}{|c|}{$\begin{array}{c}\text { First weight } \\
\text { loss step }\end{array}$} & \multirow{2}{*}{$\begin{array}{c}\text { Height loss } \\
\text { between } \\
\text { first and } \\
\text { second steps, } \\
\text { pct }\end{array}$} & \multicolumn{2}{|c|}{$\begin{array}{c}\text { Second weight } \\
\text { loss step }\end{array}$} & \multirow{2}{*}{$\begin{array}{c}\text { Total } \\
\text { weight } \\
\text { loss, } \\
\text { pct } \\
\end{array}$} \\
\hline & & & & $\begin{array}{c}\text { onset, } \\
\text { 'C } \\
\end{array}$ & $\begin{array}{c}\text { weight loss } \\
\text { during step, } \\
\text { pct }\end{array}$ & & $\begin{array}{c}\text { Onset, }{ }^{\prime} \\
\cdot C\end{array}$ & $\begin{array}{c}\text { Weight loss } \\
\text { during step, } \\
\text { pct }\end{array}$ & \\
\hline $17 \mathrm{~A}-2$ & 4.50 & 5 & 4.96 & 176 & 4.11 & 1.98 & 327 & 17.35 & 28.4 \\
\hline $17 A-1$ & 7.25 & 10 & 4.34 & 186 & 4.28 & 1.68 & 346 & 20.40 & 30.7 \\
\hline $17 \mathrm{~A}-3$ & 4.57 & 20 & 4.00 & 193 & 4.30 & 2.00 & 360 & 17.51 & 27.8 \\
\hline
\end{tabular}

sed on initial deviation of the decomposition step from the baseline. 


\section{WHC-MR-0455}

\section{BOMB CALORIMETER TESTS}

The object of these experiments was to determine the heat of reaction of the various test mixtures, to identify their reaction products, and to compare the experimental data with the stoichiometric reactions and equilibrium heats of reaction.

A model 1261 Isoperibol, microprocessor-controlled Parr bomb Calorimeter was used in conjunction with a $342 \mathrm{~cm}^{3}$ stainless steel combustion bomb having electrodes for fuse wire electrical ignition, a high pressure gas inlet and a needle valve vent. A water circulator, a water cooler, and a printer were auxiliary Parr equipment. Two liters $(1978.5 \pm .8 \mathrm{~g})$ of water at $31 \pm 1^{\circ} \mathrm{C}$ were placed in the calorimeter bucket containing the bomb, and the calorimeter jacket temperature was set at $35.00 \pm .05^{\circ} \mathrm{C}$. The energy equivalence of the calorimeter was found to be $2375 \pm 10 \mathrm{cal} /{ }^{\circ} \mathrm{C}$ for bomb/bucket No. 23167, and $2387 \pm 7 \mathrm{cal} /{ }^{\circ} \mathrm{C}$ for bomb/bucket No. 23190, based on 16 and 11 tests, respectively, of $1.000 \pm .006 \mathrm{~g}$ of benzoic acid pellets in $450 \mathrm{psig}$ of oxygen, using the standard nickel alloy fuse wire. The pellets were placed in heat-treated stainless steel capsules and only a slight staining (insignificant residue) was visible after the benzoic acid combustion.

The standard nickel alloy fuse wire is designed for use in high pressure oxygen. The electrical energy delivered will only cause the wire to glow. Excess oxygen is needed to produce the additional heat used to evaporate the wire. The hot atoms so produced can then activate the oxygen and produce efficient combustion. This wire was therefore ineffective in nitrogen or air or even in an atmosphere of oxygen in igniting the -100 mesh powders or the pellets of samples $13 A$ and $13 B$ of the sodium oxalate-sodium nitrate mixture, or of a powder sample of a mixture of 10 pct polyethylene in sodium nitrate. Even the use of a small amount of benzoic acid, of about $200 \mathrm{mg}$, or of polymethylmethacrylate pellets in contac with the fuse wire as combustion promoters, produced little change in the results for powdered samples of the oxalate-nitrate mixtures.

A special fuse wire ("Pyrofuze", made by Sigmund Cohn Corp.), was also used in some of the tests, for ignition in air or nitrogen. This wire consists of an aluminum core and a palladium sheath. When heated to $650^{\circ} \mathrm{C}$, the aluminum melts and intermetallic diffusion occurs, leading to the exothermic formation of an intermetallic compound, and the gernation of temperatures in excess of $2800^{\circ} \mathrm{C}$. This action is therefore independent of the atmosphere. One $\mathrm{g}$ mixtures of samples 13A, 13B, 14A, and 14B, and of 10 pct polyethylene in sodium nitrate were tested in nitrogen and in air using "Pyrofuze" ignition without any significant mass loss, appearance change, or formation of carbonate products. Mixtures of sample 13B, containing $1.00 \mathrm{~g}$ of the sodium oxalate component, were tested twice in a nitrogen atmosphere using the "Pyrofuze" ignitors, without significant mass change or production of sodium carbonate. Thus, electrical ignition in the Parr bomb calorimeter was ineffective in inducing the two fuel-nitrate mixtures to react.

In summary, the mixtures of sodium oxalate with sodium nitrate and of the oxalate with the equimolar sodium nitrate-sodium nitrite mixtures, (samples 
$13 \mathrm{~A}, 13 \mathrm{~B}, 14 \mathrm{~A}$, and 14B) and mixtures of $10 \mathrm{pct}$ polyethylene powder in sodium nitrate (near stoichiometric) could not be ignited in nitrogen or in air in the Parr bomb calorimeter, even with the special fuse wire whose performance is independent of the atmosphere.

\section{CONCLUSIONS}

A series of tests was conducted for Westinghouse Hanford Company on a full range of material compositions which were selected to represent the various constituents and compositions in the storage tanks. These tests evaluated the thermal characteristics and explosive nature of these compositions, which included combinations of four fuels with one or two oxidants, at various equivalence weight ratios. The fuels were sodium salts of oxalate, citrate and ethylenediamine tetraacetic acid (EDTA); polyethylene was the fourth fuel. The oxidants were sodium nitrate and sodium nitrite. Sodium aluminate was used as a diluent.

A battery of explosion and flammability tests was conducted to evaluate the friction and impact sensitivity, the internal ignition capability and the flame spread rates of the various mixtures. Negative results were found in all the tests, except for the flammability test with the citrate-nitrate mixture; thus, this mixture can be classified as a flammable solid.

In the thermal tests, using the differential scanning calorimeter and the thermogravimetric analyzer, the onset temperatures for initiation of exothermic behavior were determined for all the test mixtures. Onset temperatures as low as $200^{\circ} \mathrm{C}$ were found for: (1) the sodium citrate and its mixtures with the oxidant(s), and (2) the polyethylene and its mixtures with the oxidant $(s)$. Higher onset temperatures, which ranged from $240^{\circ}$ to $300^{\circ} \mathrm{C}$, were found for the sodium salt of EDTA and for its mixtures with the oxidant $(s)$. The highest onset temperatures, which varied between $355^{\circ}$ and $440^{\circ} \mathrm{C}$ for the DSC tests, and between $275^{\circ}$ and $420^{\circ} \mathrm{C}$ in the TGA tests, were recorded for the sodium oxalate mixtures with the oxidant(s). Thus, even for the oxalate mixtures, onset temperatures as low as $275^{\circ} \mathrm{C}$ were found when the two oxidants were present in excess.

A few tests were conducted in the bomb calorimeter to provide information about the chemistry of the thermal reactions. Specifically, information was sought about the enthalpy of the reactions, the nature of the residues and the composition of the evolved gases. However, these reactions could not be initiated in the bomb calorimeter with the test mixtures in an atmosphere of nitrogen or air.

Finally, a FeCN sample consisting of a mixture of salts, and provided by Hanford, was subjected to thermal tests and the modified Trauzle lead block test, the latter to assess the sample's explosive power. Results in the Trauzle test were negative. In the thermal tests, the onset temperature for exothermic behavior ranged from $330^{\circ}$ to $360^{\circ} \mathrm{C}$, in the $\mathrm{TGA}$, and from $350^{\circ}$ to $370^{\circ}$ in the DSC. 


\section{WHC-MR-0455}

It is important to note that predicting the thermal and kinetic behavior of large masses of reactants from results of small scale tests is difficult, owing to complex heat transfer processes, inhomogeneity of mixtures, and other complications such as interactions among the many components. 


\section{REFERENCES}

1. G.A. Beitel. Chemical Stability of Salt Cake in the Presence of Organic Materials. ARH-LD-119, Atlantic Richfield Hanford Co., Richland, WA, April, 1976.

2. F.D. Fisher. The Kyshtym Explosion and Explosion Hazards with NitrateNitrite Bearing Wastes with Acetates and Other Organic Salts.

WHC-SD-CP-LB-033. Rev. D, Westinghouse Hanford Company, August 1990.

3. U.S Congress, House, 1990. Safety Measures for Waste Tanks at Hanford Nuclear Reservation, Public Law 101-510, Section 3137, H.R. 4739, Government Printing Office, Washington, D.C.

4. H. Babad, J.C. Fulton, and C. Defigh-Price. A Strategy for Resolving High-Priority Hanford Site Radioactive Waste Storage Tank Safety Issues. WHC-SA-1661-FP, Westinghouse Hanford Company, 1993.

5. H.Babad, G.D. Johnson, D.A. Reynolds and D.M. Strachan. Understanding of Cyclic Venting Phenomena in Hanford Liquid Waste Tanks: The Evaluation of Tank 101-SY. WHC-SA-1364-FP, Presented at Waste Management 1991, Tucson, AZ, March 1-5, 1992.

6. H. Babad, R. Cash and A. Postma. Ferrocyanide Containing Tanks: Progress in Evaluation of Their Hazard. WHC-SA-1369-FP. Presented at Waste Management 1991, Tucson, AZ, March 1-5, 1992.

7. D.E. Simpson, R.P. Anantamula, G.M. Christensen, C.E. Leach and D.D. Stepnewski. Flammable Gas Savety Issue Review Tank 241-SY-101. WHC-EP-0578. Westinghouse Hanford Co., Richland, WA 99352, February, 1993.

8. W.I. Dixon and F.J. Massey. Introduction to Statistical Analysis. Third Edition, McGraw-Hill, 1969, pp. 373-393.

9. E.S. Freeman. The Kinetics of the Thermal Decomposition of Sodium Nitrate and of the Reaction Between Sodium Nitrite and Oxygen. J. Phys. Chem., v. 60, November 1956, pp. 1487-1493.

10. B.D. Bond and P.M.W. Jacobs. The Thermal Decomposition of Sodium Nitrate. J. Chem. Soc. (A), 1966, pp. 1265-1268.

11. T.M. Oza and B.R. Walawalkar. The Thermal Decomposition of Sodium and Potassium Nitrites. Part II. Action of Nitric Oxide, Oxygen and Nitrogen Peroxide on Fused Nitrites. J. Indian Chem. Soc., v. 22, 1945, pp. 243-249.

12. H.J.M. Bowen. Use of Sodium and Potassium Nitrates for Decomposing Organic Samples for Elementary Analysis. Analytical Chemistry, v. 40, No. 6, May 1968, pp. 969-970.

13. R.T. Morrison and R.N. Boyd. Organic Chemistry. Third Edition. 1973, Allyn and Bacon, Inc., pp. 583, 607. 


\section{REFERENCES -- Continued}

14. S.K. Patnaik and P.K. Maharana. Reaction Kinetics of Non-I sothermal Decomposition of Sodium Formate and Sodium Oxalate and the Effect of Gamma Radiation. Radiochem. Radioanal. Letters, v. 46, No. 5, 1981, pp. 271-284.

15. P.G. McCormick and H.S. Swofford, Jr. Electrochemical Oxidation of Nitrite and Oxide on Platinum Surfaces in Fused Potassium Nitrate-Sodium Nitrate Eutectic Melts at $250^{\circ}$ C. Analytical Chemistry. v. 41, No. 1 , January 1969, pp. 146-152.

16. A.A. El Hosary and A.M. Shams El Din. Kinetics of the Thermal Decomposition of Oxalate in Molten Alkali Nitrates. Jour. Of Electranal. Chem., v. 30, 1971, pp. 33-40.

17. A.G. Keenan and C.G. Fernandez. The Thermal Decomposition of Potassium Oxalate in Fused Nitrates. Jour. Electrochem. Soc. v. 12, No. 12, December 1973, pp. 1697-1698.

18. J.M. Schlegel and C.A. Pitak. The Oxidation of Oxalate Ion in Alkali Metal Nitrate Melts. J. Inorg. Nucl. Chem., v. 32, 1970, pp. 2088-2092.

19. E. Escrivá, A. Fuertes, J.V. Folgado, E. Martinez-Tamayo, A. Beltran-Porter and D. Beltran-Porter. Study of the Thermal Behavior of Ordered Bimetallic EDTA Complexes. Thermochim. Acta, v. 104, 1986, pp. 223-245.

20. T.R. Bhat and R.K. Iyer. Studies on EDTA Complexes-VIII Thermal Behavior in Air and in Nitrogen Atmosphere of Some Metal-EDTA Complexes. J. Inorg. Nucl. Chem., v. 29, 1967, pp. 179-185.

21. W.W. Wendlandt. Thermogravimetric and Differential Thermal Analysis of (Ethylenedinitrilo)tetraacetic Acid and Its Derivatives. Analytical Chemistry, v. 32, No. 7, June 1960, pp. 848-850.

22. A. Mercandante, M. Ionashiro, L.C.S. De 01iveira, C. A. Ribeiro and L. Moscardini D'Assuncão. Preparation and Thermal Decomposition of Solid State Lanthanide(III) and Yttrium(III) Chelates of Ethylenediaminetetraacetic Acid. Thermochim. Acta, v. 216, 1993, pp. 267-277.

23. A. Srivastava, P. Singh, V.G. Gunjikar and C.I. Jose. Thermal Decomposition of Barium Citrate. Thermochim Acta, v. 76, 1984, pp. 249-254.

24. J.I. DiCosimo and C.R. Apesteguia. Preparation of Ternary $\mathrm{Cu} / \mathrm{Co} / \mathrm{Al}$ Catalysts by the Amorphous Citrate Process. Journal of Catalysis, v. 116, 1989, pp. $71-81$.

25. P.L. Courty, H. Ajot and C.H. Marcilly. Oxydes Mixtes ou en Solution Solide sous Forme Trés Divisée Obtenus par Décomposition Thermique de Précursors Amorphes. Powder Technology, v. 7, 1973, pp. 21-38. 


\section{REFERENCES -- Continued}

26. I.R. Shannon. Hazards of Metal Oxide Preparation. Chemistry and Industry, January 30, 1971, p. 149.

27. T. Greweling. Explosion Hazard When Decomposing Organic Matter with Nitrates. Analytical Chemistry, v. 41, 1969, pp. 540-541.

28. T. Morimoto, T. Mori, and S. Enomoto. Ignition Properties of Polymers Evaluated from Ignition Temperature and Ignition Limiting 0xygen Index. Jour. of Applied Polymer Science, v. 22, 1978, pp. 1911-1918.

29. M. Paabo and B.C. Levin. A Literature Review of the Chemical Nature and Toxicity of the Decomposition Products of Polyethylenes. NBSIR 85-3268, January 1986, 63 pp.

30. Lange's Handbook of Chemistry, revised tenth edition, 1967. 
Curve 1: DSC

File info: indium_chk Mon Jan 4 14: 15: 091993

Sample Weight: $0.000 \mathrm{mg}$

indium

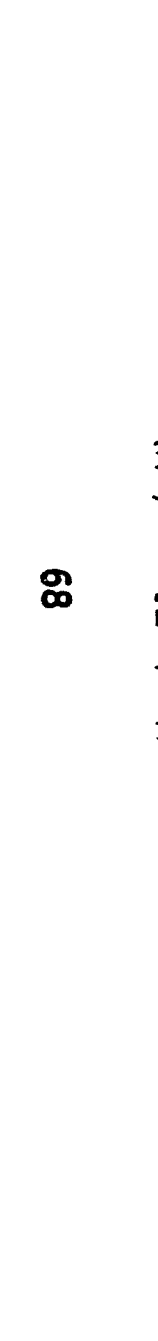

Heat flow (nW)

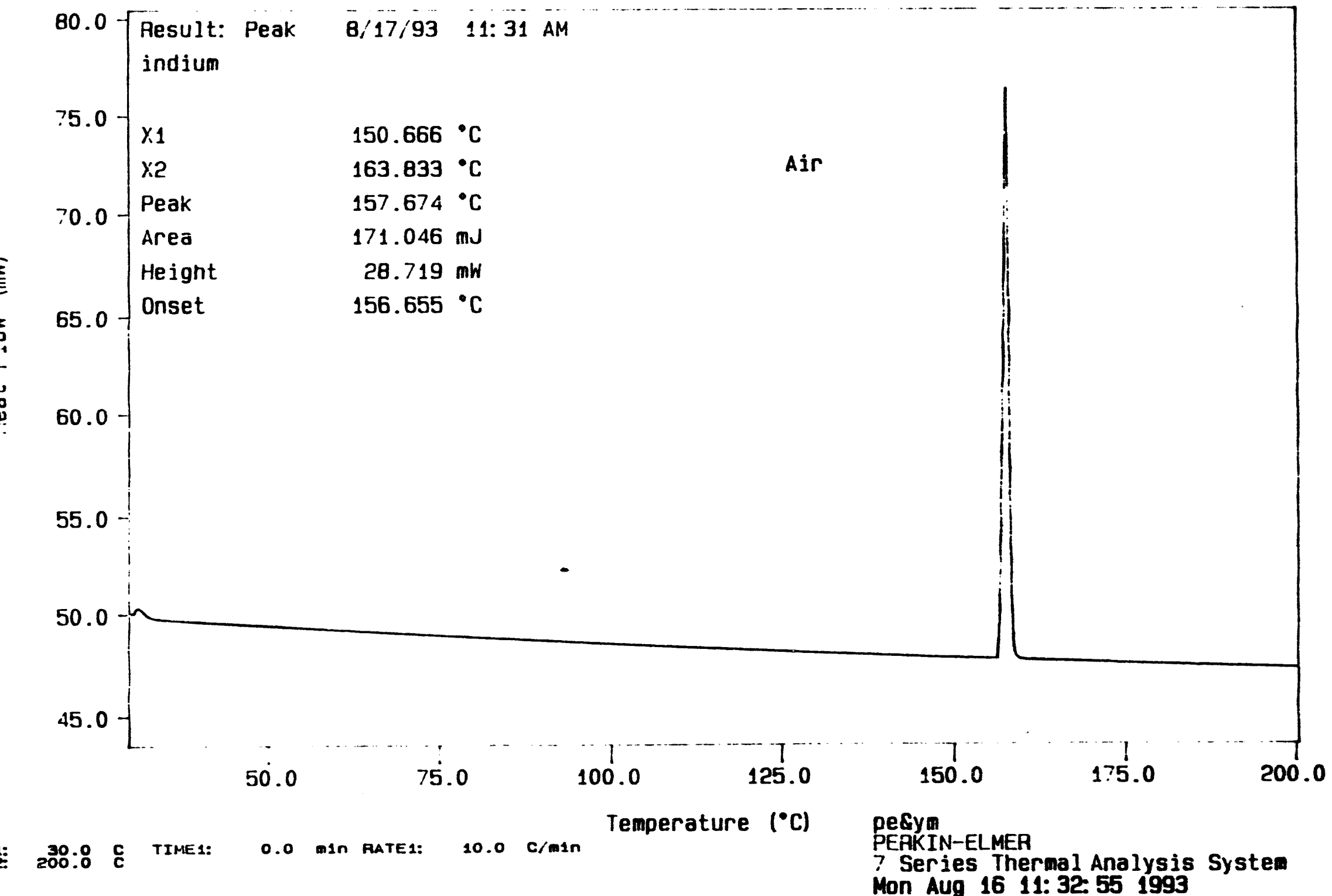

Figure 1. - DSC thermogram for indium 
Curve 1: DSC

File info: Zinc-chk4 Mon May 24 10: 14: 0? 1993

Sample Weight: $5.600 \mathrm{mg}$

Zinc Standard

\# 1 Zinc Standard

Heat Flow $(\mathrm{mW})$

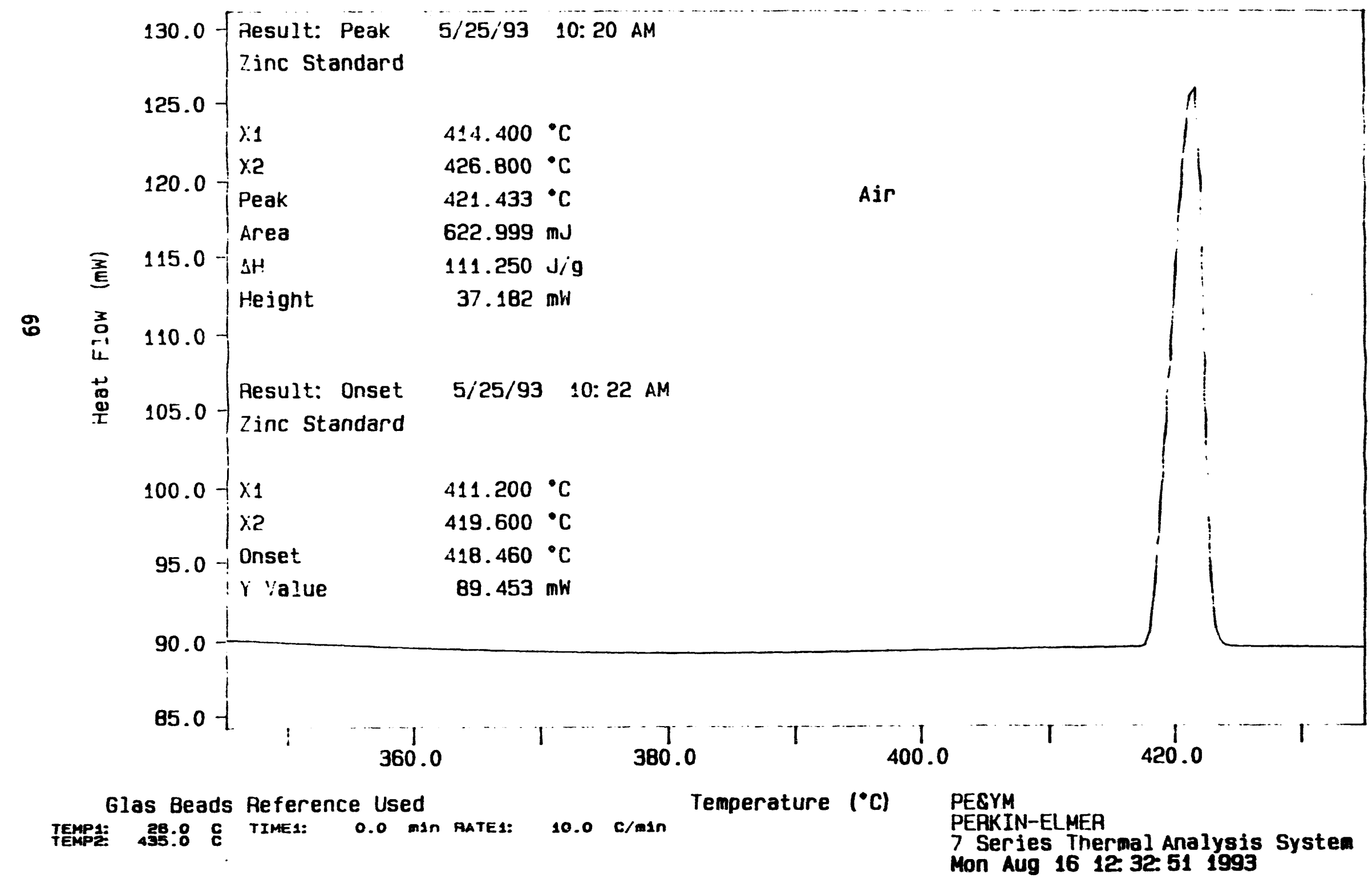

Figure 2. - DSC thermogram for zinc 
Curve 1: TGA

F1le info: N1PerkCk6 Thu Apr 29 15: $13: 541993$

Sample Height: 3.155

ag

N1 Perk Ck 6

- 1 NI Pork Ck 6

8 Waiont (it. 8 )

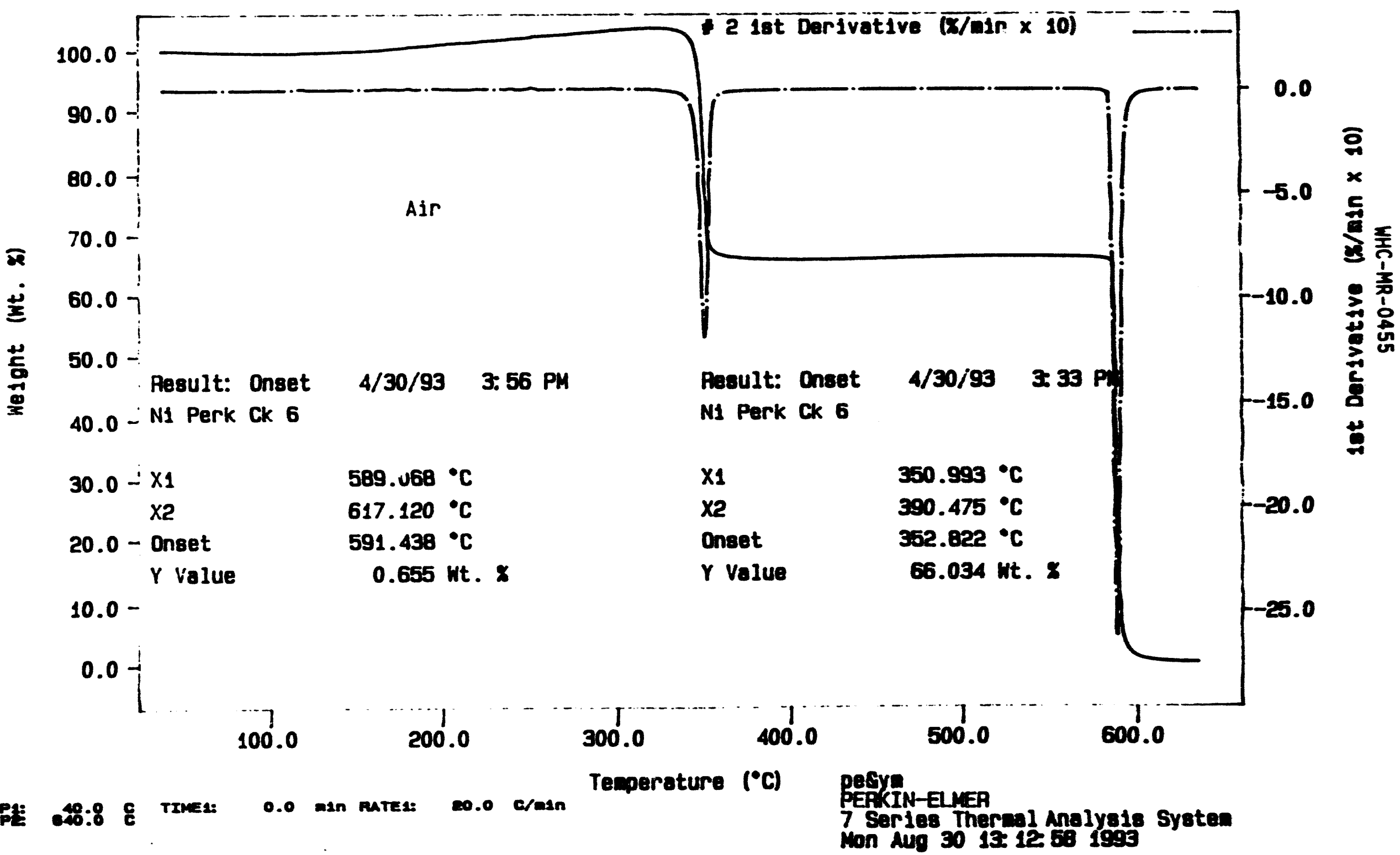

Figure 3. -, TGA calibration thermogram for nickel-perkatloy 
Curve 1: DSC

File info: s.nitrate1 Wed Dec 23 14: 33: 281992

Sample Weight: 2.000

sodium nitrate

mg

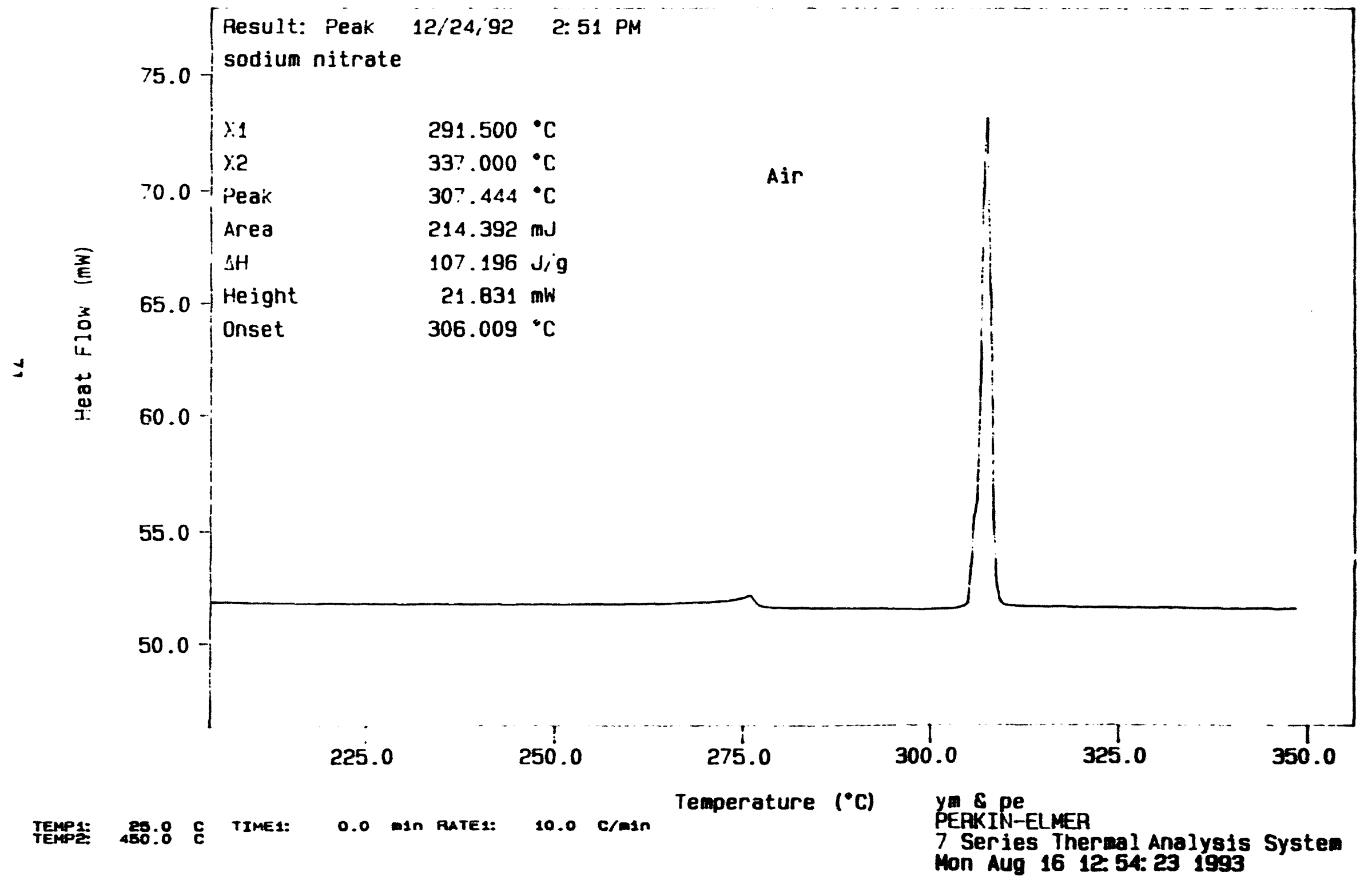

Figure 4. - DSC thermogram for sodium nitrate

* 1 sodiun nitrate Heat Flow (nW) 
Curve 1: DSC

File info: 18A-4

Fri Jun 4 12: 19: 401993

Sample Weight: 3.170

Na Nitrite 18A (4)

m

- 1 Na Nitrite 18A (4)

Hat flow (an)

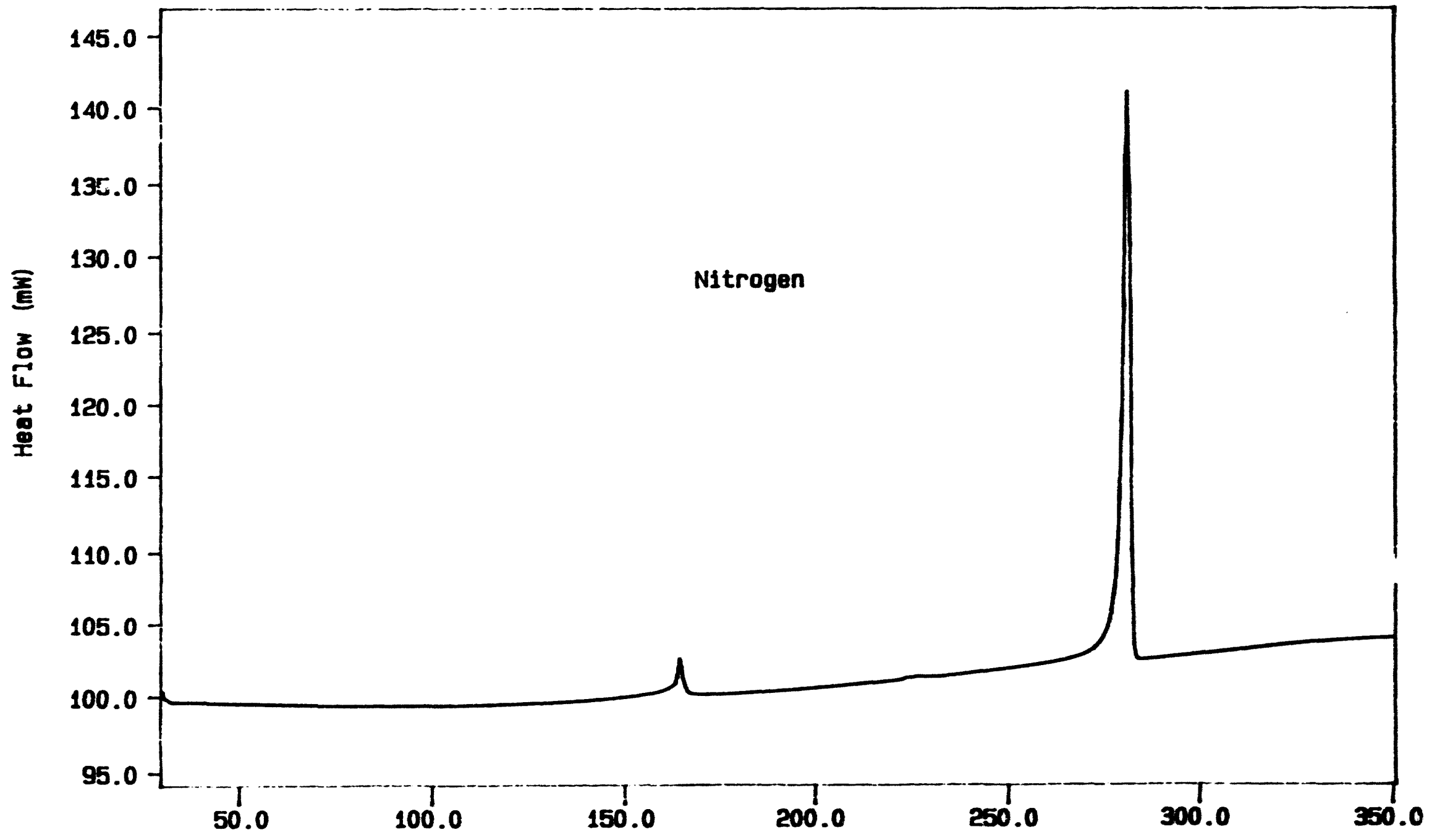

Glass Beads in Reference Text: $=0.8$

Temperature $\left({ }^{\circ} \mathrm{C}\right)$

YERTIN-ELVER

7 Serles Thernal Analyale Syaten mon Aug 23 og 3a 351993

Figure 5. - DSC thermogram for sodium nitrite 
Curve 1: DSC

File info: MIX.7A-5 Fri Jun 4 14:03:04 1993

Sample Weight: $5.670 \mathrm{mg}$

Na Nitrate-Na Nitrite $7 A$ (5)

- 1 Na Nitrate-Na Nitrite 7A (5) Heat Flow (min)

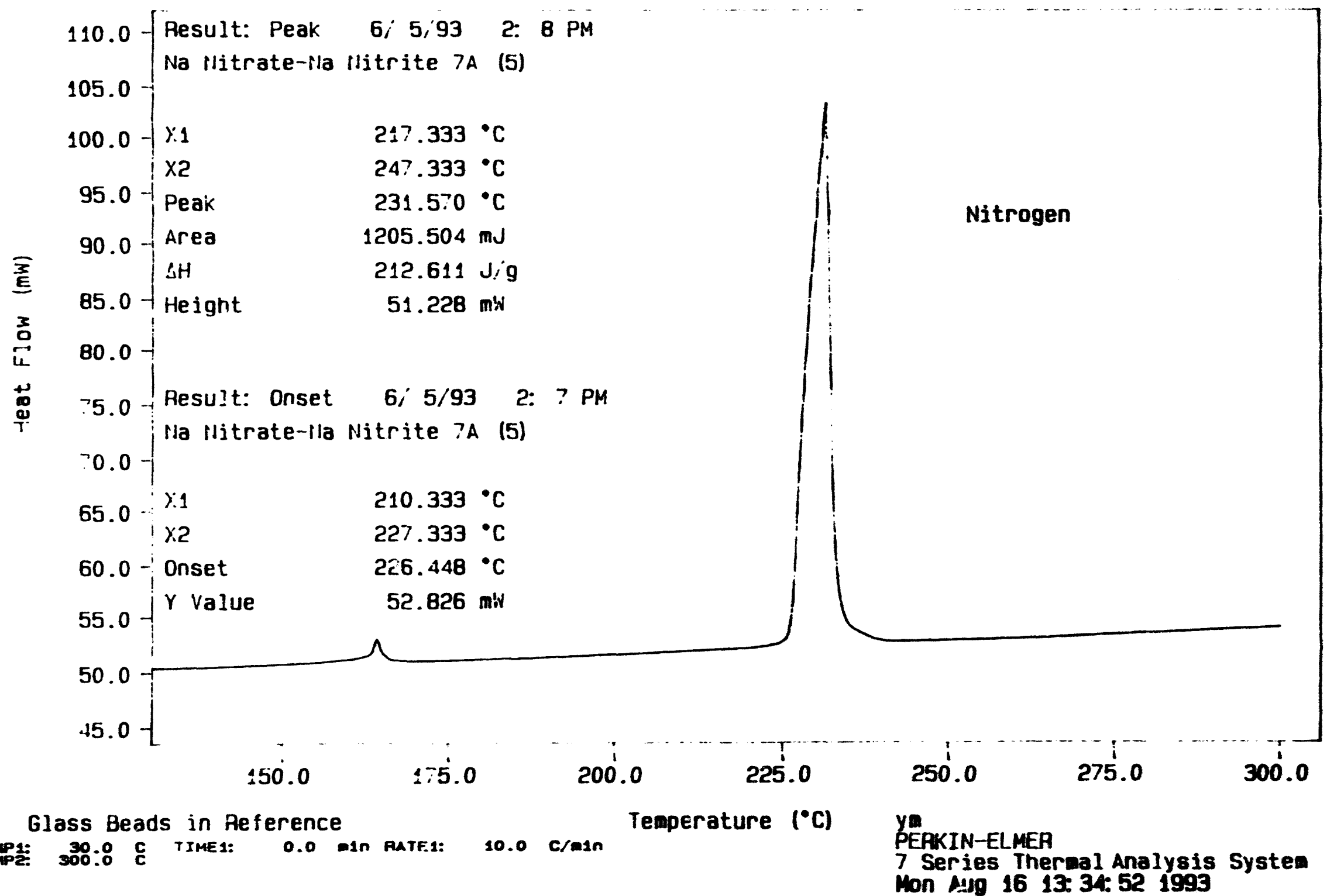

Figure 6. - DSC thermogram for sodium nitrate-sodium nitrite mixture 
Curve 1: TGA

File info: s.nitrate1 Tue Mar 30 11: 40:04 1993

Sampie Weight: 2.382

mg

Na llitrate (1)

* 1 Na Nitrate (1)

1st Derivative $\left(x / \min \times 10^{-2}\right)$

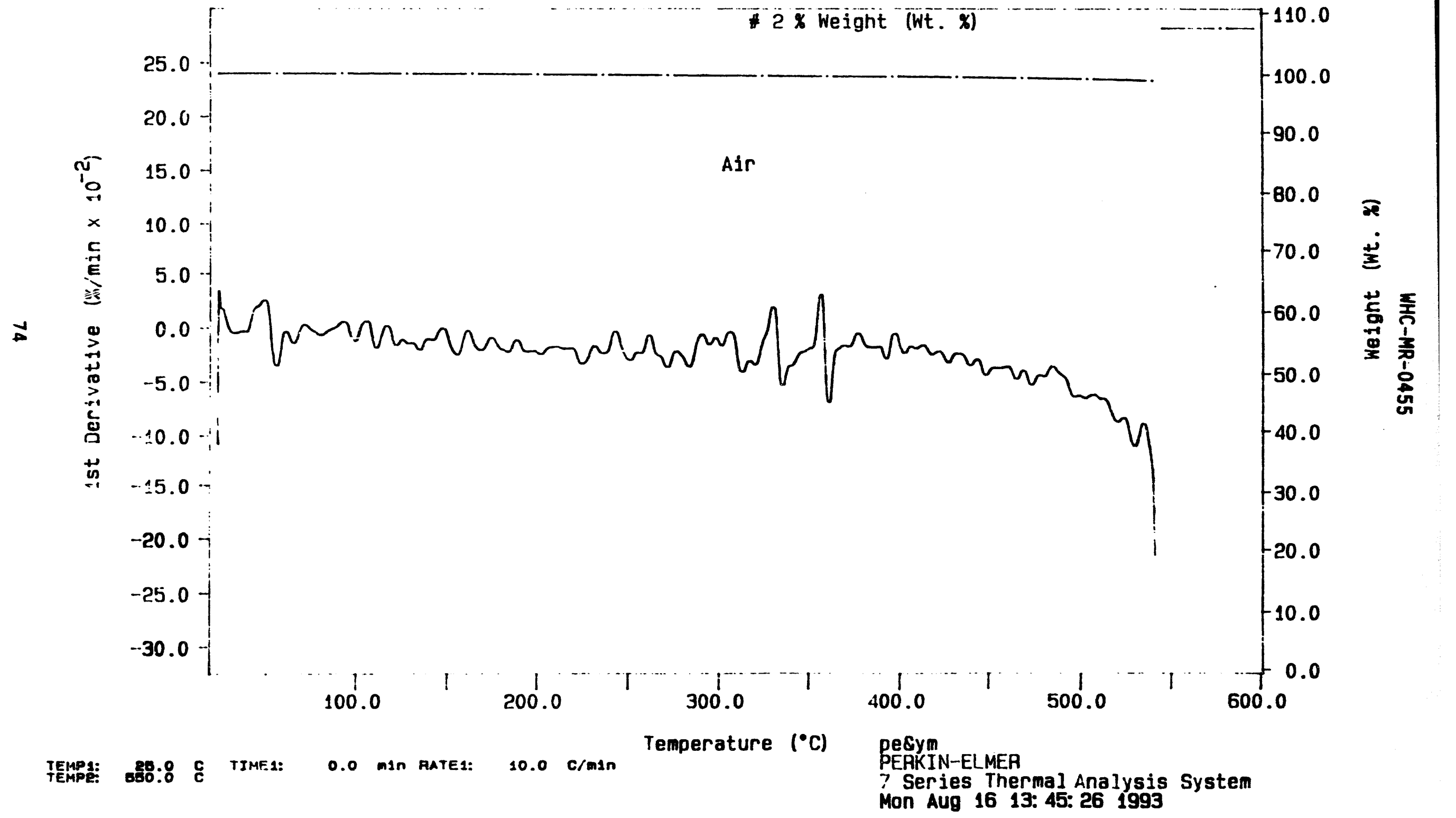

Figure 7. - TGA thermogram for sodium nitrate 
Curve 1: TGA

File info: $18 A-1$

Tue Mar 30 13:06:06 1993

Sample Weight: 4.189

mg

Na Nitrite 18A (1)

Na Nitrite 18A (1)

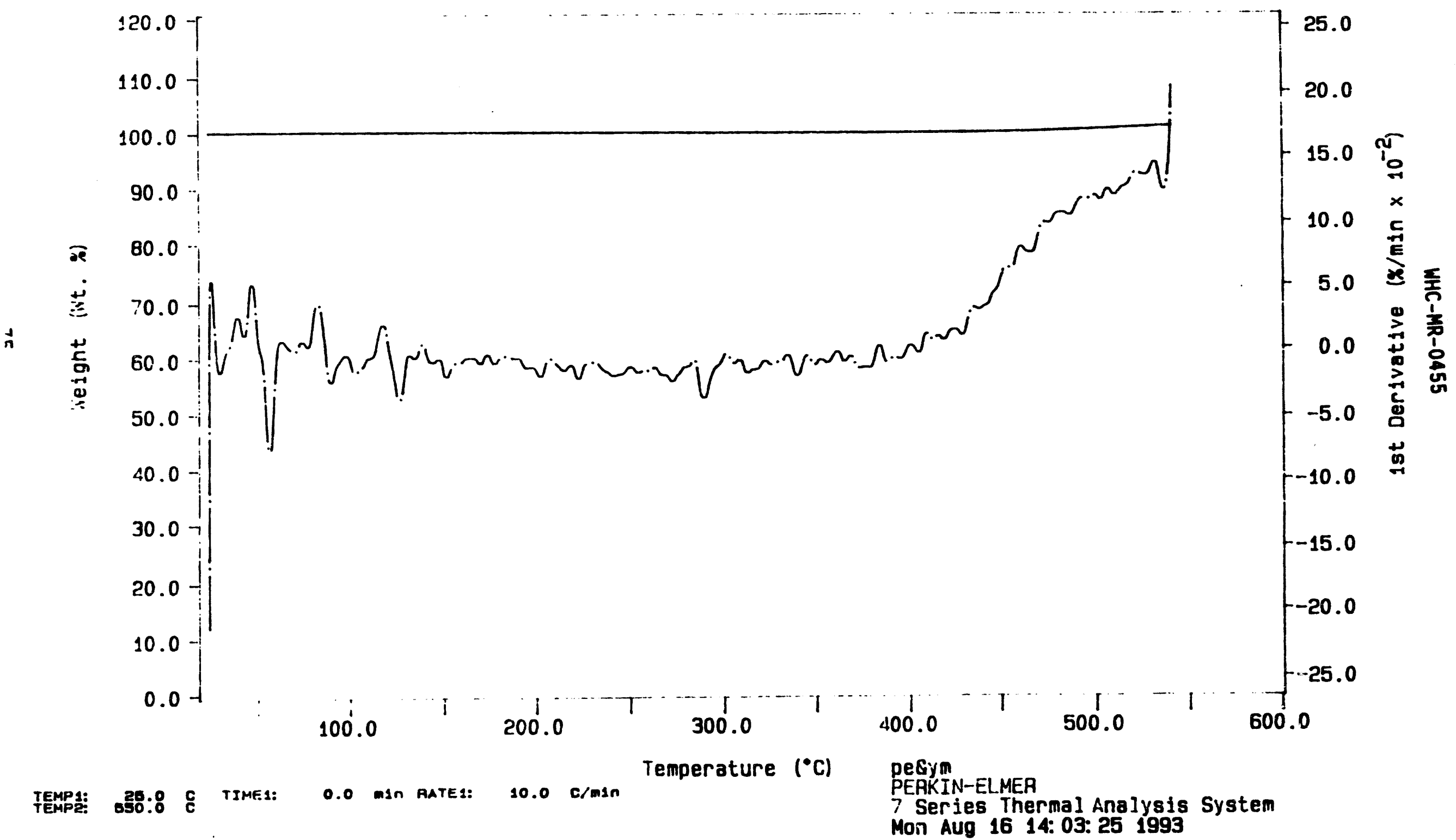

Figure 8. - TGA thermogram for sodium nitrite 
Curve 1: TGA

File info: Mix7A-1 Tue Mar 30 14: 43: 501993

Sample Weight: $4.296 \mathrm{mg}$

Na Nitrate-Na Nitrite 7A (1)

1 Na Nitrate-Na Nitrite 7A (1) _.....

* Weight (Wt. X)

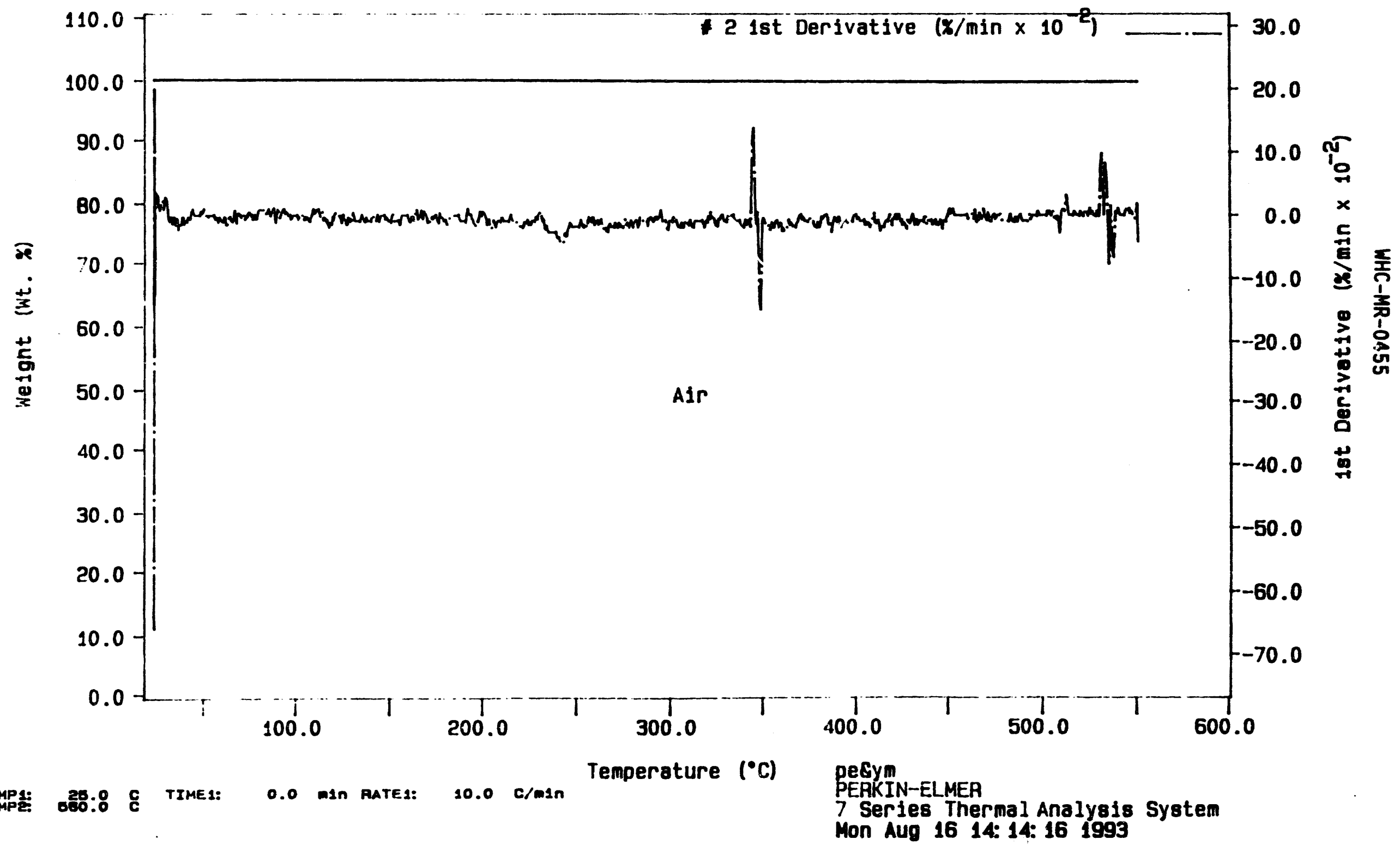

Figure 9., - TGA thermogram for sodium nitrate-sodium nitrite mixture 
Curve 1: DSC

File info: $0 \times 4 A-4$

Sample Weight: 3.430

lia OX 4A (4)

Frj Jan 29 15: 06: 581993

ng

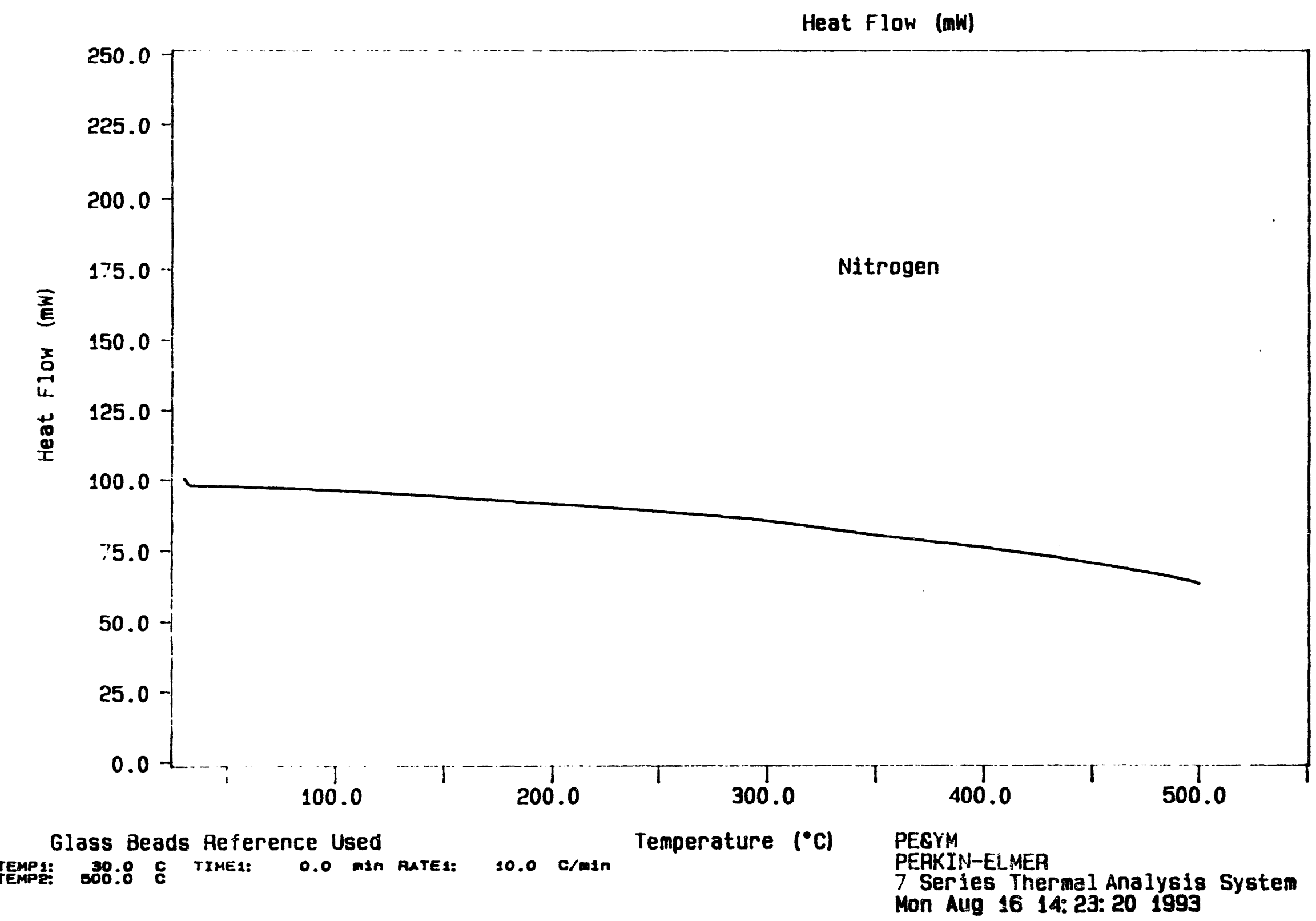

Figure 10. - DSC thermogram for sodium oxalate 
Curve 1: DSC

File info: Ox:13A-4 Fri Jan 22 09: 18:05 1993

Sample Weight: $5.970 \mathrm{mg}$

Na OxiNa Nitrate 13A (4)

* 1 Na Ox/lia Nitrate $13 \mathrm{~A}$ (4)

Heat Flow (mW)

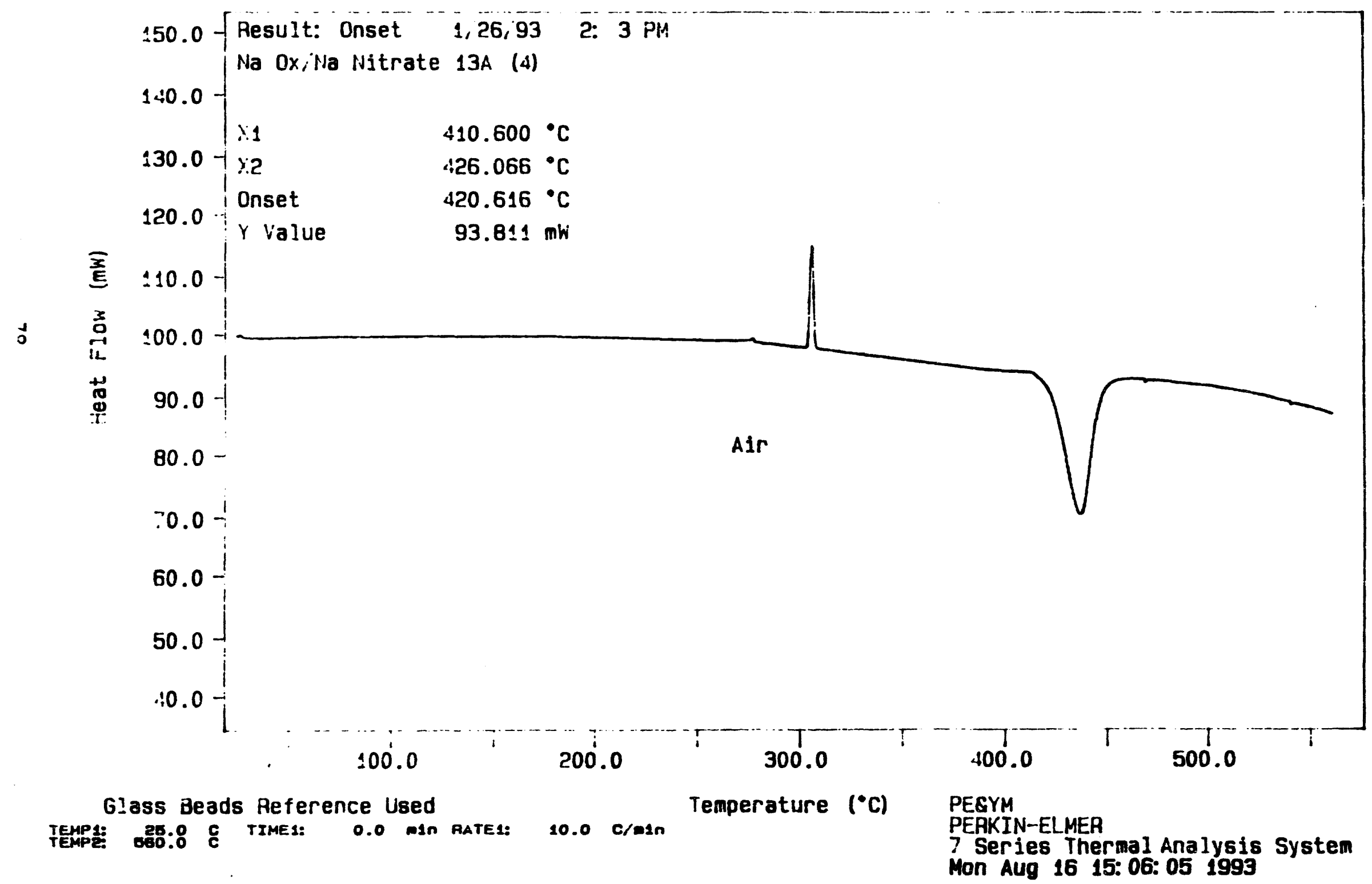

Figure 11. - DSC thermogram for oxalate-nitrate mixture 13A (1:1) 
Curve 1: DSC

F1le infa: 0x13A-4 Fr1 Jan 22 09: 18:05 1993

Sample Weight: $\mathbf{5 . 9 7 0} \quad \mathrm{g}$

Na Ox/Na Nitrate 13A (4)

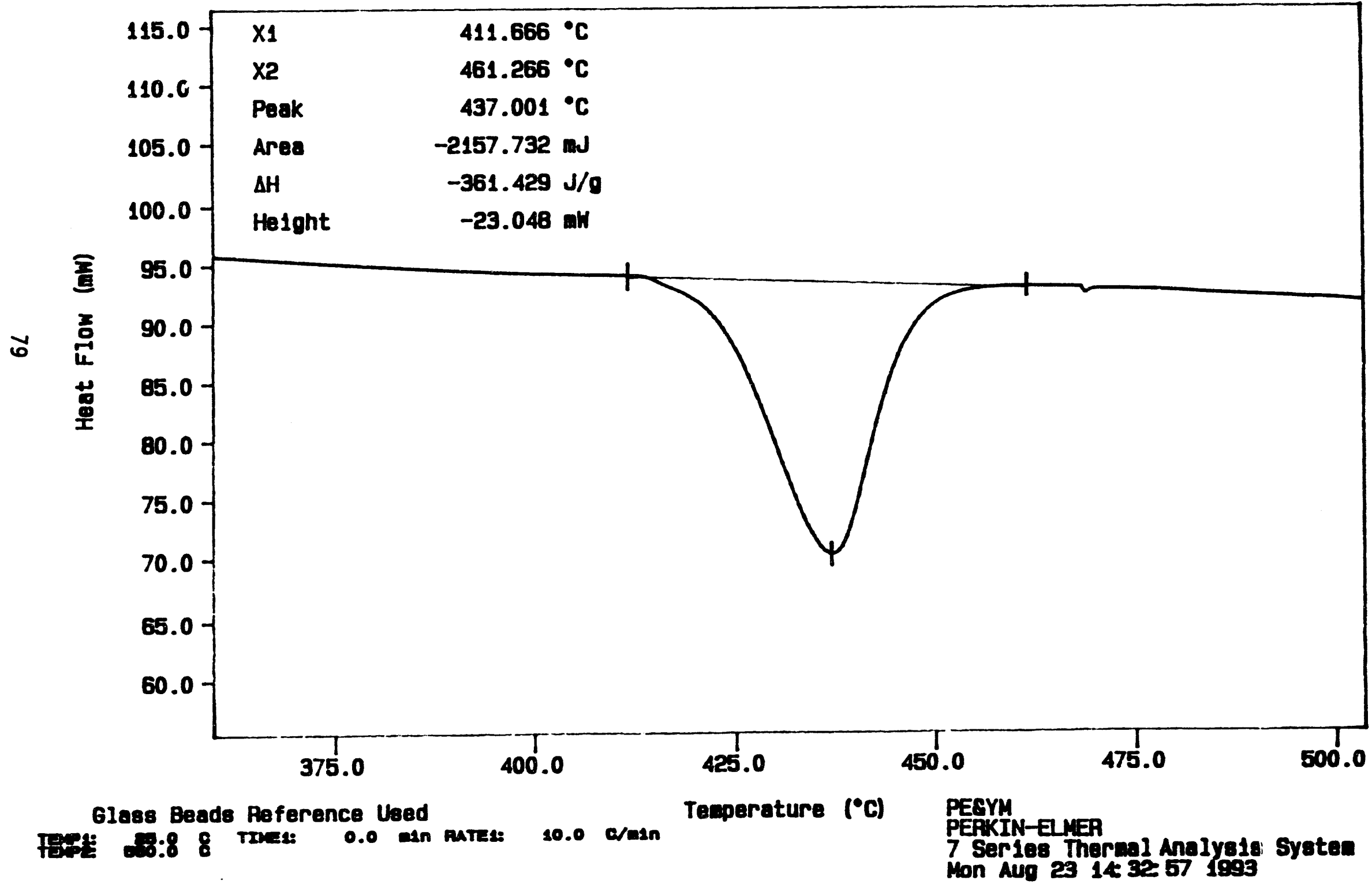

Figure 12. - Optimized and scaled DSC thermogram of the exotherm in figure 11, 
Curve 1: DSC

File info: 0x13A-5 Wed Jan 27 08: 20: 461993

Sample Weight: $5.7 .40 \mathrm{mg}$

lla Oxilla Nitrate 13A (5)

* 1 Na Ox/Na Witrate 13A (5) Heat Flow (mw)

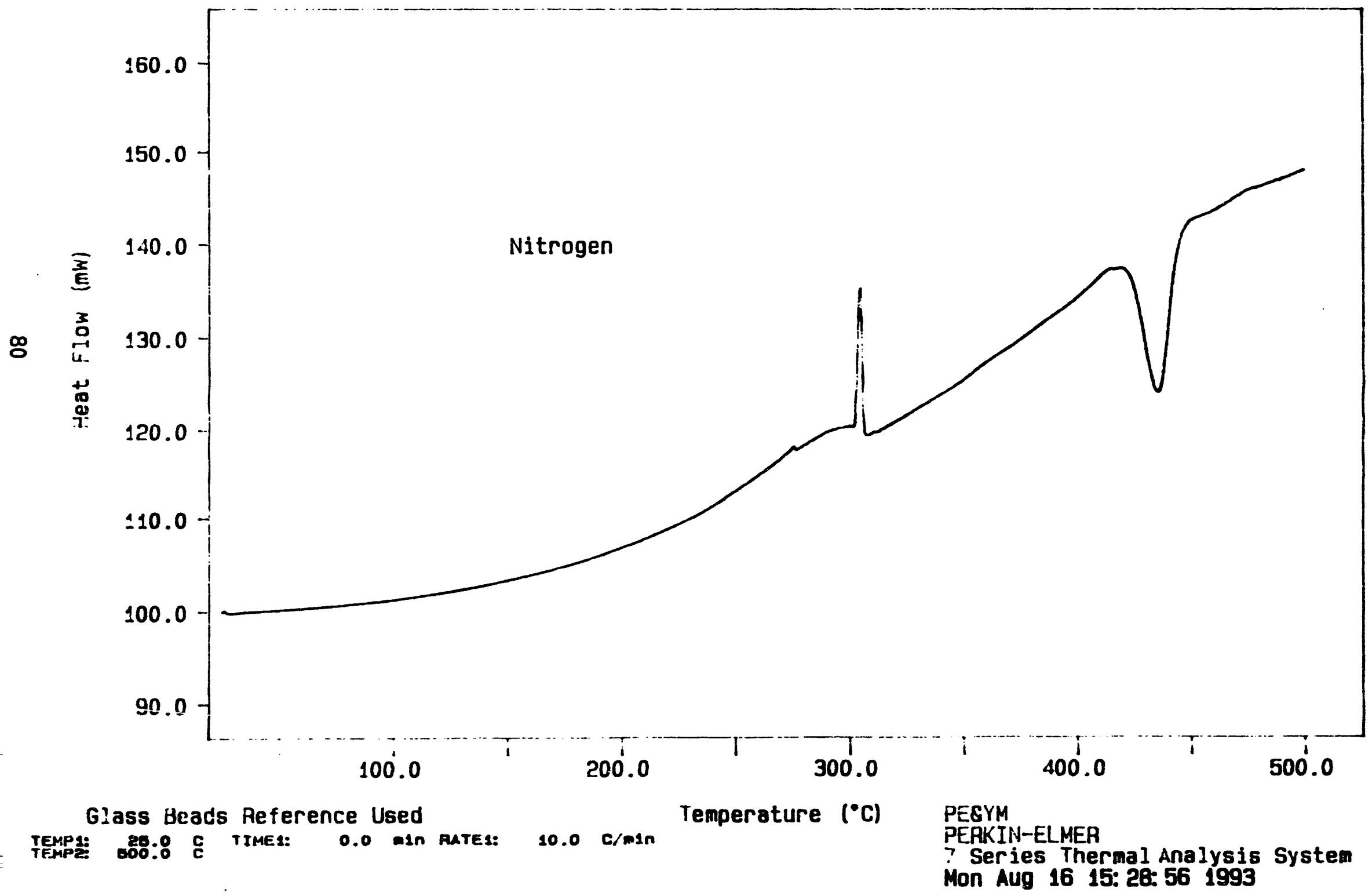

Figure 13. - DSC thermogram for oxalate-nitrate mixture 13A (1:1) 
Curve 1: DSC

File info: OxMix138-1 Wed Jan 6 08: 33: 301993

Sample Weight: 5.500 mg

Na OX/Na Nitrate $13 B$ (1)

- $1 \mathrm{Na}$ Ox/Na Nitrate 13B (1) Heat Flow (mW)

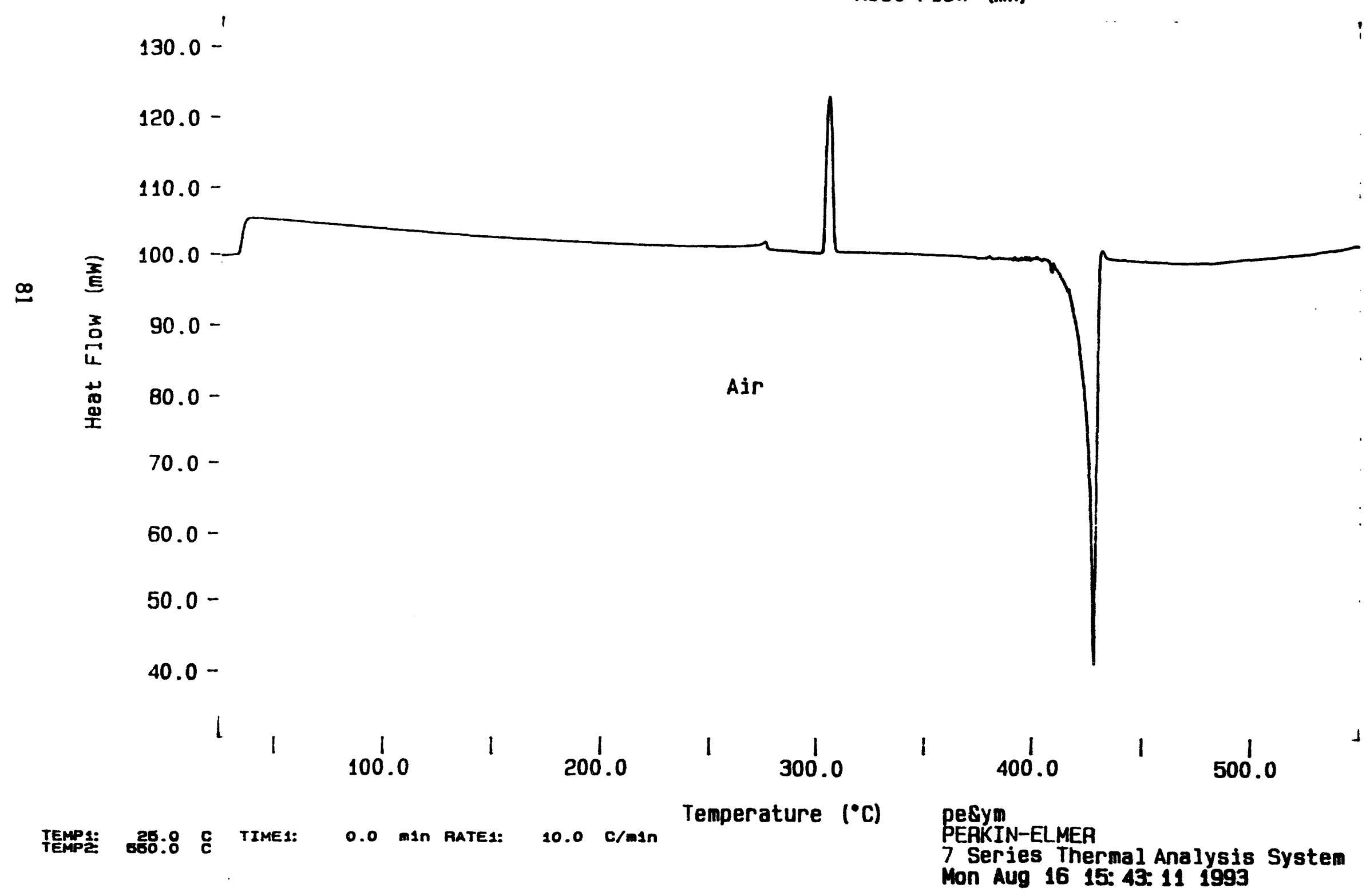

Figure 14. - DSC thermogram for oxalate-nitrate mixture $13 B(1: 3)$ 
Curve 1: DSC

File info: 0x13C-2 Wed Jan 6 15: 46:56 1993

Sample Weight: $7.500 \mathrm{mg}$

Na Ox/Na Nitrate $13 \mathrm{C}$ (2)

* $1 \mathrm{Na} \mathrm{Ox/Na} \mathrm{Nitrate} \mathrm{13C} \mathrm{(2)}$ Heat Flow (mw)

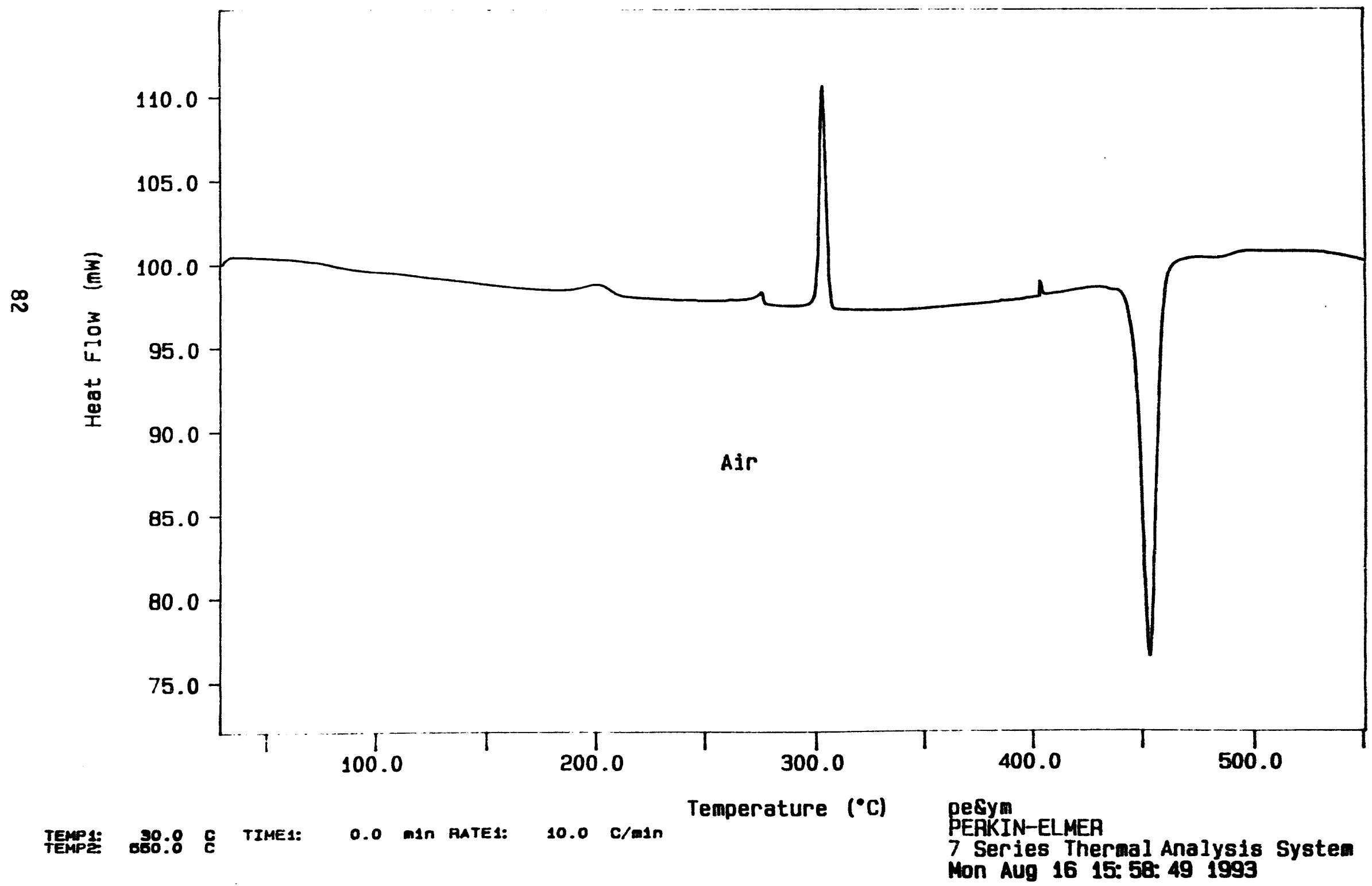

Fig. 15. - DSC thermogram for oxalate-nitrate mixture $13 \mathrm{C}(1: 3 ;$ dil) 
Curve 1: DSC

File info: 0x130-1 Wed Jan 6 16: 46: 101993

Sample Weight: $4.000 \mathrm{mg}$

Na Ox/Na Nitrate 13D (1)

* $1 \mathrm{Na}$ Ox/Na Nitrate 130 (1)

Heat Flow (nW)

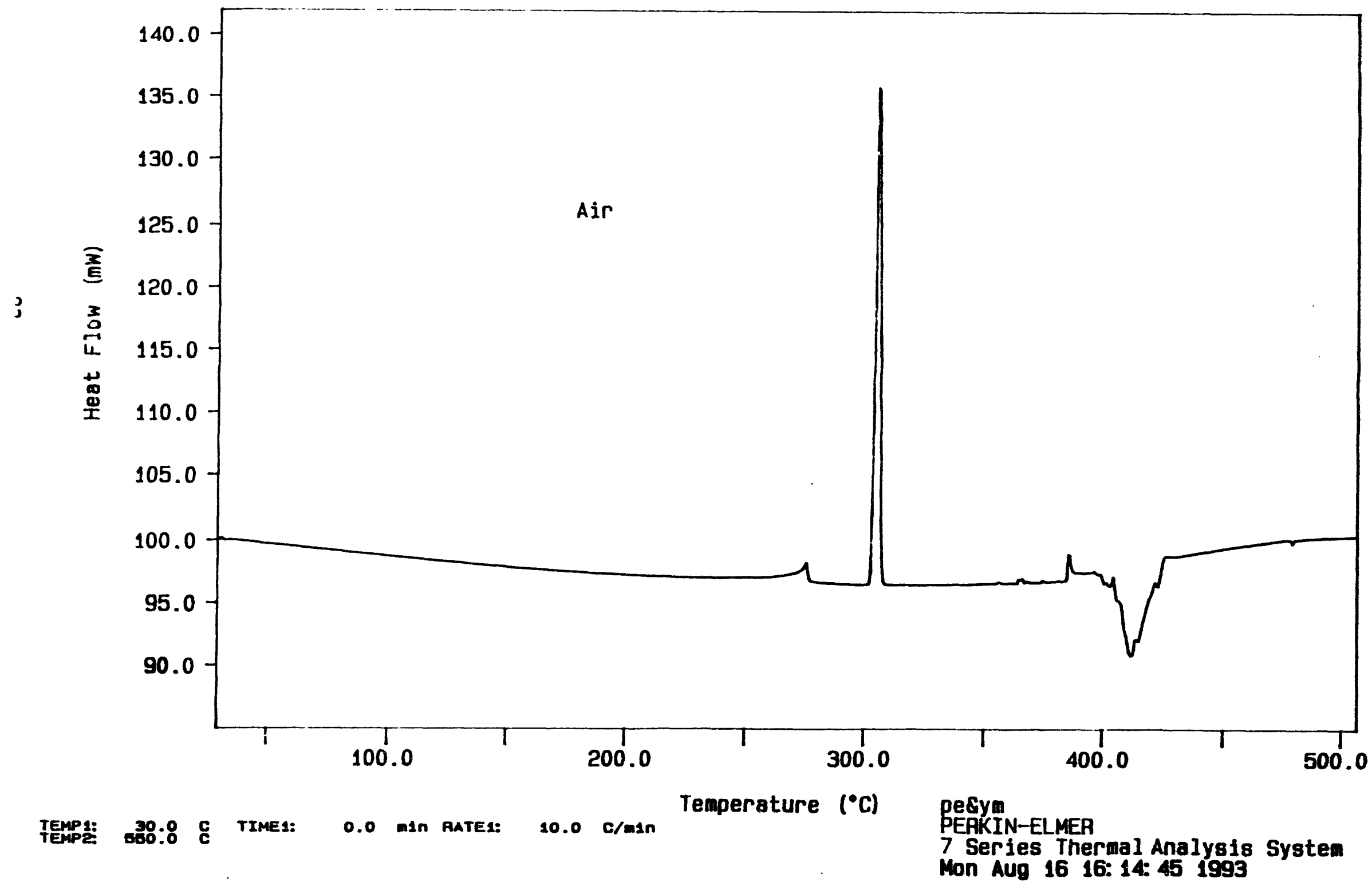

Figure 16. - DSC thermogram for oxalate-nitrate mixture $130(1: 10)$ 
Curve 1: DSC

File info: OxMix14A-4 Mon Jun 7 13:00:03 1993

Sample Height: $2.800 \mathrm{mg}$

Na $0 x /$ Na Nitrate-Nitrite $14 A$ (4)

$1 \mathrm{Na}$ Ox/ Na Nitrate-Nitrite $14 \mathrm{~A}(\ldots$ Heat Flow (mW)

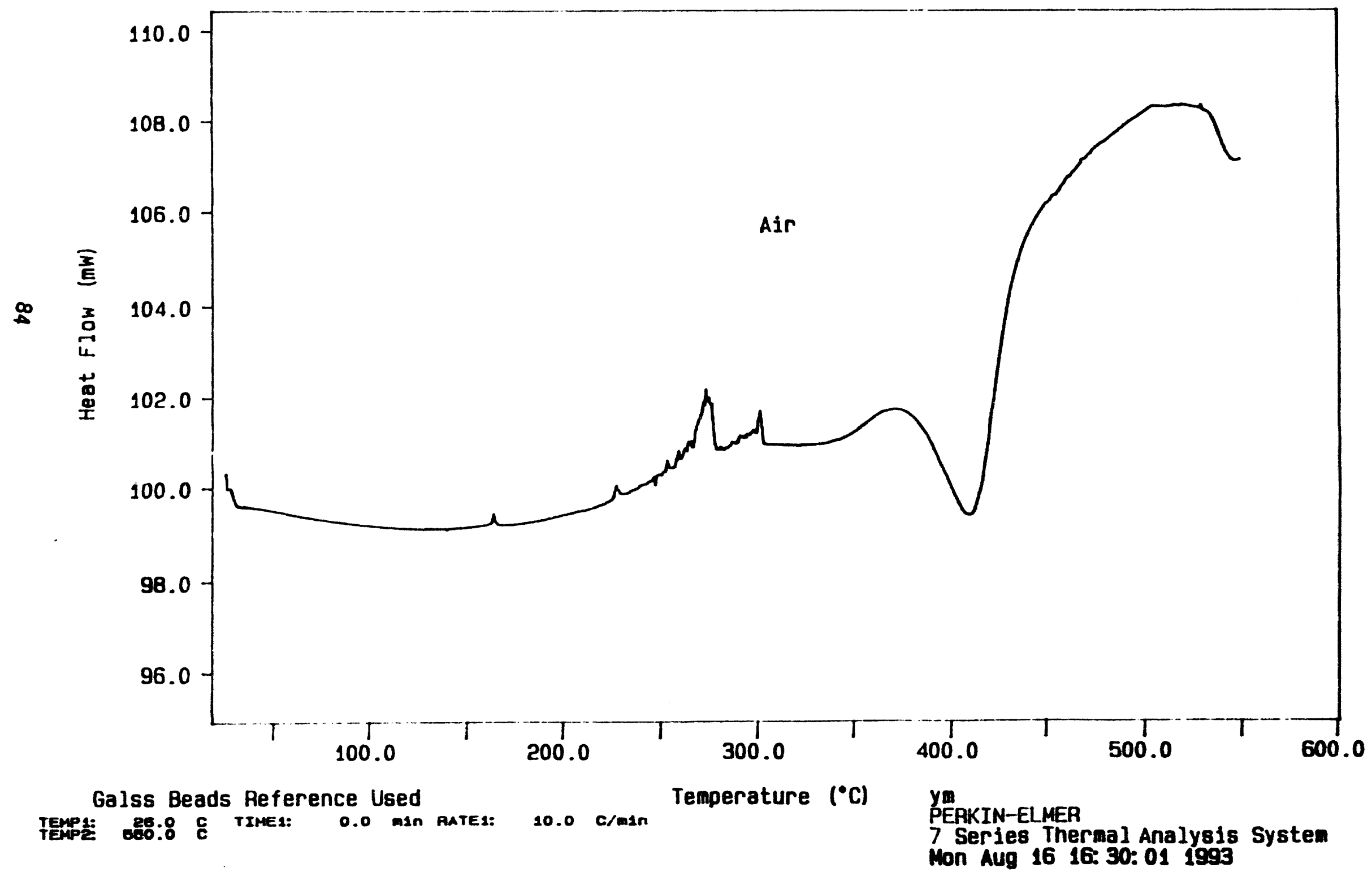

Figure 17. - DSC thermogram for oxalate-nitrate-nitrite mixture $14 \mathrm{~A}(1: 1)$ 
Curve 1: DSC

File info: OxMix14A-1 Thu Jan 7 13: 32: 051993

Sample Weight: $4.000 \mathrm{mg}$

Na Ox/Nitrate-Nitrite 14A (1)

* 1 Na Ox/Nitrate-Nitrite 14A (1) Heat Flow (mW)

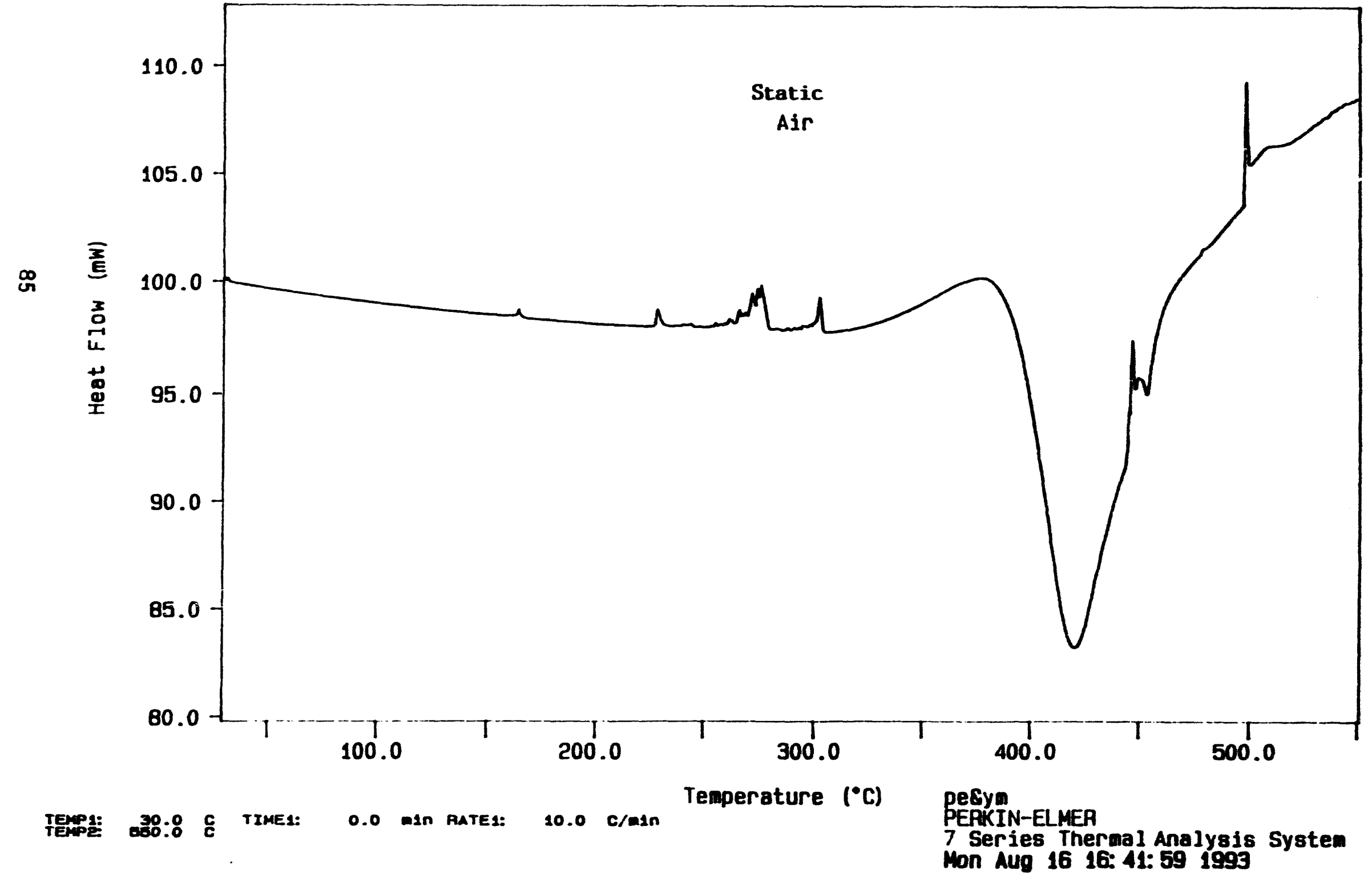

Figure 18. - DSC thernogran for oxalate-nitrate-nitrite aixture $14 \AA(1: 1)$ 
Curve 1: DSC

File info: OxMix14A-3 Thu Jan 28 11: 52: 481993

Sample Weight: $3.970 \mathrm{mg}$

Na Ox/Na Nitrate-Nitrite 14A (2)

- $1 \mathrm{Na}$ OxiNa Nitrate-Nitrite 14A ( Heat Flow (niw)

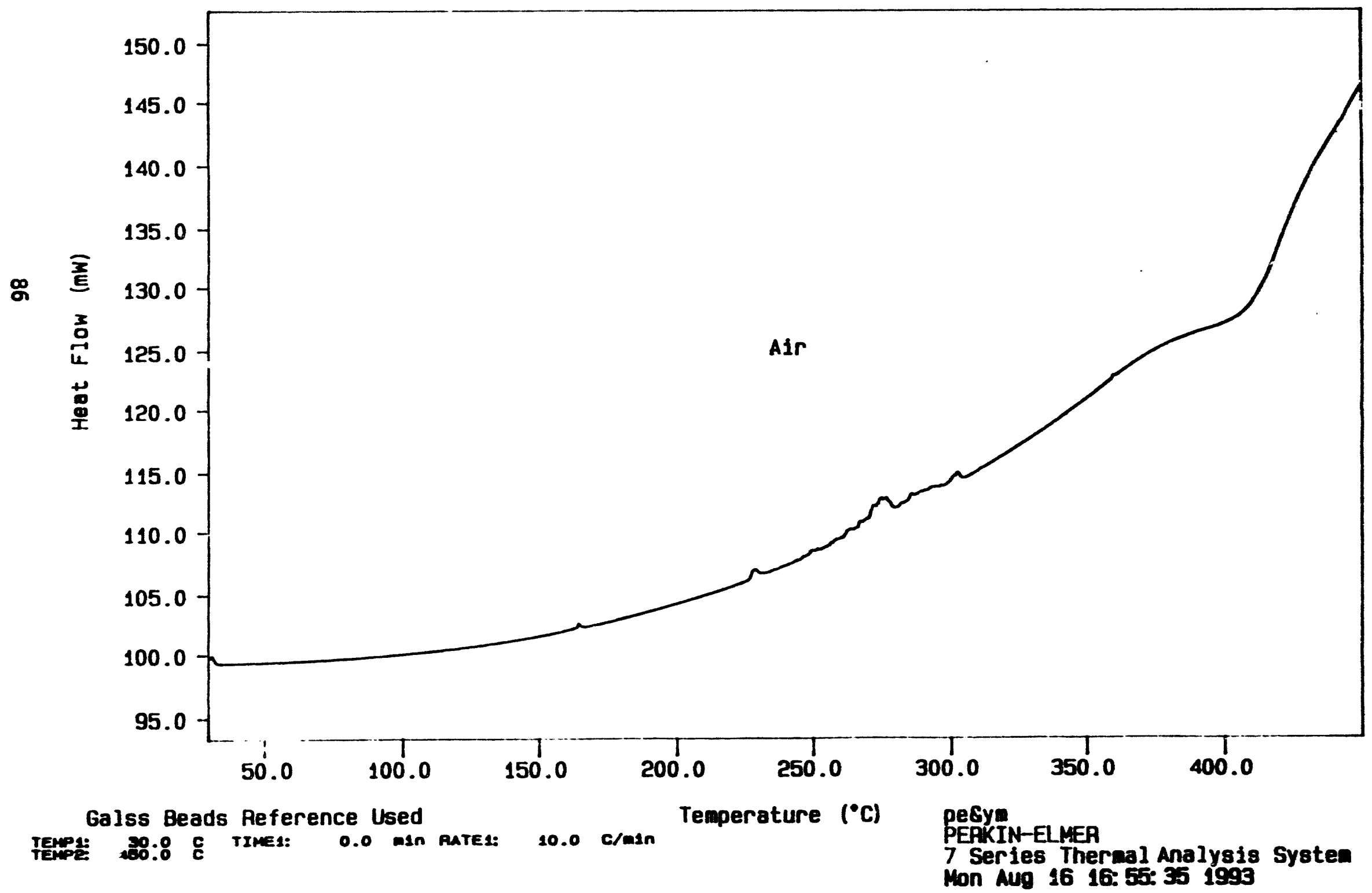

Figure 19. - DSC thermogram for oxalate-nitrate-nitrite mixture $14 A(1: 1)$ 
Curve 1: DSC

File info: OxMixi4B-2 Thu Jan 7 16: 08: 371993

Sampli: Weight: $8.000 \mathrm{mg}$

Na OxiNitrate-Nitrite 14B (2)

* 1 Na Ox/Nitrate-Nitrite 148 (2) Heat Flow (nw)

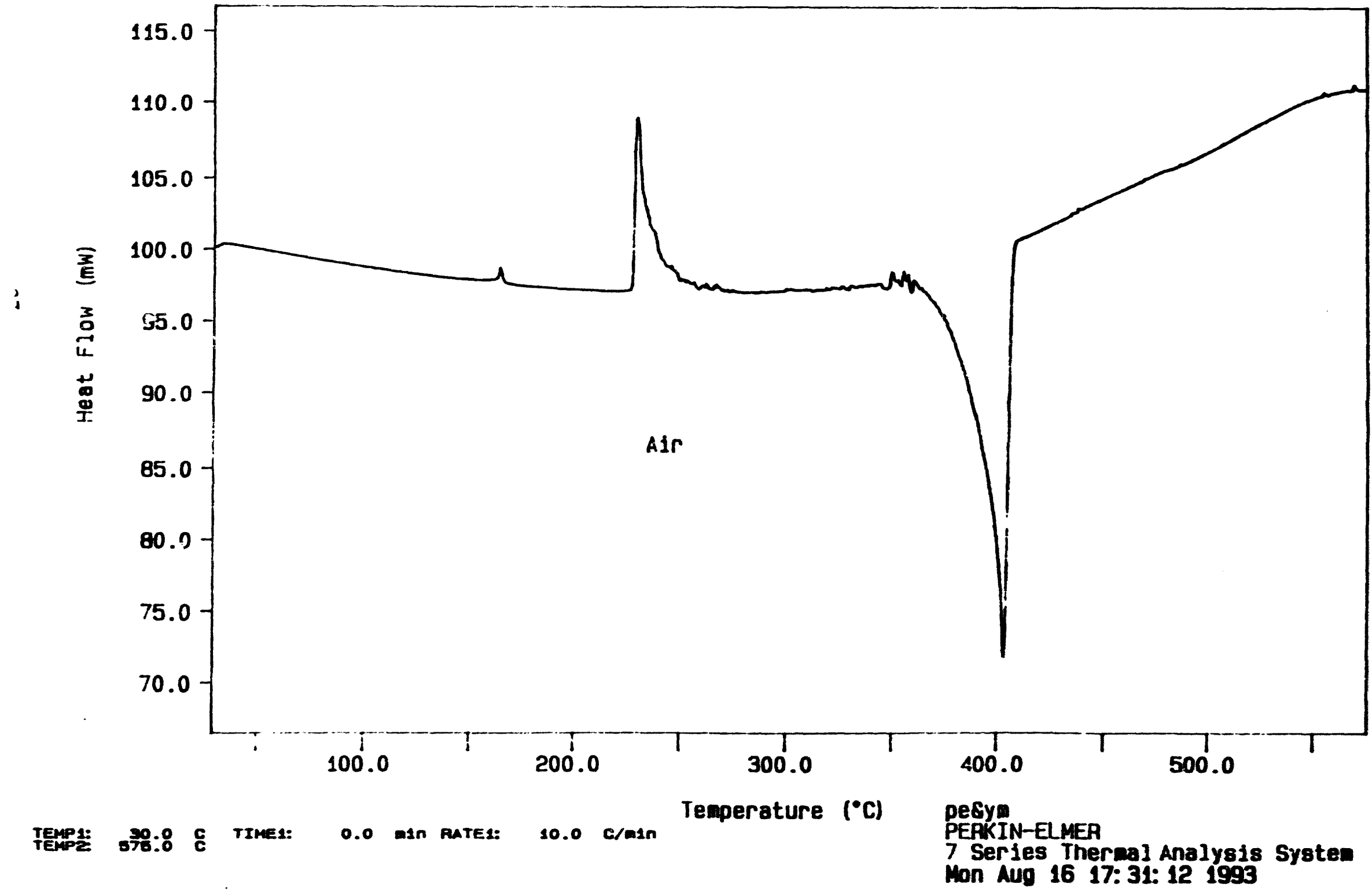

Figure 20. - DSC thermogran for oxalate-nitrate-nitrite aixture 14B (1:3) 

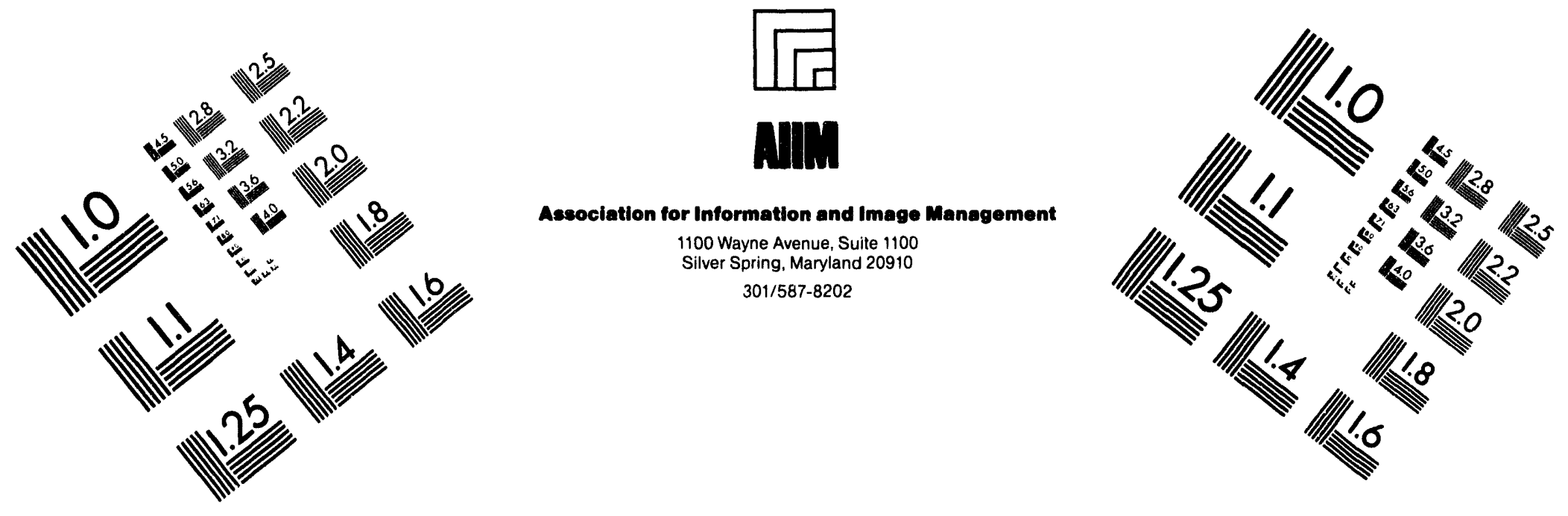

\section{Centimeter}

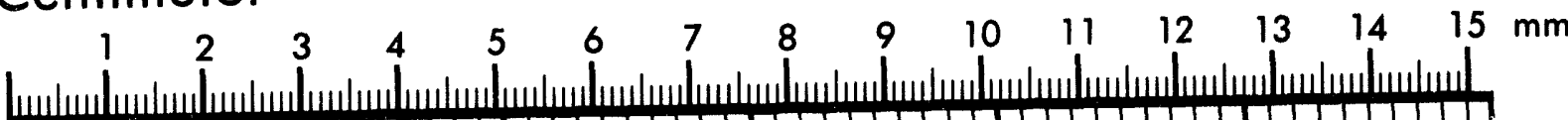

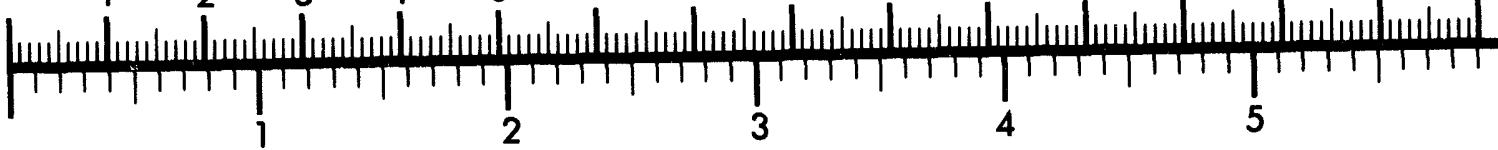
Inches

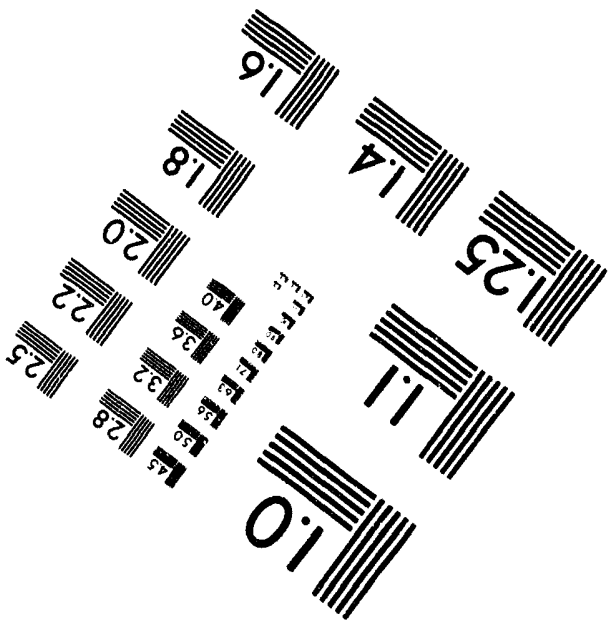

MANUFACTURED TO AIIM STANDARDS

BY APPLIED IMAGE, INC.

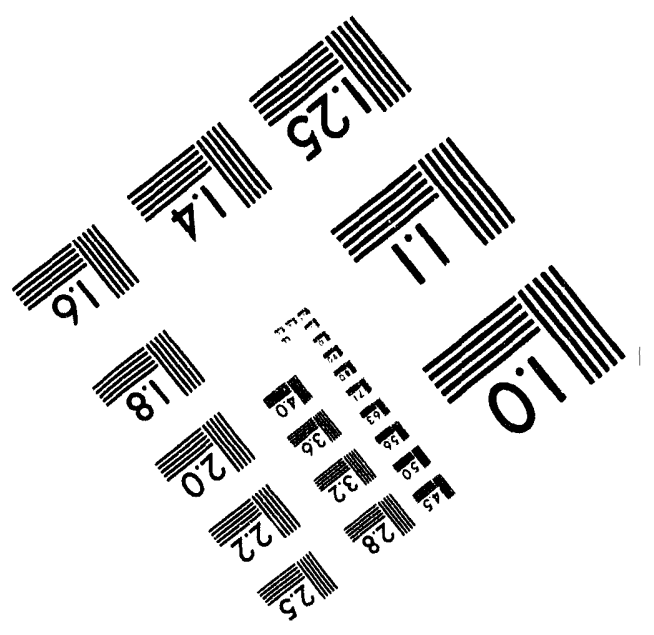



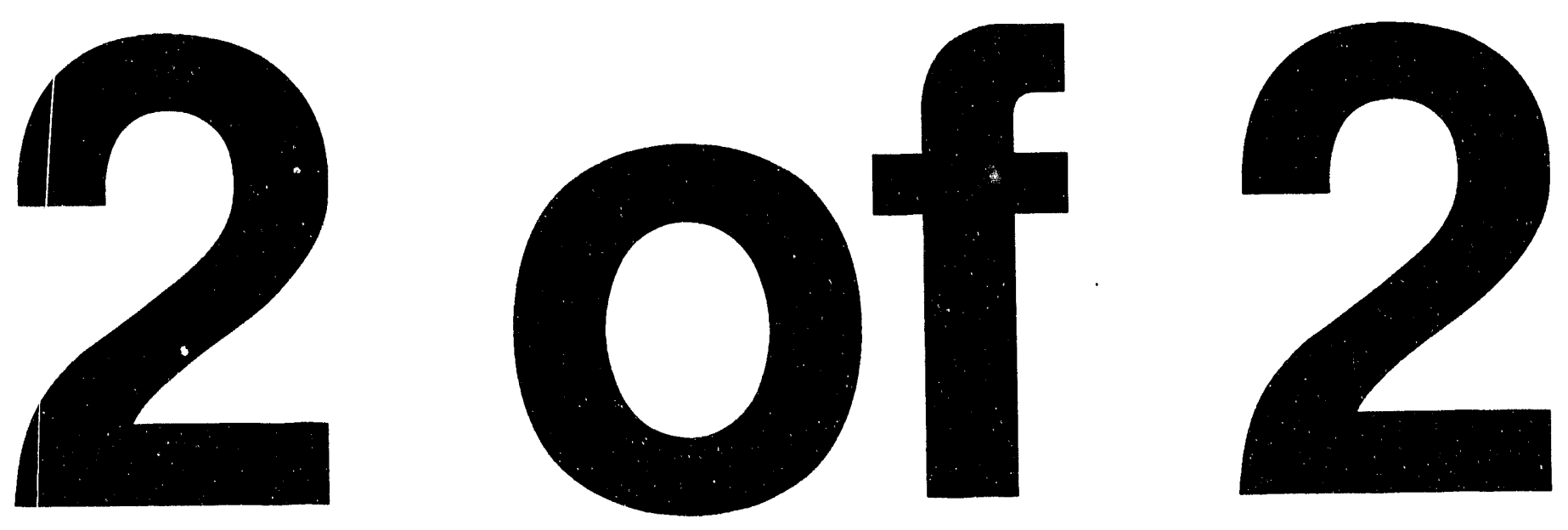
Curve 1: DSC

File info: OxMix 14C-1 Fri Jan 8 07:56: 301993

Sample Weight: $4.000 \mathrm{mg}$

Na OxiNitrate-Nitrite $14 \mathrm{C}$ (1)

* 1 Na OxiNitrate-Nitrite 14C (1) _..... Heat Flow (mW)

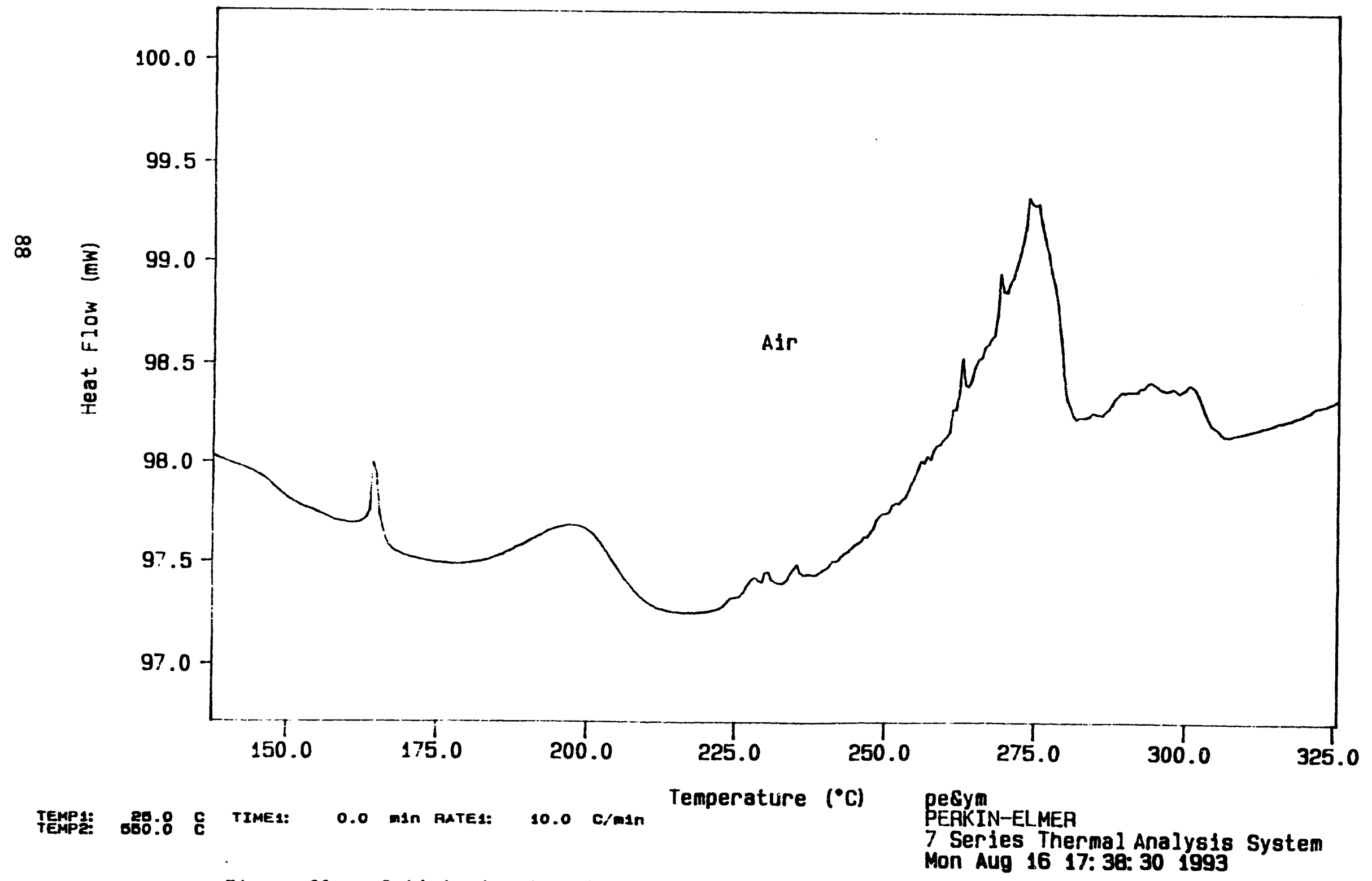

Figure 21. - Optimized and scaled DSC thermogram for endotherms in oxalatenitrate-nitrite mixture $14 C(1: 3 ; d i 1)$. Complete thermogram in figure $21 \dot{A}$ 
Curve 1: DSC

File info: OxM1X14C-1 Fr1 Jan 8 07:56: 301993

Sample Weight: 4.000

mg

Na Ox/Nitrate-Nitrite 14C (1)

- 1 Na Ox/Nitrate-Nitrite 14C (1)

Heat Flow (mW)

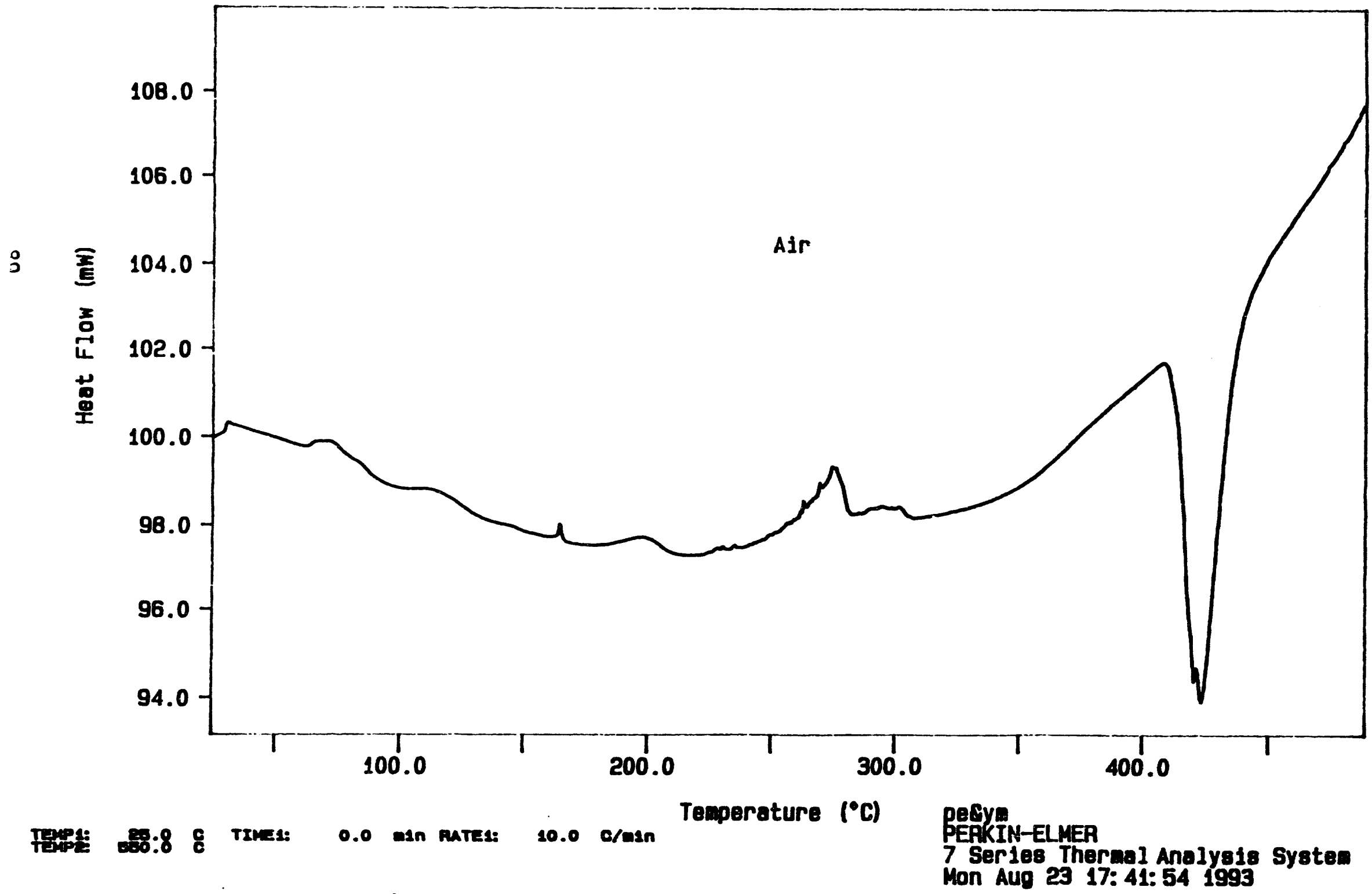

Figure 21A. - DSC thermogram for oxalate-nitrate-nitrite mixture

$14 \mathrm{C}(1: 3 ; \mathrm{di} 1)$ 
Curve 1: DSC

File info: 0xMix14D-1 Fri Jan 8 09: 03: 181993

Sample Weight: 4.500

$\mathrm{mg}$

Na Ox/ Nitrate-Nitrite 140 (1)

* $1 \mathrm{Na}$ Ox/ Nitrate-Nitrite 14D (1) _....... Heat Flow (nw)

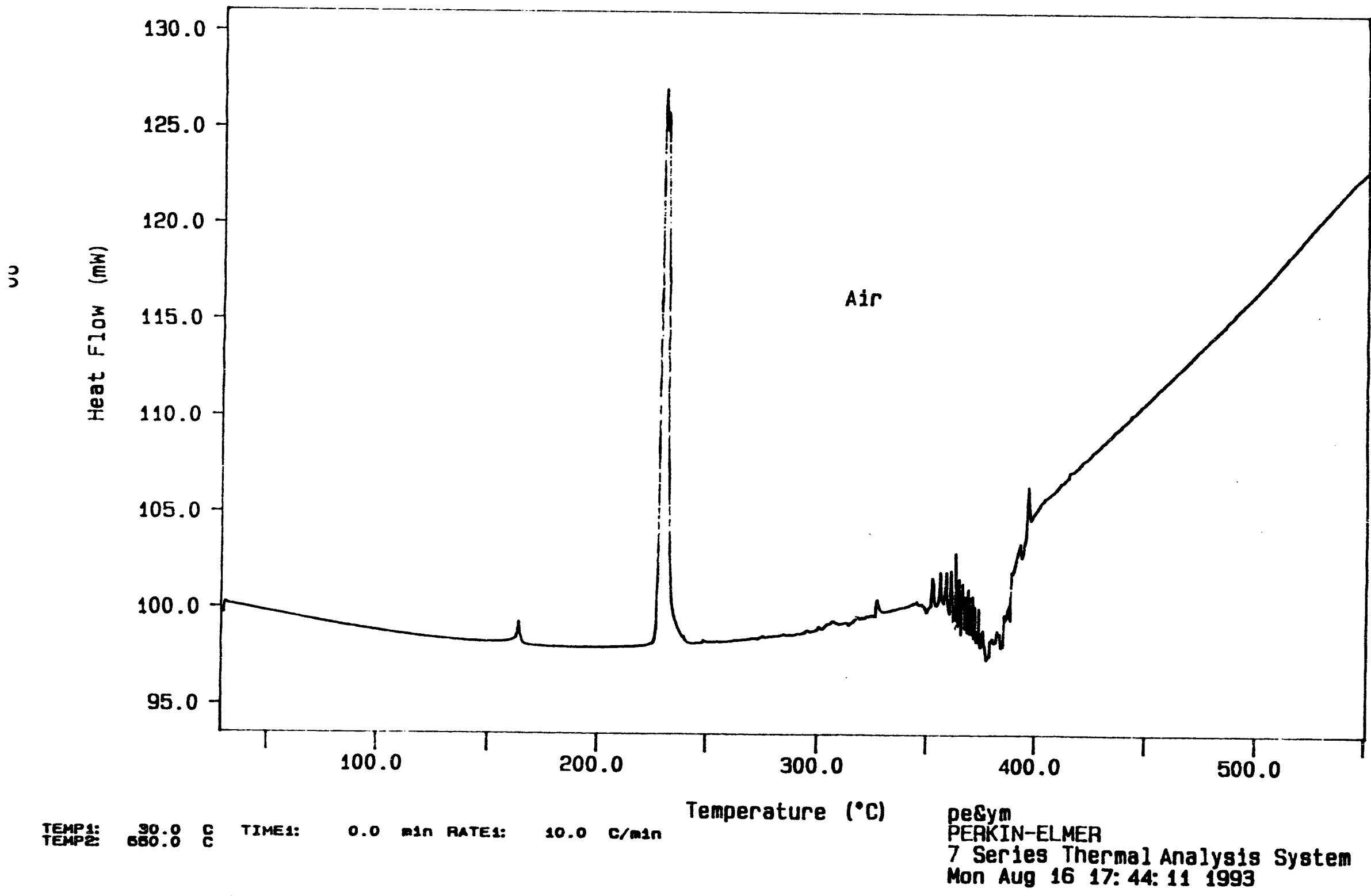

Figure 22. - DSC thermogram for oxalate-nitrate-nitrite mixture $140(1: 10)$ 
Curve 1: DSC

File info: 0xMix14D-2 Fri Jan 8 10:23:04 1993

Sample Weight: $8.500 \mathrm{mg}$

Na Ox/Nitrate-Nitrite 140 (2)

* 1 Na Ox/Nitrate-Nitrite 140 (2) _....... Heat Flow (nW)

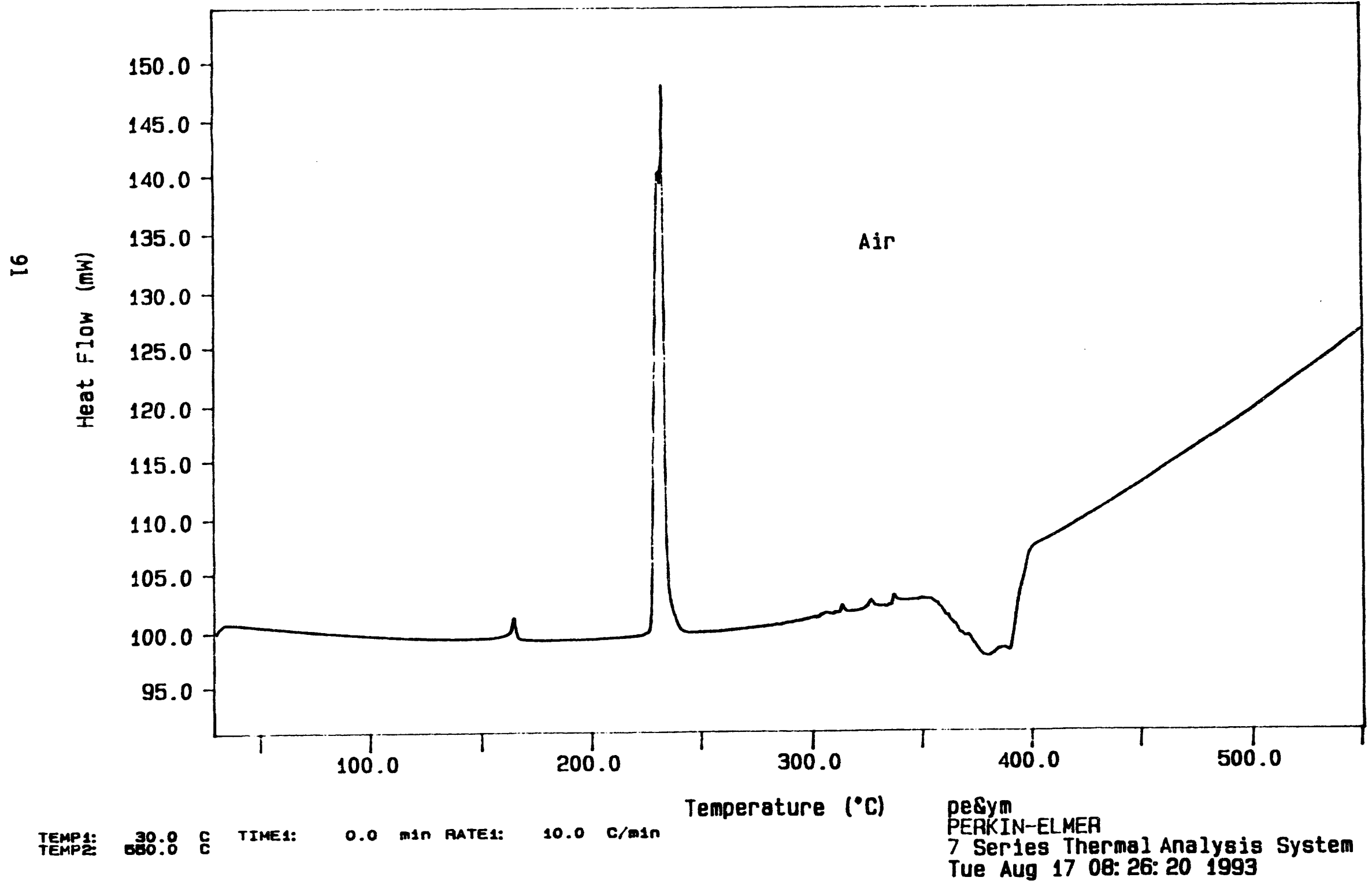

Figure 23. - DSC thermogram for oxalate-nitrate-nitrite mixture $140(1: 10)$ 
Curve 1: DSC

File info: OxMix14D-3 Fri Jan 8 11: 33: 451993

Sample Weight: $6.000 \mathrm{mg}$

Na Ox/Nitrate-Nitrite 14D (3)

* 1 Na Ox/Nitrate-Nitrite 14D (3) _........ Heat Flow (nW)

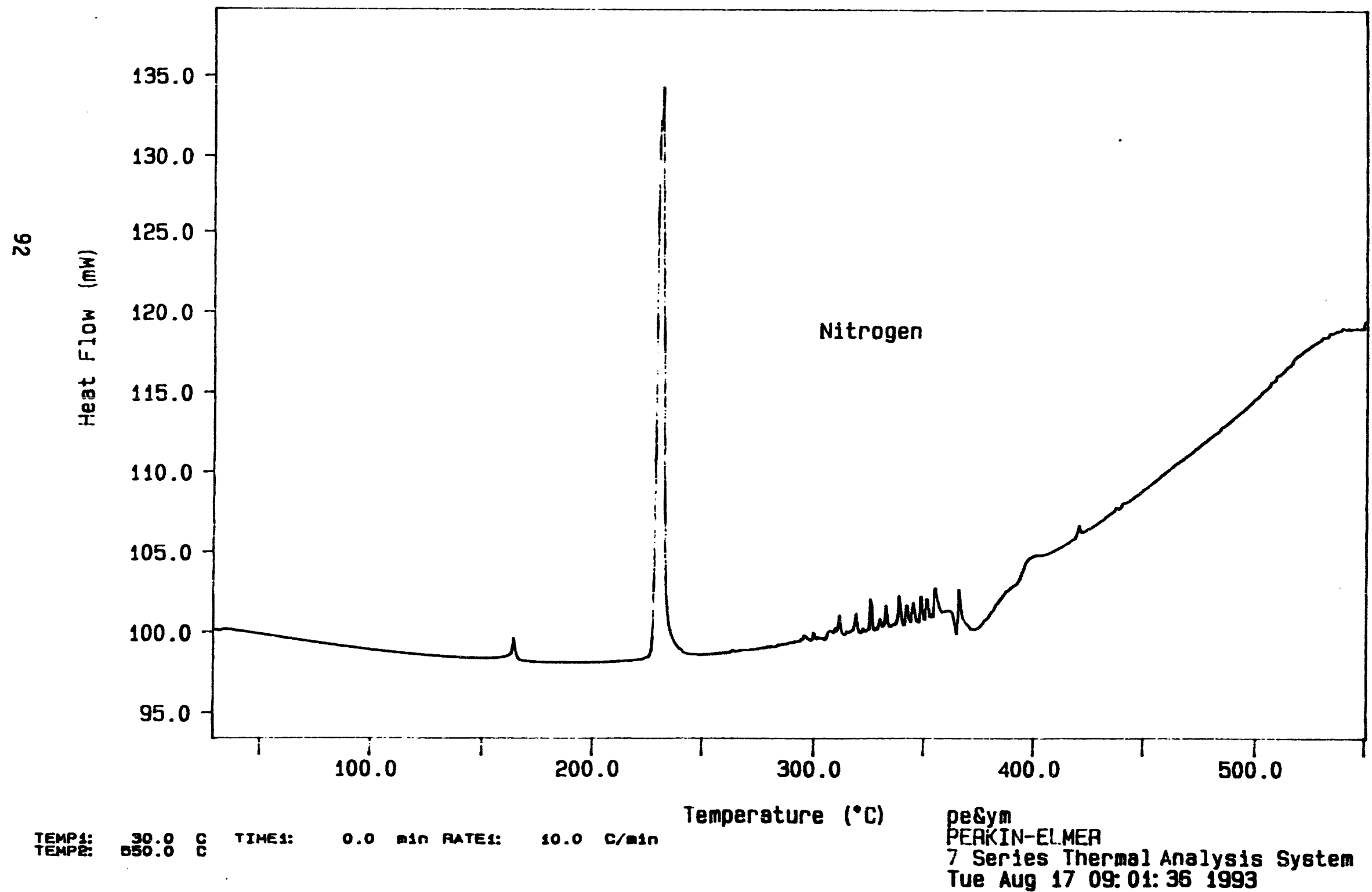

Figure 24. - DSC thermogram for oxalate-nitrate-nitrite mixture $140(1: 10)$ 
Curve 1: DSC

File info: OxMix14D-5 Tue Jan 12 09: 14: 141993

Sample Weight: $3.900 \mathrm{mg}$

Na Ox/Nitrate-Nitrite 140 (5)

* 1 Na Ox/Nitrate-Nitrite 140 (5)

Heat Flow (mW)

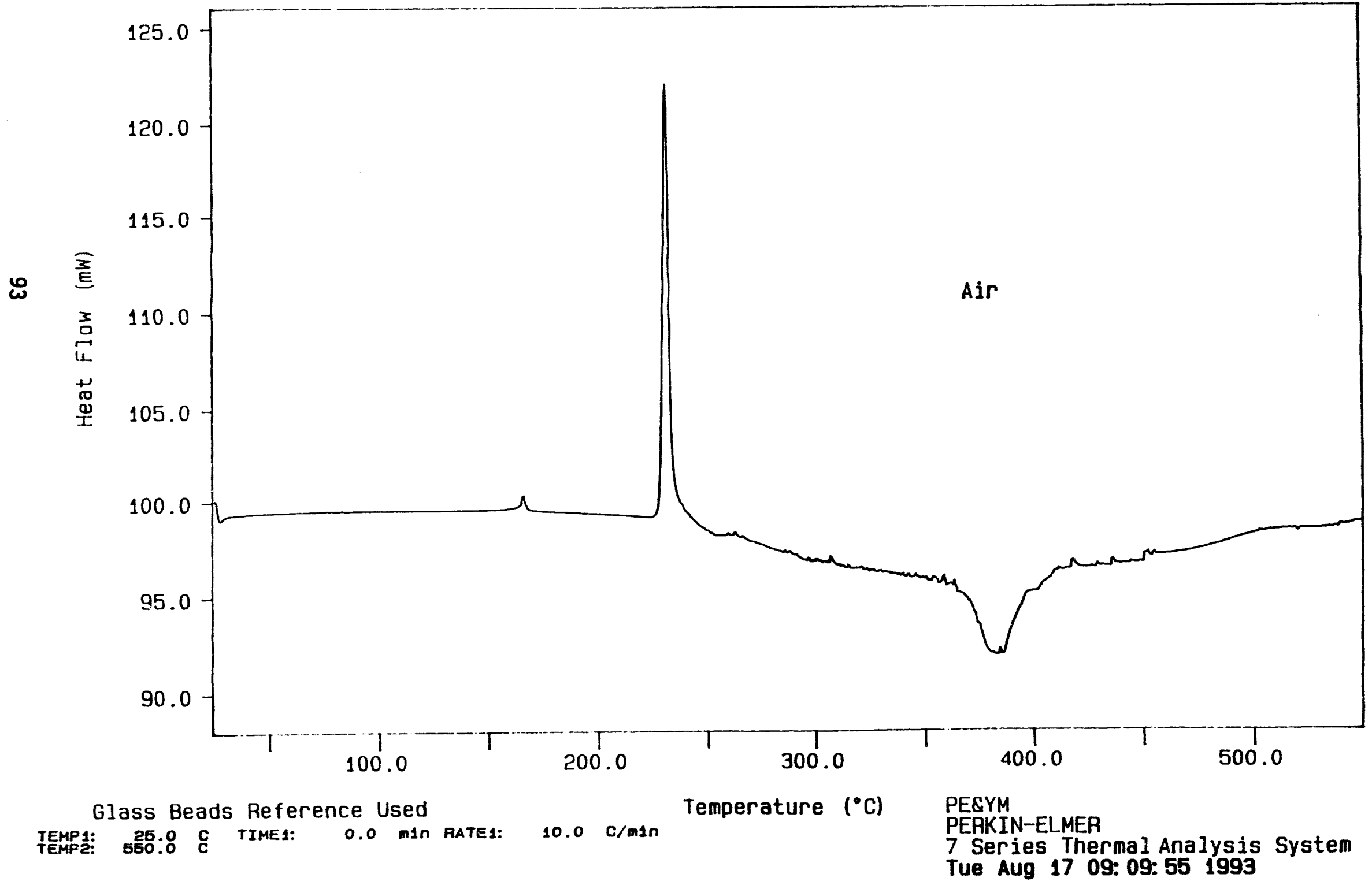

Figure 25. - DSC thermogram for oxalate-nitrite mixture 
Curve 1: TGA

File info: $0 \times 4 A-2$

Sample Weight: 4.000

Thu Jan 21 10: 39: 491993

Na OX $4 A$ (2)

$\mathrm{mg}$

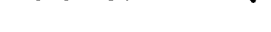

* 1 Na OX 4A (2)

$x$ Weight (Wt. X)

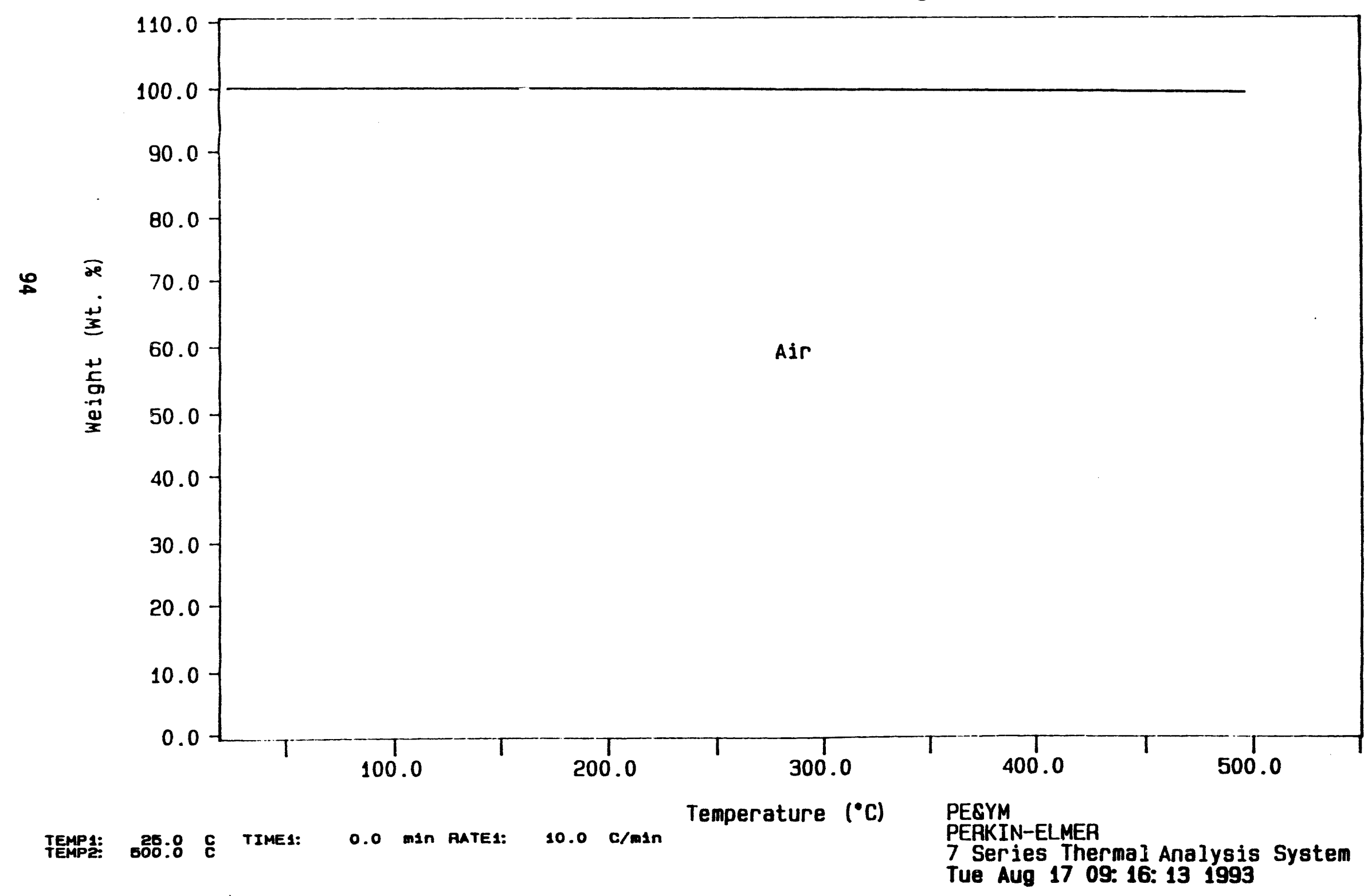

Figure 26. - TGA thermogram for sodium oxalate 
Curve 1: TGA

File info: $0 \times 13 A-1$ Tue Jan 12 13: 50: 401993

Sample Weight: $3.780 \mathrm{mg}$

Na Ox/Na Nitrate 13A (1)

* $1 \mathrm{Na}$ Ox/Na Nitrate 13A (1)

$x$ weight (Wt. $x$ )

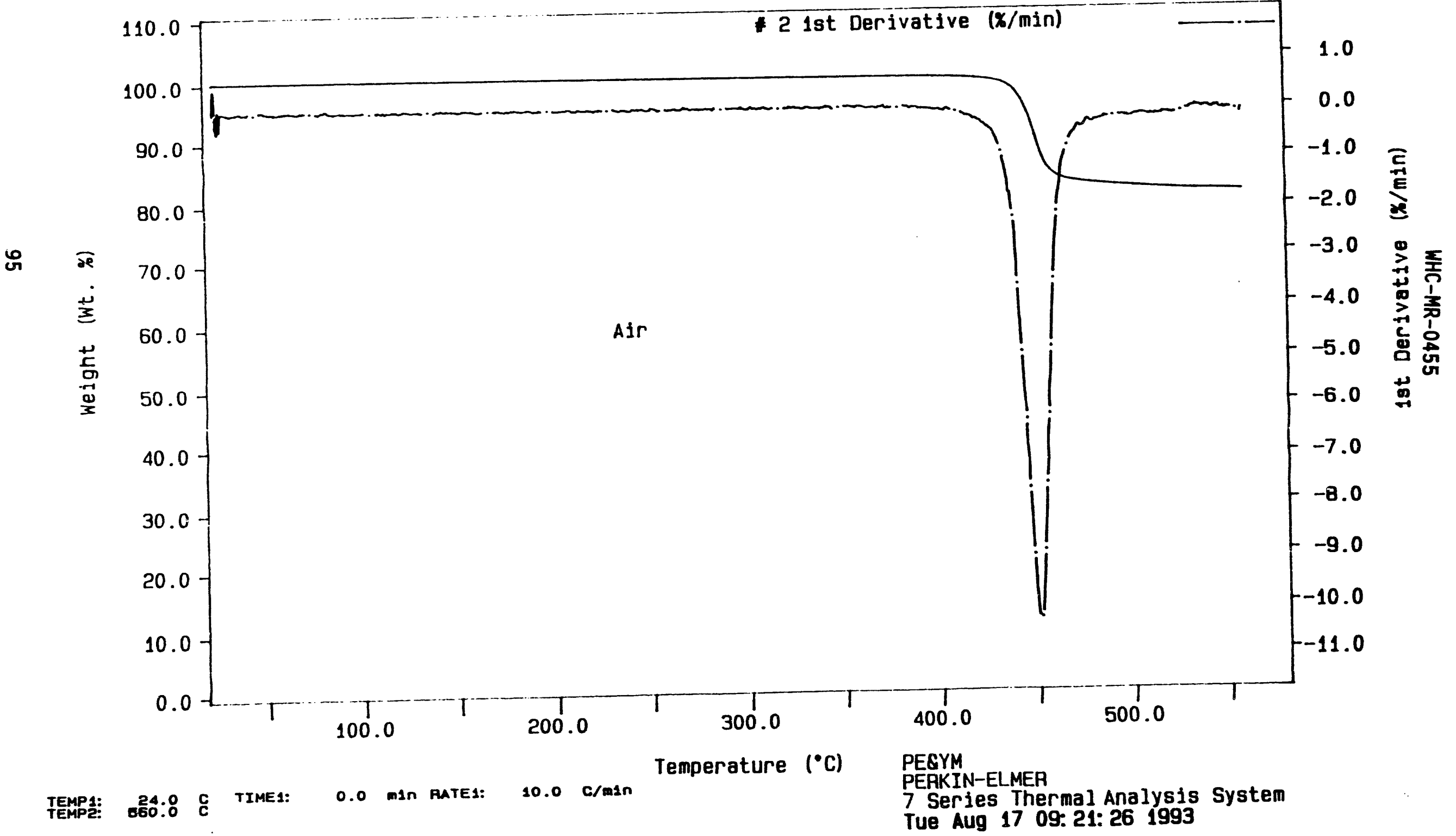

Figure 27. - TGA thermogram for oxalate-nitrate mixture 13A (1:1) 
Curve 1: TGA

File info: 0x13C-2 Fri Jan 15 14: 38: 321993

Sample Weight: $5.145 \mathrm{mg}$

Na Ox/Na Nitrate 13C (2)

* $1 \mathrm{Na}$ Ox/ Na Nitrate 13C (2)

$x$ Weight (wt. $x$ )

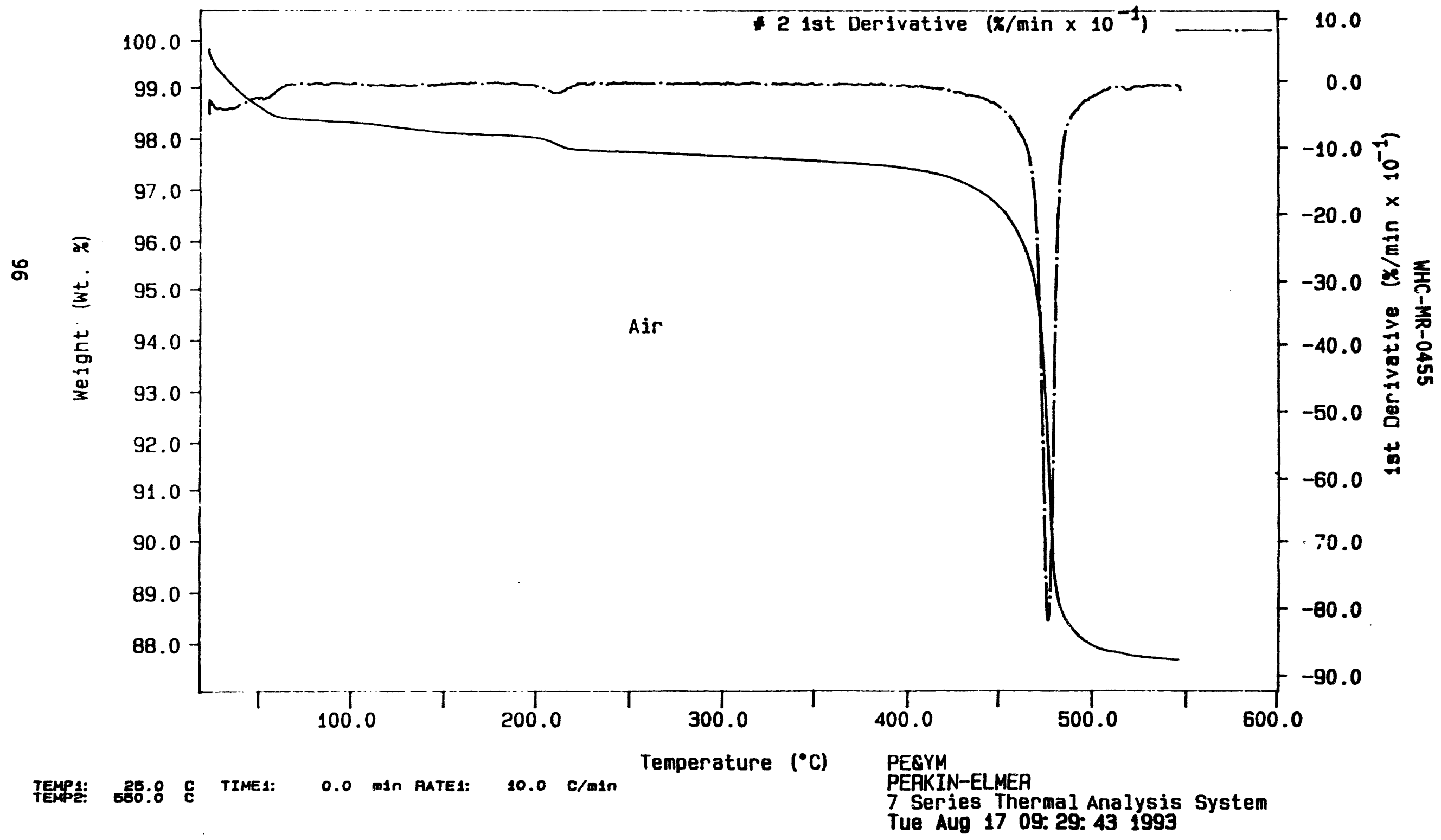

Figure 28. - TGA thermogram for oxalate-nitrate mixture $13 \mathrm{C}(1: 3 ;$ dil) 
WHC-MR-0455

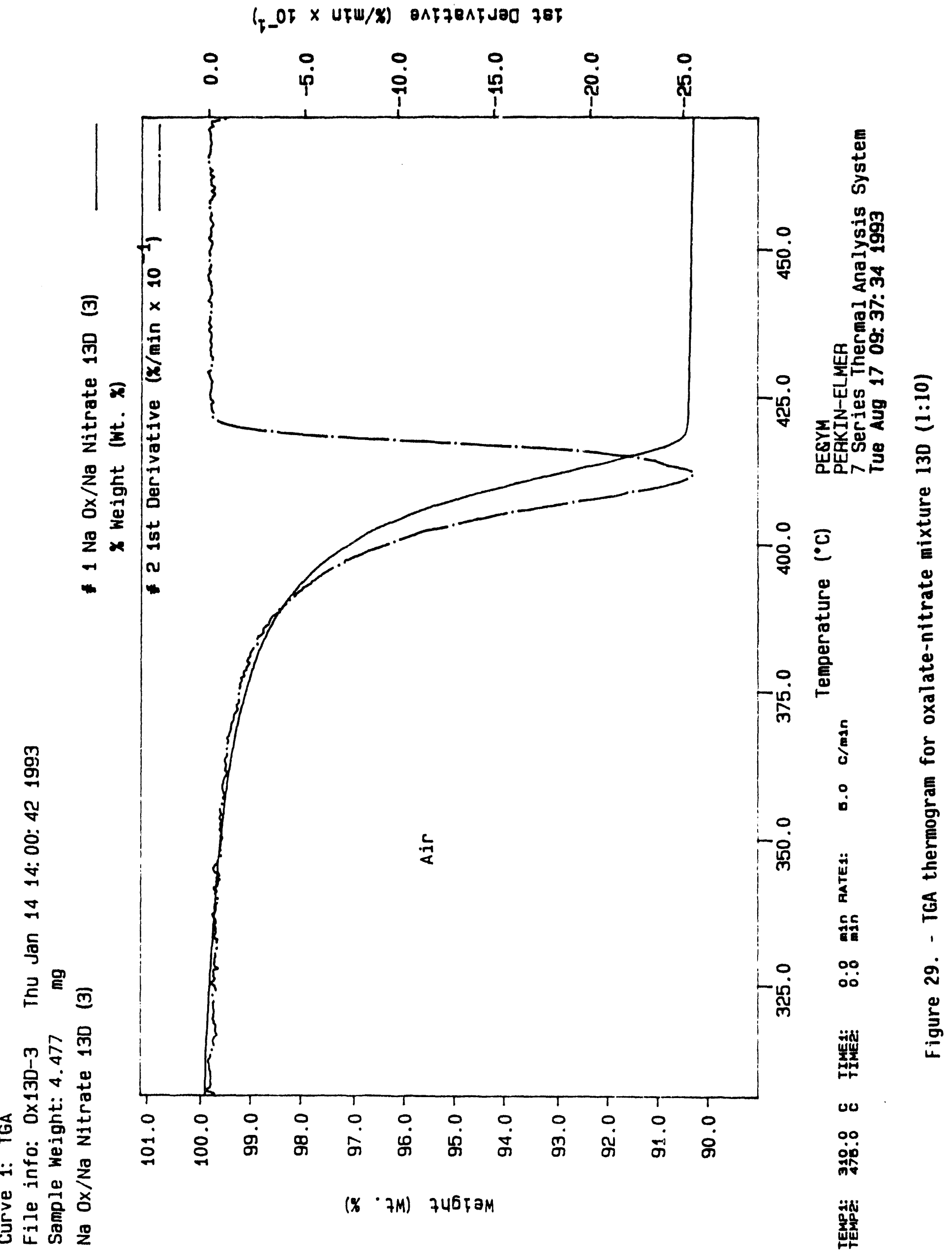


Curve 1: DSC

File info: 0x13A-9 Fri Jun 4 16: 54: 581993

Sample Weight: $3.500 \mathrm{mg}$

Na OxiNa Nitrate 13A (9)

- 1 Na Ox/Na Nitrate 13A (9)

Heat Flow (mw)

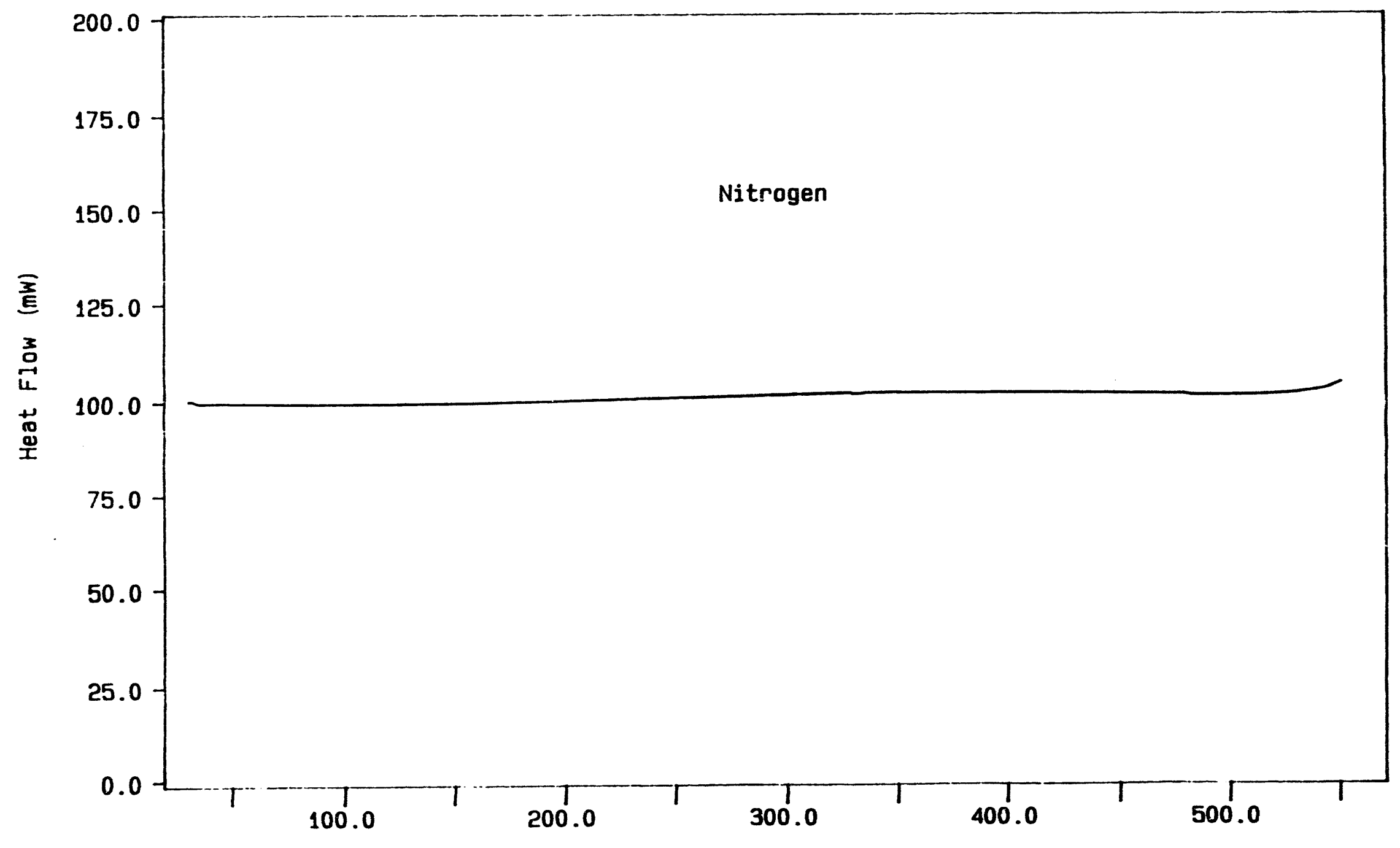

Glass Beads In Reference

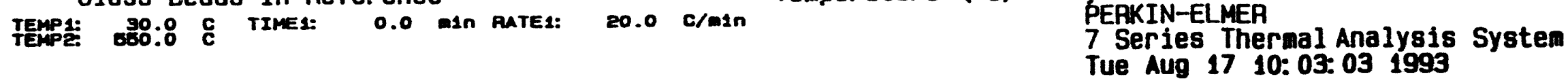

Figure 30. - DSC thermogram for residue from DSC test with oxalate-nitrate 
Curve 1: Dec

F11e Info: Ox13A-7 Tue Fob 9 10:51:07 1993

8amie Me1ont: 5.690 an

No Ox/Na Nitrate 13A (7)

- 1 No Ox/Na Nitrate $13 A$ (7) Hat Flow (nin)

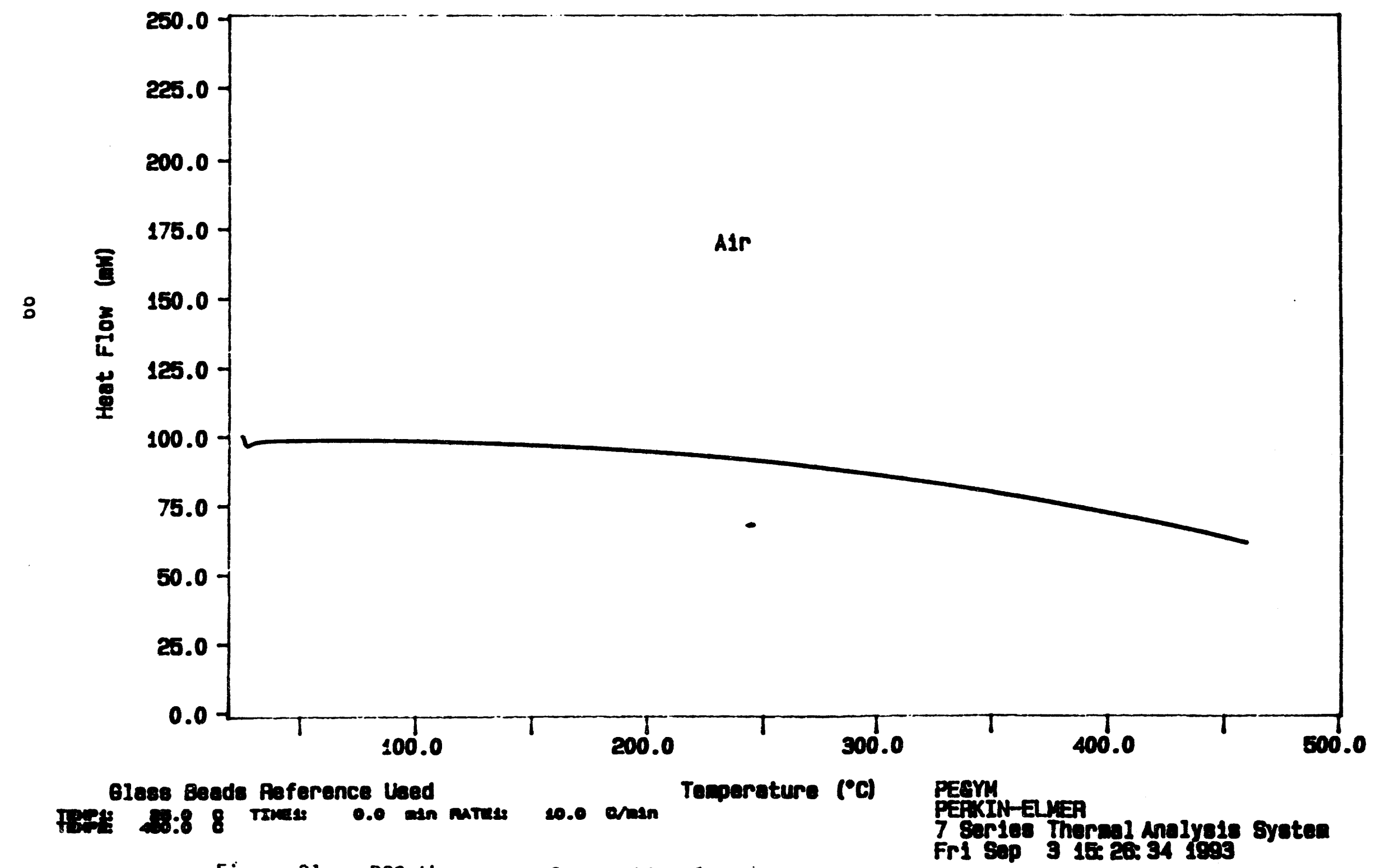

Figure 31. - DSC thermogram for residue from DSC test with oxalate-nitrate mixture $13 A(1: 1)$ 
Curve 1: DSC

File info: EDTAZA-3 Thu Feb 11 08: 13:53 1993

Sample Weight: 2.670

mg

EDTA 2A (3)

- 1 edta 2a (3)

Heat Flow (mW)

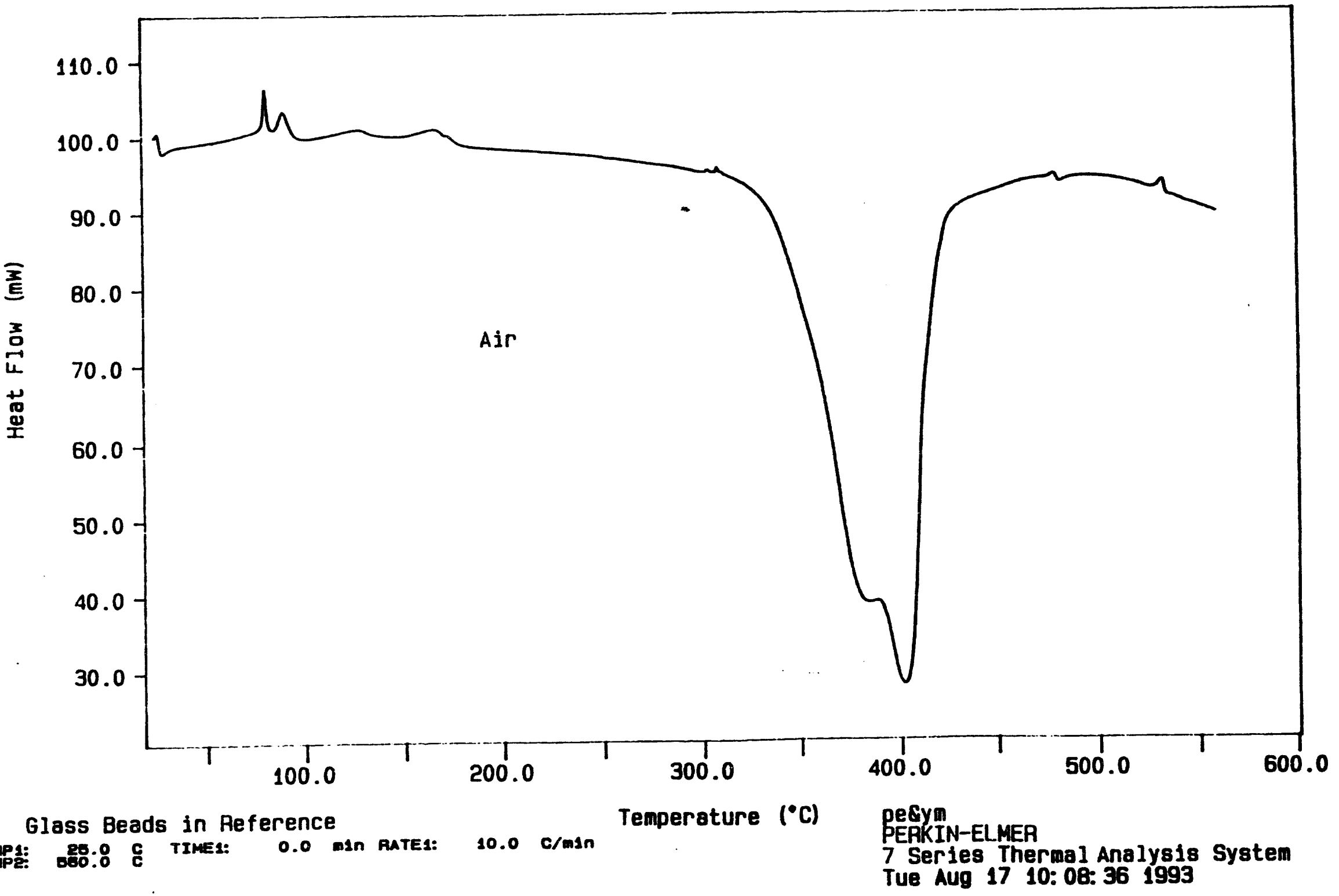

Figure 32., - DSC thermogram for sodium EDTA 
Curve 1: DSC

File info: EOTAZA-4 Wed Mar 10 08: 22: 231993

Sample Weight: $2.910 \mathrm{mg}$

EDTA $2 A$ (4)

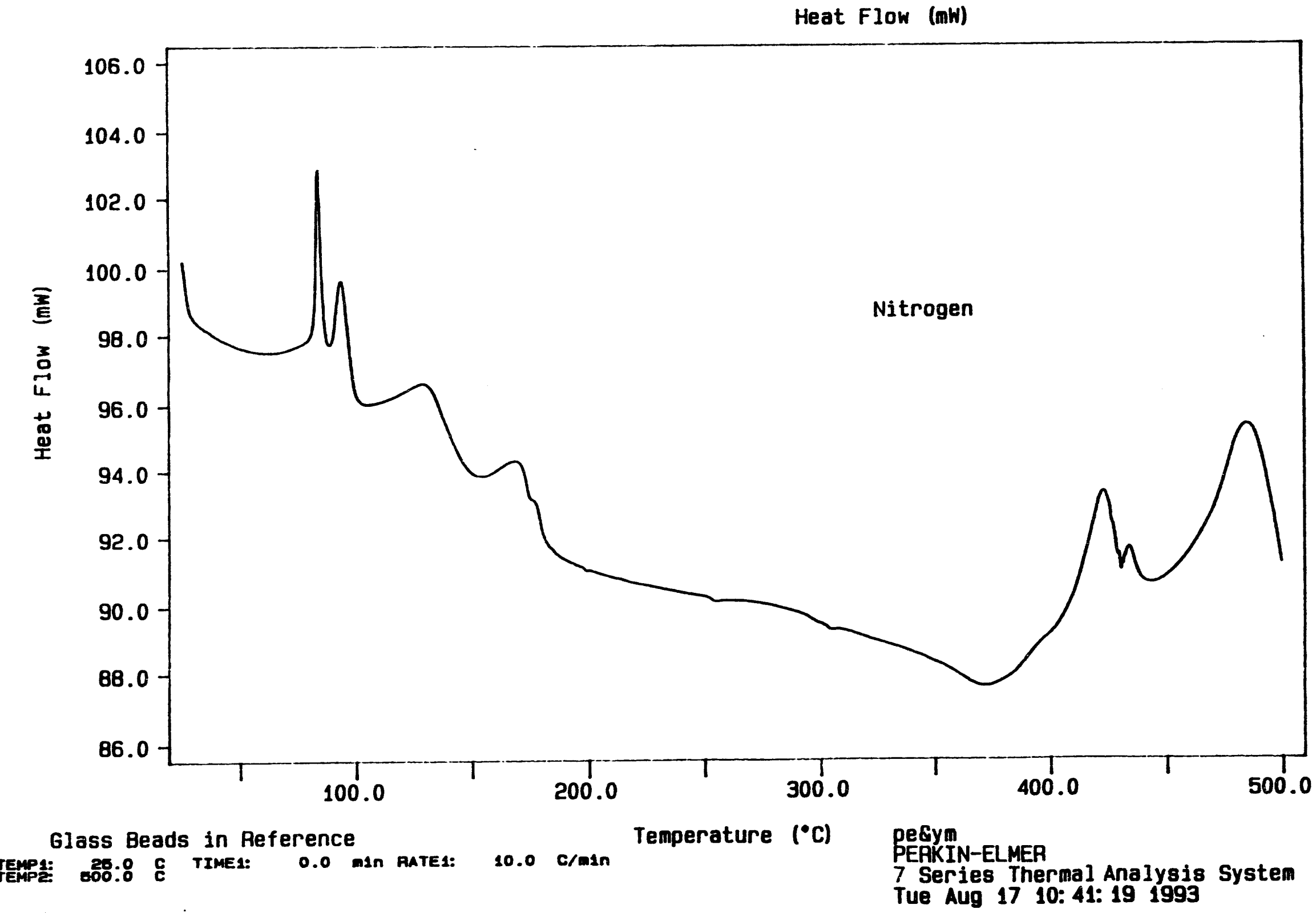

Figure 33. - DSC thermogram for sodium EDTA 
Curve 1: DSC

File info: EDTA9A-1 Mon Jan 25 14: 40:09 1993

Sample Weight: 3.950

EDTA 9A (1)

mg

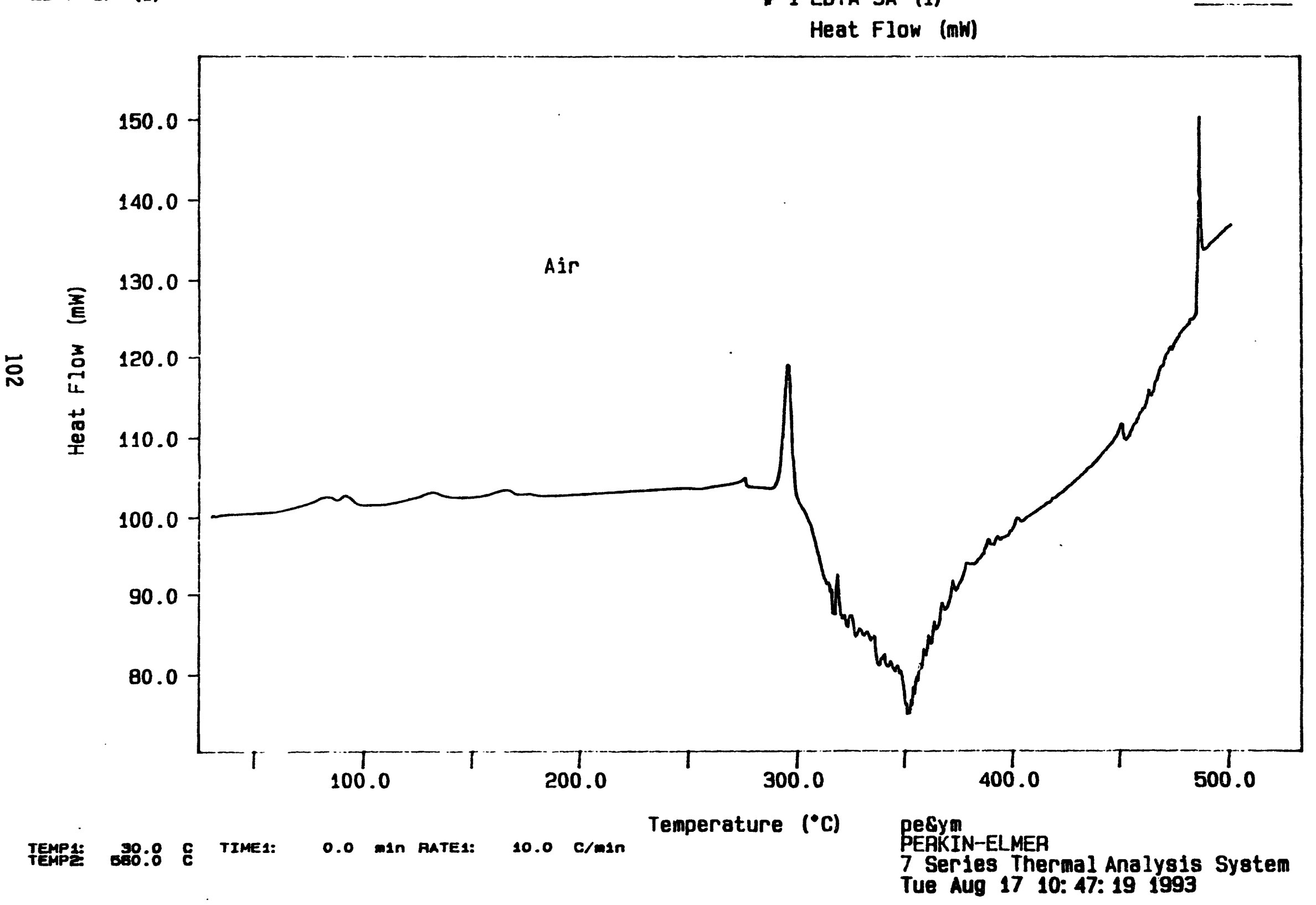

* 1 edta 9a (1)

Heat Flow (mW)

Figure 34. - DSC thermogram for EDTA-nitrate mixture 9A (1:1) 
Curve 1: DSC

File info: EDTA9B-2

Sample Weight: 3.500

EDTA 98 (2)

Tue Jan 26 08: 36: 541993

mg

* 1 EDTA 9B (2)

Heat Flow (mW)

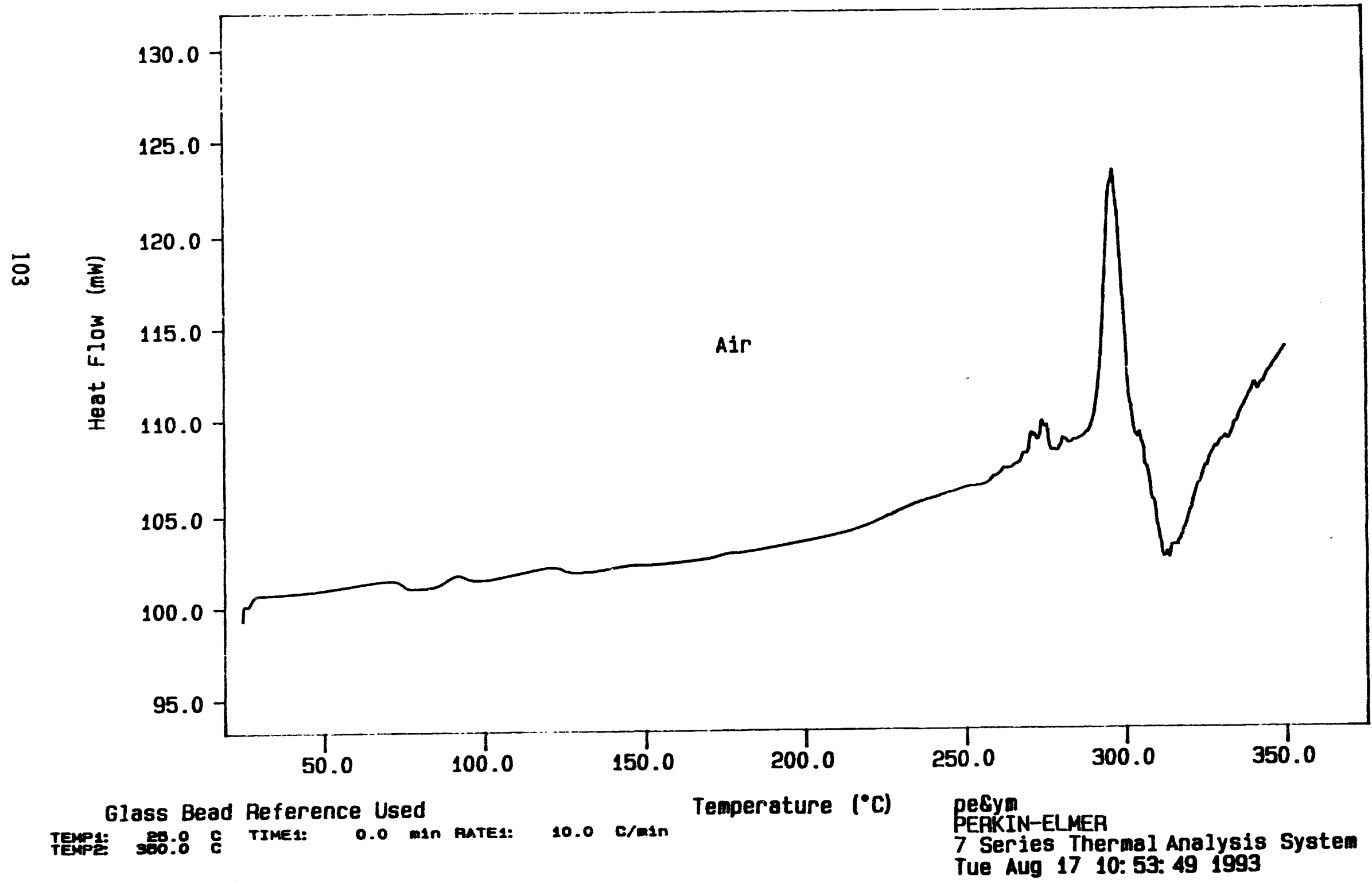

Figure 35. - DSC thermogram for EDTA-nitrate mixture 9B $(1: 3)$ 
Curve 1: DSC

File info: EDTA10A-1 Thu Jan 28 14: $42: 341993$

Sample Weight: $3.540 \mathrm{mg}$

EDTA 10A (1)

* 1 edta 10a (1)

Heat Flow (mw)

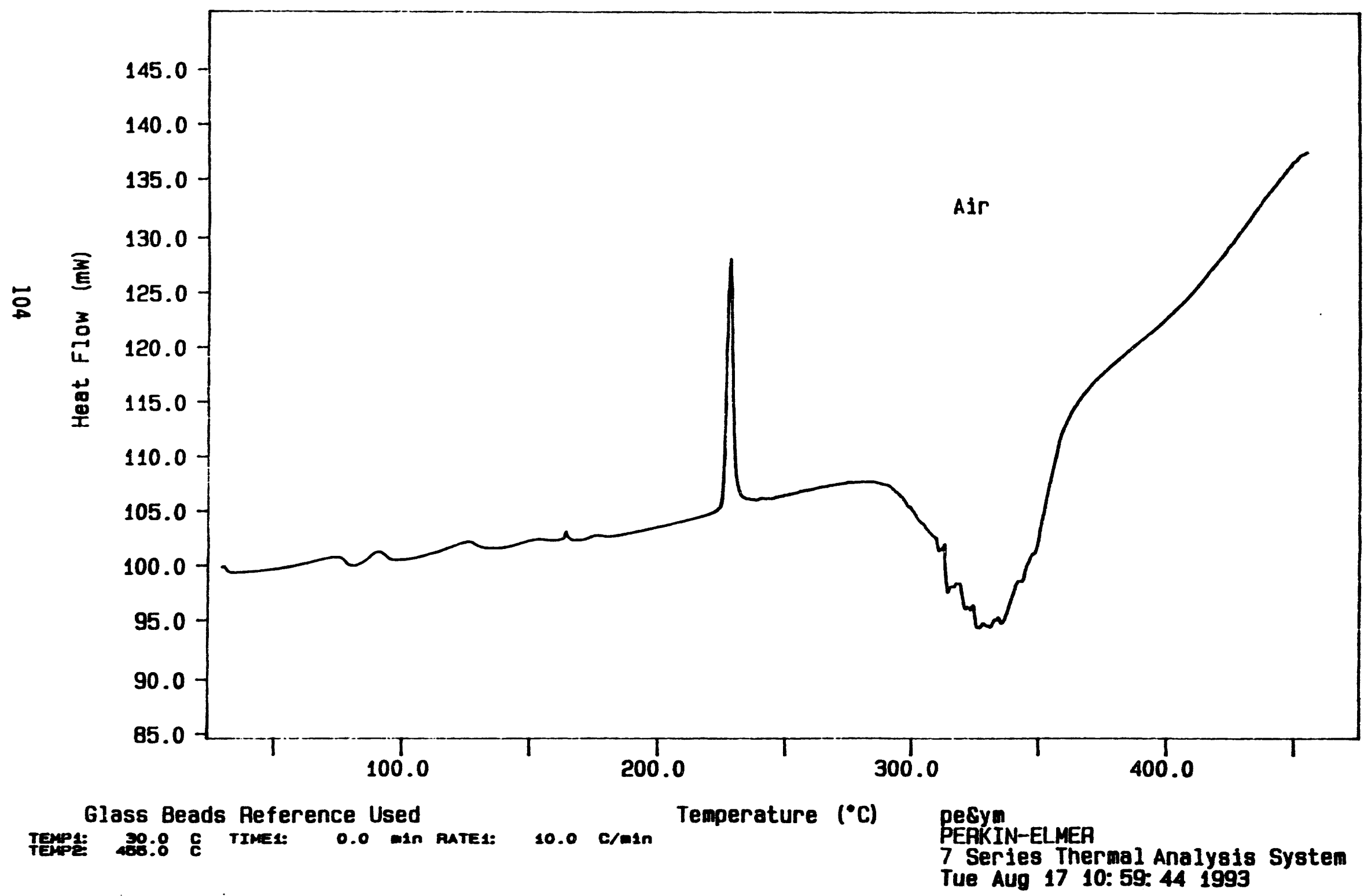

Figure 36. - DSC thermogram for EDTA-nitrate-nitrite mixture 10A (1:1) 
Curve 1: DSC

File info: EDTA10A-2 Wed Mar 10 09:02: 271993

Sample Weight: 4.200

mg

EDTA 10A (2)

* 1 EDTA 10A (2)

Heat Flow (mW)

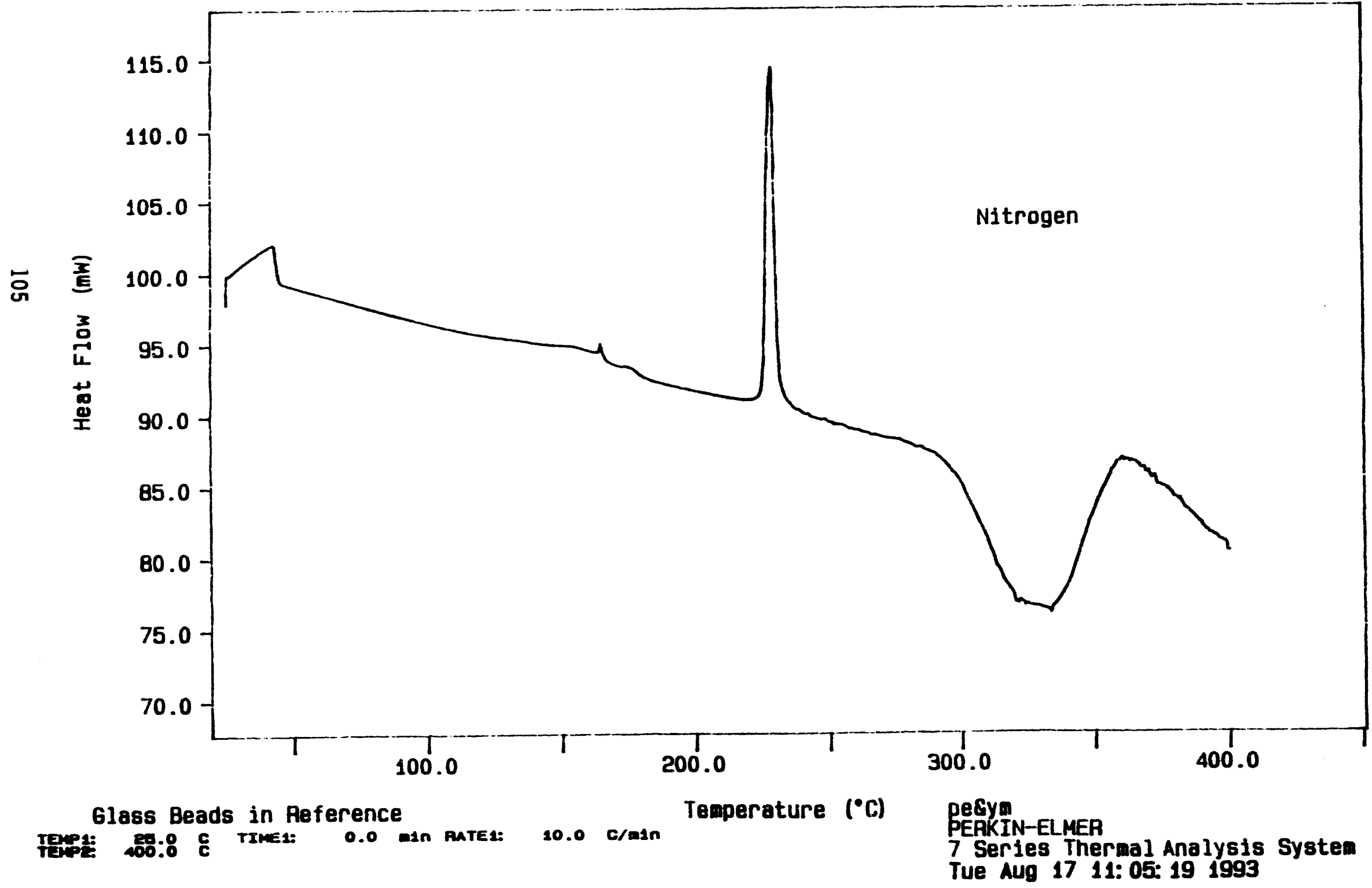

Figure 37. - DSC thermogram for EDTA-nitrate-nitrite mixture 10A (1:1) 
Curve 1: TGA

File info: EDTA2A-1 Tue Mar 9 11: 26: 131993

Sample Weight: 3.126

mg

EDTA-2A (1)

1 EDTA-2A (1)

$x$ Weight (Wt. X)

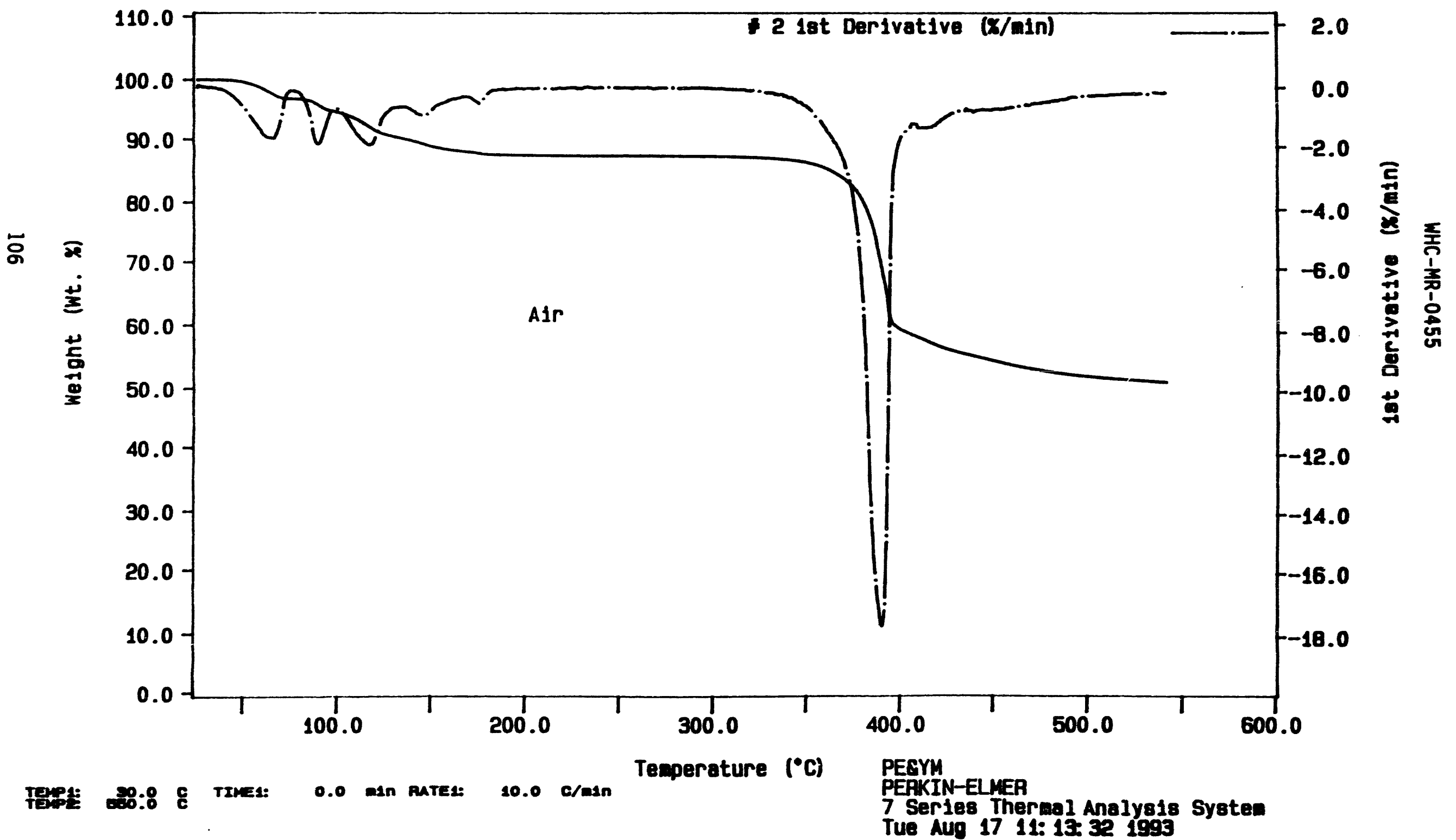

Figure 38. - TGA thermogram for sodium EDTA 
WHC-MR-0455

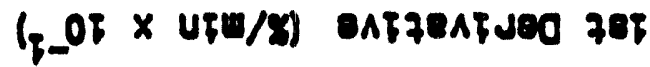

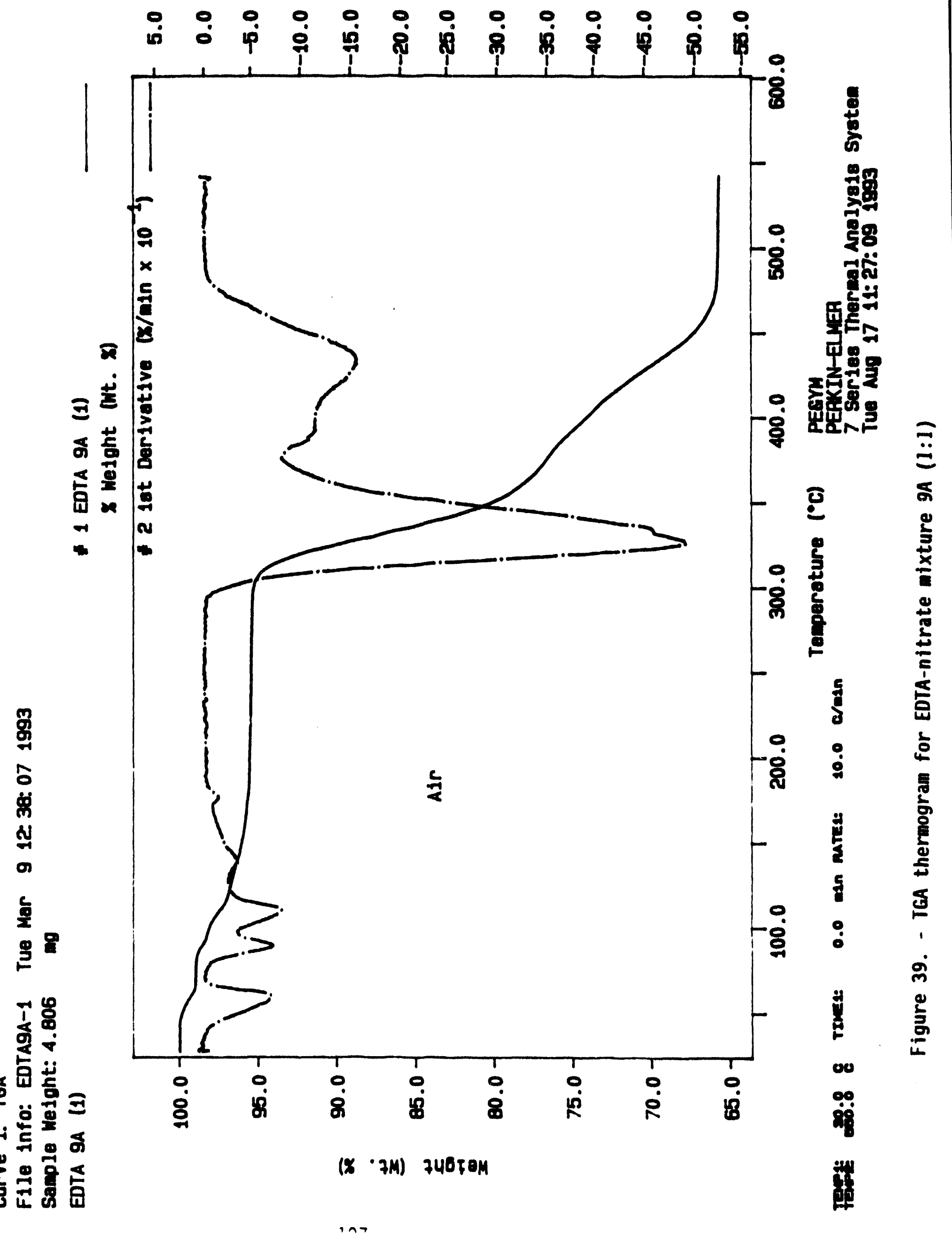


WHC-MR-0455

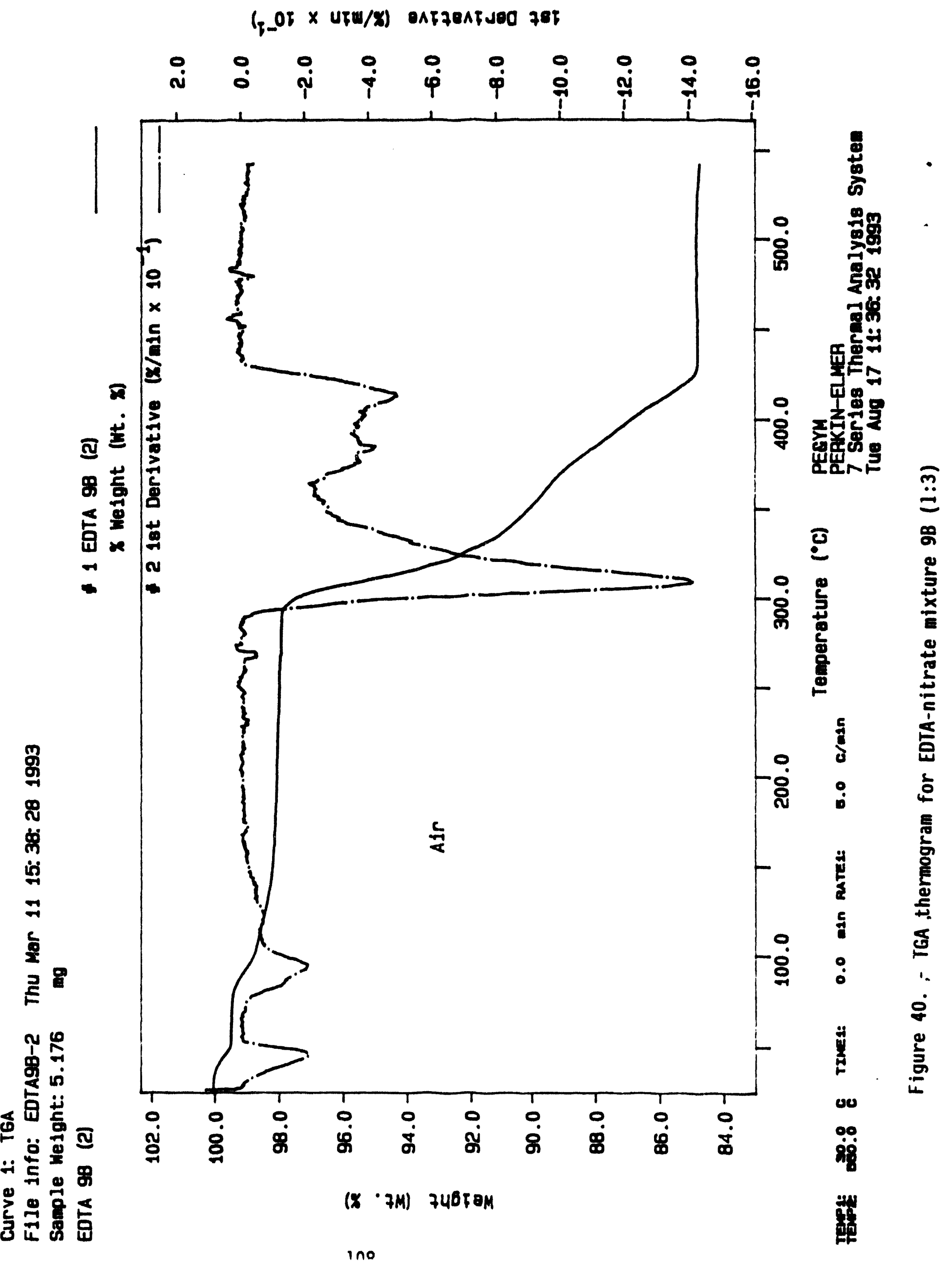


Curve 1: TGA

File info: EDTA9C-2

Fr1 Mar 12 08: 44: 591993 Sample We1ght: 6.096

EDTA 9C (2)

ag

\& EDTA 9C (2)

$x$ weight (wt. X)

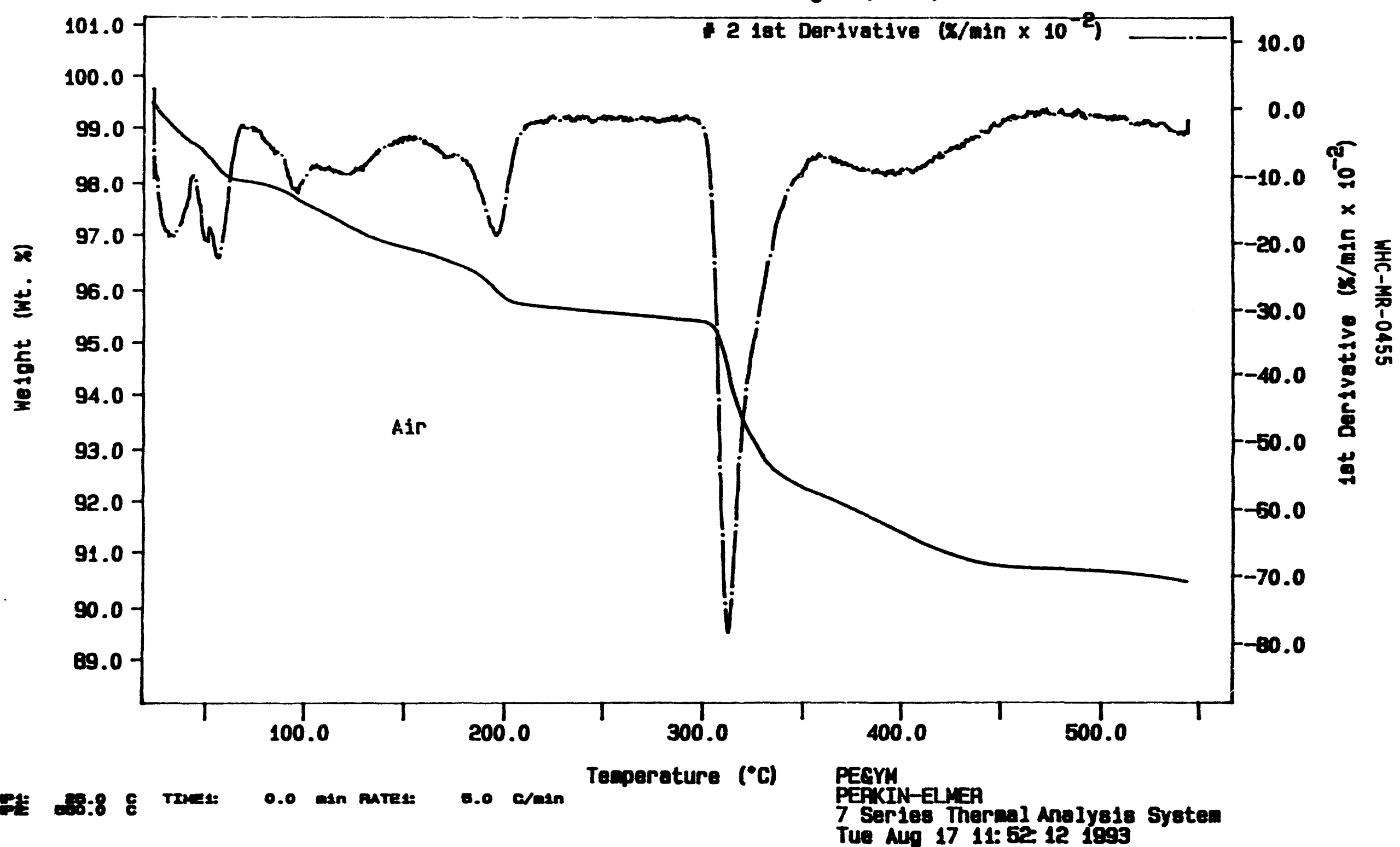

Figure 41. - TGA thermogram for EDTA-nitrate mixture $9 C(1: 3$; dil) 
Curve 1: TGA

F1le info: EDTASD-1 Wed Mar 10 16: 04:53 1993 Sanple Weight: 6.958 mg EDTA 90 (1)

1 EDTA 90 (1)

8 Weight (it. X)

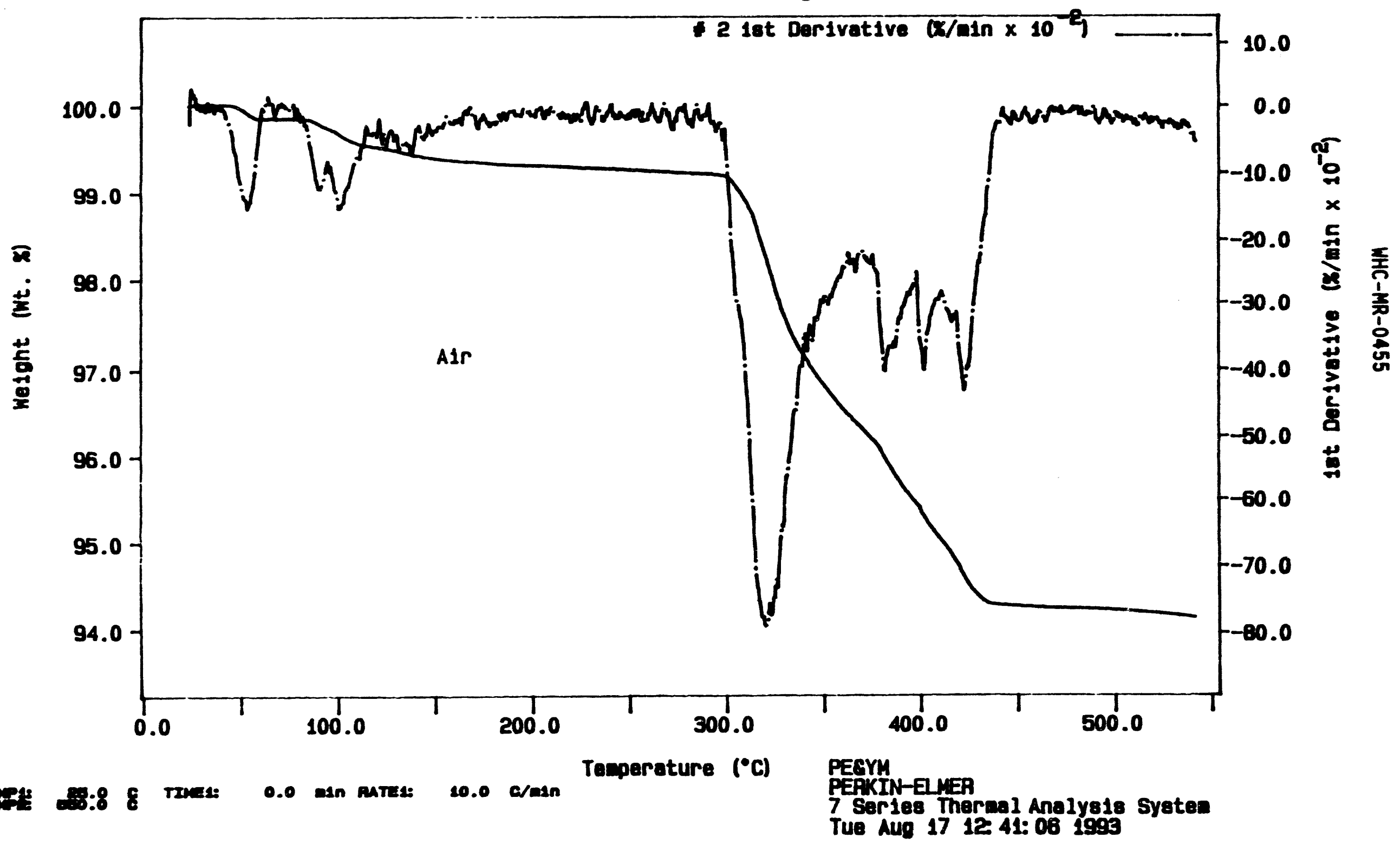

Figure :?. - TGA thermogram for EDTA-nitrate mixture $90 \quad(1: 10)$ 


\section{Curve 1: T6A}

F1le Info: EDTA10A-1 Hed Mar 10 17: 15: 021993

Sample Weight: 4.298

EDTA $10 A$ (1)

mg

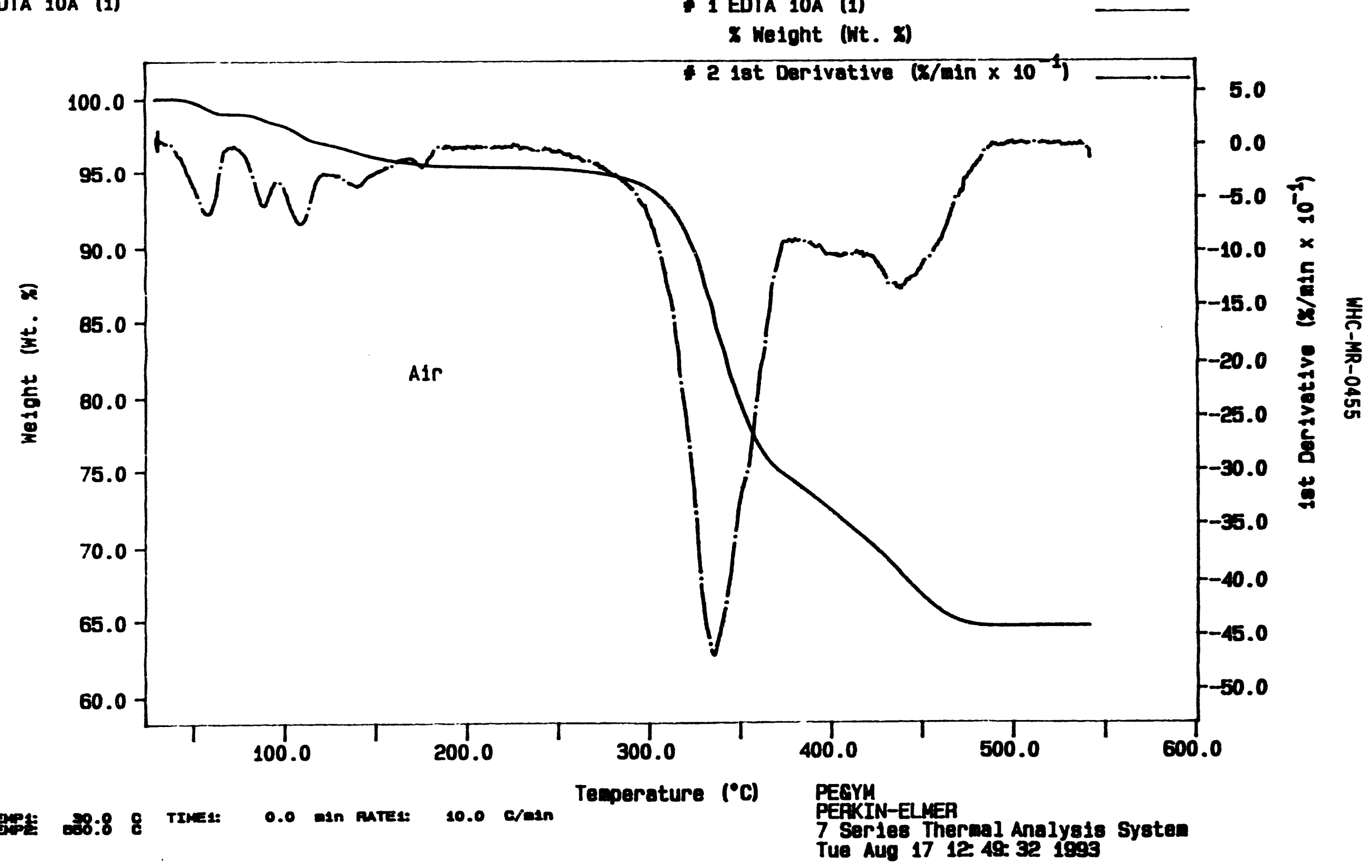

Figure 43. - TGA thermogram for EDTA-nitrate-nitrite mixture 10A (1:1) 
Curve 1: TGA

F1le Info: EDTA10B-2 Mon Mar 15 10: 48: 391993

Sample Welght: 5.271 ing

EDTA 108 (2)

- 1 eDTA 10B (2)

$x$ Weight (wt. $x$ )

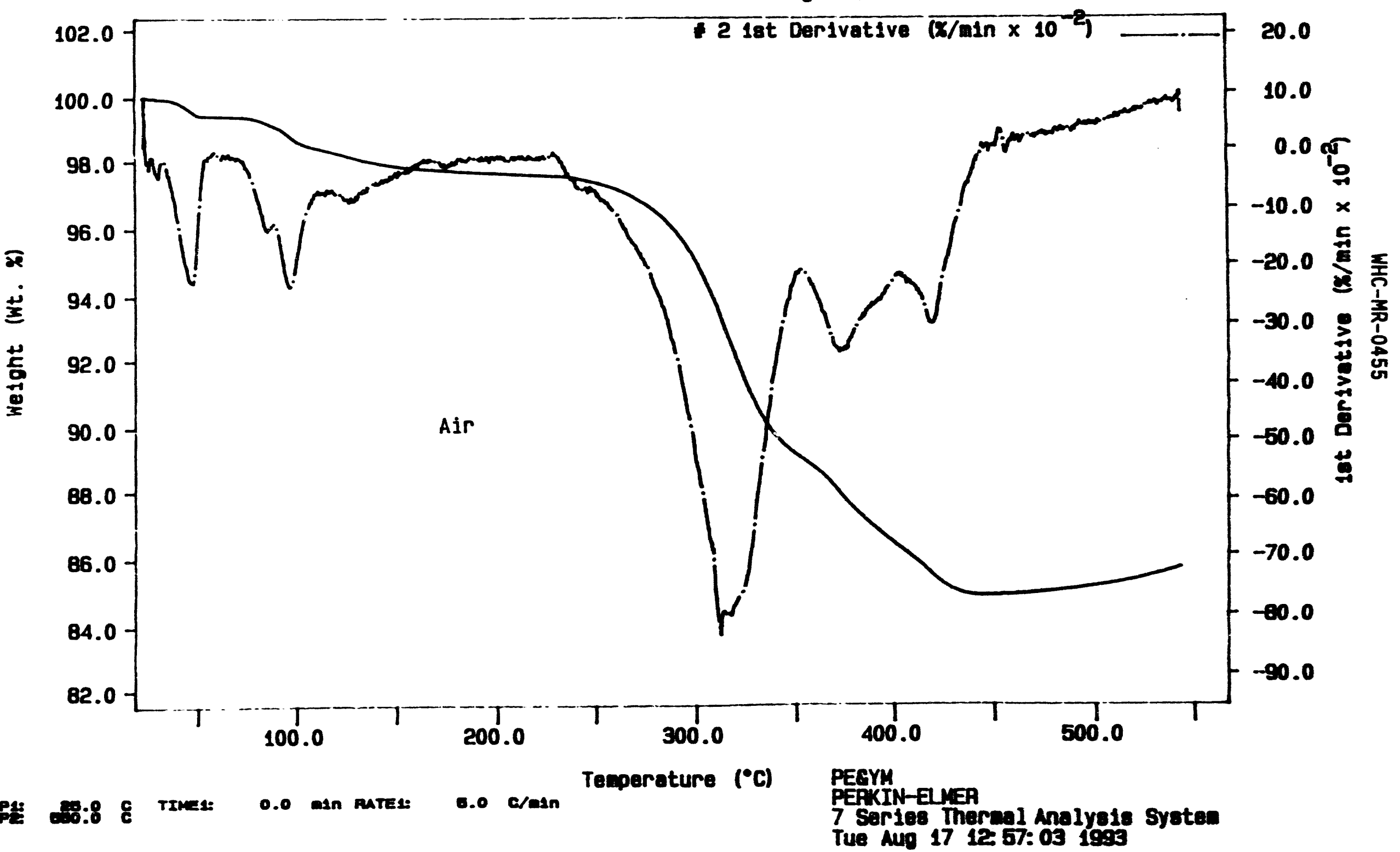

Figure 44. - TGA thermogram for EDTA-nitrate-nitrite mixture 10B (1:3) 
Curve 1: TGA

F1le Info: EOTA10C-2 Mon Mar 15 12: 57: 311993 Sample Weight: 4.818 $\mathrm{mg}$

EOTA 10C (2)

\section{EOTA 10C (2)}

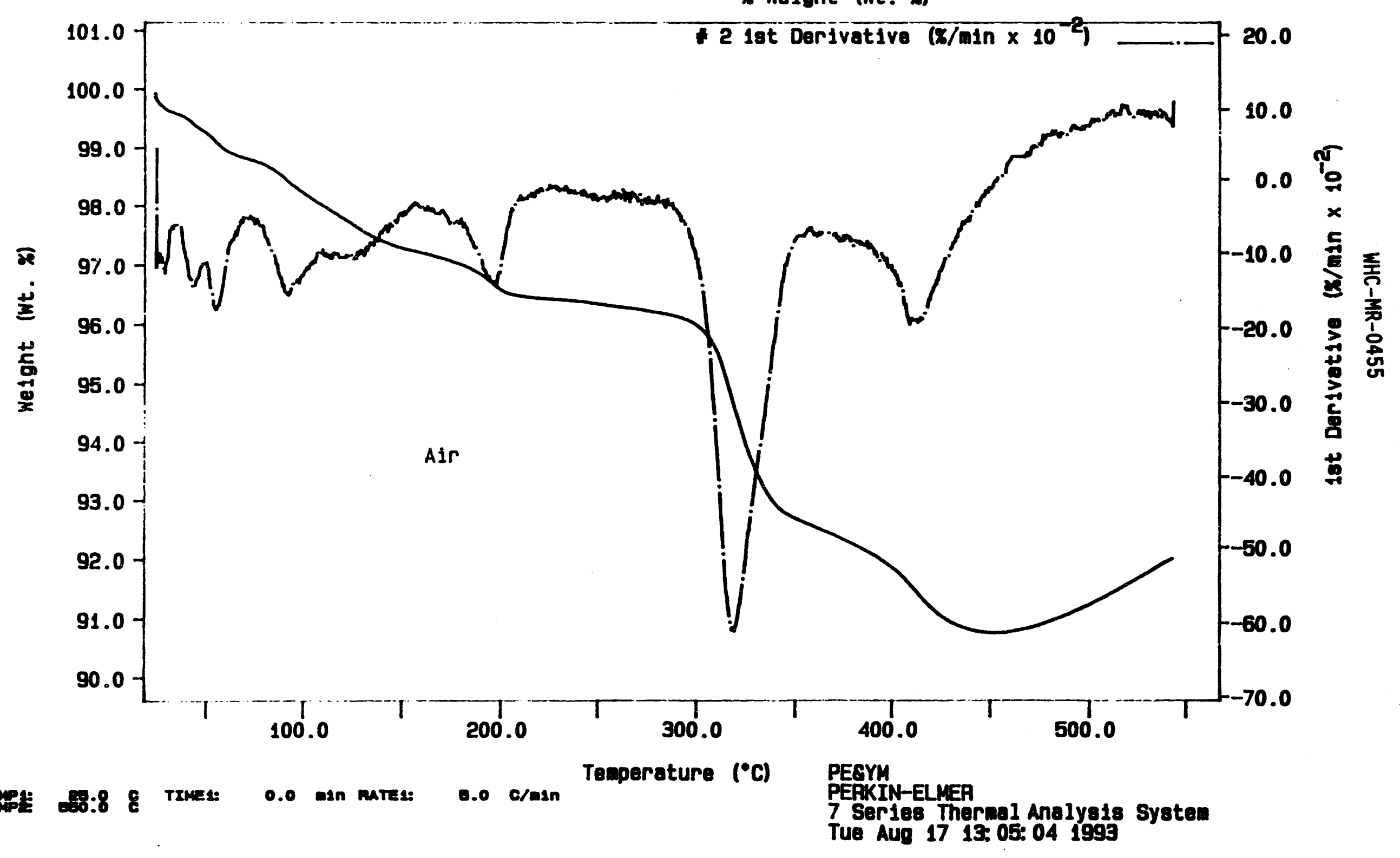

Figure 45. - TGA thermogram for EDTA-nitrate-nitrite mixture $10 \mathrm{C}(1: 3 ; \mathrm{di1})$ 
Curve 1: TGA

F1le info: EDTA10D-2 Mon Mar 15 15: 01: 051993

Sample Welght: 5.359

EDTA 100 (2)

mg

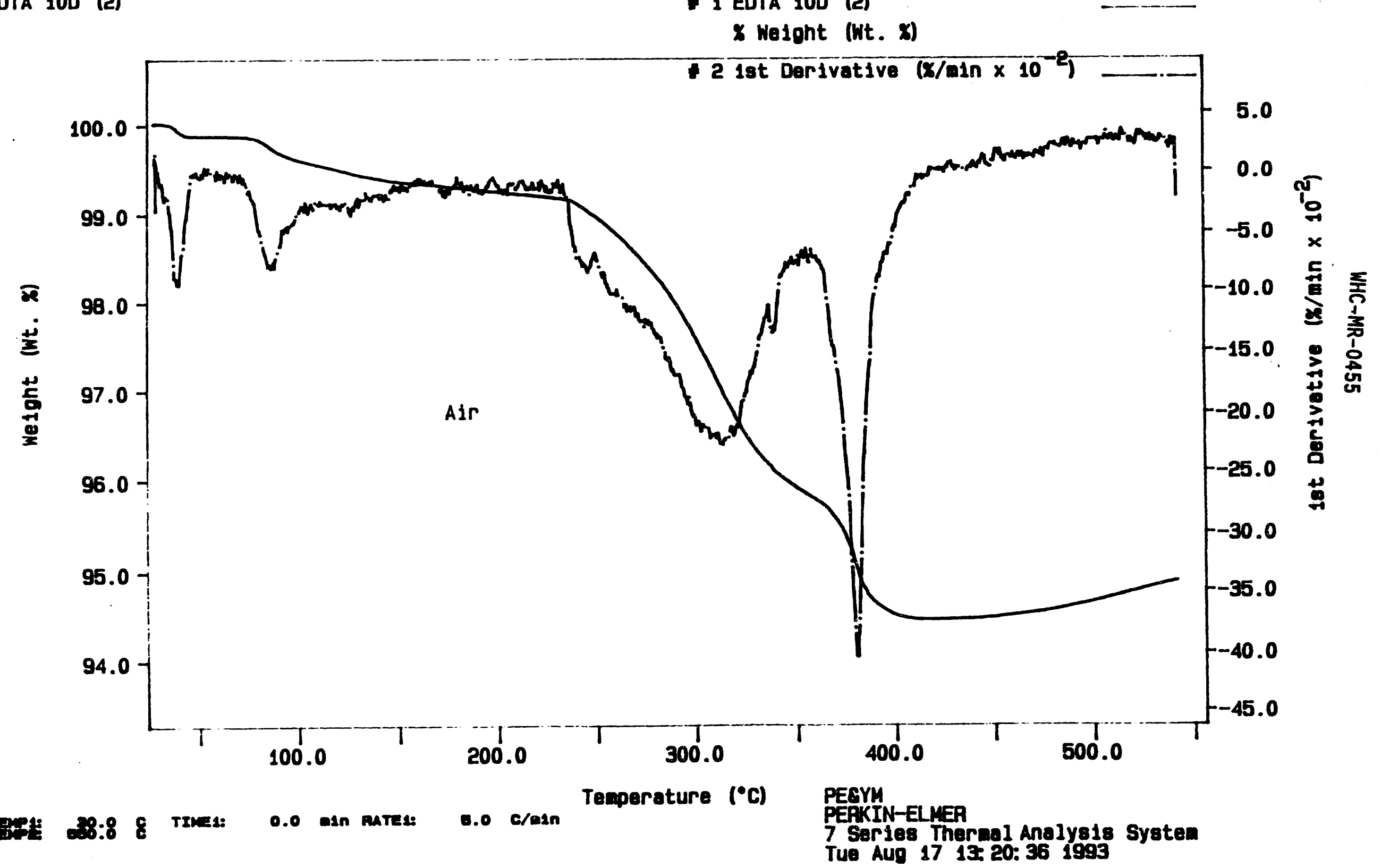

Figure 46. - TGA thermogram for EDTA-nitrate-nitrite mixture 10D (1:10) 
Curve 1: DSC

File info: Cit3A-1 Mon Feb 1 11:03: 431993

Sample Weight: $3.430 \quad \mathrm{mg}$

Na Citrate 3A (1)

- 1 Na Citrate 3A (1)

Heat Flow (niw)

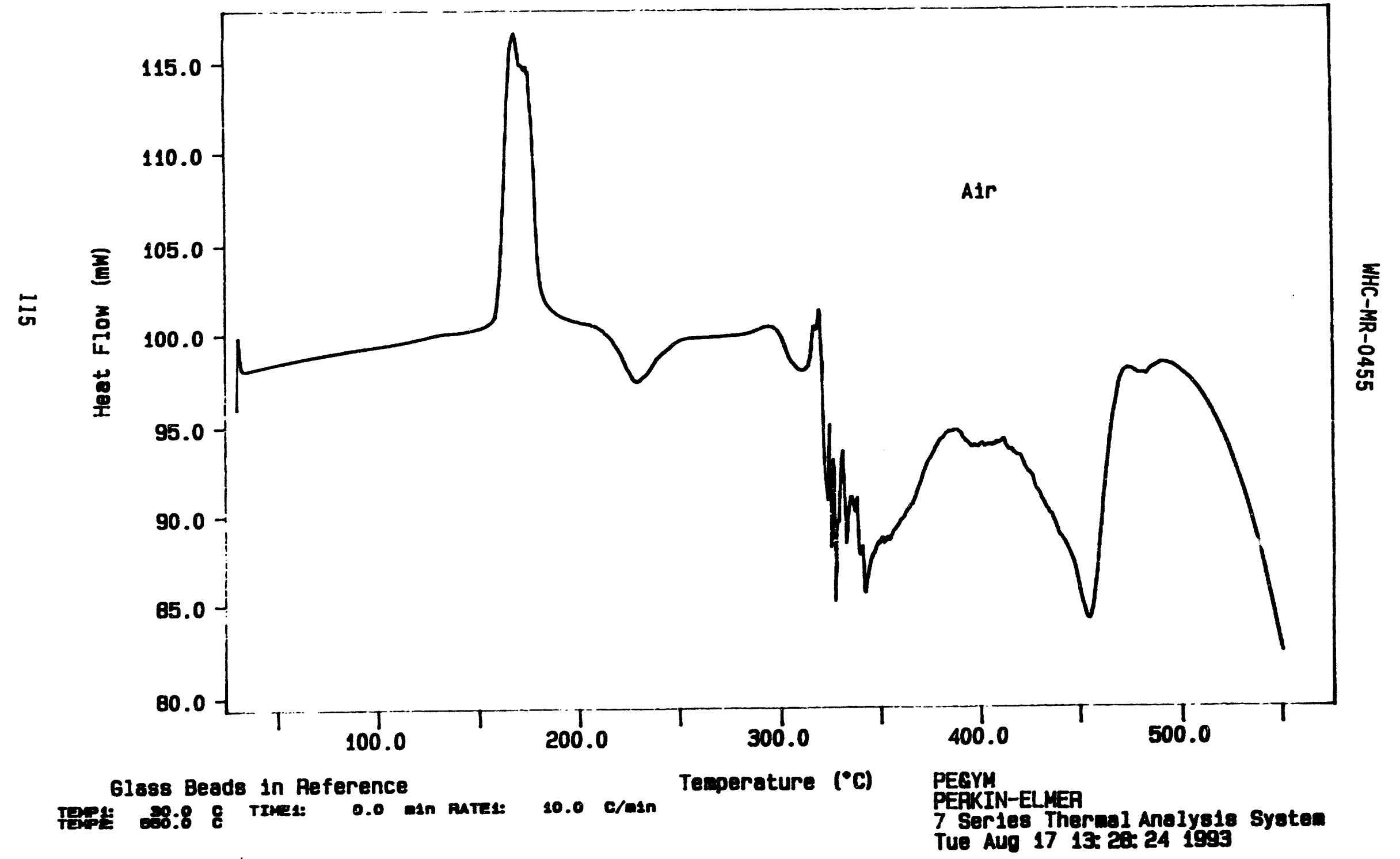

Figure 47. - DSC thermogram for sodium citrate 
Curve 1: DSC

F1le info: Cit11A-1 Mon Feb 1 11: 49: 281993

Sample Weight: $3.710 \mathrm{mg}$

Na Citrate 11A (1)

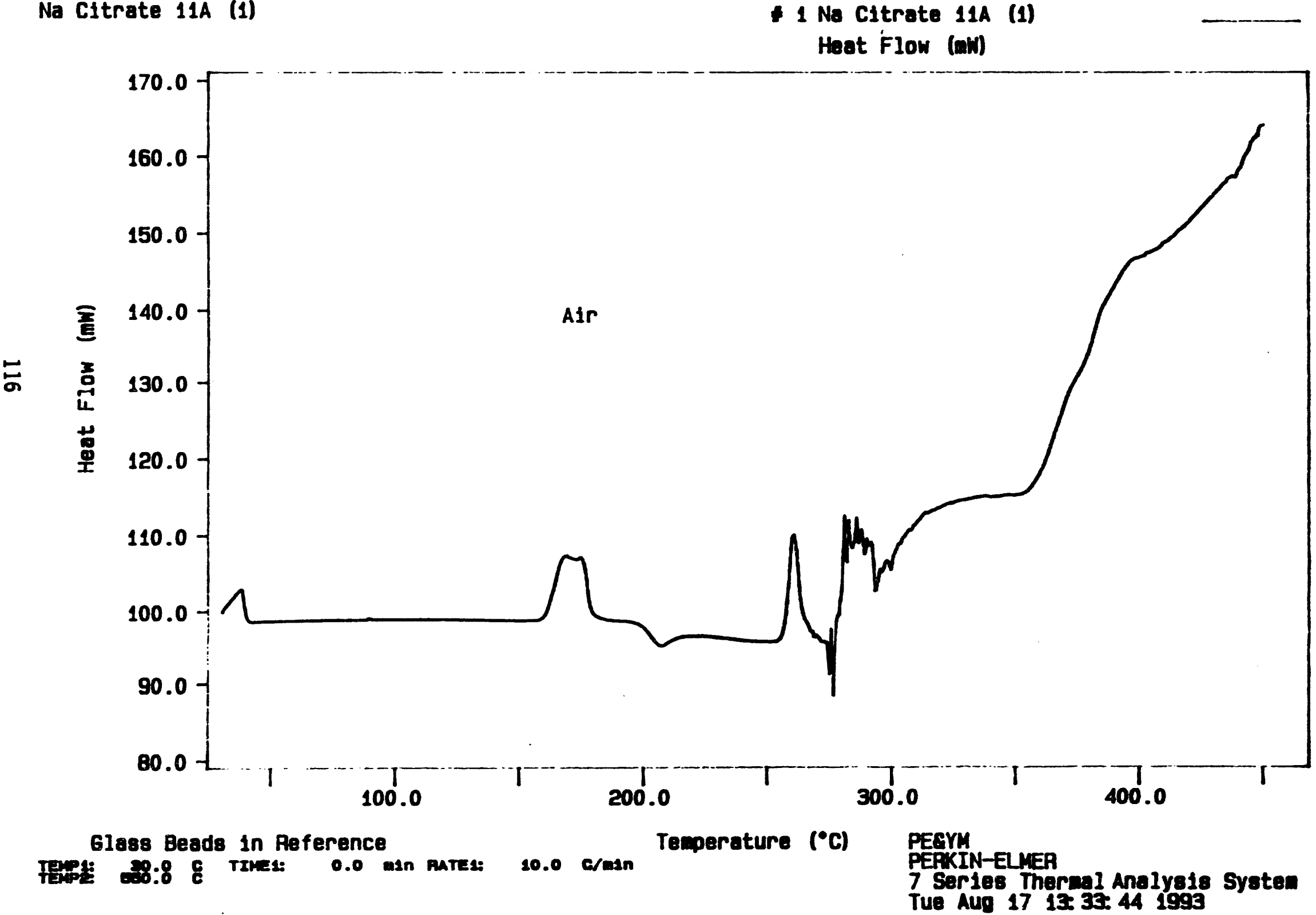

Figure 48., - DSC, thermogram for citrate-nitıate mixture $11 \mathrm{~A}(1: 1)$ 
Curve 1: DSC

File info: Cit11A-2 Tue Feb 2 08: 21: 391993

Sample Weight: $4.140 \mathrm{mg}$

Na Citrate $11 \mathrm{~A}$ (2)

- 1 Na Citrate 11A (2) Heat flow (nit)

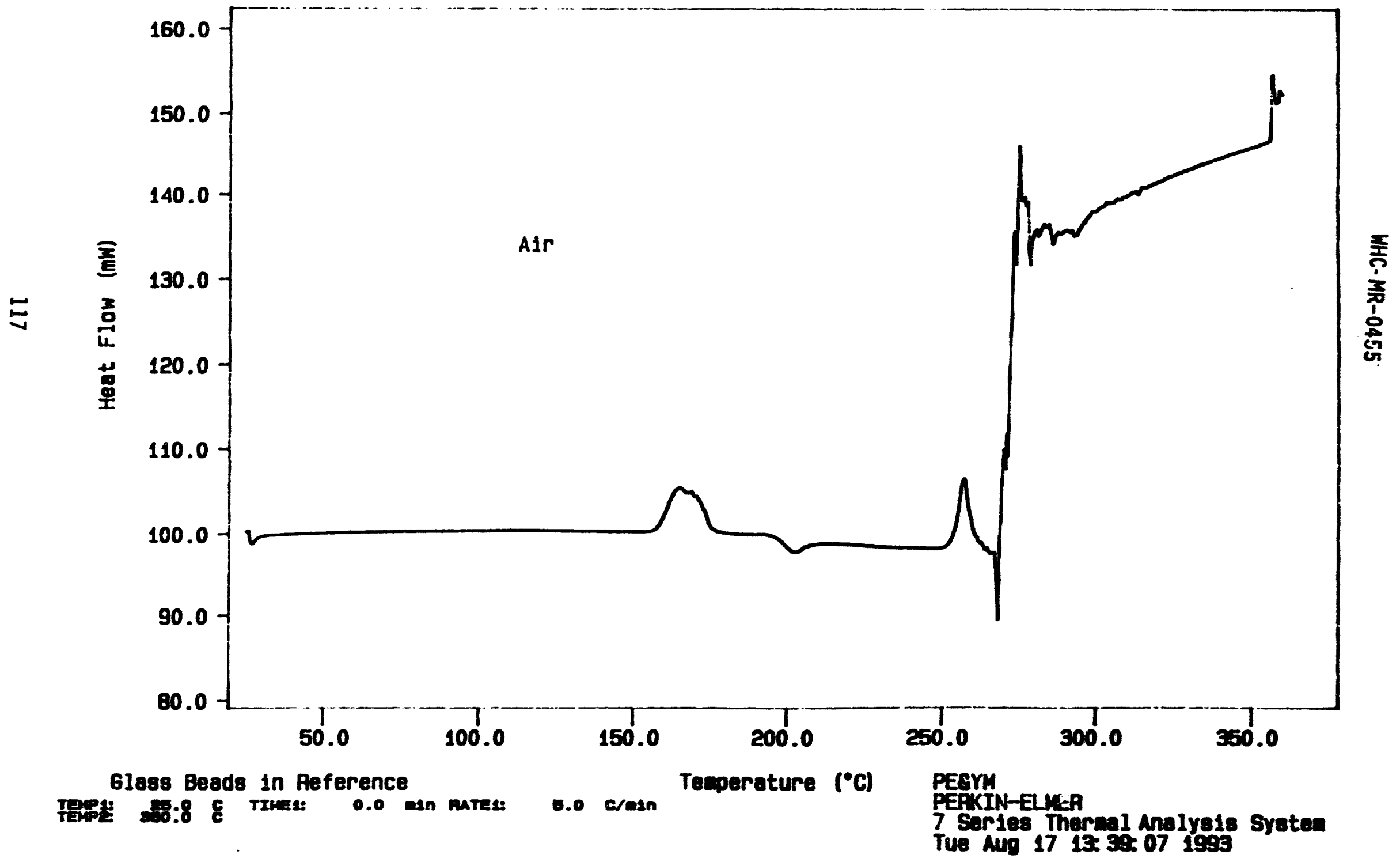

Figure 49. - DSC thermogram for citrate-nitrate mixture $11 \mathrm{~A}(1: 1)$ 
Curve 1: DSC

File info: Cit11B-1 Mon Feb 1 13: 40:54 1993

Sample Weight: $4.040 \mathrm{mg}$

Na Citrate 11B (1)

- 1 Na Citrate 118 (1)

Heat flow (nw)

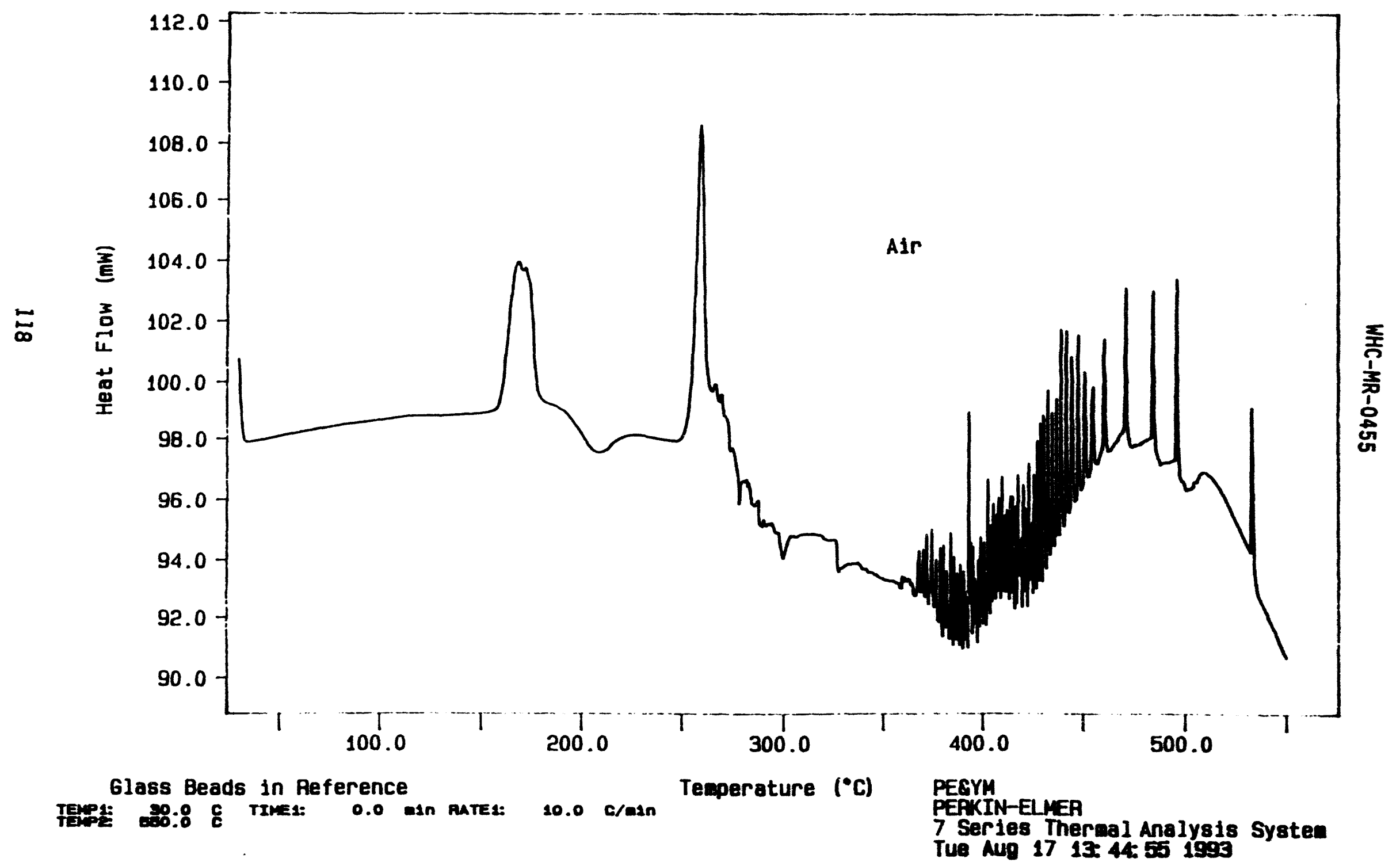

Figure 50. - DSC thermogram for citrate-nitrate mixture 118 (1:3) 
Curve 1: DSC

File info: Cit11C-1 Mon Feb 1 15: $36: 331993$

Sample Weight: 5.370 ag

Na Citrate 11C (1)

- 1 Na Citrate 11C (1)

Heat flow (nid)

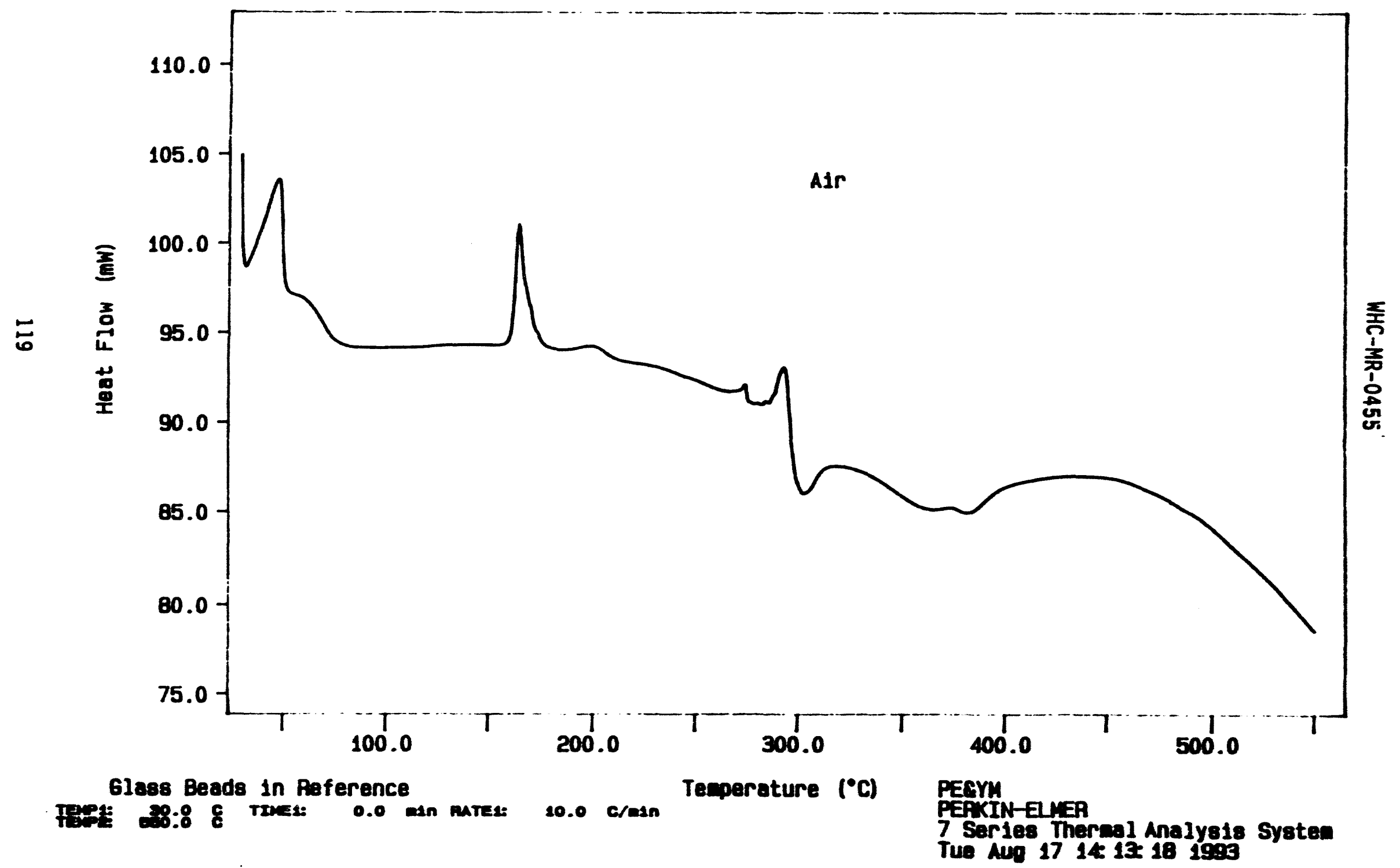

Figure 51. - DSC thermogram for citrate-nitrate mixture $11 C(1: 3 ;$ dil $)$ 
Curve 1: DSC

File info: Cit11D-1 Mon Feb 1 16: 30: 181993

Sample Weight: 3.760

Na Citrate 110 (1)

- 1 Na Citrate 110 (1)

Heat flon (an)

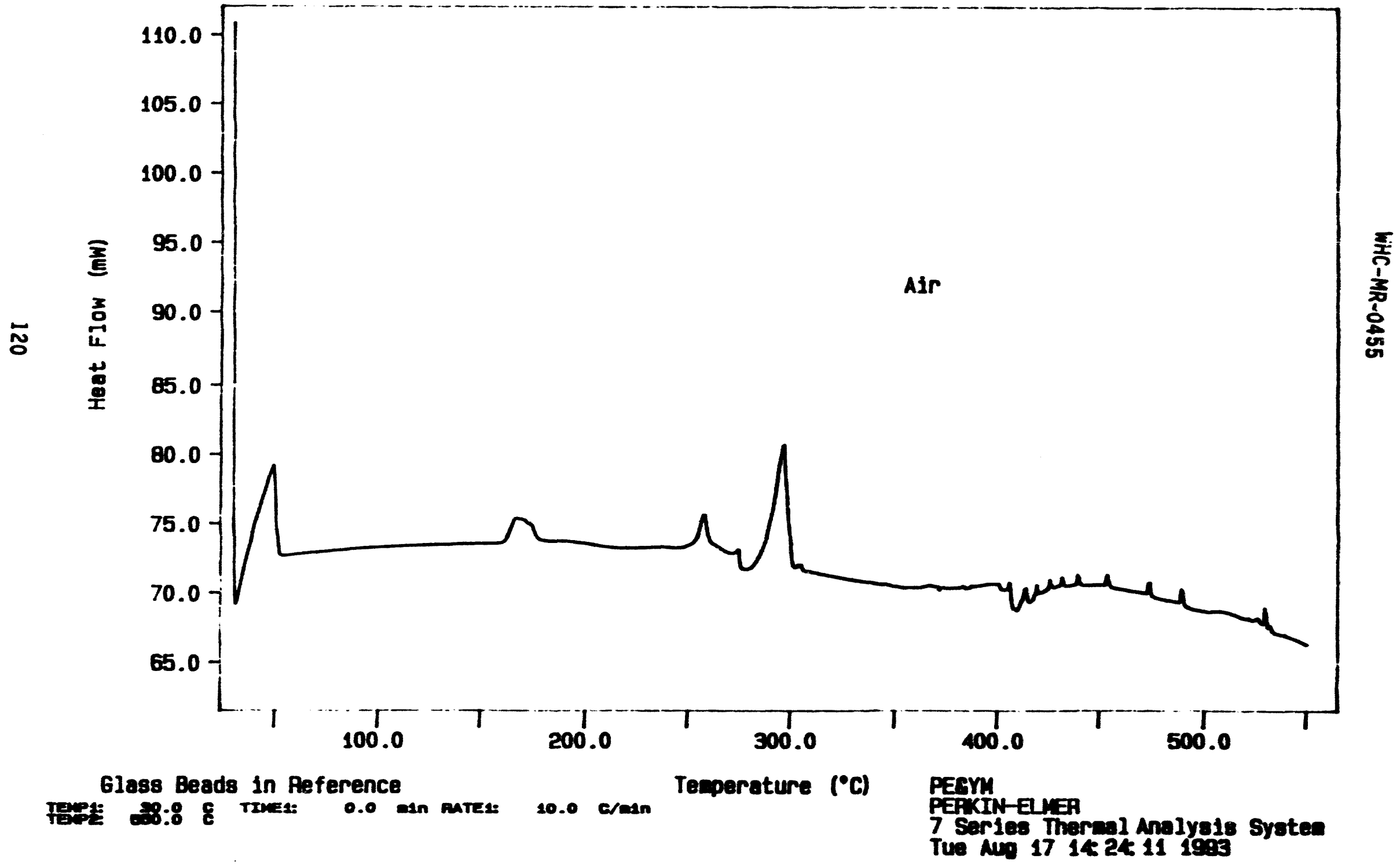

Figure 52. - DSC thermogram for citrate-nitrate aixture $110(1: 10)$ 
Curve 1: DSC

File info: C1t110-3 Thu Feb 11 13: 33: 151993

Sample Weight: $2.750 \mathrm{mg}$

Na Citrate 110 (3)

- 1 No Citrate 110 (3)

Heat ilow (nin)

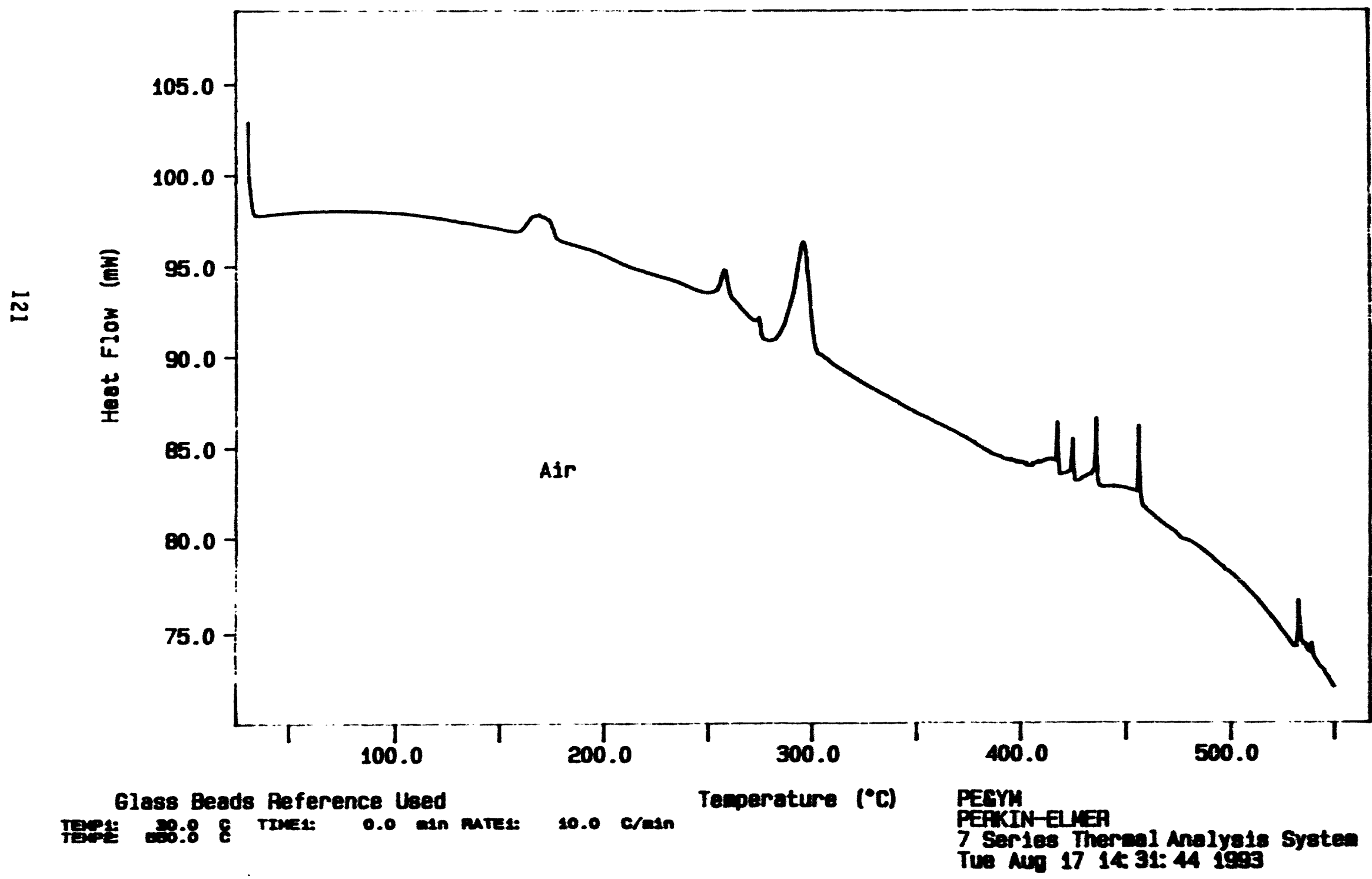

Figure 53. - DSC thermogran for citrate-nitrate aixture $110(1: 10)$ 
Curve 1: DSC

File info: Cit12a-1 Tue Feb 2 12:30: 121993

Sanple Weight: 2.940

ng

Na Citrate 12A (1)

1 Na Citrate 12A (1)

Hoat flow tan

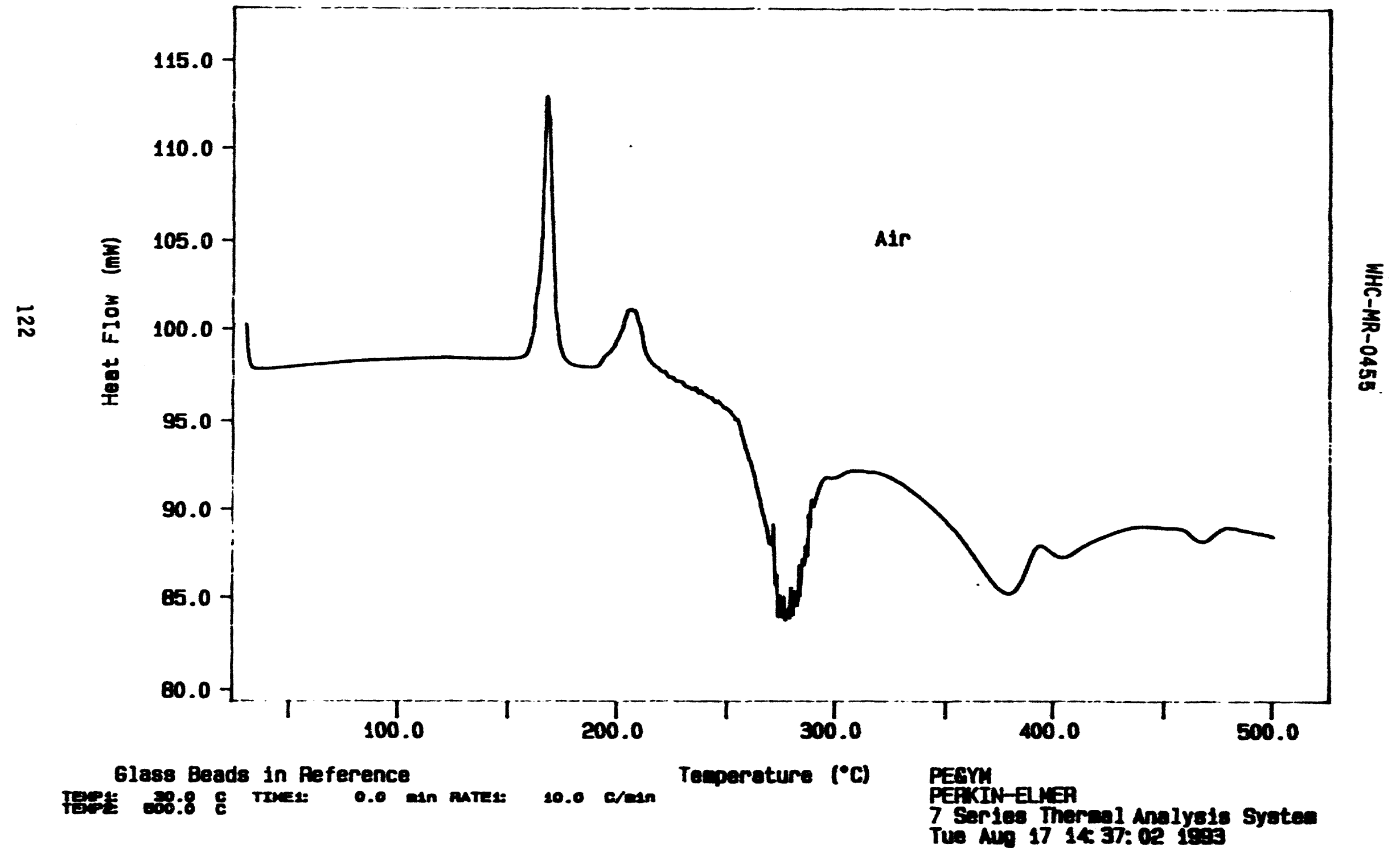

Figure 54. - DSC thermogram for citrate-nitrate-nitrite mixture $12 A(1: 1)$ 
Curve 1: DSC

File info: Cit128-3 Thu Feb 11 12:09:55 1993

Sample Weight: 2.950 ag

Na Citrate 128 (3)

- 1 Na Citrate 128 (3)

Heat Flow (nil)

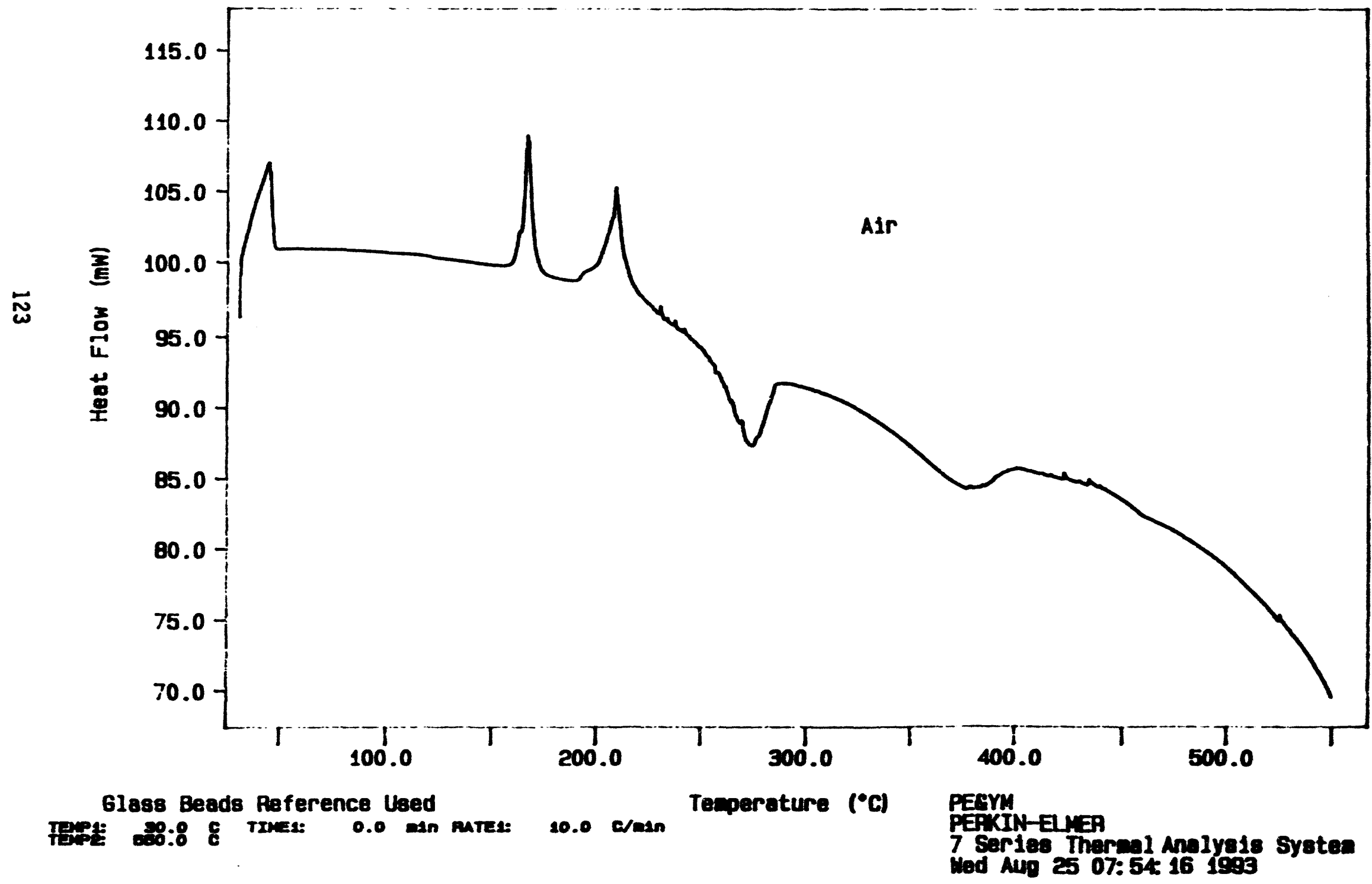

Figure 55. - DSC thermogram for citrate-nitrate-nitrite mixture 12B $(1: 3)$ 
Curve 1: DSC

File info: Cit12C-3 Thu Feb 11 14: 30:09 1993

Sample Weight: $\mathbf{5 . 0 7 0}$

Na Citrate $12 \mathrm{C}$ (3)

$\mathbf{m g}$

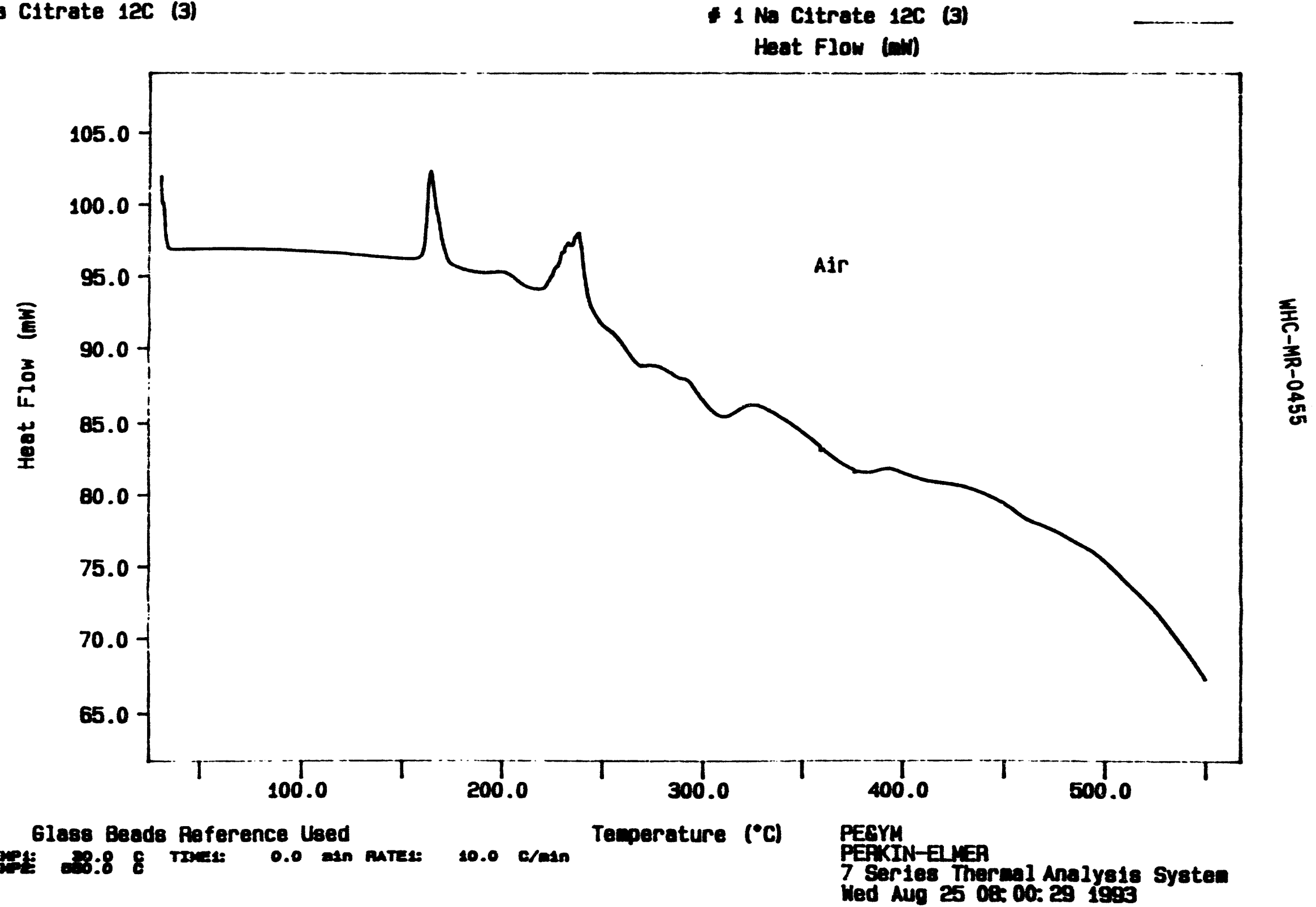

Figure 56. - DSC thermogram for citrate-nitrate-nitrite mixture $12 C(1: 3$; dil) 
Curve 1: DSC

File Info: Cit120-3 Thu Feb 11 15: 24: 181993 Sample Weight: 3.270

Na Citrate 120 (3)

ag

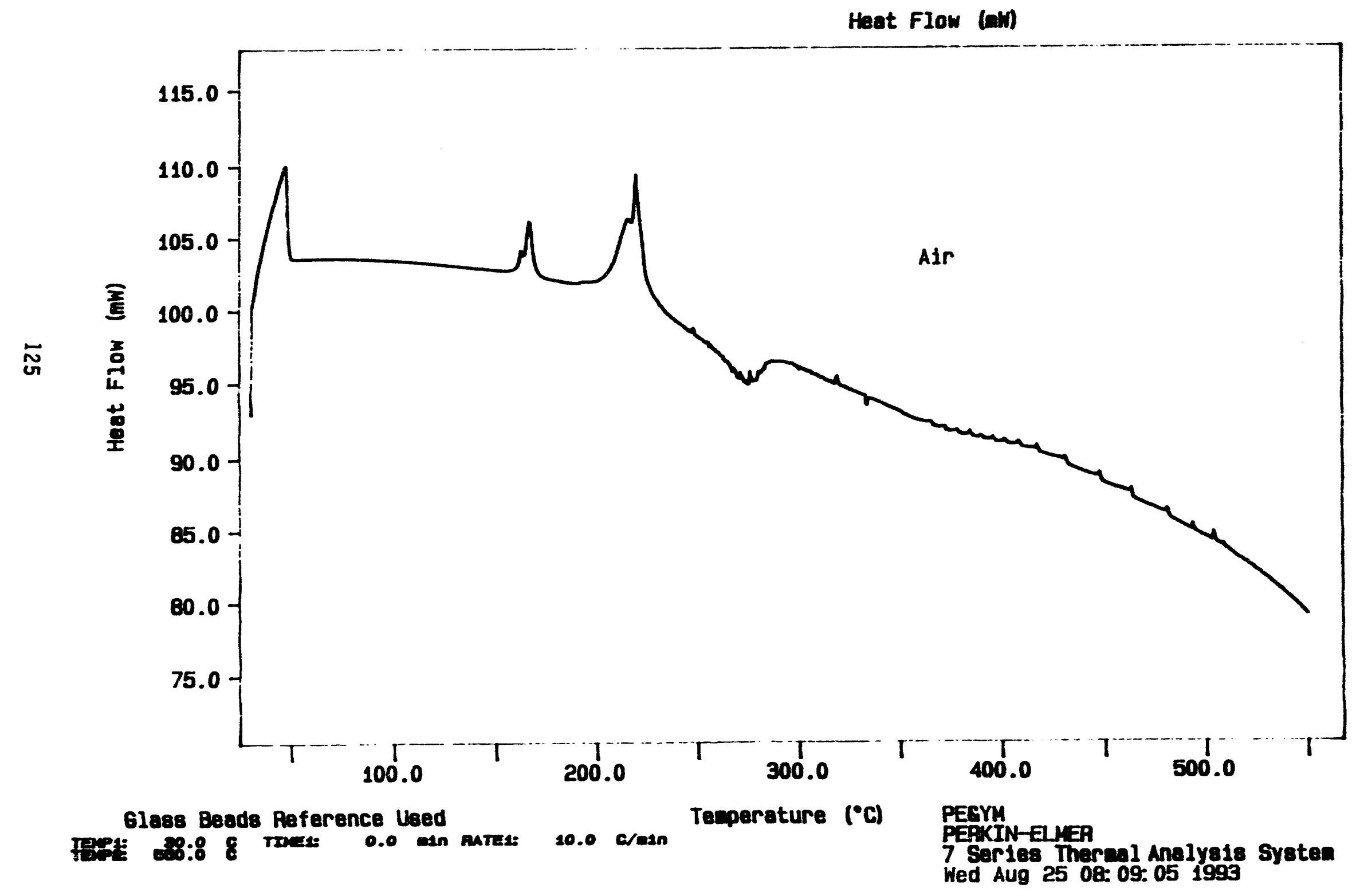

Figure 57. - DSC thermogram for citrate-nitrate-nitrite mixture $120(1: 10)$ 
Curve 1: TGA

F1le info: Cit3A-1 Mon Mar 15 16: 11: 391993

Sample Neight: 5.298 ag

Na Citrate 3A (1)

1 Na citrate $3 A$ (1)

$x$ Woight (It. $x$ )

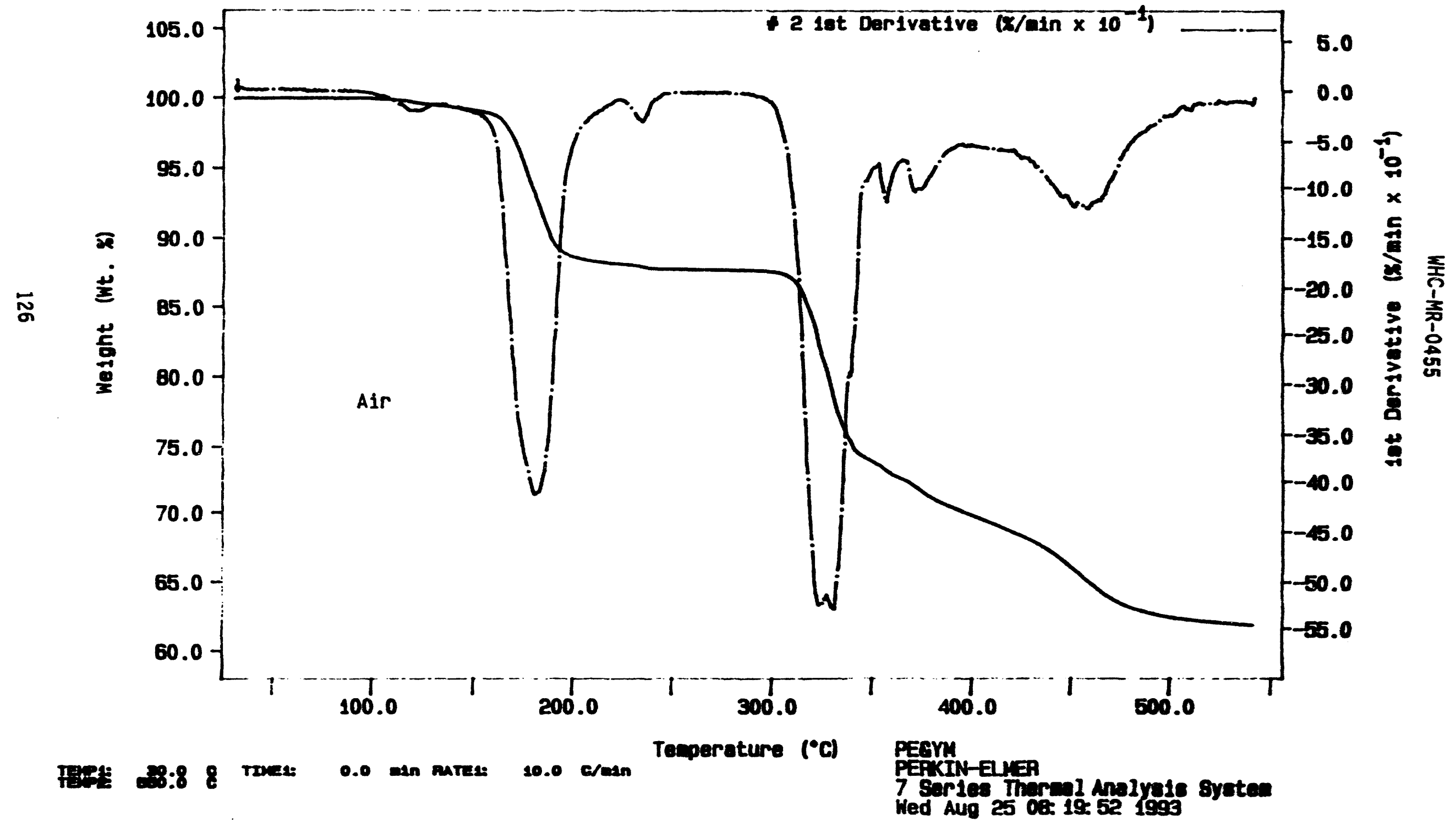

Figure 58. - IGA thermogram for sodium citrate 
Curve 1: TGA

F1le info: Cit11A-1 Tue Mar 16 07:59: 211993

Sample Welght: 3.393

mg

Na Citrate 11A (1)

* 1 Na Citrate 11A (1)

$x$ Weight (Wt. X)

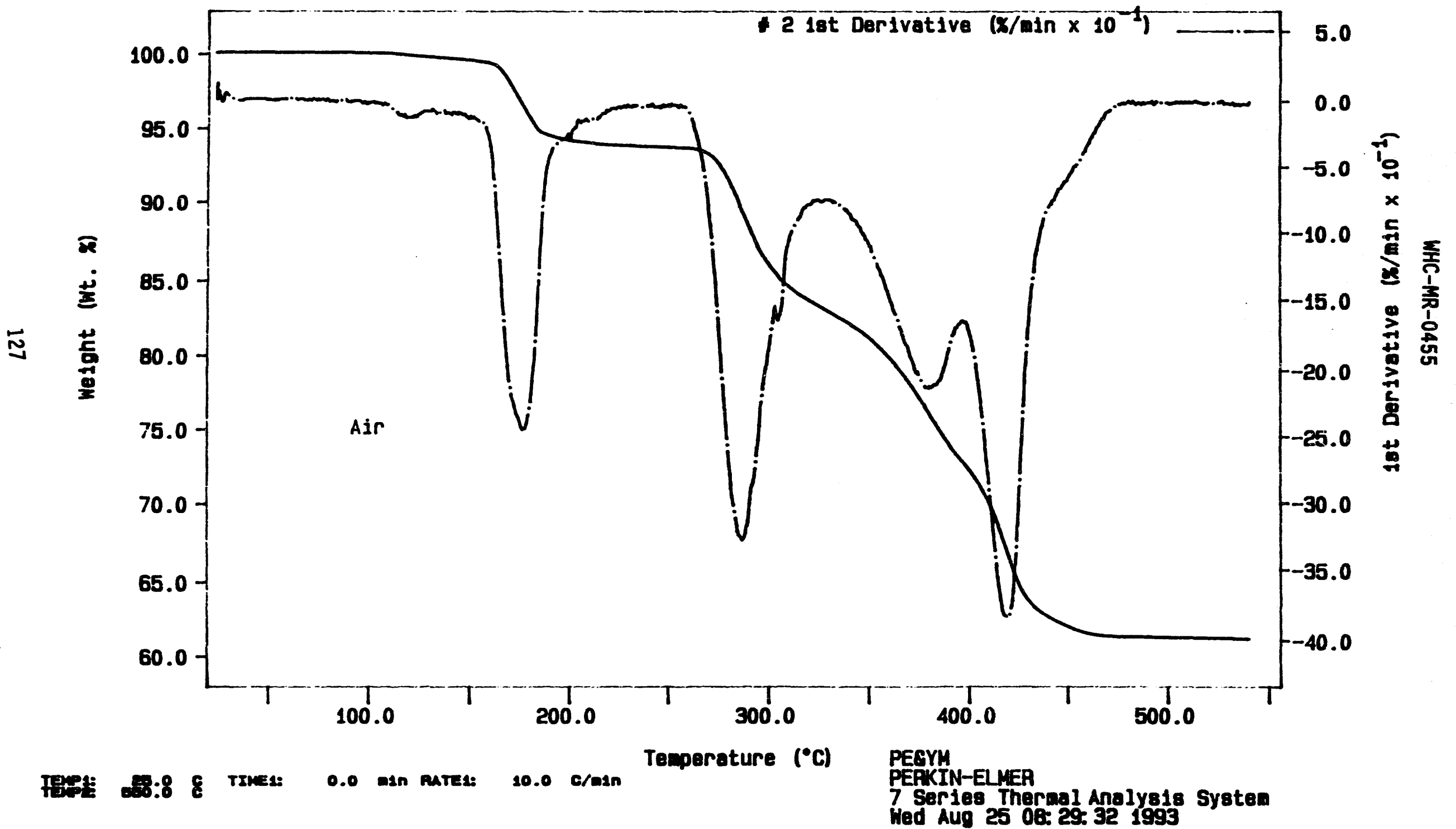

Figure 59. - TGA thermogram for citrate-nitrate mixture $11 \mathrm{~A}(1: 1)$ 
WHC-MR-0455

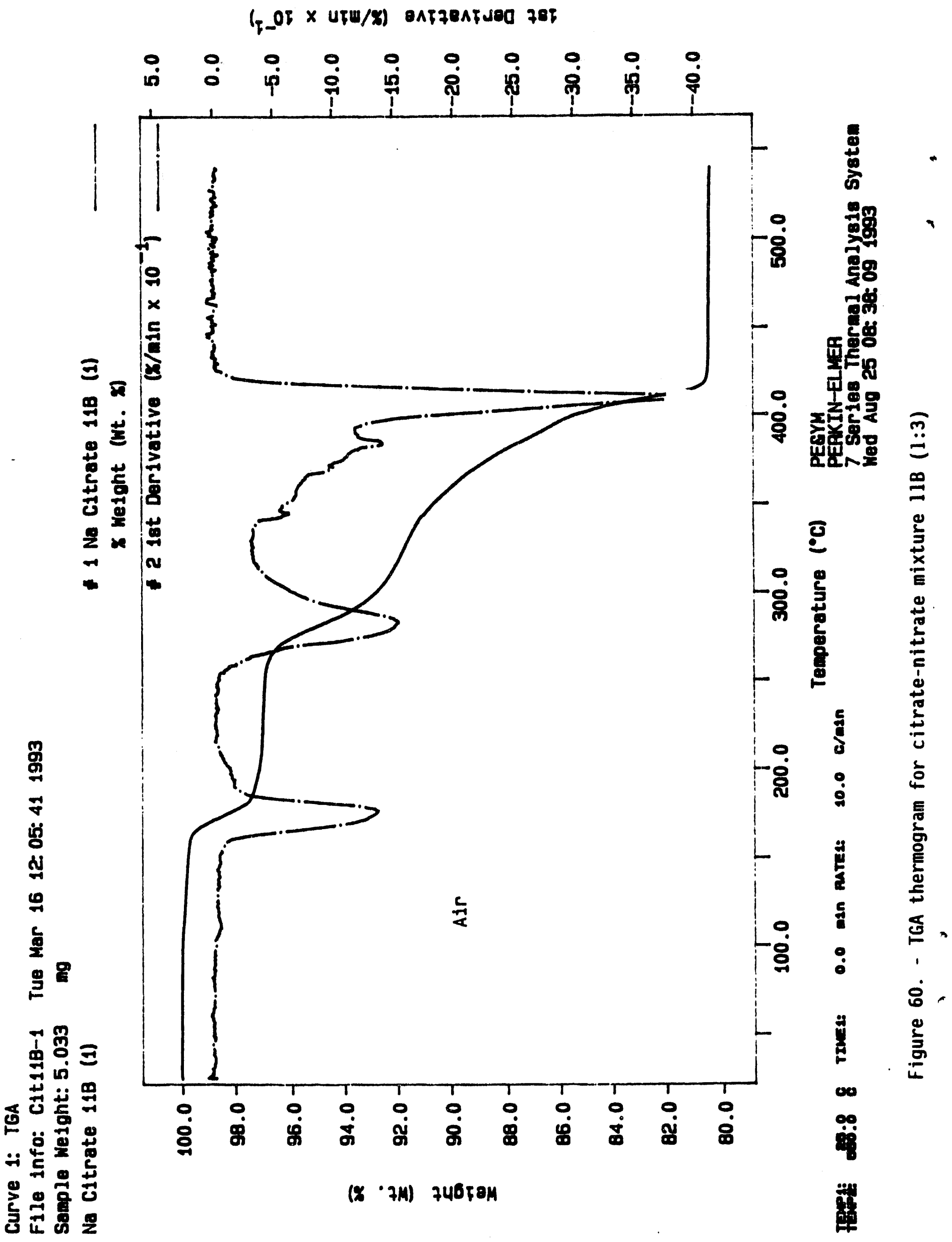


Curve 1: TGA

File info: Cit11C-1 Tue Mar 16 13: 19: 021993

Sample Weight: $4.913 \mathrm{mg}$

Na Citrate 11C (1)

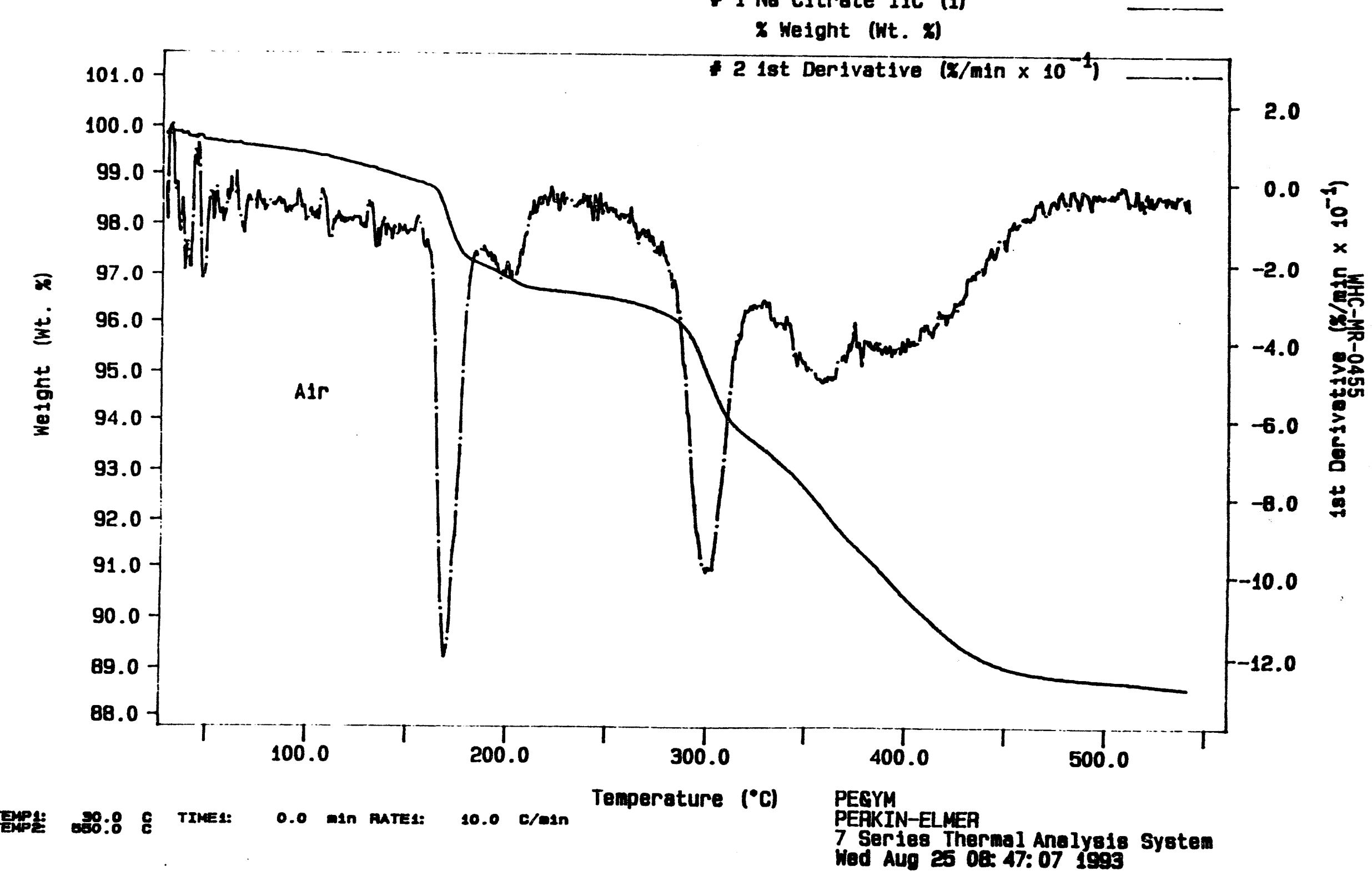

Figure 61. - TGA thermogram for citrate-nitrate mixture $11 \mathrm{C}(1: 3 ;$ di1) 
Curve 1: TGA

F1le info: Cit110-1 Tue Mar 16 14: 30: 301993

Semple Weight: 4.762

mg

Na Citrate 110 (1)

1 Na Citrate 110 (1)

$x$ Weight (Wt. $x$ )

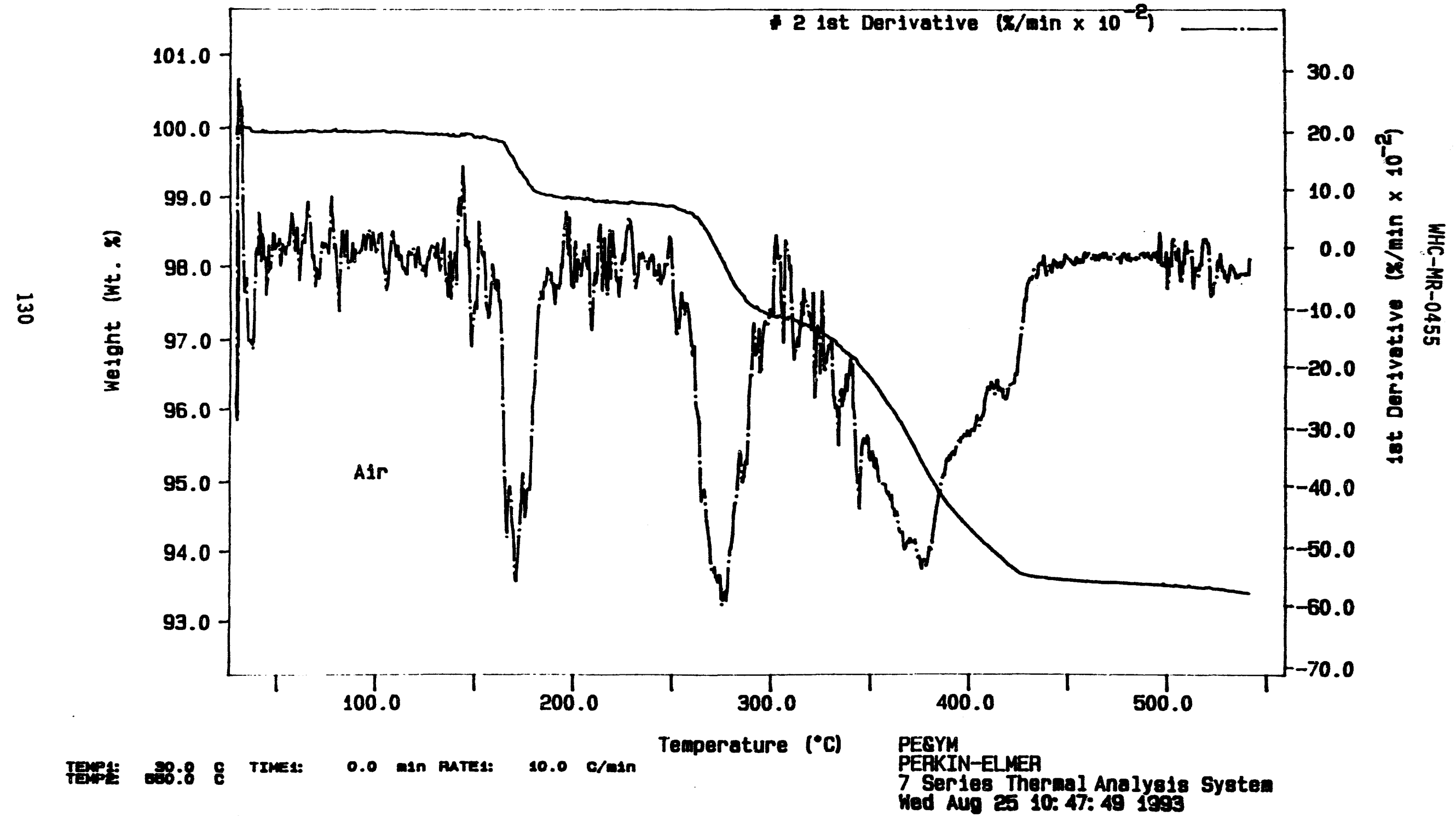

Figure 62. - TGA thermogram for citrate-nitrate mixture $110(1: 10)$ 
Curve 1: TGA

File info: Cit11A-2 Tue Mar 16 10:03: 041993

Sample Weight: $3.288 \mathrm{mg}$

Na Citrate $11 \mathrm{~A}$ (2)

* 1 Na Citrate 11A (2)

$x$ Weight (Wt. $x$ )

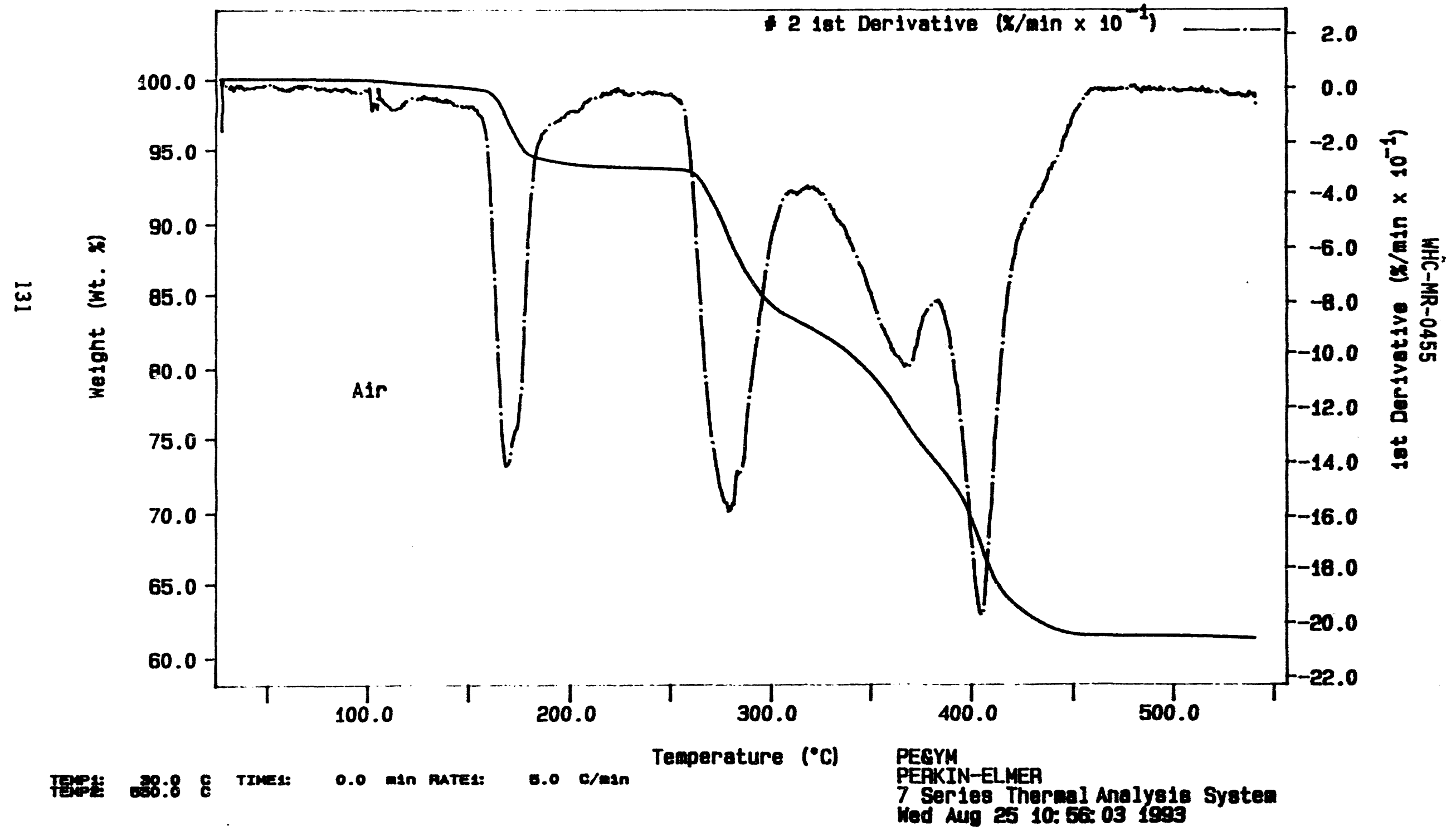

Figure 63. - TGA thermogram for citrate-nitrate mixture 11A (1:1) 
Curve 1: TGA

File info: Cit11D-2 Wed Mar 17 14: $42: 401993$

Sample Weight: 5.855

mg

Na Citrate 110 (2)

- 1 Na Citrate 110 (2)

$x$ Weight (Wt. $\mathrm{x}$ )

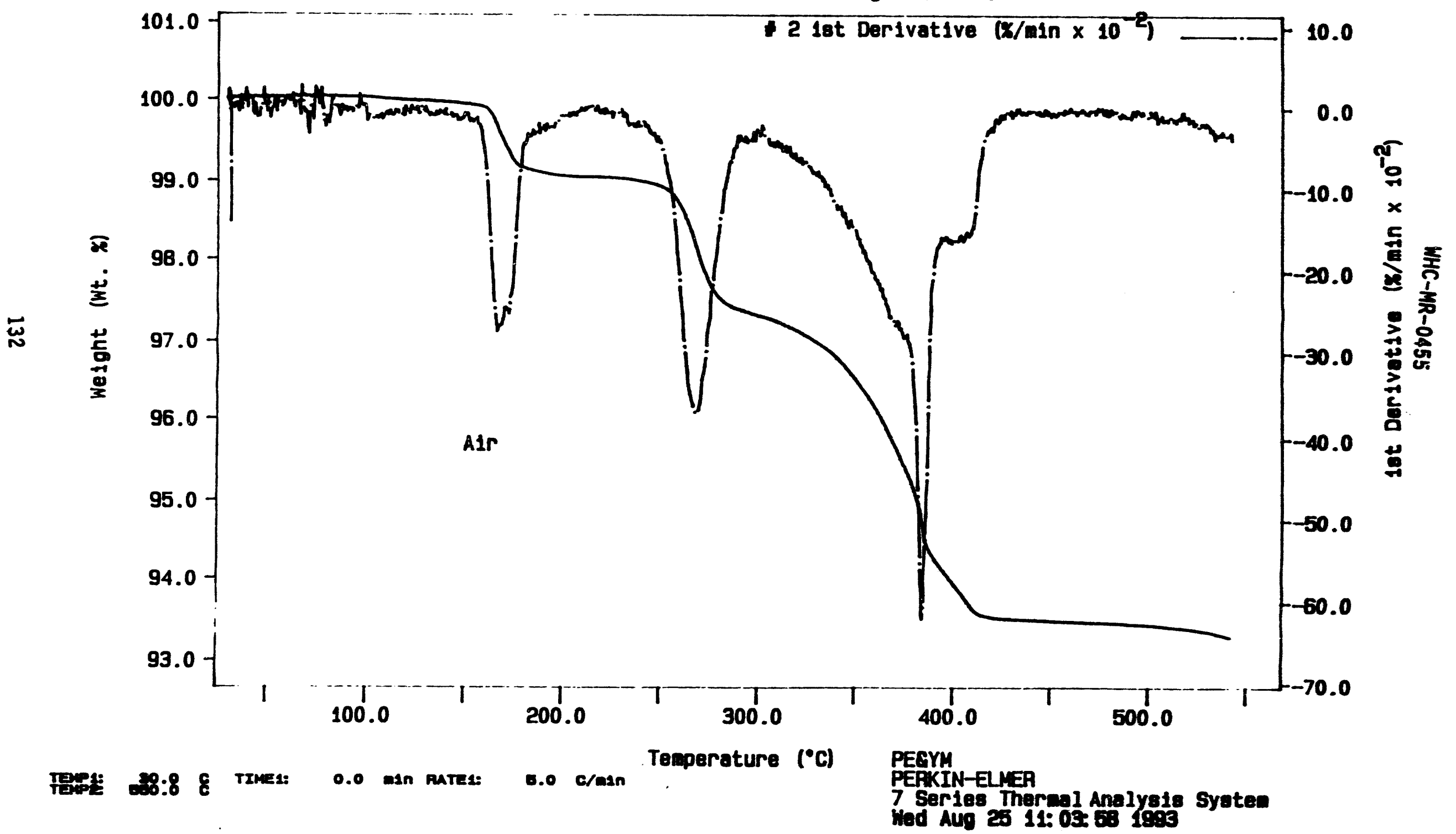

Figure 64. - TGA thermogram for citrate-nitrate mixture 110 (1:10) 


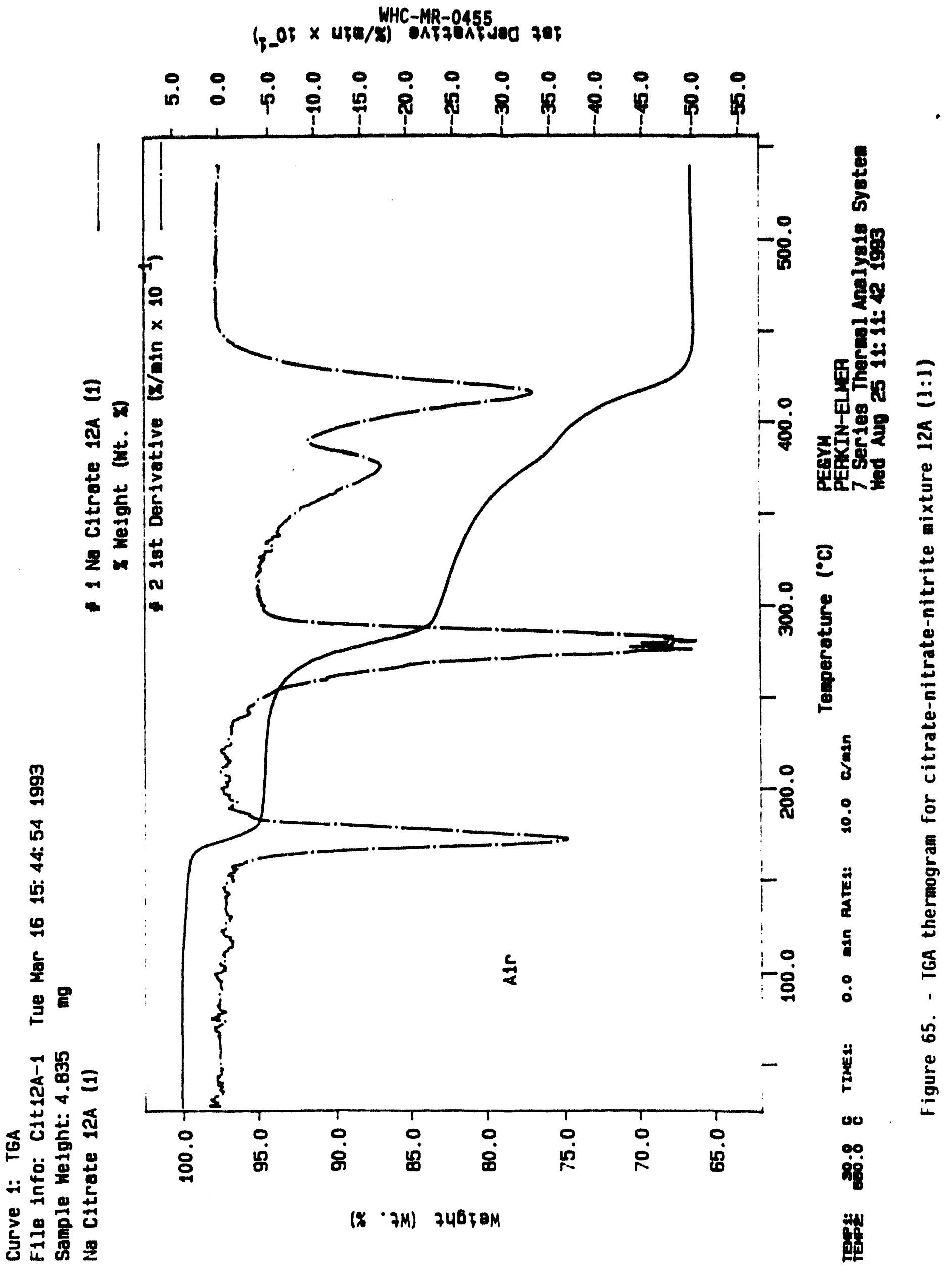


Curve 1: TGA

F1le info: Cit12B-1 Hed Mar 17 10: 34: 031993

Sample Weight: 6.041

mg

Na Citrate $12 B$ (1)

- 1 Na Citrate 128 (1)

$x$ Weight (int. $x$

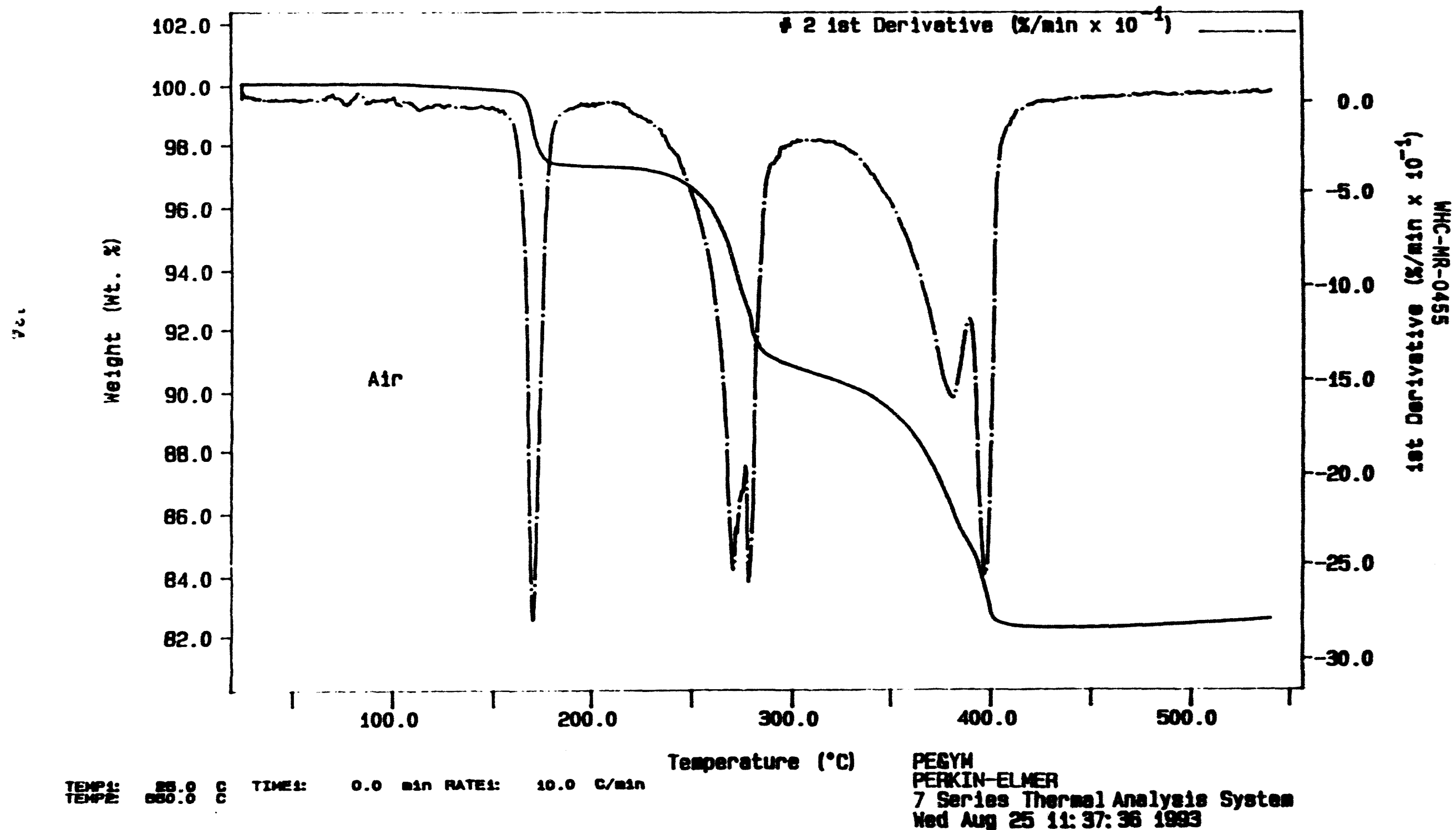

Figure 66, - TGA thermogram for citrate-nitrate-nitrite mixture $12 B(1: 3)$ 


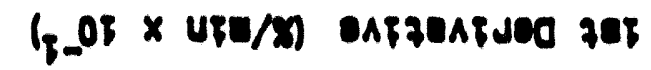

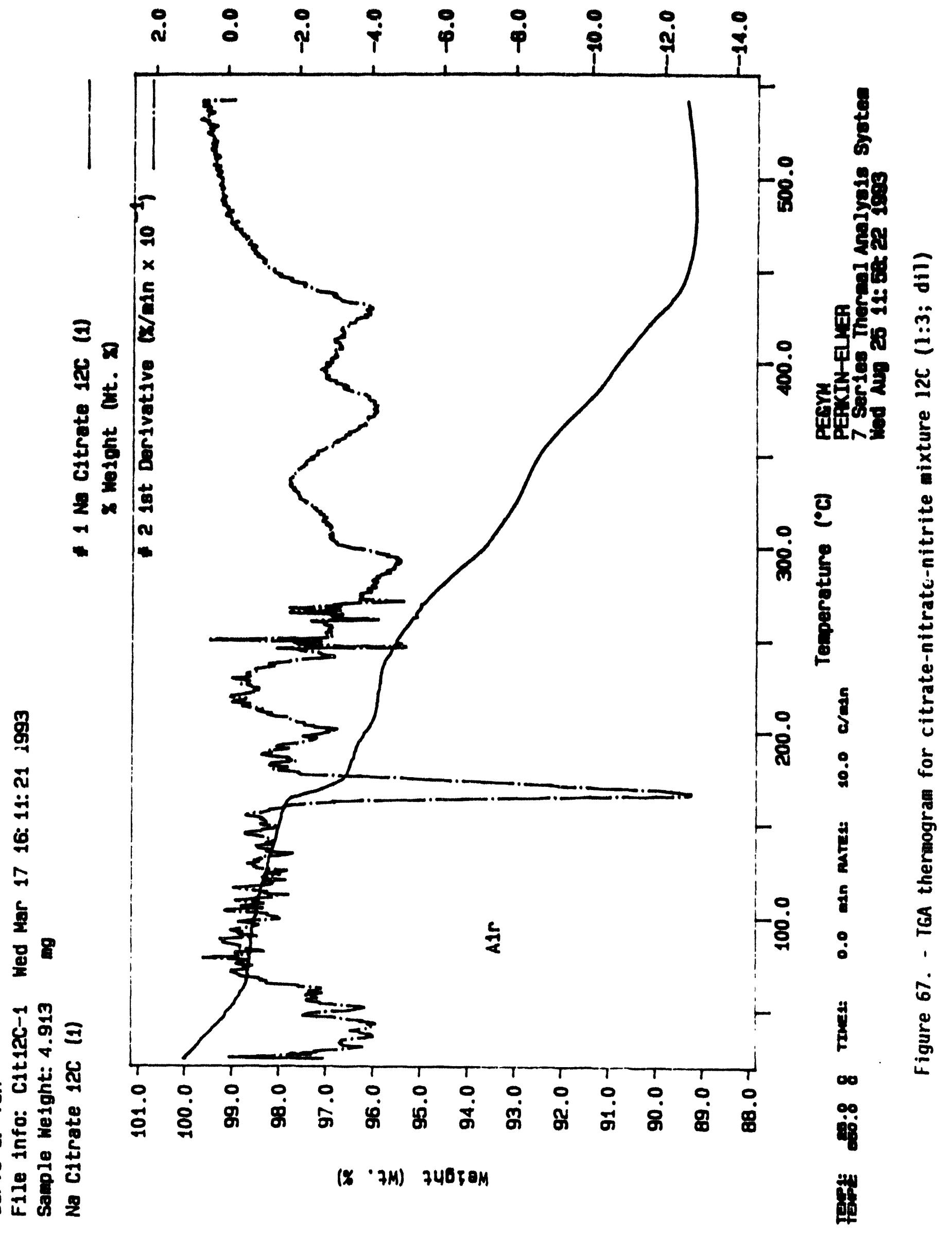


Curve 1: TGA

File info: cit120-1

Sample Weight: 5.013

Thu Mar 18 07: 52: 371993

Na Citrate 120 (1)

mg

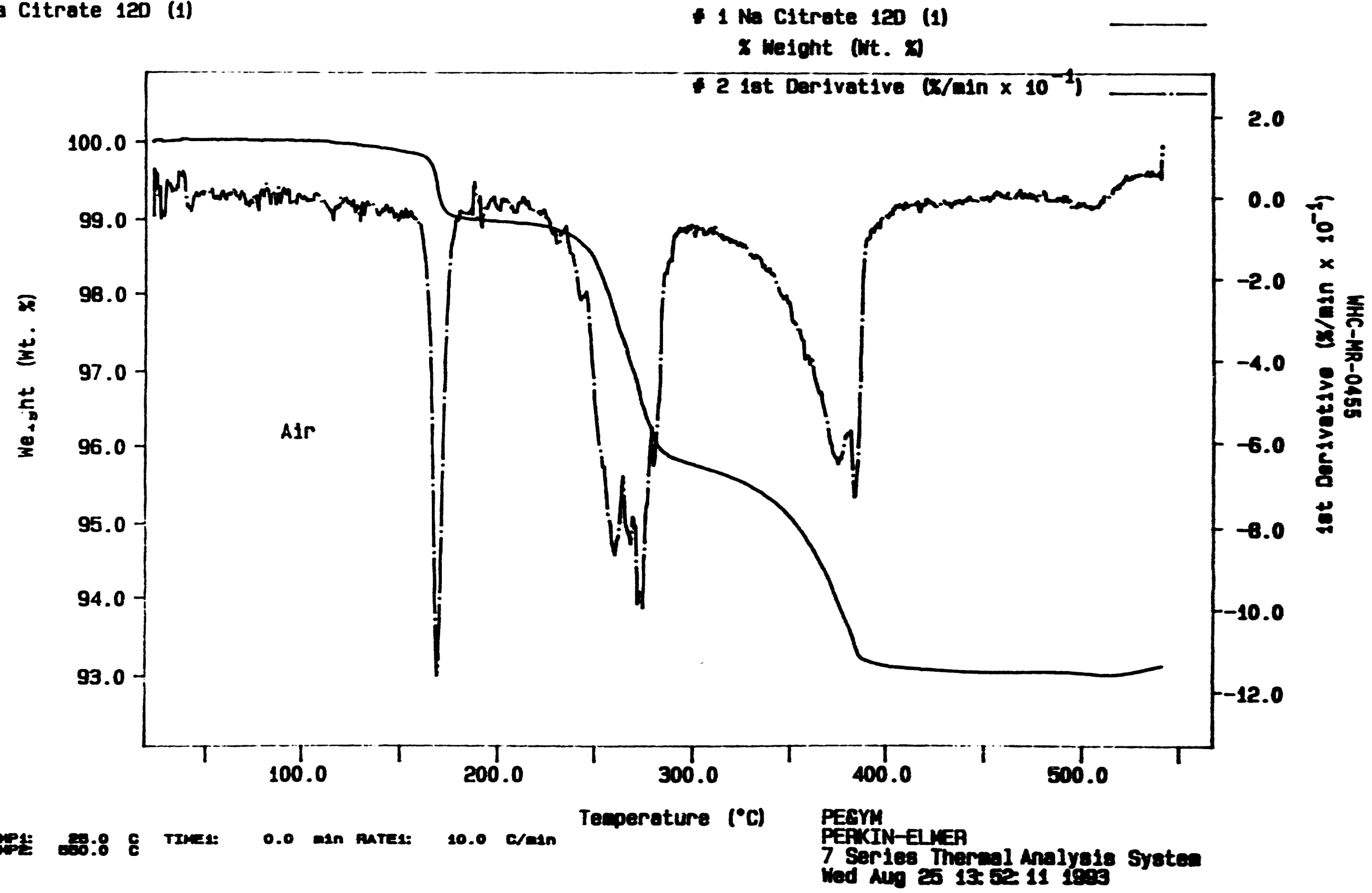

Figure 68. - TGA thermogram for citrate-nitrate-nitrite mixture $120(1: 10)$ 
Curve 1: DSC

File info: PE5A-2

Sanple Neight: $\mathbf{3 . 9 3 0}$

Tue Feb 16 16: 19: 491993

Polyethylene 5A (2)

$\boldsymbol{m}$

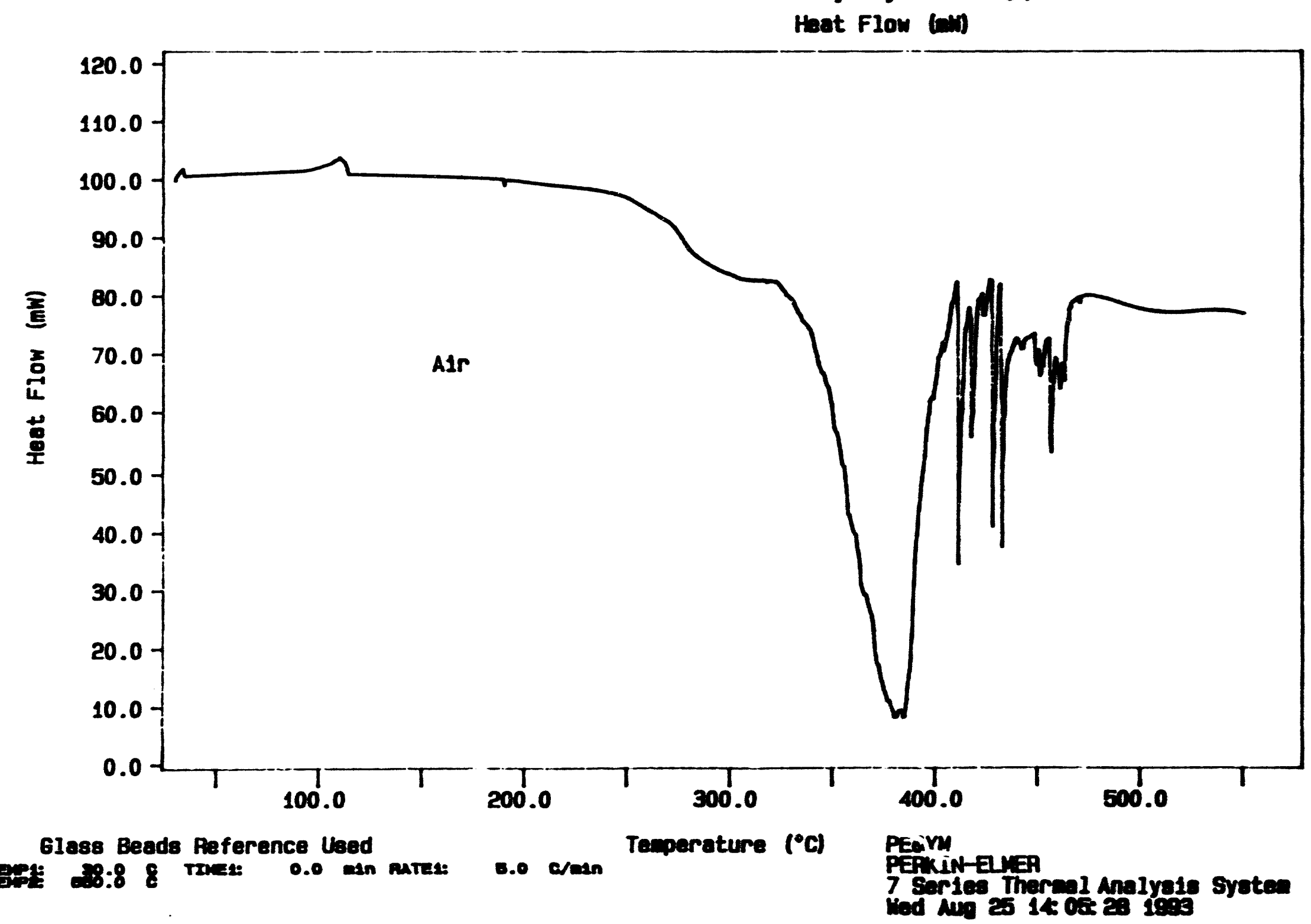

Figure 69. - DSC thermogram for polyethylene 
Curve 1: DSC

F1le info: PE5A-1

Sample Weight: 3.000

Polyethylene 5A (1)

Fr1 Feb 12 14: 45: 261993

ag

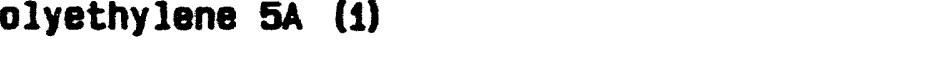

1 Polyethylene 54 (1) 
Curve 1: DSC

F1le info: PE5A-3 Thu Feb 25 14: $01: 531993$

Sanple Welght: 3.510

Polyethylene 5A (3)

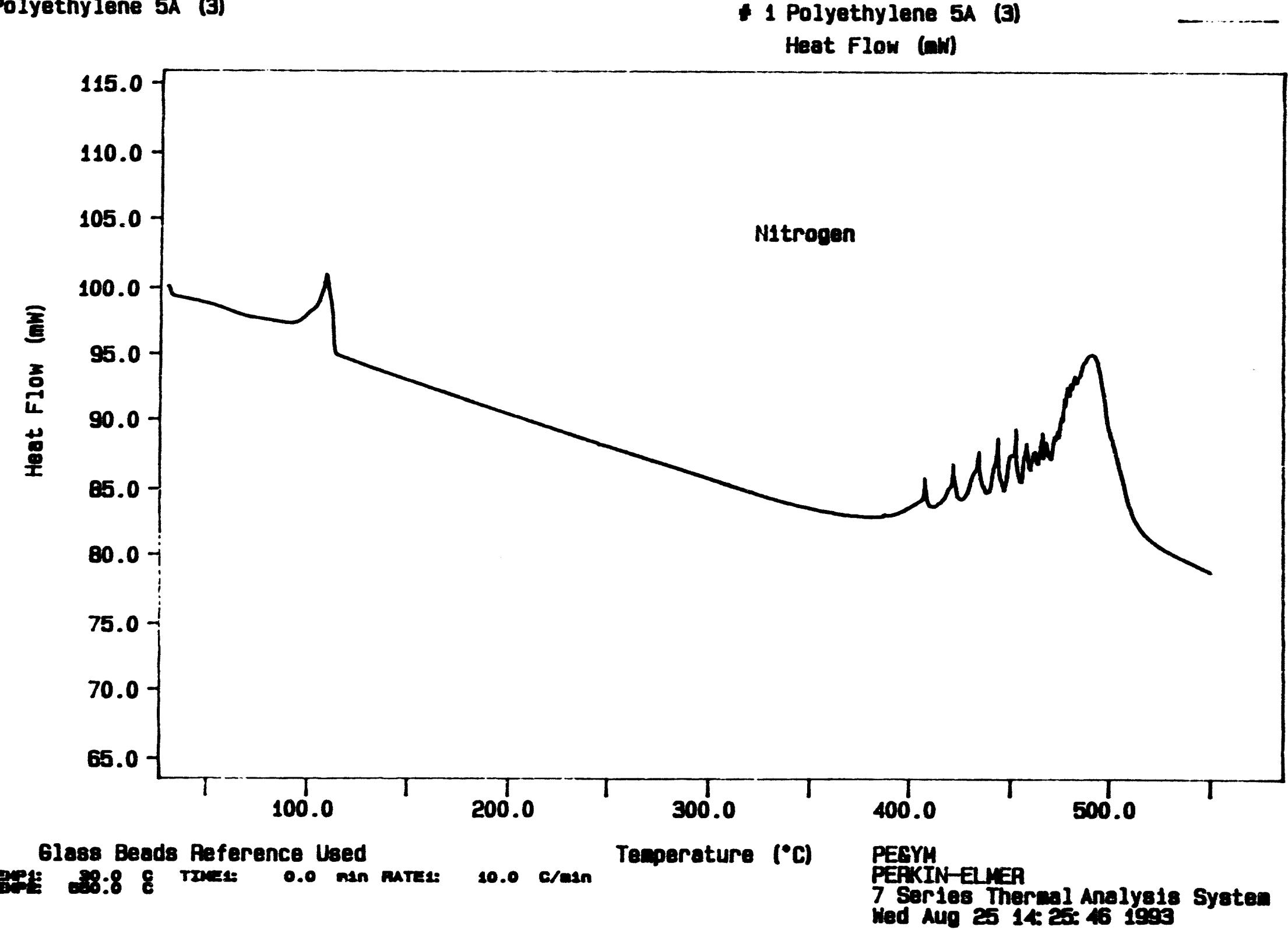

Figure 71. - DSC thermogram for polyethylene 
Curve 1: DSC

F1le Info: PE15A-1 Fri Feb 12 15: $45: 091993$

Sample We1ght: 2.900

Polyethylene 5A (1)

$m g$

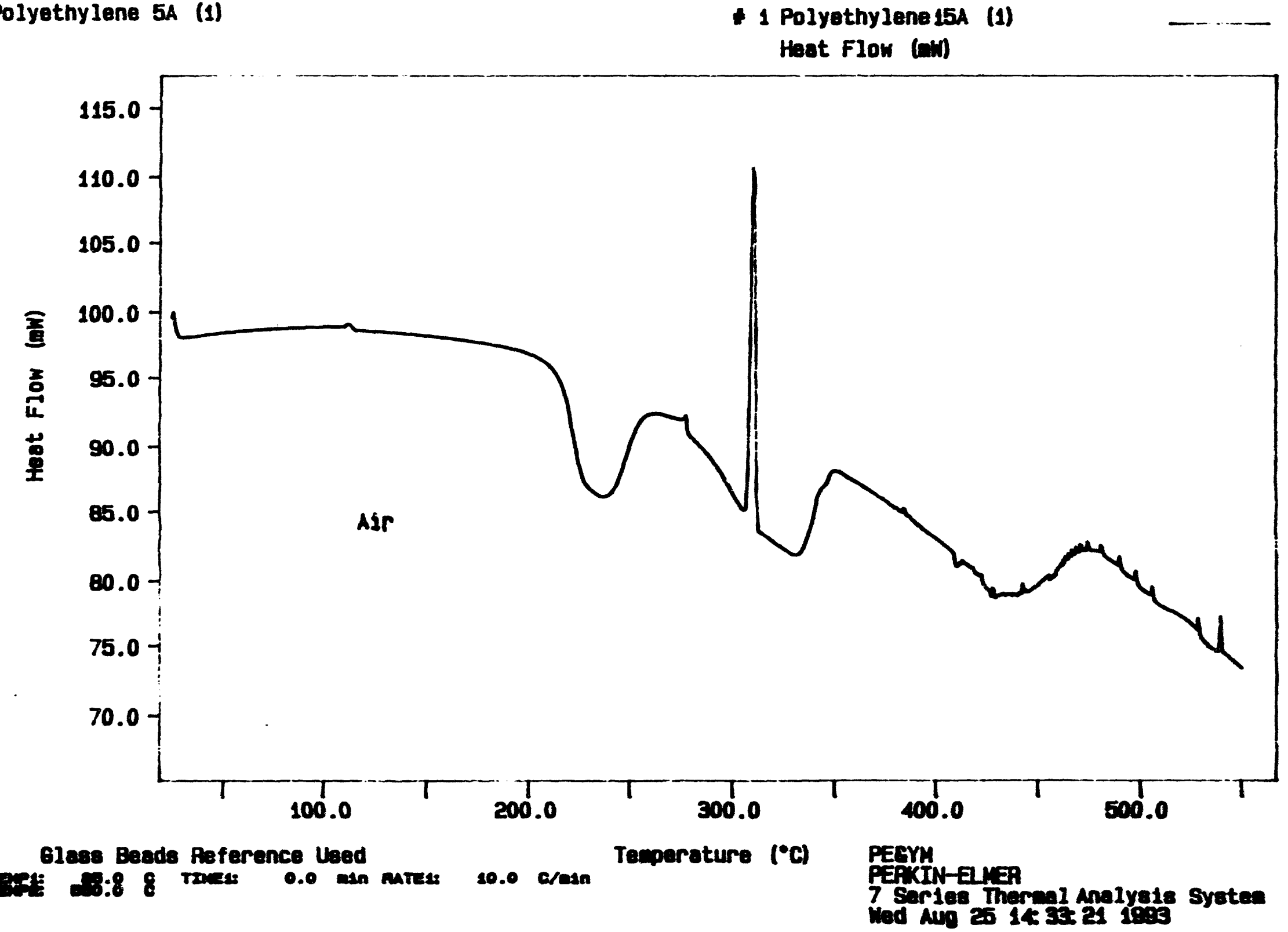

Figure 72. - DSC thermogram for polyethylene-nitrate mixture 15A (1:1) 
Curve 1: DSC

F110 Info: PE15A-1

Sample Me1ght: 2.900

Fr1 Feb 12 15: 45: 091993

ad

Polyethylene 5A (1)

- 1 Polyethylene 5A (1) Hat flow (nis)

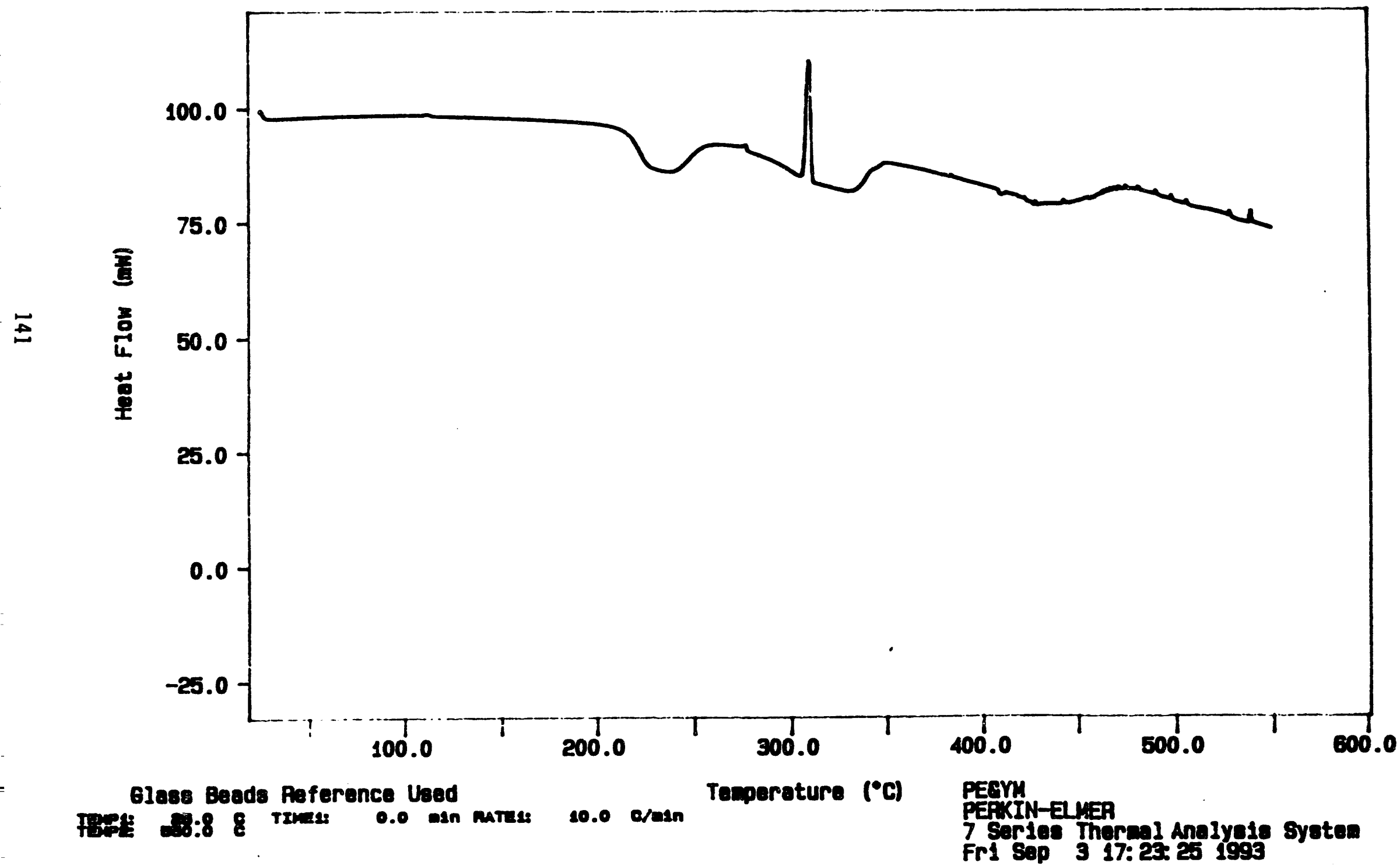

Figure 72A. - Optimized and scaled DSC thermogram of figure 72, for nolvethulane-nitrate mixture 15A 11.11 
Curve 1: DSC

F11e Info: PE158-1 Tue Feb 16 07:52 551993

Sample Veloht: 4.340

Polyethylene 158 (1)

m

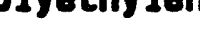

- 1 Polyethylene 158 (1)

Heat Flow (an)

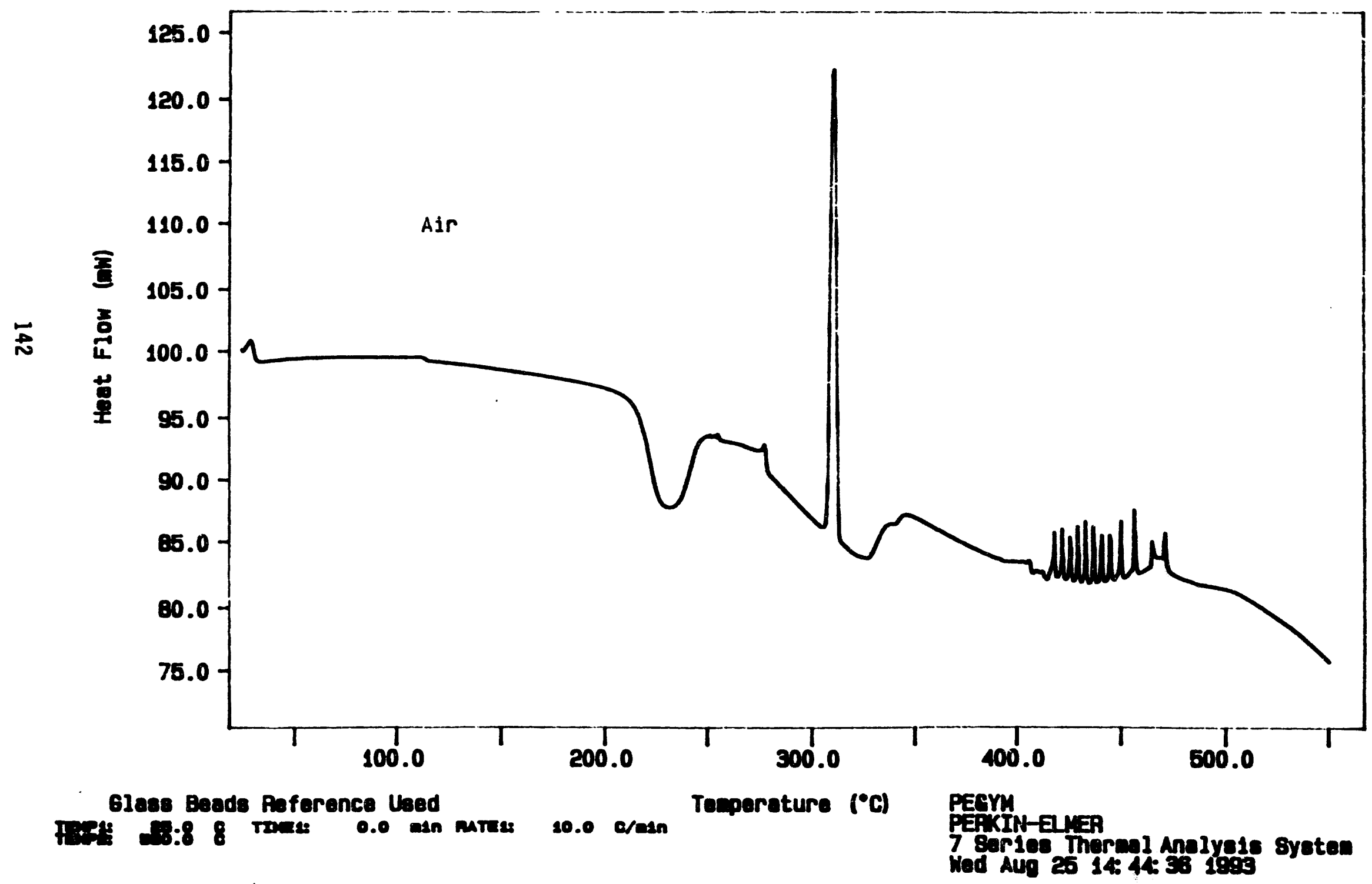

Figure 73. - DSC thermogram for polyethylene-nitrate mixture 15B (1:3) 
Curve 1: DSC

File info: PE15C-1 Tue Feb 16 08: 48: 311993

Sample Weight: 4.070

mg

Polyethylene 15C (1)

- 1 Polyethylene 15C (1)

Heat flow (aw)

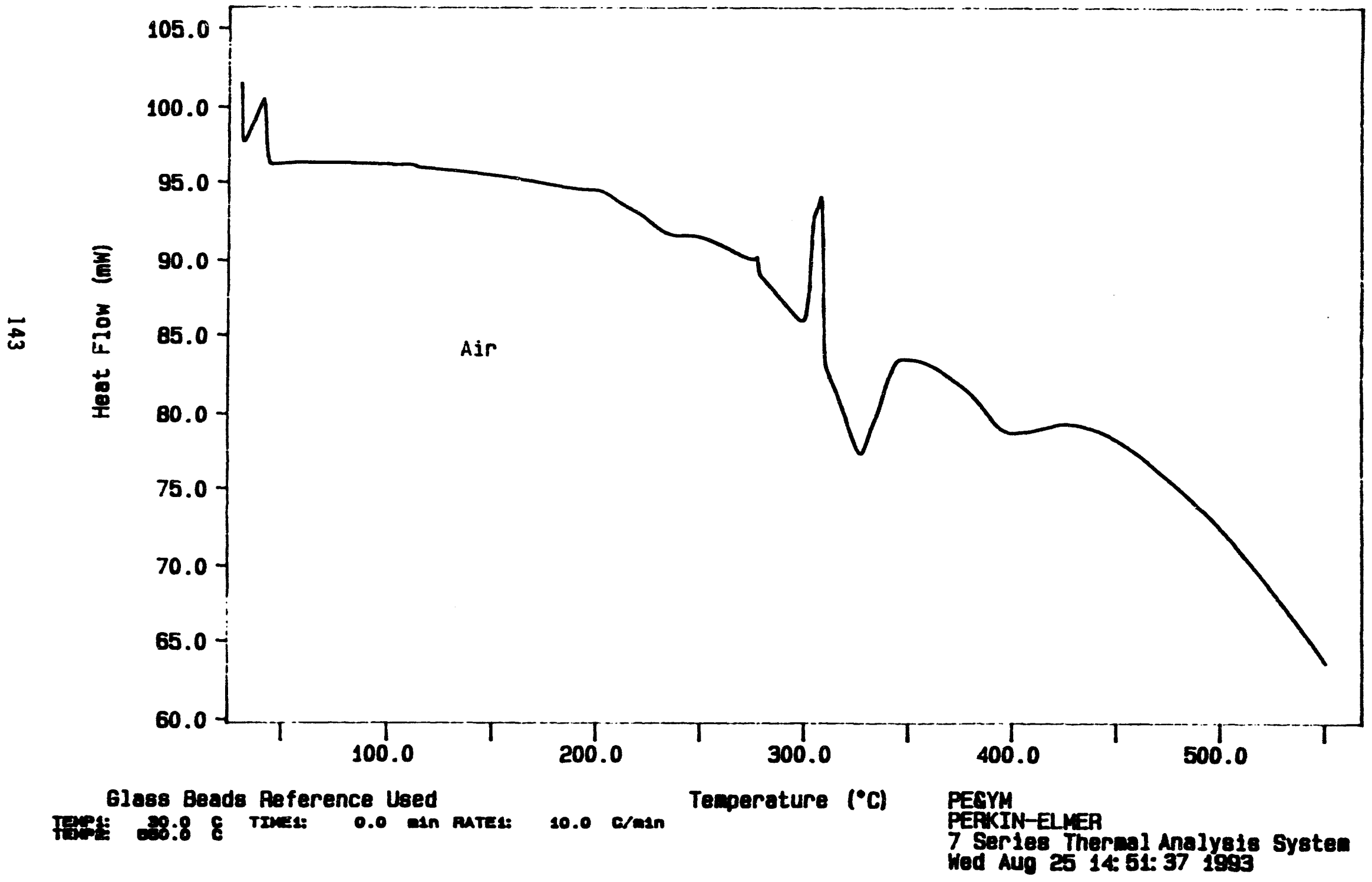

Figure 74. - DSC thermogram for polyethylene-nitrate mixture $15 \mathrm{C}(1: 3 ;$ dil) 
Curve 1: DSC

F1le Info: PE15D-1 Tue Feb 16 09: 50: 281993

Somple We1ght: 4.250

an

Polyethylene 150 (1)

1 Polyethylene 150 (1)

Heat Flow (nW)

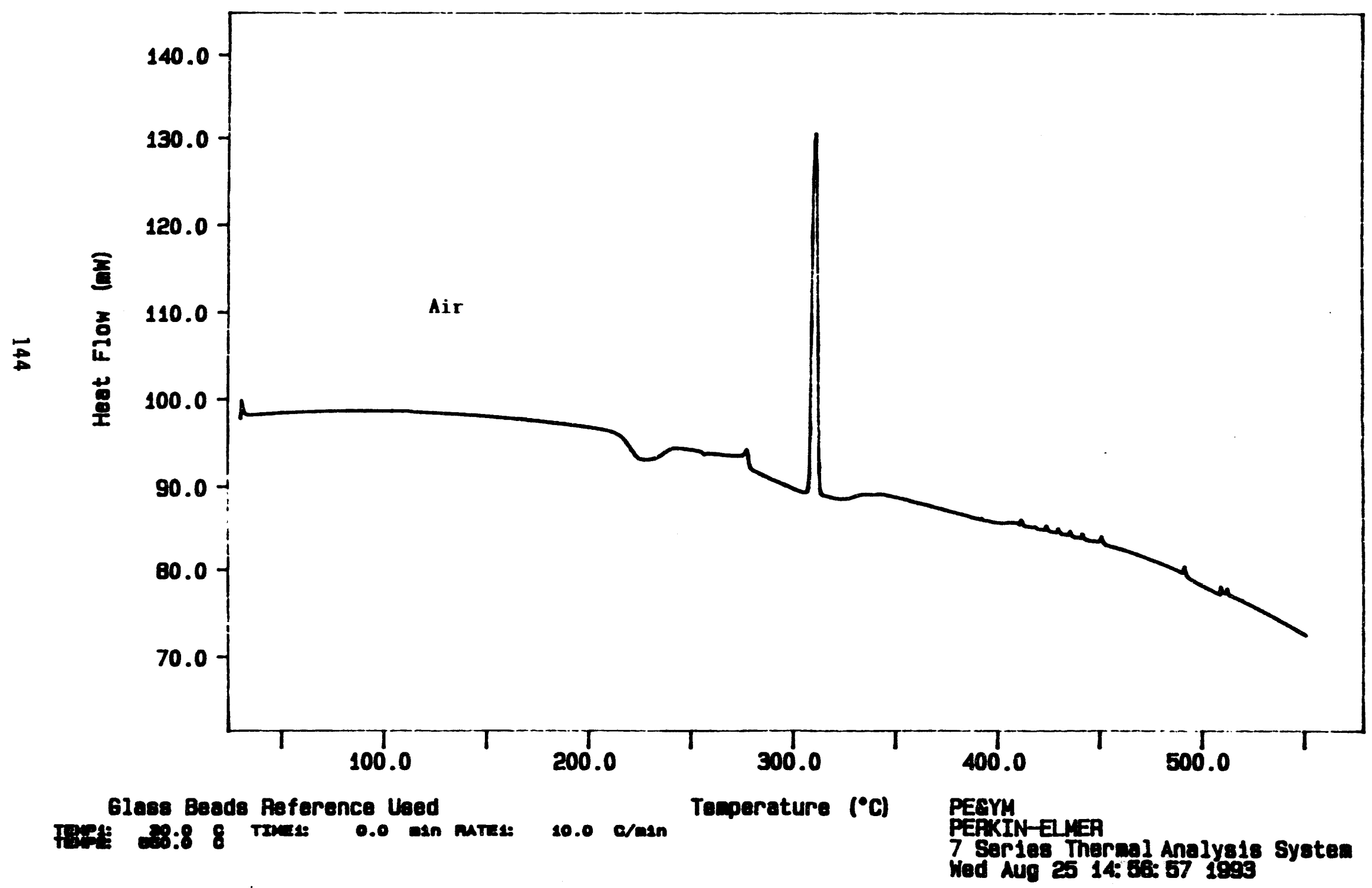

Figure 75. - DSC thermogram for polyethylene-nitrate mixture 15D (1:10) 
Curve 1: DSC

F1le info: PE16A-1 Tue Feb 16 10: $48: 411993$

Sample Weight: 4.920

ag

Polyethylene 16A (1)

1 Polyethylene 16A (1)

Heat Flow (nw)

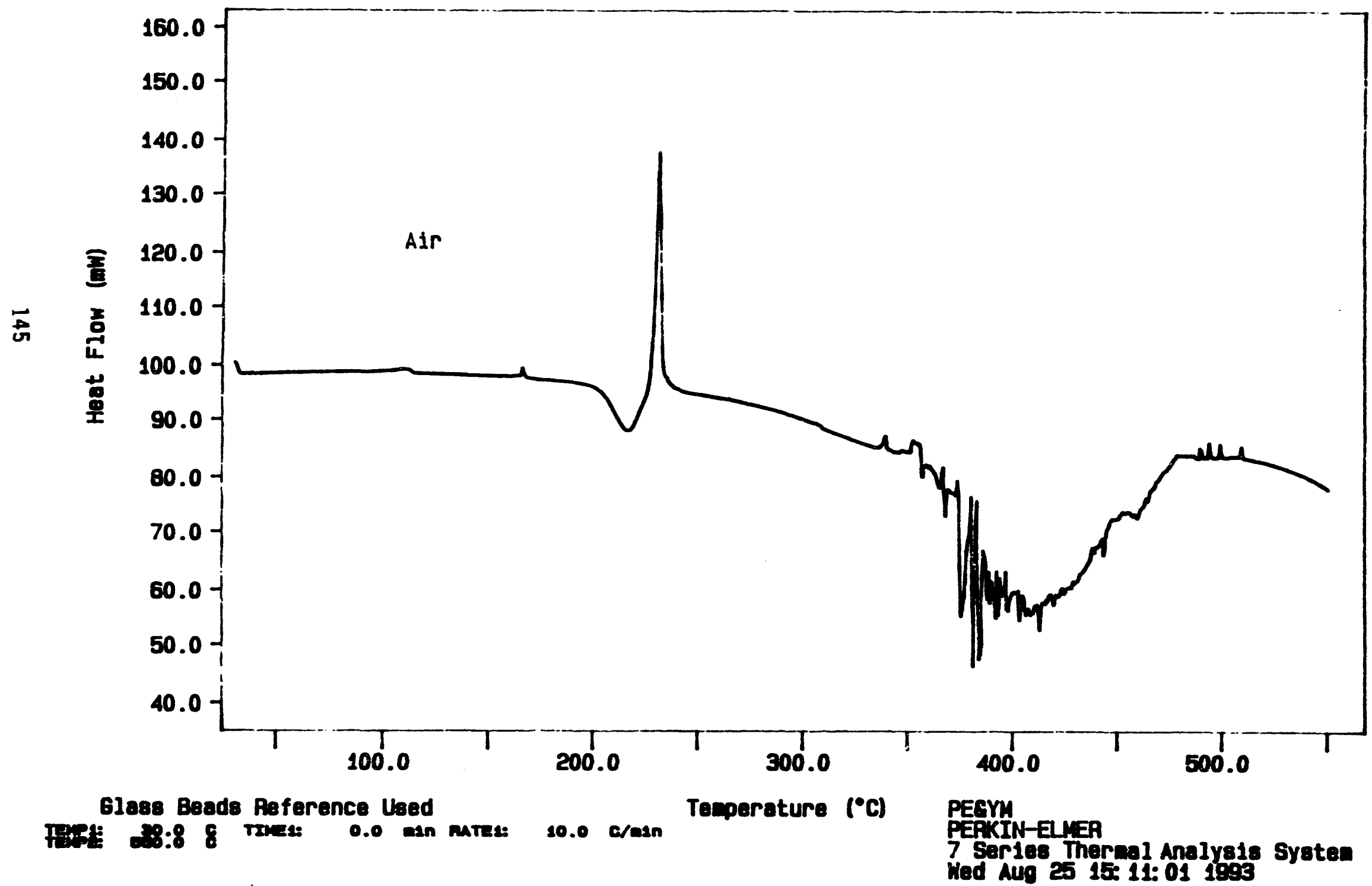

Figure 76. - DSC thermogram for polyethylene-nitrate-nitrite mixture $16 \mathrm{~A}(1: 1)$ 
Curve 1: DSC

File info: PE16B-1

Tue Feb 16 12: $37: 561993$

Sample Weight: 4.790

mg

Polyethylene 16B (1)

1 Polyethylene 168 (1)

Heat Flow (nW)

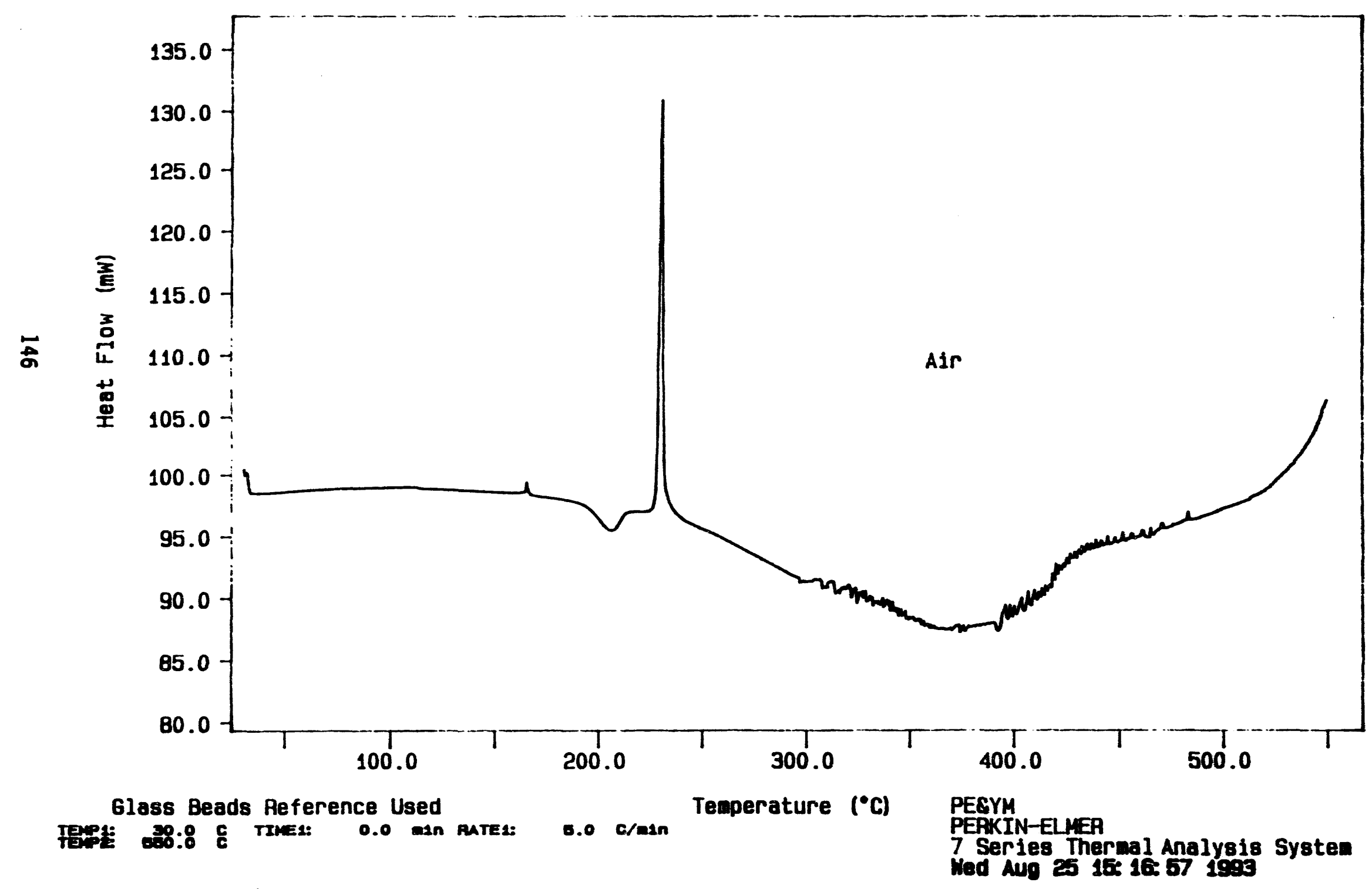

Figure 77. - DSC thermogram for polyethylene-nitrate-nitrite mixture 16B $(1: 3)$ 
Curve 1: DSC

File info: PE16C-1 Tue Feb 16 13: 35: 211993

Sample Weight: 4.000

mg

Polyethylene 16C (1)

* 1 Polyethylene 16C (1)

Heat Flow (aw)

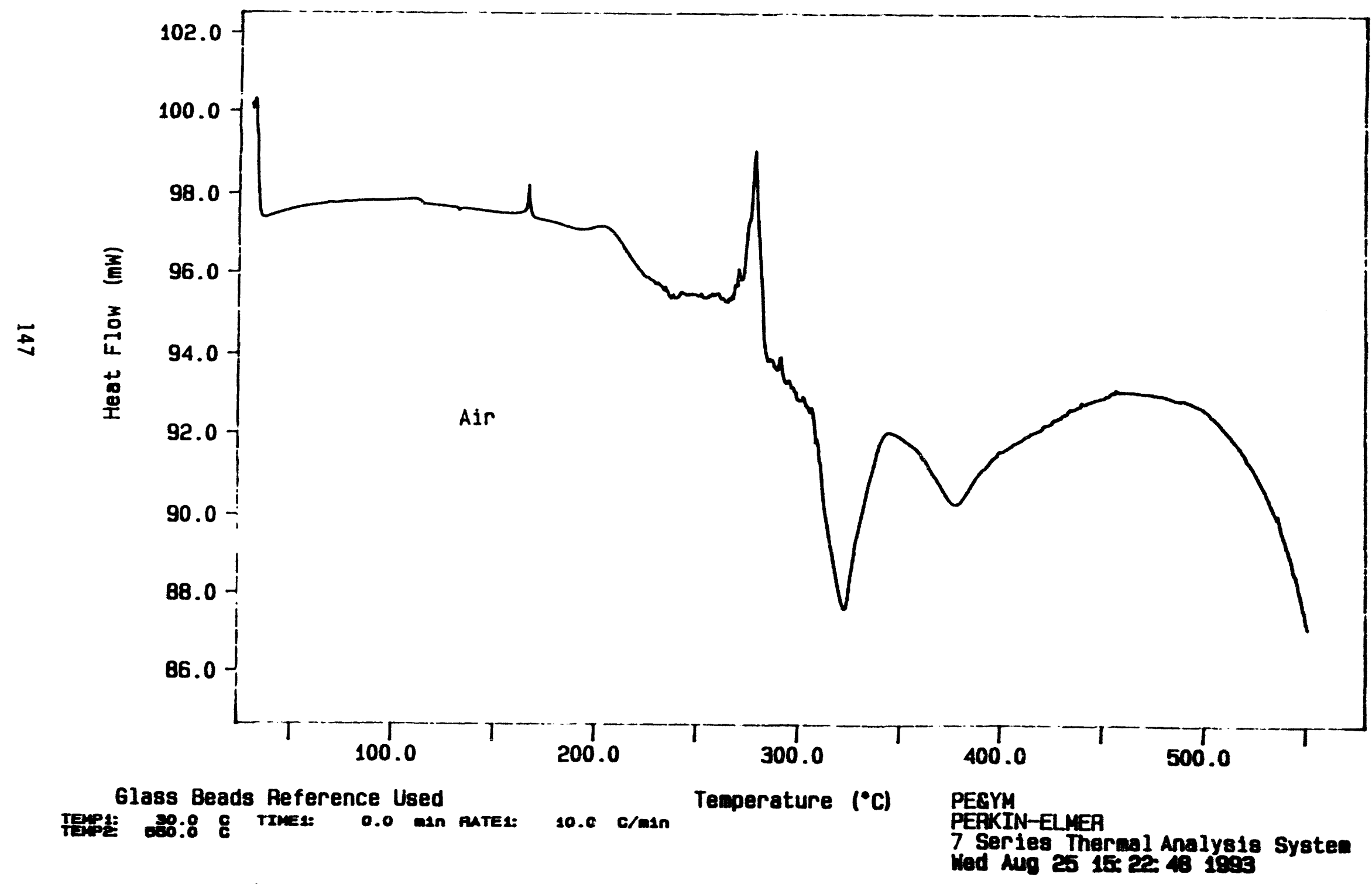

Figure 78. - DSC thermogram for polyethylene-nitrate-nitrite mixture $16 C$ 
Curve 1: DSC

File info: PE160-1 Tue Feb 16 14: 31: 171993

Sanple Weight: 4.020 mg

Polyethylene 160 (1)

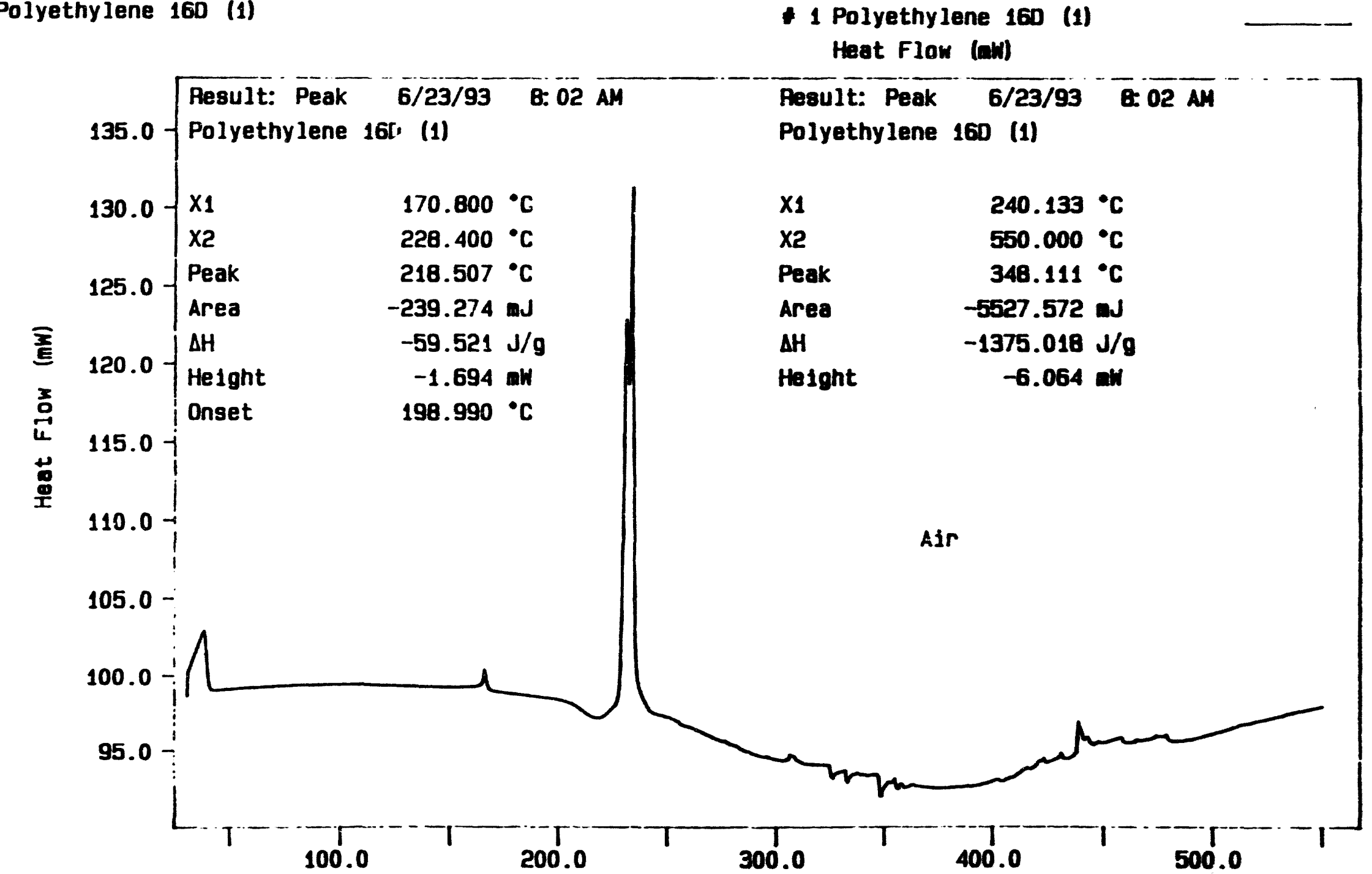

Glass Beads Reference Used

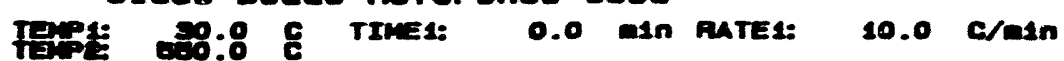

Tesperature $\left({ }^{\circ} \mathrm{C}\right.$

\section{PECYM}

PEAKIN-ELMER

7 Ser 1 es Thernal Analysis Systen hed Aus es 152 2e 14 1993

Figure 79. - DSC thermogram for polyethylene-nitrate-nitrite mixture 160

$$
\text { - }(1: 10)
$$




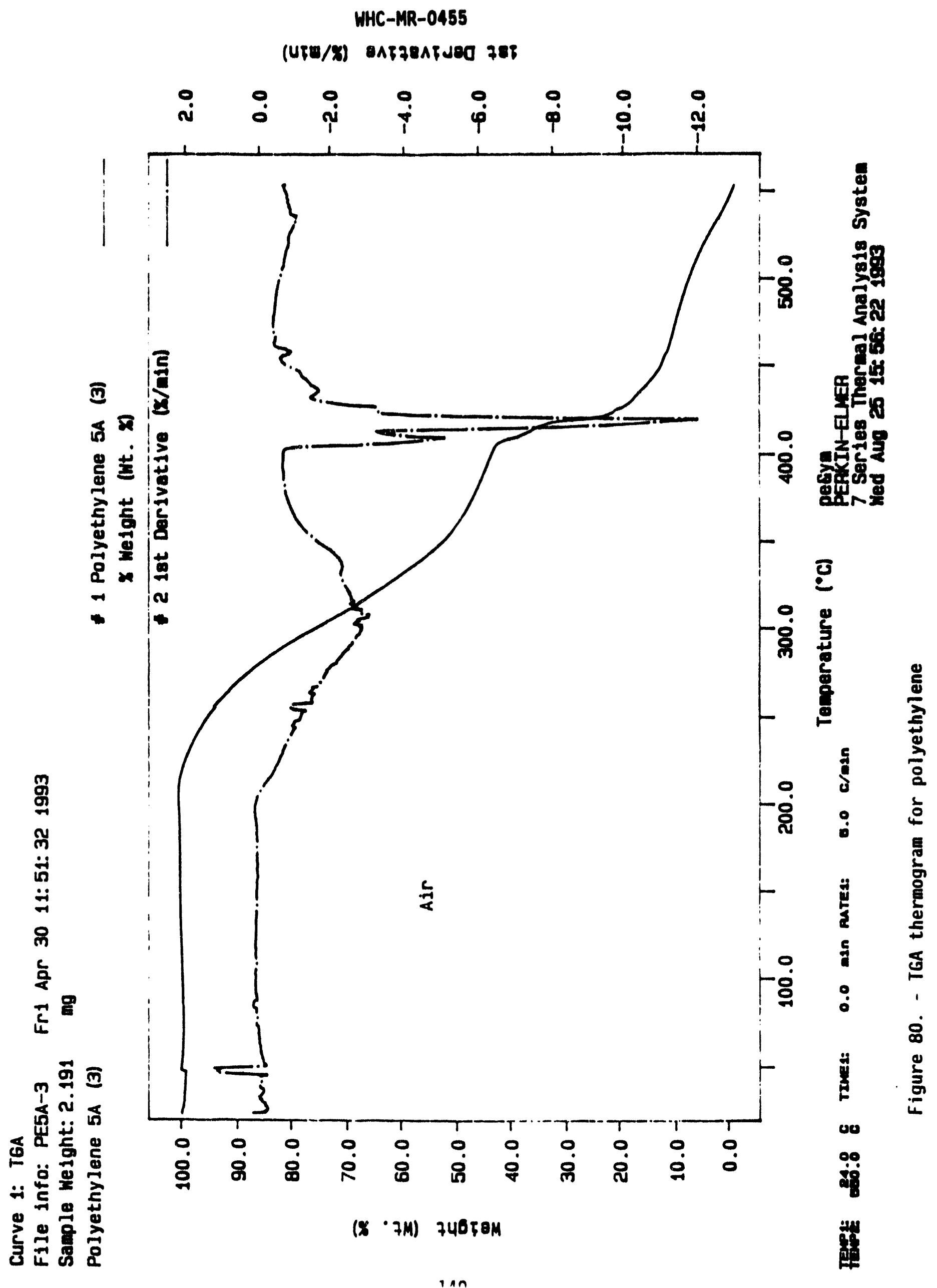




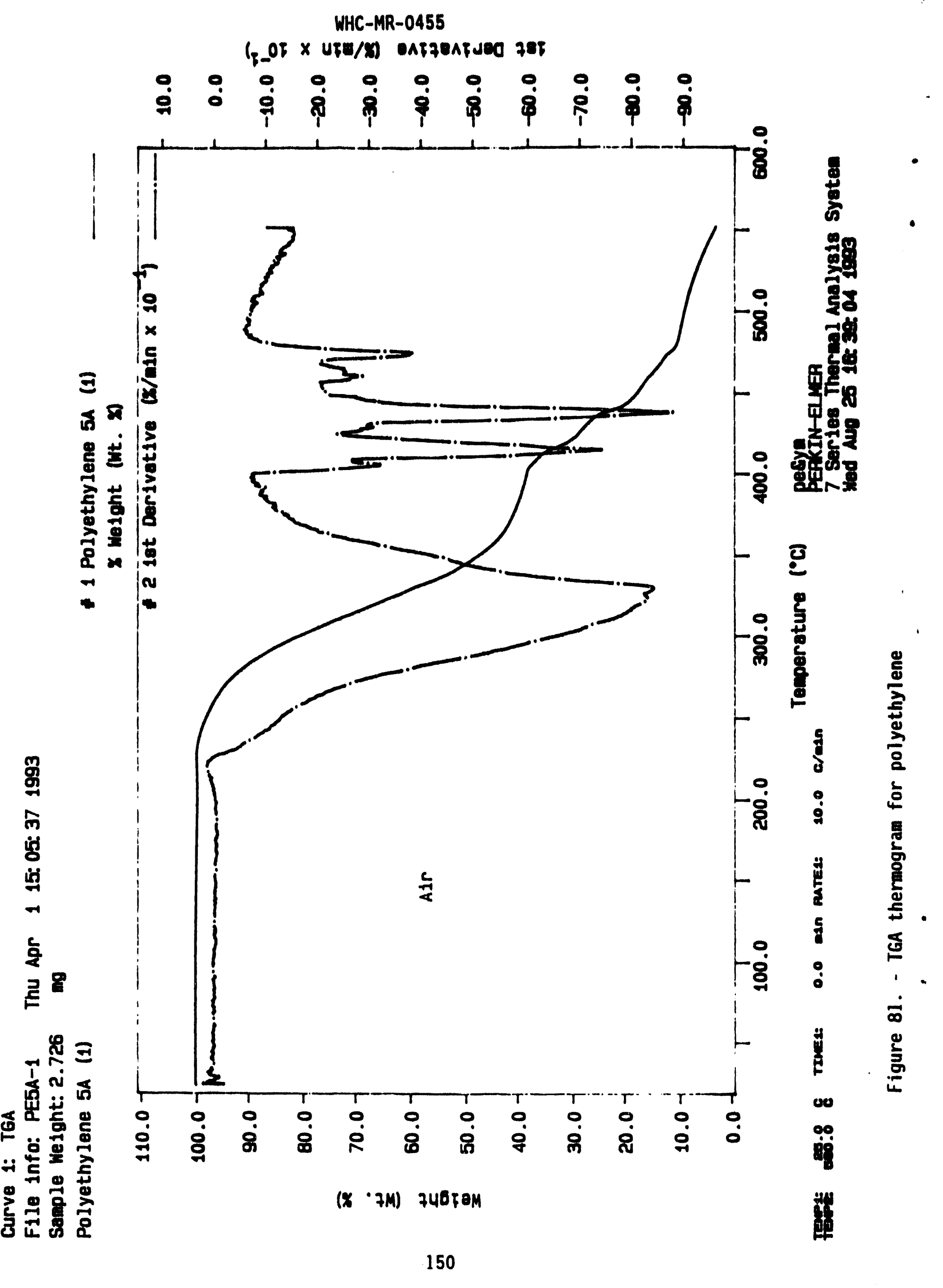


Curve 1: TGA

File info: PE15A-1 Sanple Weight: 5.766

Fri Apr 30 13: 11: 201993

Polyethylene 15A (1)

mg

1 Polyethylene $15 A$ (1)

8 Weight (it. 8$)$

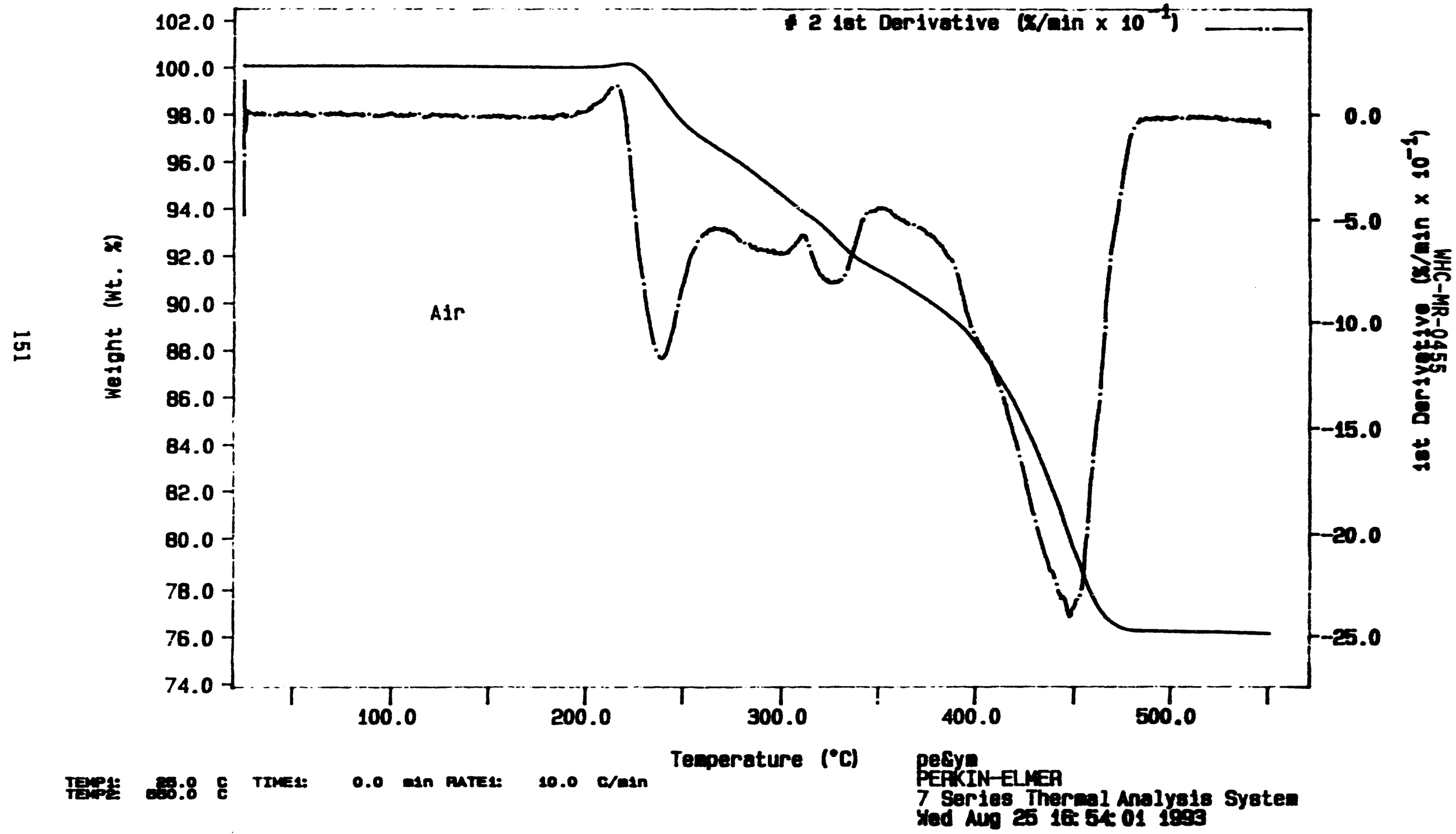

Figure 82. - TGA thermogram for polyethylene-nitrate mixture 15A (1:1) 
Curve 1: T6A

F1le Info: PE158-2 Mon May 3 11:50: 121993

Sample We1ght: 5.753

Polyethylene 158 (2)

mo

\& 1 Polyethylene 158 (2)

$x$ Waight (Wt. 9

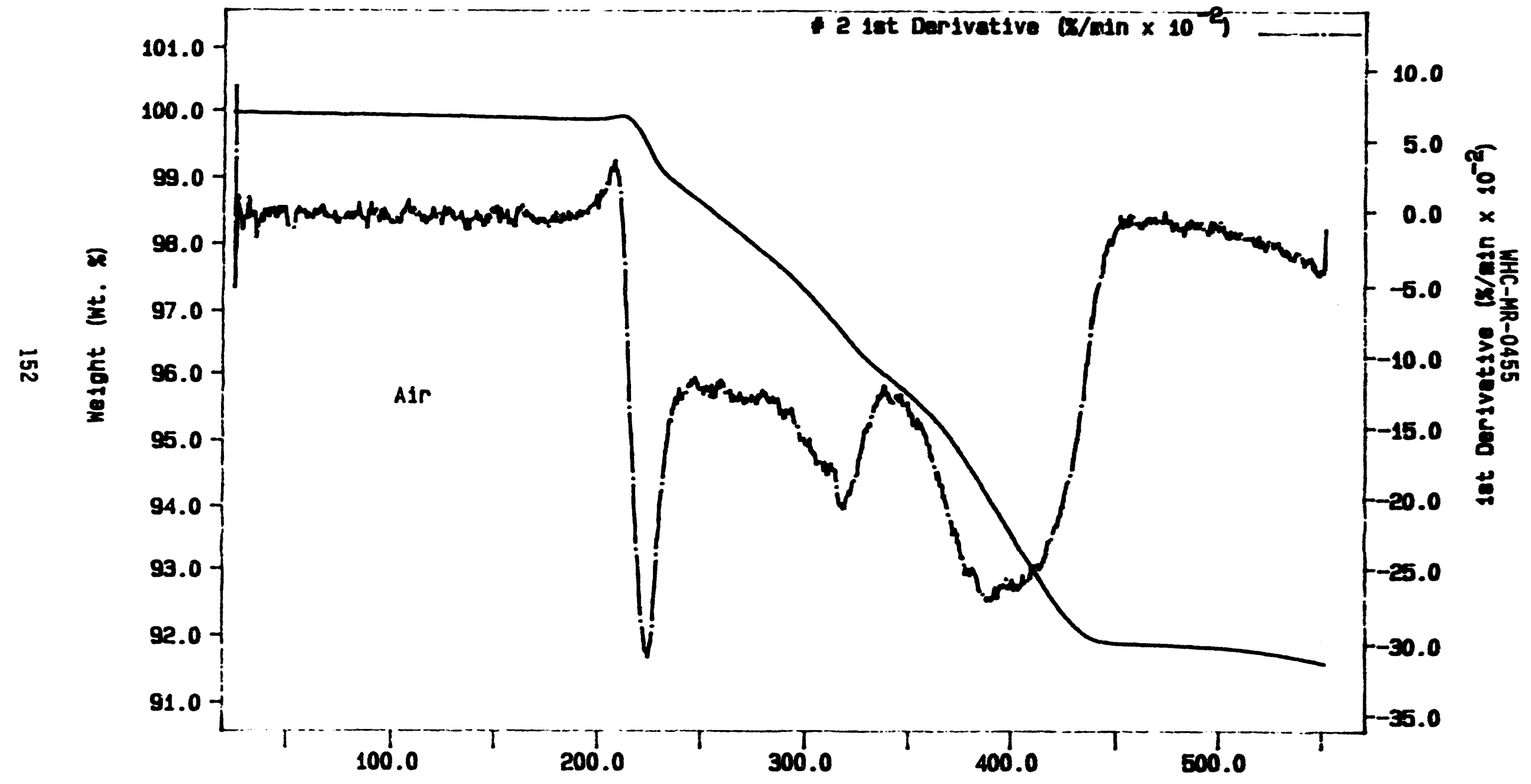

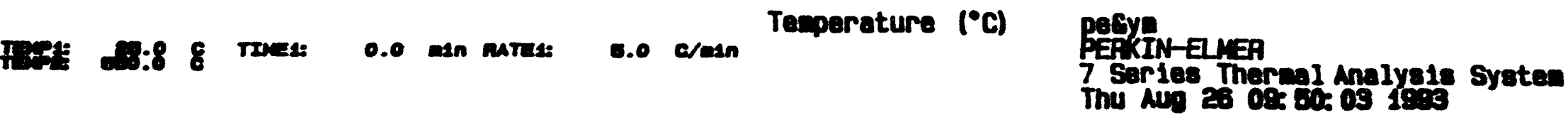

Figure 83. - T6A thermogram for polyethylene-nitrate mixture 15B (1:3) 
Curve 1: TGA

File info: PE15C-1 Mon May 3 13: 06: 361993

Sample Weight: $5.063 \mathrm{mg}$

Polyethylene 15C (1)

- 1 Polyethylene 15C (1)

$x$ weight (Wt. $x)$

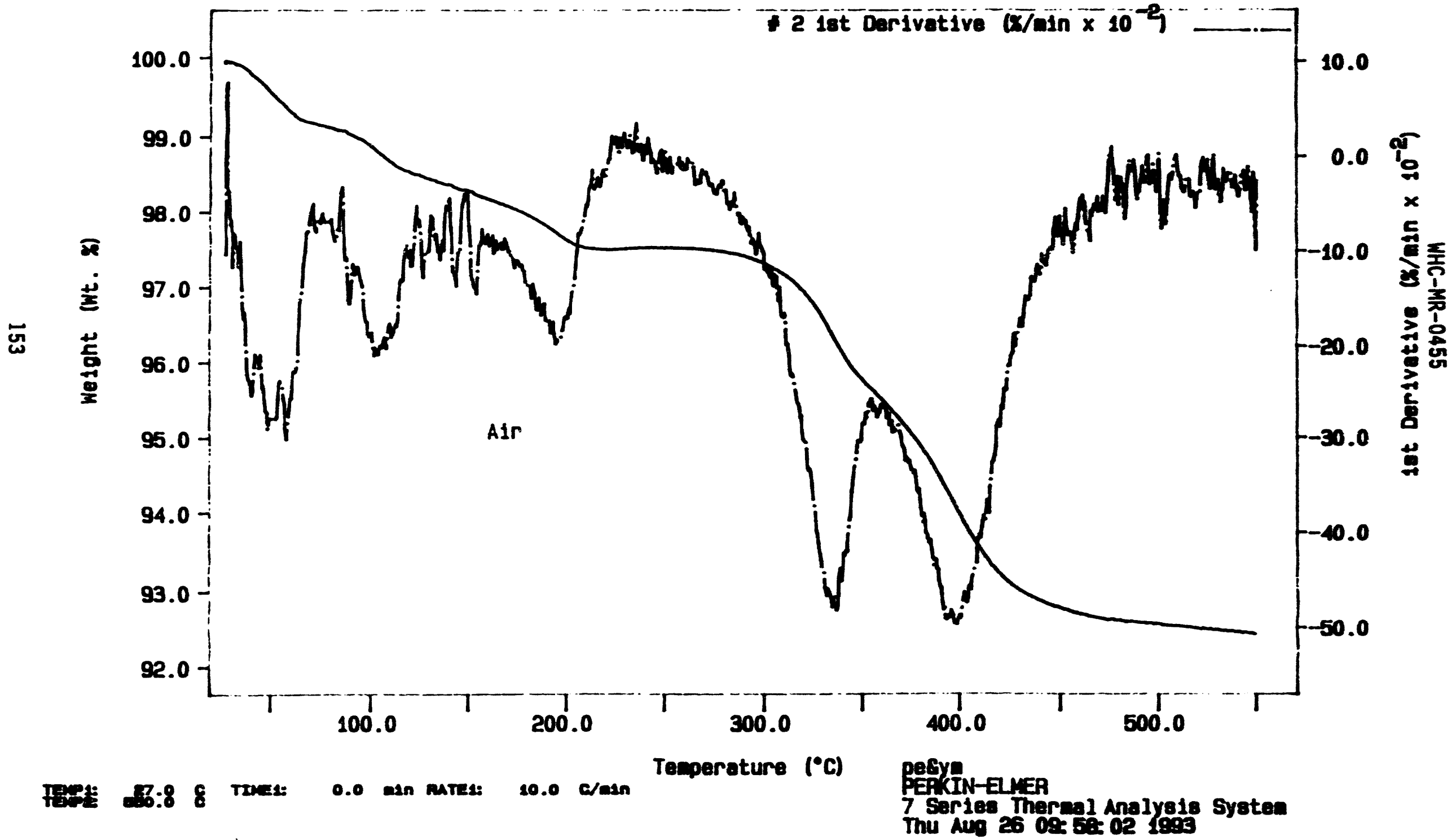

Figure 84. - TGA thermogram for polyethylene-nitrate mixture $15 \mathrm{C}(1: 3$; dil) 
Curve 1: T6A

F1le info: PE150-1 Mon May 3 16: $37: 151993$

Sample We1ght: 8.629

ag

Polyethylene 150 (1)

- 1 Polyethylene 150 (1)

$x$ weight (itt. $x$

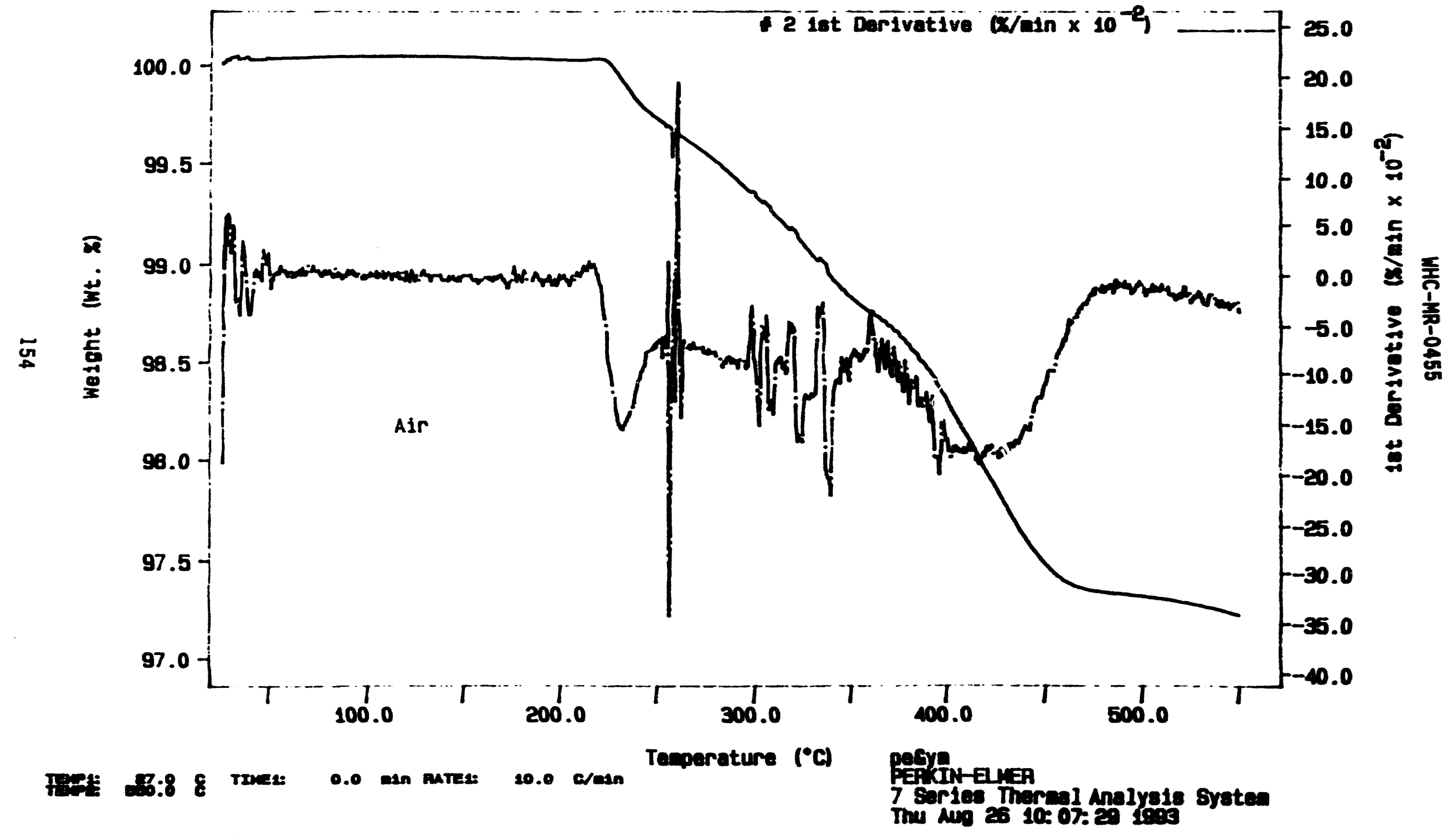

Figure 85. - TGA thermogram for polyethylene-nitrate mixture 150 (1:10) 
Curve 1: TGA

F1le info: PE16A-1 Tue May 4 12: 32131993

Sample Weight: $4.329 \mathrm{mg}$

Polyethylene 16A (1)

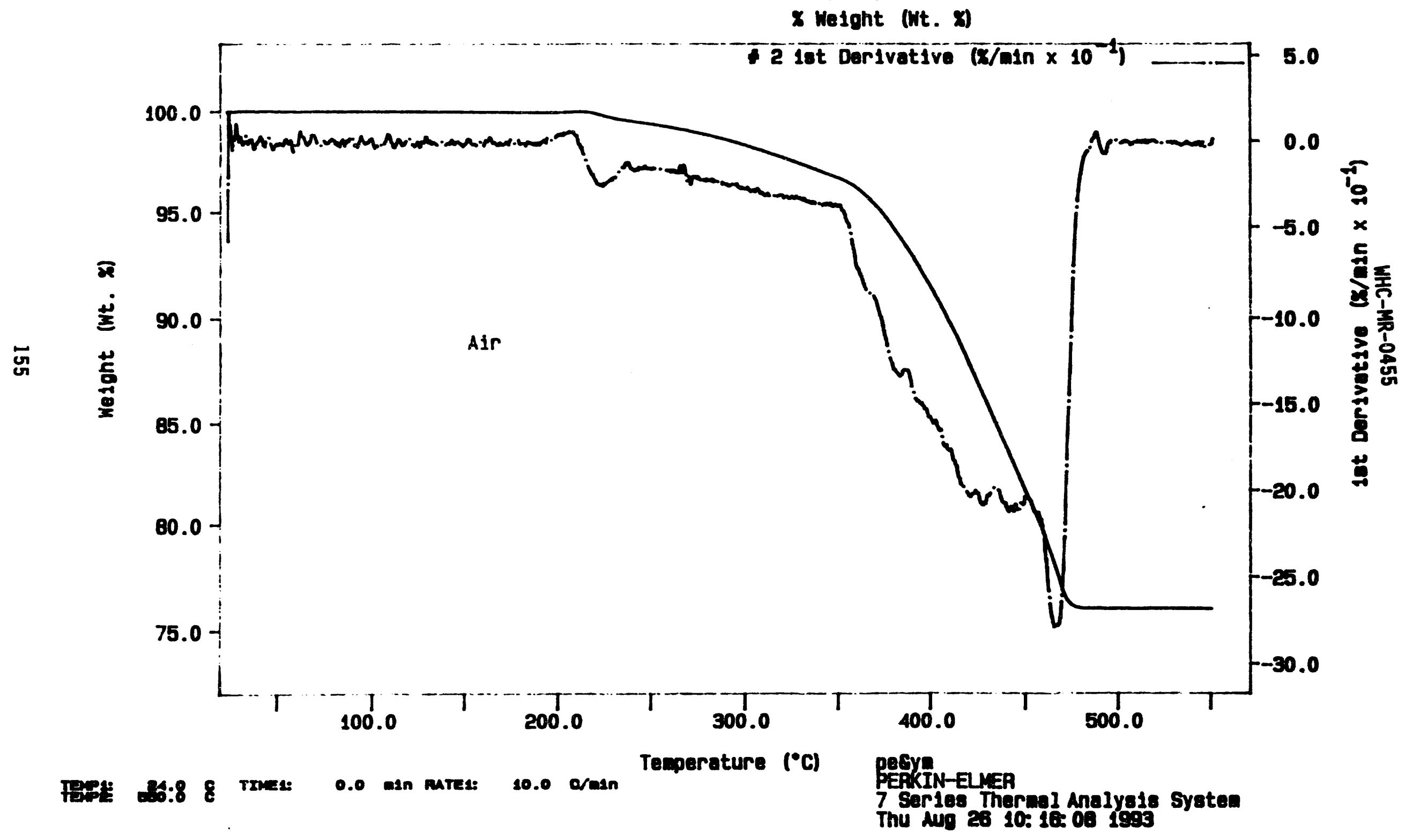

Figure 86. - TGA thermogram for polyethylene-nitrate-nitrite mixture 16A (1:1) 

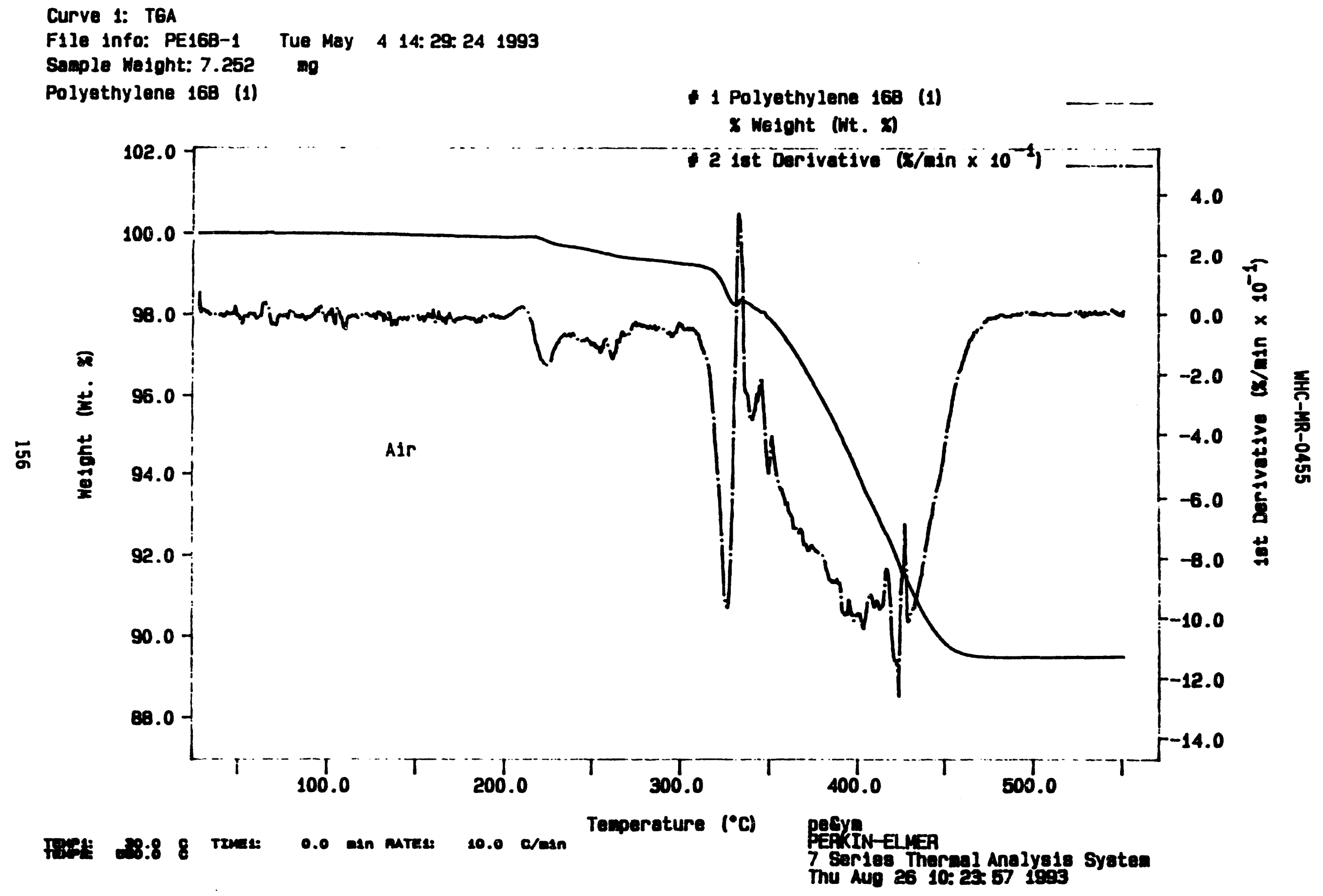

Figure 87 . TGA thermogram for polyethylene=nitrate-nitrite mixture $16 B(1: 3)$ 
WHC-MR-0455

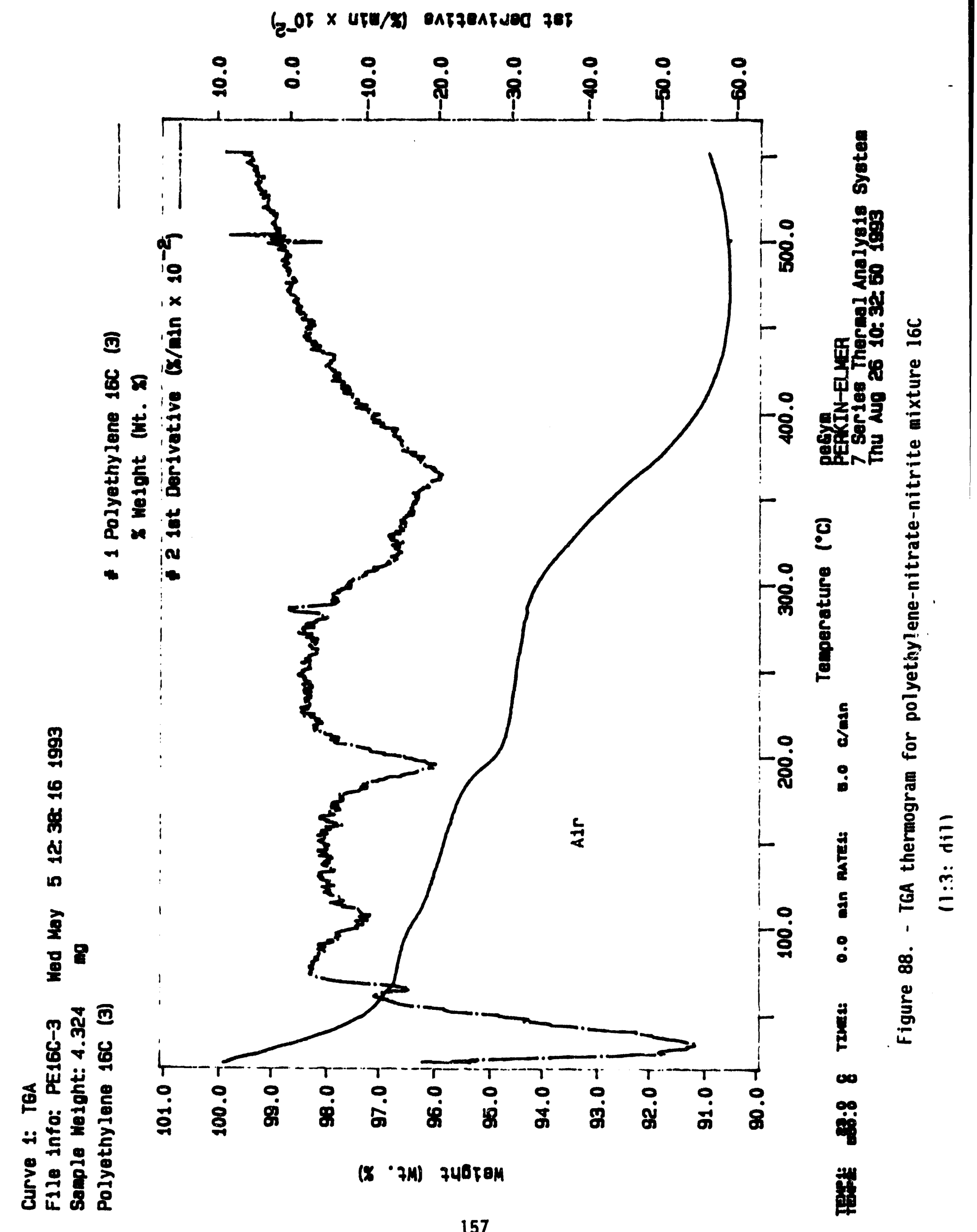


Curve 1: TGA

F1le info: PE160-2 Wed May 5 15: 03.571993

Sample Weight: 6.946 ing

Polyethylene 160 (2)

Polyothylono 160 (2)

1 Polyethylene 160 (2)

$x$ Weight (it. $x)$

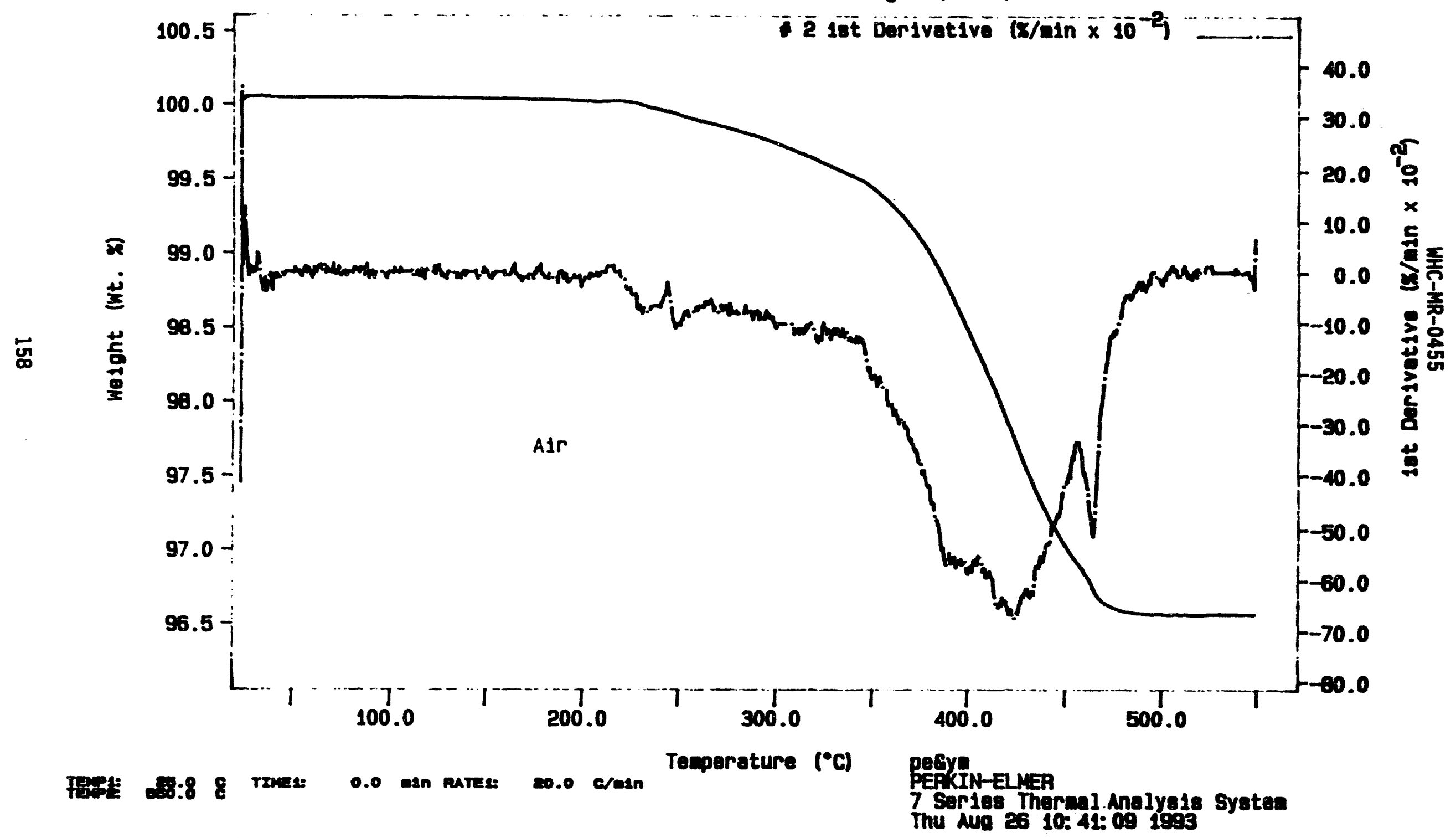

Figure 89. - TGA thermogram for polyethylene-nitrate-nitrite mixture 160 
Curve 1: DSC

F1le info: FeCN17A-2 Wed Mar 10 14: $18: 121993$

Sample Welght: $4.040 \quad \mathrm{mg}$

FeCN $17 A$ (2)

- 1 FeCN 17A (2)

Haat Flow (nW)

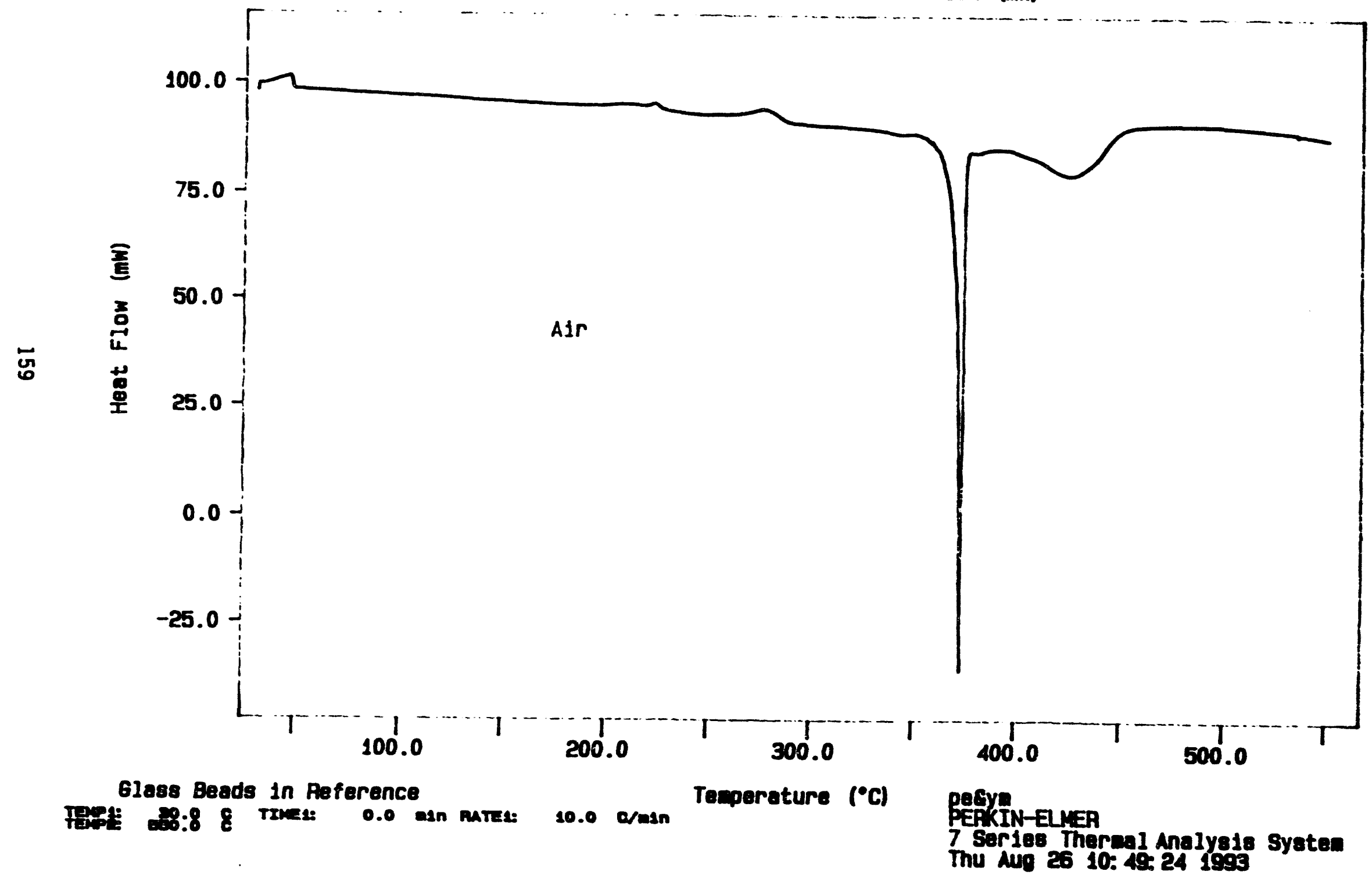

Figure 90. - DSC thermogram for predried FeCN sample 17A 
Curve 1: DSC

F1le info: FeCN17A-3 Thu Mar 25 11:09: 151993

Sample Weight: 6.900

FeCN 17A (3)

ing

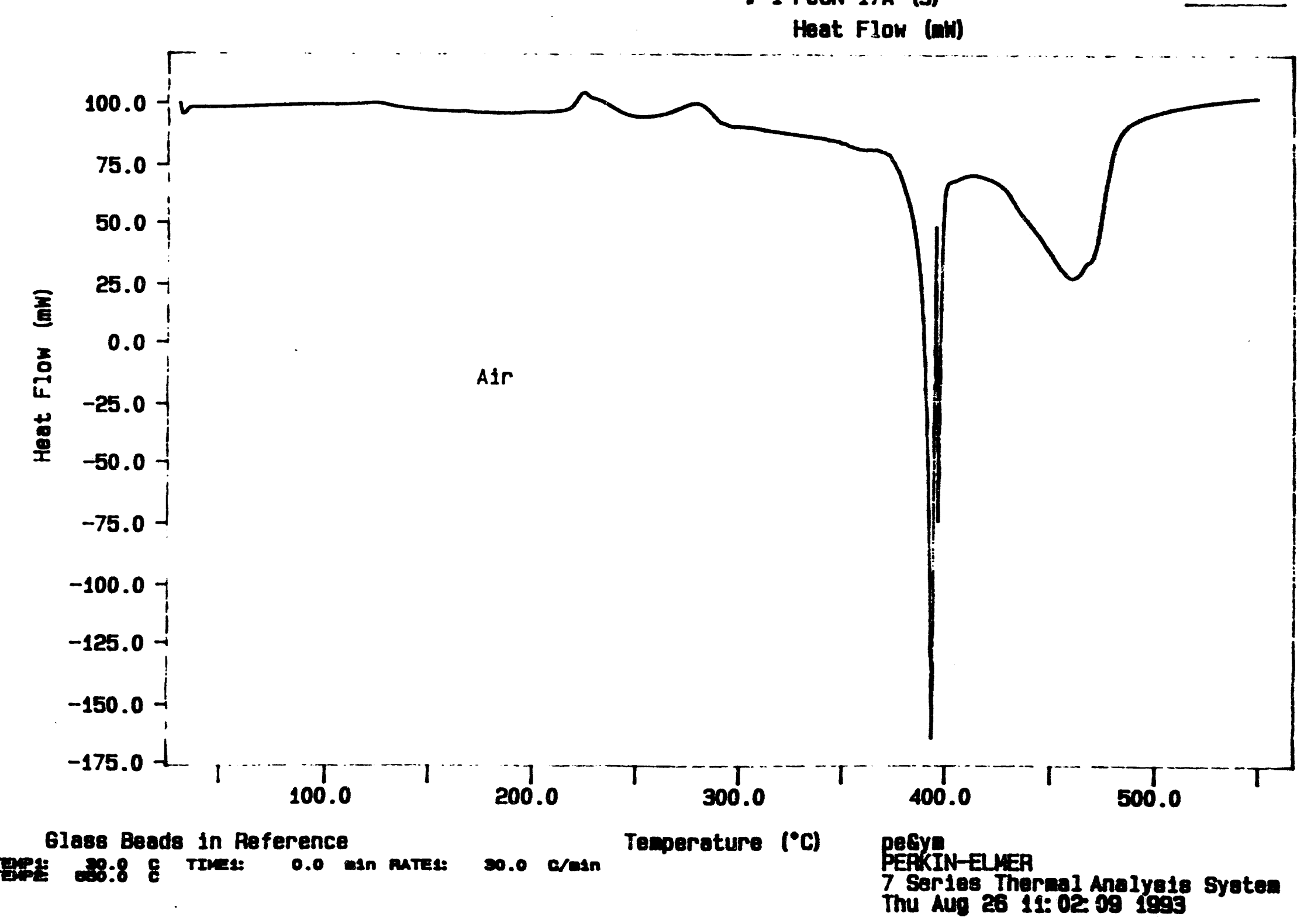

Figure 91., - DSC, thermogram for predried FeCN sample 17A 
Curve 1: DSC

F1le Info: FeCN17A-5 Thu Mar 25 13: 41: 461993

Sample Weight: 9.770

mg

FeCN 17A (5)

- 1 FeCN 17A (5)

Heat Flow (nW)

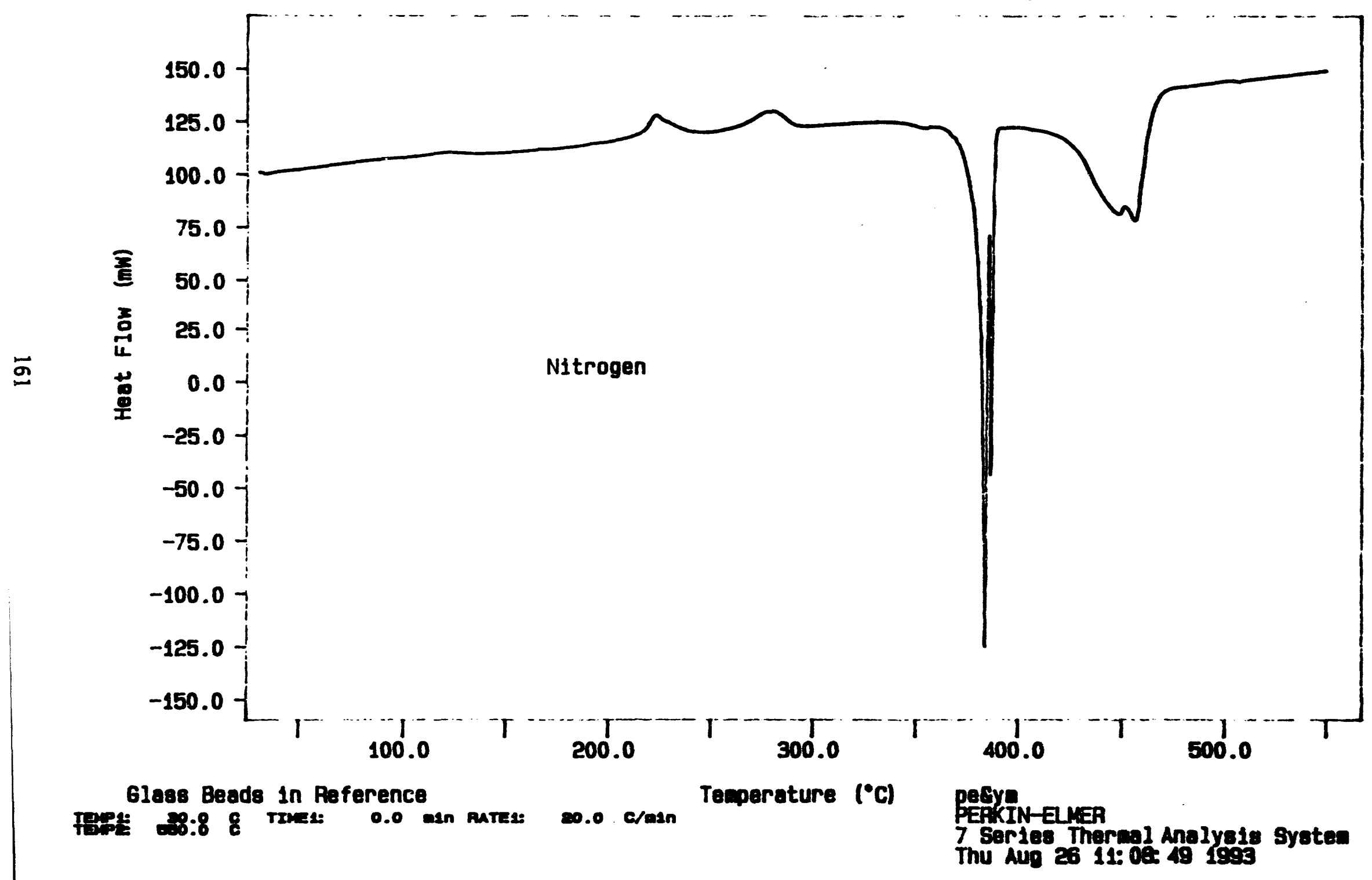

Figure 92. - DSC thermogram for predried FeCN sample 17A 


\section{Curve 1: DSC}

F1le info: FeCN17A-1 Wed Mar 10 13: 23: 331993

Sample Welght: 11.870

FeCN $17 A$ (1)

ag

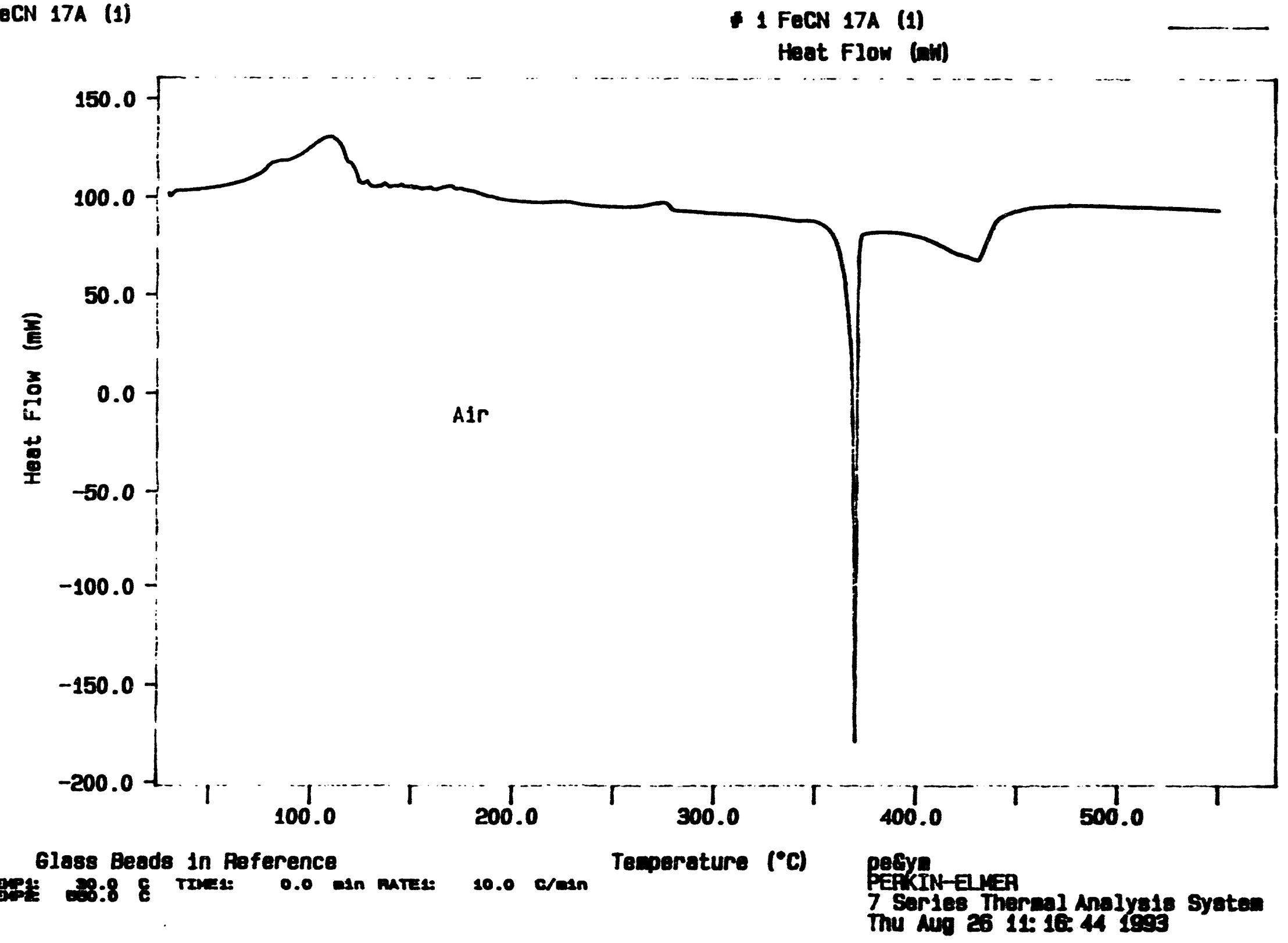

퐇

Figure 93: - DSC thermogram for paste FeCN sample 17A 
Curve 1: DSC

F1le info: FeCN17A-6 Thu Mor 25 15: 20: 291993

Sanple Weight: $\mathbf{5 . 0 6 0}$

FeCN 17A (6) White Crystals

- 1 FeCN 17A (6) inite Cryatalo Heat Flow (nii)

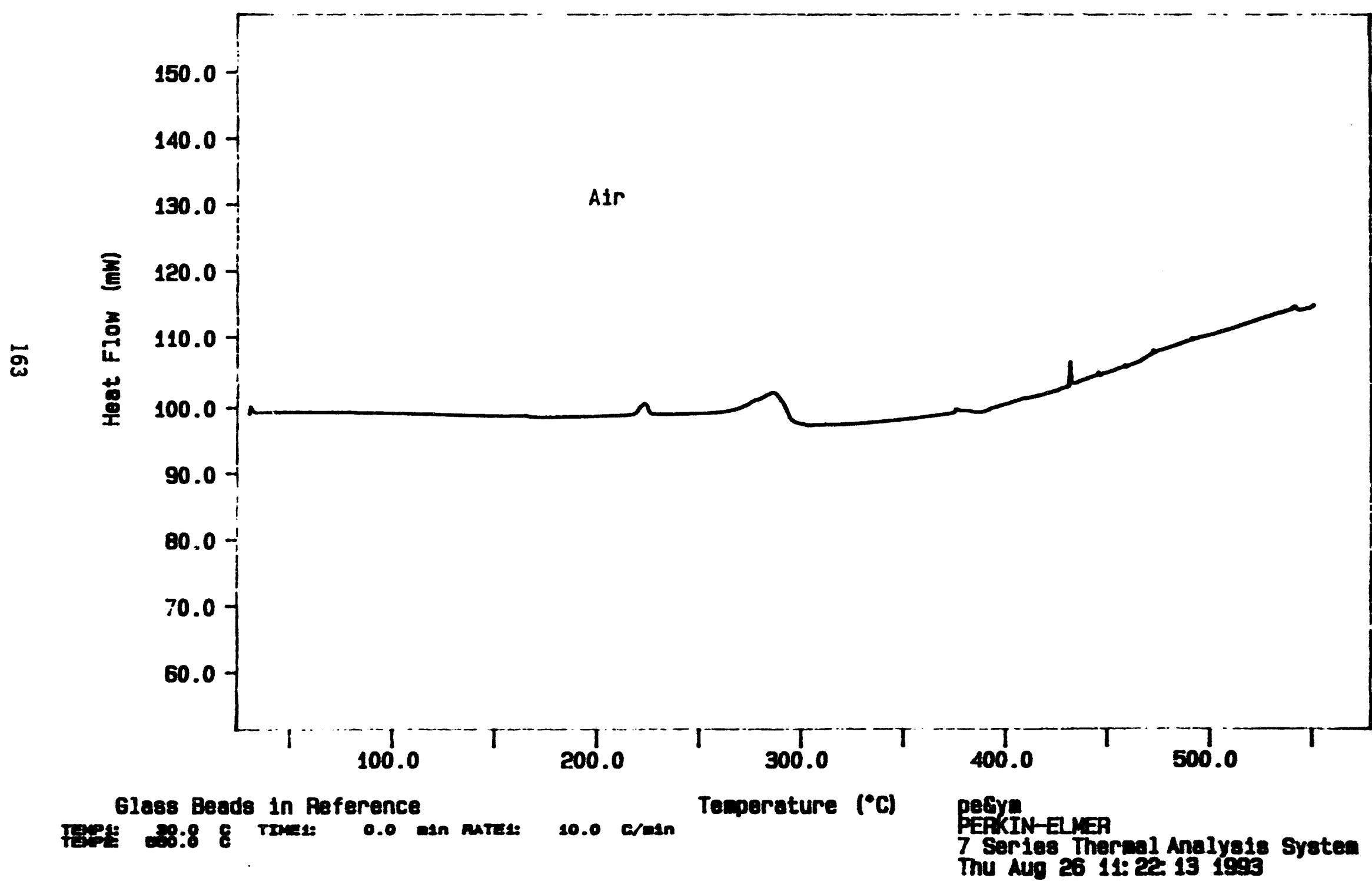

Figure 94. - DSC thermogram for white crystals, formed on surface of FeCN 
Curve 1: DSC

F110 Info: FocN17A-6 Thu Mar 25 15: 20: 291993

Sample Veight: 5.060 og

FoCN $17 A$ (6) White Crystals

- 1 FeCN 17A (6) inite Cryotals

Haat flow (nin)

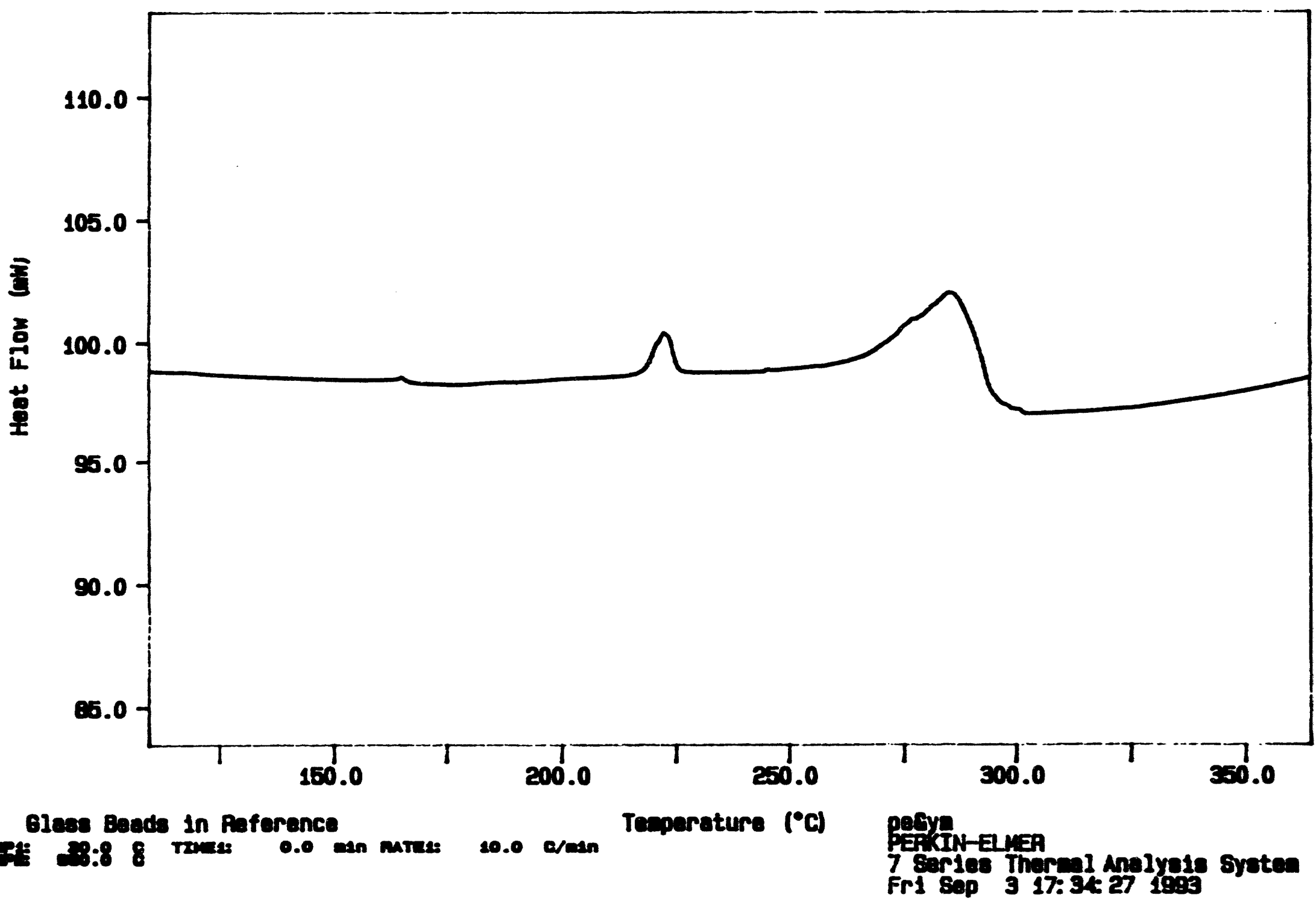

Figure 95. - Optimized and scaled DSC theremogran of figure 94 , for white

- crystals forned on the surface of FeCr sample during drying 
Curve 1: TGA

File info: FeCN17A-2 Thu Apr 1 12: 42: 011993

Sample Weight: 4.495 ig

FeCN 17A (2)

- 1 FeCN 17A (2)

x weight (int. $x$

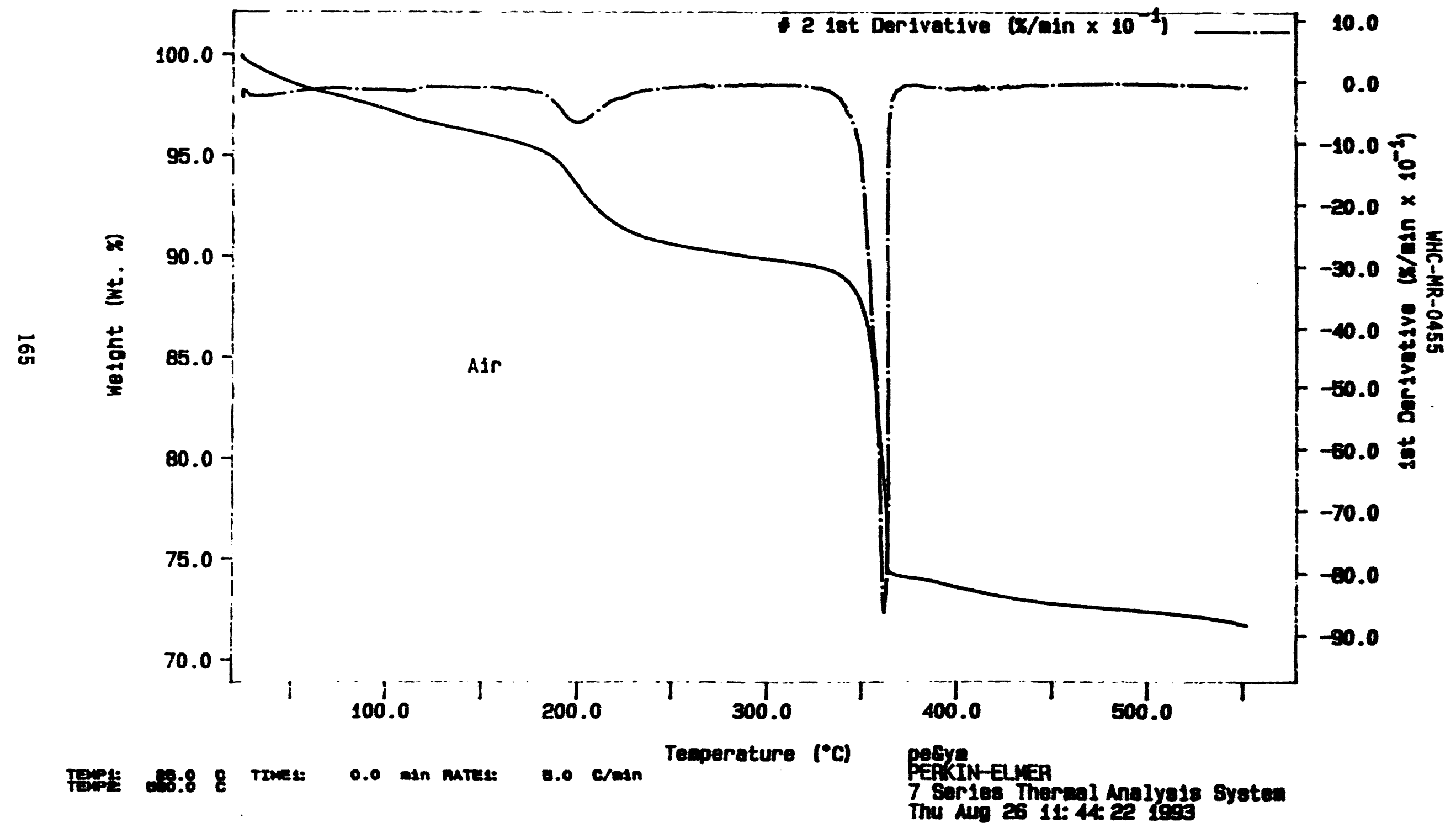

Figure 96. - TGA thermogram for predried FeCN sample 17A 


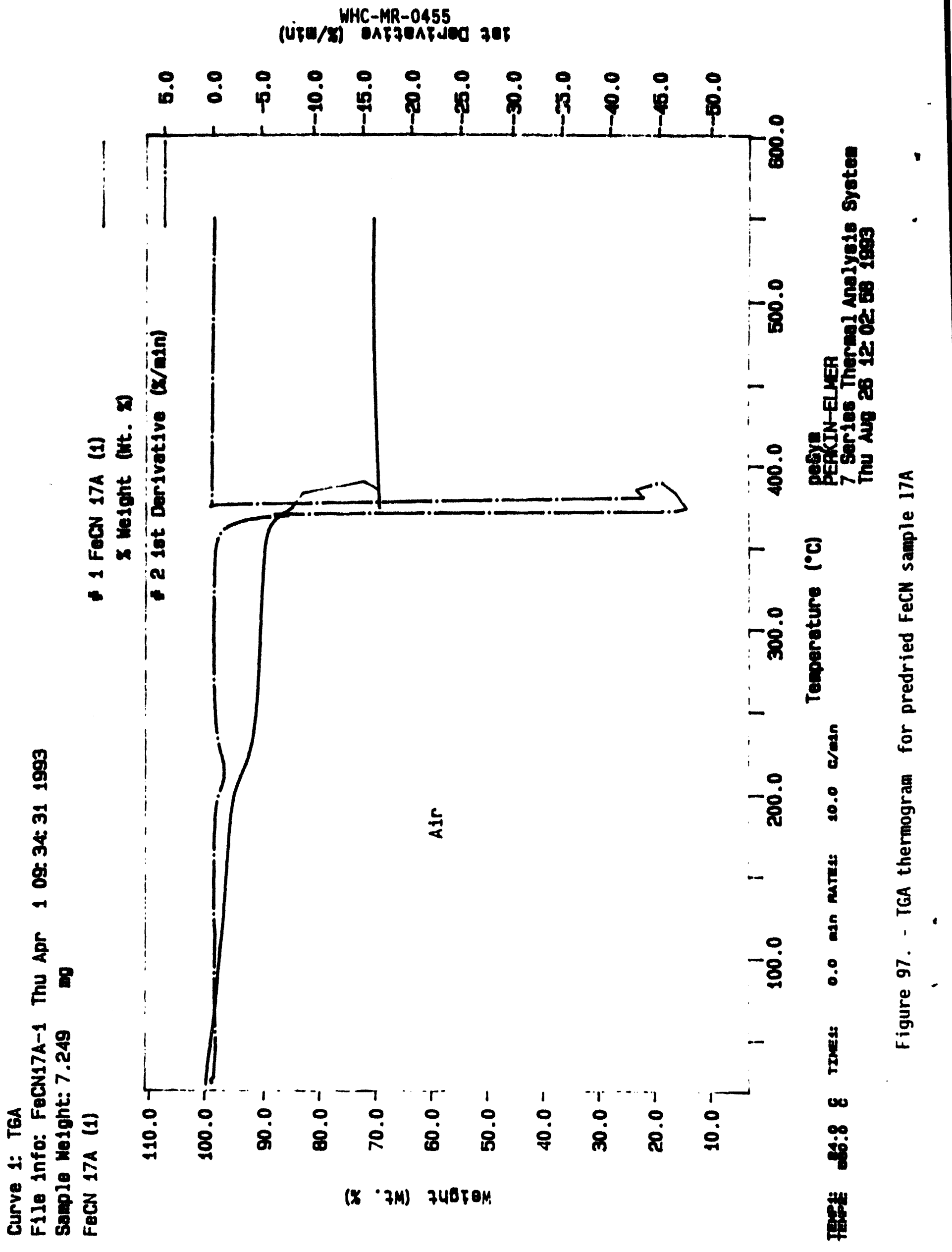


Curve 1: TGA

File info: FeCN17A-3 Thu Apr 1 13: 41: 361993

Sanple Welght: 4.571

FeCN $17 A$ (3)

ag

8 weight (int. 8$)$

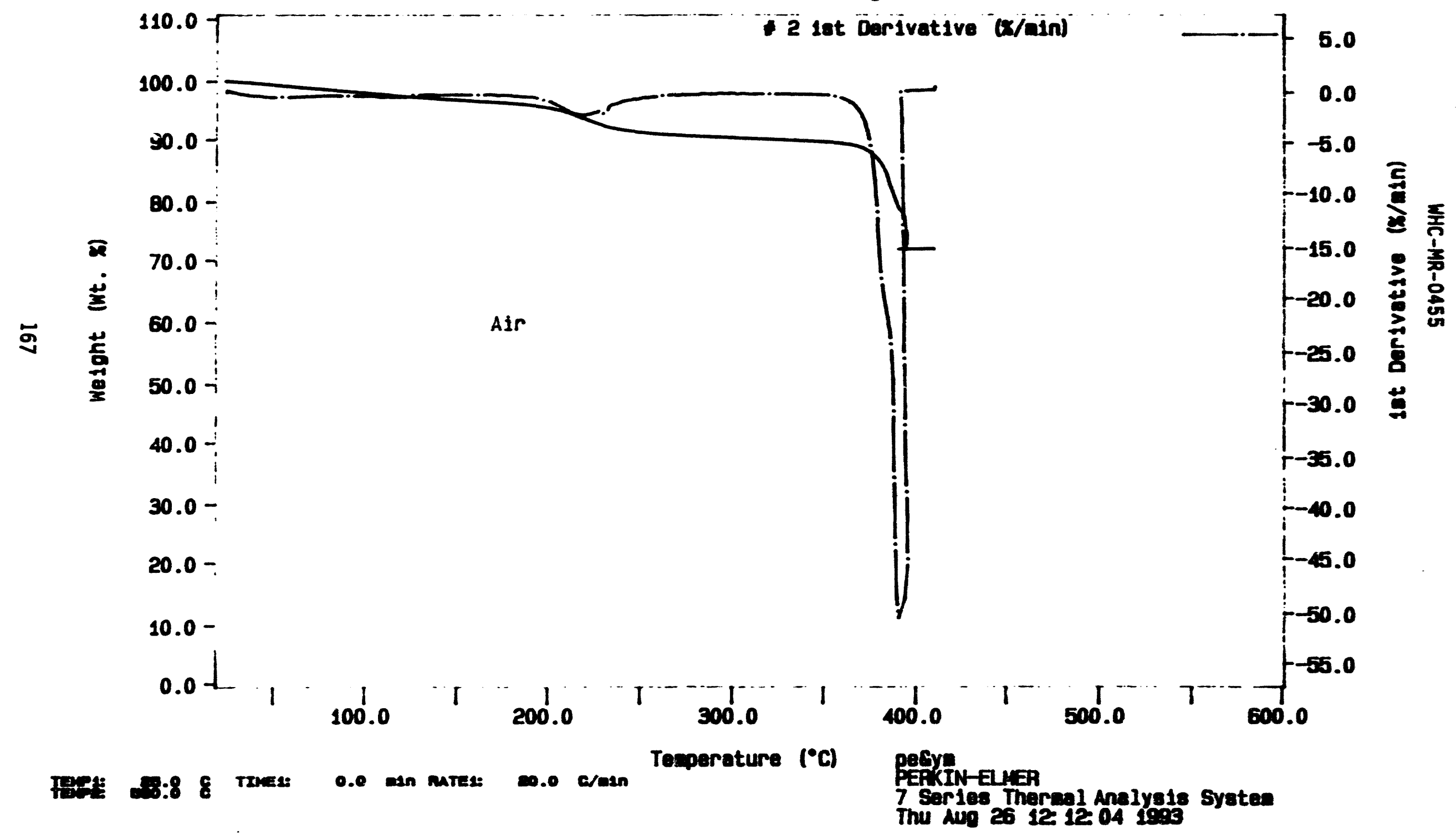

Figure 98. - TGA thermograms for predried FeCN sample 17A 
Curve 1: T6A

File info: FeCN17A-1 Thu Apr 1 09:34: 311993

Sanple Weight: $7 . \mathrm{E}_{19} \mathrm{mg}$

FeCN 17A (1)

1 FoCN $17 A$ (1)

8 weight (itt. $\$$

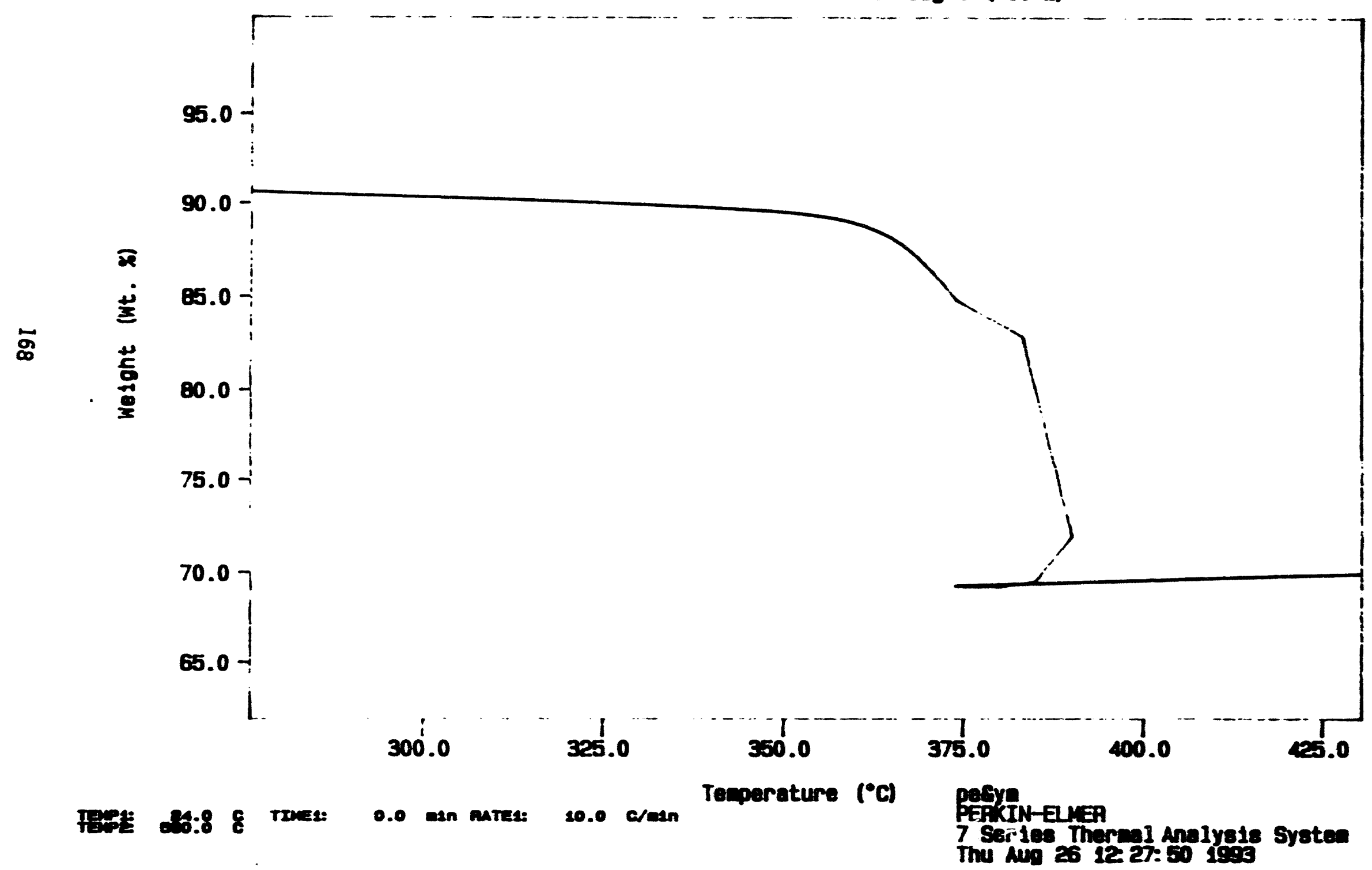

Figure 99. - Optimized and scaled DSC thermogram of figure 97, for predried 
WHC-MR-0455

\section{APPENDIX \\ PRECISION AND ACCURACY OF TEST RESULTS}

\section{Differential Scanning Calorimeter}

High purity standard materials with known temperature transitions are used in calibration of the differential scanning calorimeter (DSC). The standards chosen for calibration depend on the temperature range used in the tests, which was ambient to $550^{\circ} \mathrm{C}$. Transition temperatures for indium and zinc are $156.60^{\circ}$ and $419.47^{\circ} \mathrm{C}$, respectively. Thus, a two-point temperature

calibration, with indium and zinc, was used. This procedure affords a linear temperature calibration over the range of the melting temperatures of these two standards.

Temperatures for indium transition varied between $156.1^{\circ}$ and $156.7^{\circ} \mathrm{C}$ during spot checks. Average value and standard deviation were $156.3^{\circ} \pm 0.3^{\circ} \mathrm{C}$. When the measured temperature was less than $156.4^{\circ} \mathrm{C}$ the instrument was calibrated according to the prescribed procedure for a one-point temperature calibration. Temperatures for zinc transition varied between $417.0^{\circ}$ and $419.5^{\circ} \mathrm{C}$, during spot checks. Average value and standard deviation were $418.8^{\circ} \pm 0.8^{\circ} \mathrm{C}$. When measured temperature was less than $419.0^{\circ} \mathrm{C}$, the DSC was calibrated, using the one-point temperature calibration, for fine tuning.

Sodium nitrate was one of the ingredients present in all the test samples. Its melting point is known quite accurately. In some of the test mixtures its melting point was not affected by the presence of the fuel. In tests with these test mixtures, it served as an internal standard; its melting temperature could be used to check the temperature calibration. In tests with these mixtures its melting point was usually within $\pm 0.5^{\circ} \mathrm{C}$ of the literature value.

Measurements of onset temperatures are based on the initial deviation from the baseline of a thermogram, as determined by the experimenter. Optimization and scaling of plots, a procedure provided by the computer program of the DSC, provides better resolution of the temperature scale. As a result, repeated readings of the onset temperature of a thermogram were within $1^{\circ} \mathrm{C}$. The accuracy of the onset temperature is also a function of the homogeneity of the mixtures. Homogeneity entails accurate weighing of the ingredients, extensive mixing and representative sampling. Of these, representative sampling, which depended on sample size was the main determinant of the precision and accuracy of onset temperature values. Small samples, evenly distributed in the sample pan, are preferred for thermal allalysis. Heat transfer is enhanced and selfheating is minimized. When samples are mixtures of a faw ingredients the need for representative samples prescribes the size of the sample. On the other hand, when samples are reactive, a small sample is required. These conflicting constraints were present throughout this test series, and dictated the small size of the samples, as detailed in the final report. Comparisons of thermograms, obtained for samples of any specific mixture show good reproducibility as regards the overall shape of the thermograms, as well as onset and peak temperatures. 
Onset temperatures presented for the citrate ixtures (tables 18 and 19) and for the polyethylene mixtures (tables 22 and 23) show excellent reproducibility. In these two sets of mixtures, initiation of exothermic behavior was due to the decomposition of the fuel itself, and was less dependent on the fuel-oxidant ratio and therefore less dependent on sample size. Onset temperatures for the EDTA and oxaiate mixtures were not as reproducible, and varied by as much as $\pm 10^{\circ} \mathrm{C}$. These onset temperatures were indicative of the initiation of chemical reaction between the fuel and $\operatorname{oxidant}(s)$, and therefore depended to a larger extent on the proportions of the ingredients, and hence, on the size of the sample.

\section{Thermogravimetric Analysis}

Calibration of the thermogravimetric analyzer (TGA) required calibration of the temperature. Nickel, with a magnetic transition temperature at $354^{\circ} \mathrm{C}$ and Perkalloy, with a magnetic transition temperature of $596^{\circ} \mathrm{C}$, were used as standards. Spot checks were performed with both metals, and recalibration was done if the transition temperature for Nickel or Perkalioy was off by one or more degrees Celsius. Either a one- or a two-temperature calibration procedure was done, as needed.

Onset temperatures for initiation of weight loss due to decomposition or reaction were determined from the deviation from the baseline of a thermogram. However, initial deviation from the baseline was in general due to loss of moisture and of water of hydration. Each loss in weight shifted the position of the baseline; as a result, each portion of the baseline at the new position was often short. Determination of onset temperatures is more precise when a long, horizontal baseline precedes a deviation. Adsorption of oxygen by a few of the samples also affected baseline position. On the whole, onset temperatures varied by as much as $\pm 13^{\circ} \mathrm{C}$.

Calibration of the TGA balance was conducted with a $100 \mathrm{mg}$ standard calibration weight. The TGA microbalance is highly sensitive and excellent reproducibility was found for weight loss values, of the order of \pm 1 pct, for all the samples.

\section{Bomb Calorimetry}

The bomb calorimeter used in the trials was a Parr instrument model 1261 Isoperibol calorimeter. Two sets of bombs and water buckets were obtained and these were calibrated with benzoic acid pellets supplied by Parr. The heat of combustion of these pellets in oxygen is $6318 \mathrm{cal} / \mathrm{g}$.

The oxygen used was supplied as high pressure reagent grade gas (450 psig) to insure complete combustion. The $1.000 \mathrm{~g}$ pellets were contained in stainiess steel capsules supplied by Parr. These capsules were conditioned in a $500^{\circ} \mathrm{C}$ oven for 4 hours, as recommended by the manufacturer, in order to provide an oxidized surface to help insure total combustion. The electrical ignition was conducted using a nickel alloy fuse wire supplied by Parr. The wire was 
shaped into a loop whose bottom contacted the top of the pellet. The current supplied to the wire resulted in oxidation and evaporation of the wire with only small droplets of melt adhering to the ends of the wire. This wire residue was subtracted from the initial mass of the wire in calculating the weat contribution of the wire, which averaged $13 \mathrm{cal}$. The calorimeter bucket water weight, delivered at $31^{\circ} \pm 1^{\circ} \mathrm{C}$, was $1978.5 \pm .8 \mathrm{~g}$. The calorimeter jacket water temperature was set at $35.00 \pm .05^{\circ} \bar{C}$. The average temperature rise in the buckets was $2.66^{\circ} \mathrm{C}$, and the calculated energy equivalents (cal/ $\left.{ }^{\circ} \mathrm{C}\right)$ of the two bomb/bucket sets were $2375 \pm 10( \pm 0.43 \%)$ and $2387 \pm 7$ $( \pm 0.31 \%)$, based on 16 and 11 calibration runs, respectively.

The above precision of the calorimetric values is somewhat outside the range recommended by ASTM $(0.15 \%)$. The additional variability is due primarily to the use of a balance that weighs to the nearest milligram. An uncertainty of 1 or more milligrams in amount of benzoic acid leads to an uncertainty of at least $6.3 \mathrm{cal}$ and to an estimated uncertainty of at least $3 \mathrm{cal} /{ }^{\circ} \mathrm{C}$ in energy equivalence. An analytical balance was obtained subsequently for use in calorimetric measurements, but has not been used to recalibrate the calorimeter in view of the compleie failure to achieve significant ignition of the nitrate/nitrite mixtures with organic salts or polyethylene in an inert atmosphere. This inability to ignilie the mixtures in powder or pellet form was not limited to the nickel alloy fuse wire, which is designed for use in a high pressure oxygen atmosphere, but was also true of a special aluminum/palladium composite fuse wire ("Pyrofuze") which is independent of atmosphere. Even a much more energetic pyrotechnic match failed to effectiveiy ignite the mixtures in a nitrogen atmosphere.

\section{Explosive Testing}

\section{Internal Ignition Test}

The internal ignition test does not specify a calibration procedure. The criterion used in the interpretation of this test is that for a positive result either the pipe or a least one of the end caps be fragmented into at least two distinct pieces. Examples of results are the following:

\begin{tabular}{||l|c|}
\hline Test Substance & $\begin{array}{c}\text { Results with a } \\
20 \mathrm{~g} \text { igniter }\end{array}$ \\
\hline TNT, granular & + \\
\hline Water Gel Explosive & + \\
\hline ANFO, aluminized & + \\
\hline Nitrocarbonitrate & + \\
\hline Ammonium perchlorate, 45 $\mu$ & + \\
\hline AN prills, agricultural & - \\
\hline AN prills, porous, low density & - \\
\hline
\end{tabular}


WHC-MR-0455

$\checkmark$

-

$\lambda$

$\checkmark$ 
WHC-MR-0455

\section{DISTRIBUTION}

Number of Copies

OFFSITE

2

U. S. Department of Energy

1000 Independence Avenue SW EM-35

Washington, DC 20585

Charles 0'Dell

Kenneth Lang

\section{ONSITE}

42

U. S. Department of Energy

R. F. Christensen

S. 0. Branch

R3-72

R3-72

Pacific Northwest Laboratory

R. M. Bean P8-08

D. M. Camaioni K2-38

R. D. Scheele P7-25

Westinghouse Hanford Company

H. Babad R2-78

G. S. Barney T5-12

D. B. Bechtold T6-09

D. C. Board \$1-57

R. G. Brown R2-11

R. J. Cash R2-78

G. M. Christensen H4-21

M. D. Crippen L5-31

K. D. Fowler (3) R2-11

J. M. Grigsby H4-62

R. L. Guthrie H4-61

G. D. Johnson R2-78

N. W. Kirch R2-11

J. W. Lentsch R2-78

J. E. Meacham R2-78

M. G. Plys H4-62

A. K. Postma H4-62

T. E. Rainey R4-02

J. P. Sederburg R2-11

M. J. Sutey R1-49

L. E. Thomas R3-08

D. A. Turner (5) R2-78

0 . S. Wang R2-78

TFIC R2-95

DOE-RL Public Reading Room A1-65

Document Processing and Distribution (2) L8-15

Central Files

Information Release Administration (3) R1-05 

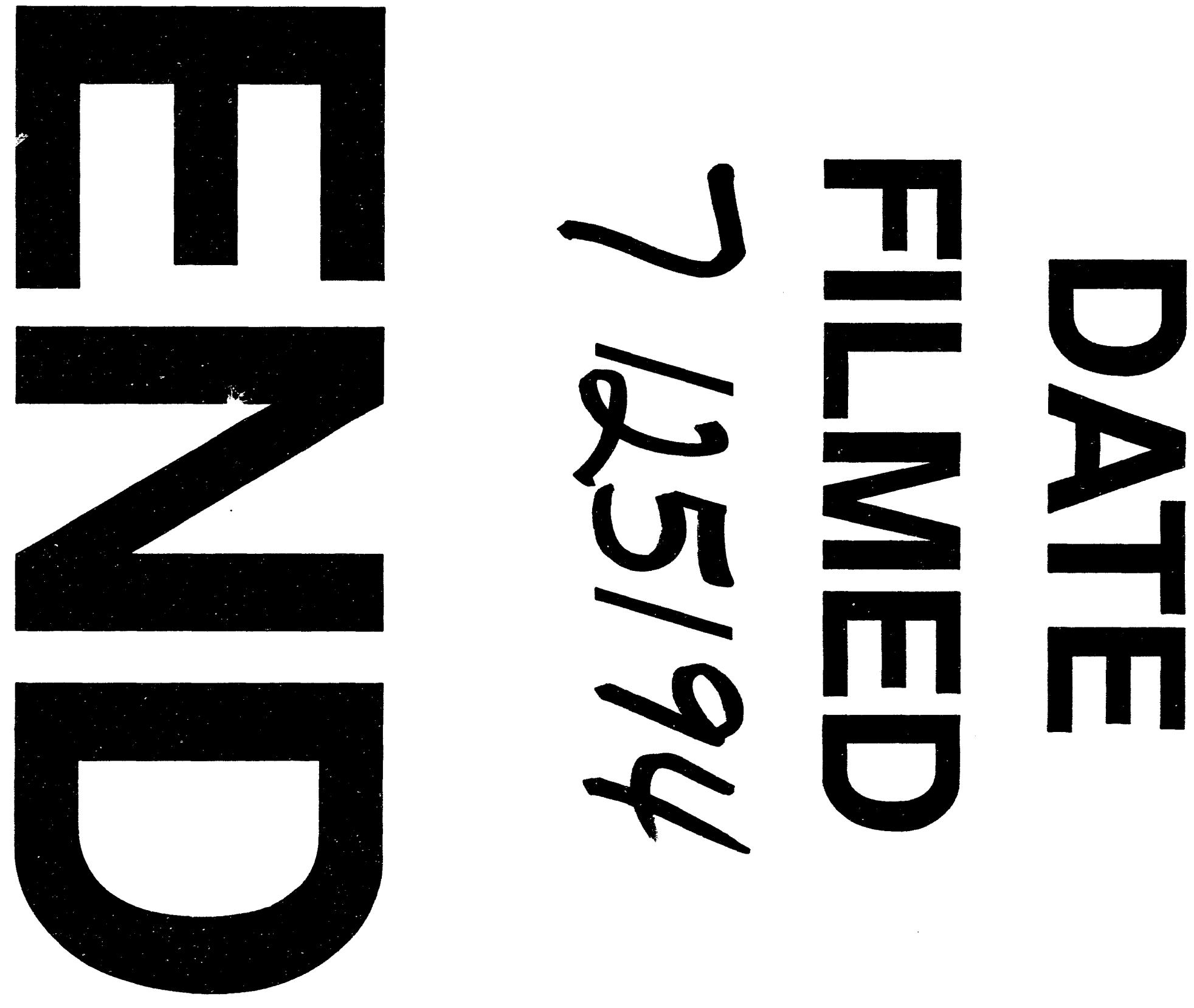
